
REPORT

\title{
INSTALLATION GUIDELINES FOR SOLAR HEATING SYSTEM, SINGLE-FAMILY RESIDENCE AT NEW CASTLE, PENNSYLVANIA
}

Prepared from documents furnished by

Honeywell, Inc.

Energy Resources Center

2600 Ridgway Parkway

Minneapolis, Minnesota 55413

Under Contract NAS8-32093 with

National Aeronautics and Space Administration

George C. Marshall Space Flight Center, Alabama 35812

For the U. S. Department of Energy

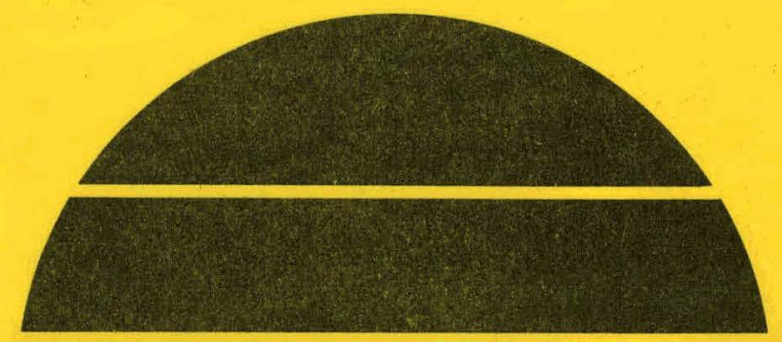

\section{U.S. Department of Energy}




\section{DISCLAIMER}

This report was prepared as an account of work sponsored by an agency of the United States Government. Neither the United States Government nor any agency Thereof, nor any of their employees, makes any warranty, express or implied, or assumes any legal liability or responsibility for the accuracy, completeness, or usefulness of any information, apparatus, product, or process disclosed, or represents that its use would not infringe privately owned rights. Reference herein to any specific commercial product, process, or service by trade name, trademark, manufacturer, or otherwise does not necessarily constitute or imply its endorsement, recommendation, or favoring by the United States Government or any agency thereof. The views and opinions of authors expressed herein do not necessarily state or reflect those of the United States Government or any agency thereof. 


\section{DISCLAIMER}

Portions of this document may be illegible in electronic image products. Images are produced from the best available original document. 
NOTICE

Th1s report was prepared to document work sponsored by the United States Government. Ne1ther the Unfted States nor 1 ts agents the Unfted States Department of Energy, the United States Nat1onal Aeronautics and Space Adminlstration, nor any federal employees, nor any of their contractors, subcontractors or the1r employees, make any warranty, express or 1 mplled, or assume any legal llabllity or responsibllity for the accuracy, completeness, or usefulness of any informat1on, apparatus, product or process disclosed, or represent that 1ts use would not infringe privately owned rights. 
TECHNICAL REPORT ST ANDARD TITLE PAGE:

\begin{tabular}{|c|c|}
\hline $\begin{array}{l}\text { 1. REPORT NO. } \\
\text { DOE/NASA CR-161355 }\end{array}$ & 2. GOVERNMENT ACCESSION NO. \\
\hline
\end{tabular}

Installation Guidelines for Solar Heating System, Single-Family Residence at New Castle, Pannsylvania

3. RECIPIENT'S CATALOG NO.

5. REPORT DATE

January 1980

6. PERFORMING ORGANIZATION CODE

7. AUTHOR(S)

8. PERFORMING ORGANIZATION REPORT \#

9. PERFORMING ORGANIZATION NAME AND ADDRESS

10. WORK UNIT, NO.

Honeywell, Inc.

2600 Ridgway Parkway

Minneapolis, Minnesota 55413

12. SPONSORING AGENCY NAME AND ADDRESS

National Aeronautics and Space Administration

Washington, DC 20546

11. CONTRACT OR GRANT NO.

NAS8-32093

13. TYPE OF REPORI \& PERIOO COVERED

\section{Contractor Report}

14. SPONSORING. AGENCY CODE

15. SUPPLEMENTARY NOTES

This work was done under the technical management of Mr. John Parker, George C. Marshall Space Flight Center, Alabama.

16. ABSTRACT

This document provides the Solar Heating System installer guidelines for each sybsystem and includes testing and filling the system. This single-family residential heating system is a solar-assisted, hydronic-to-warm-air system with solar-assisted domestic water heating. It is composed of the following major components:

- Liquid cooled flat plate collectors

- Water storage tank

o. Passive solar-fired domestic water preheater

- Electric hot water heater

- Heat pump with electric backup

- Solar hot water coil unit

- Tube-and-shell heat exchanger, three pumps, and associated pipes and valying in an energy transport module

- Control system

- Air-cooled heat purge unit

This document also provides information on the operating procedures, controls, caution requirements, and routine and schedule maintenance. Information consists of written procedures, schematics, detail drawings, pictures and manufacturer's component data.

\begin{tabular}{|c|c|c|c|c|c|}
\hline \multicolumn{3}{|c|}{ 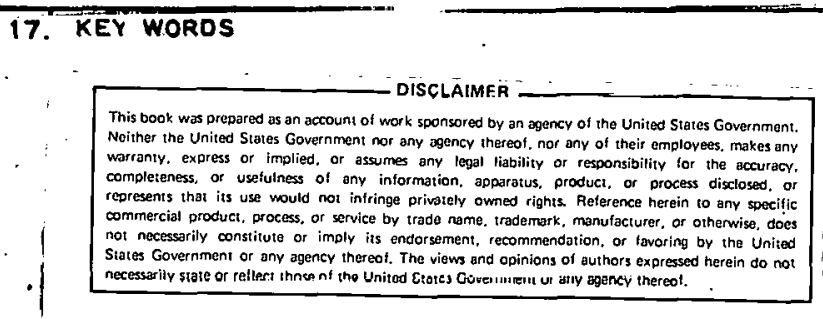 } & \multicolumn{3}{|c|}{$\begin{array}{l}\text { 18. DISTRIBUTION STATEMENT } \\
\text { Unclassified-Unlimited } \\
\text { WILLIAM A, BROOKSBANK, JR. } \\
\text { Mgt, Solar Energy Applications Projects }\end{array}$} \\
\hline & SECURITY CLASSIF. (of thls report) & 20. SECUR & शiTY CLASSIF. (of thle page) & $\begin{array}{c}\text { 21. NO. OF PAGES } \\
170\end{array}$ & $\begin{array}{r}\text { 22. } \\
\text { PRICE } \\
\text { NTI S }\end{array}$ \\
\hline
\end{tabular}


THIS PAGE

\section{WAS INTENTIONALLY LEFT BLANK}


TABLE OF CONTENTS

$\underline{\text { Page }}$

SECTION 1 INTRODUCTION .

SCOPE $\quad \cdot \quad 1-1$

SINGLE-FAMILY RESIDENTIAL HEATING SỴSTEM DESCRIPTION $\ldots 1-1$.

SYSTEM OPERATION" .

SECTION 2 SOLAR HEATING SUBSYSTEMS AND COMPONENTS $\cdot \cdot{ }^{\circ}-1$

COLLECTOR SUBSYSTEM $\quad \therefore \cdot 2-1$

Solar Collectors . 2-?

Purge Coil Unit . : : . . $2-2$

Diverting Valve . . . 2-2

Collector Plate Temperature Sensor $\quad 2-2$

Installation. $\quad: 2-2$

Operation and Maintenance Data. . . 2-2

STORAGE SUBSYSTEM * 2-6

AUXILIARY ENERGY AND SPACE HEATING SUBSYSTEMS 2-6

DOMESTIC HOT WATER SUBSYSTEM ? 2-8

ENERGY TRANSPORT SUBSYSTEM *. $\cdot 2-8$

CONTROL SUBSYSTEM $2-16$

SITE DATA ACQUISITION SUBSYSTEM (SDAS) .. $\quad$ 2-16

Data Collection 2-20

Data System Overview _. . $2-20$

Sensor Locations 2-22:

Operation and Maintenance 2-22

SECTION.3 - NEW CASTLE SYSTEM TEST AND FILLING

TESTING 3-1

FLUSHING ANI) CLEANING

Collector Loop $3-1$

Storage and Heating System Loop 3-3

BALANCING 3-4 
TABLE OF CONTENTS (Concluded)

\begin{tabular}{|c|c|}
\hline $\begin{array}{ll}. \cdot & \vdots\end{array}$ & Page \\
\hline STARTUP & $3-5$ \\
\hline Collector Loop (approximately 30 gallons total) & $3-5$ \\
\hline System Pressurization & $3-5$ \\
\hline ROUTINE MAINTENANCE & $4-1$ \\
\hline COLLECTOR SUBSYSTEM & $4-1$ \\
\hline Solar Collectors (r.ss 18-1) & $4=1$ \\
\hline Purge Init: (HRW-1-30) & $1-1$ \\
\hline STORAGE SUBSYSTEM & $4-1$ \\
\hline AUXILIARY ENERGY AND SPACE HEAT SUBSYSTEM & $4-2$ \\
\hline HOT WATER SUBSYSTEM & $4-2$ \\
\hline ENERGY TRANSPORT SYSTEM & $4-3$ \\
\hline CONTROL SUBSYSTEM & $4-3$ \\
\hline MAINTENANCE SCHEDULE & $5-1$ \\
\hline
\end{tabular}

APPENDIX

A. CONTROI SUBSYSTEM A-I

B. COLLECTOR SUBSYSTEM B-1

C. AUXILIARY ENERGY \& SPACE HEATING SUBSYSTEMS C-1

D. INSTALLATION OF DOMESTIC HOT WATER SUBSYSTEM D D 1

E. ENERGY TRANSPORT SUBSYSTEM E-1

F. SDAS SENSOR INSTALLATION F-1

G. GENERAL SDAS INSTAILATION G-1 
2-1 Single Family Residence Collector Subsystem

2-9 Control Subsystem Wiring

2-10 Site Instrumentation Interface Hardware

\section{LIST OF TABLES}

\section{Tablc}


SECTION i

INTRODUCTION

SCOPE

This document provides a description to the Solar Heating System owner of each subsystem as well as testing and filling the system.

SINGLE-FAMILY RESIDENTIAL HEATING SYSTEM DESCRIPTION

The single-family residential heating system is a solar-assisted, hydronic-towarm-air heating systemwith solar-assisted domestic water heating. The system is composed of the following major components:

- Liquid cooled flat plate collectors

- A water storage tank

- A.passive solar-fired domestic water preheater

- An electric hot water heater

- A heat pump with electric backup

- A solar hot water coil unit

- A tube-and-shell heat exchanger, three pumps, and associated pipes and valving in an energy transport module.

- A control system

- An air-cooled heat purge unit

The arrangement of components within the system is shown on Figure 1-1. The system consists of a glycol/water collector loop that interfaces with a water storage loop through a tube-and-she11 heat exchanger. A domestic hot water preheat coil is located in the storage tank. 

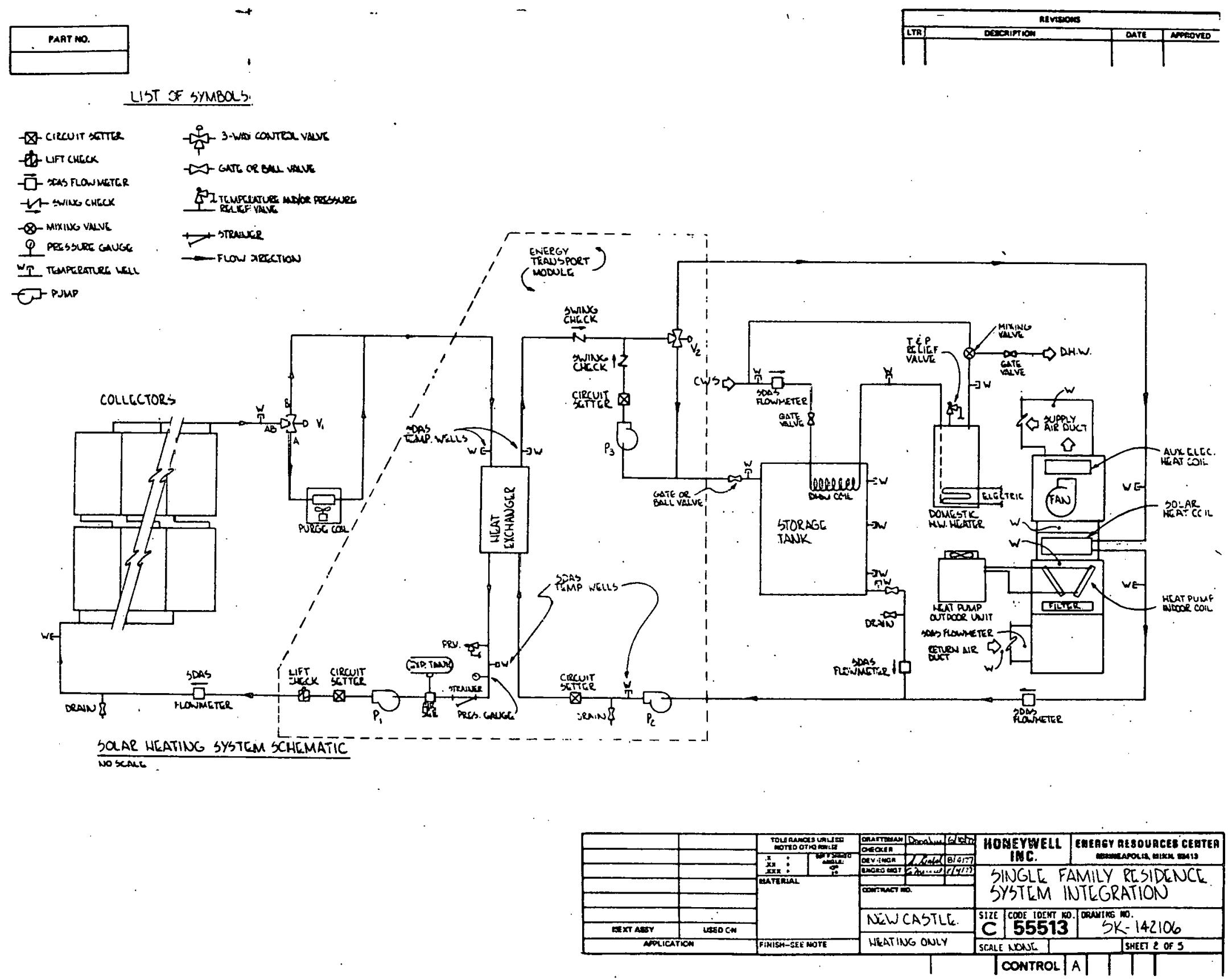

Figure 1-1 
The glycol/water collector loop consists of solar collectors, the shell side of the heat exchanger, the purge coil and pump $\mathrm{P}_{1}$; and a control valve as required for the different modes of operation.

The water side of the heat exchanger is a direct heating/storage loop consisting of the storage tank, control valve, pumps $\mathrm{P}_{2}$ and $\mathrm{P}_{3}$, the tube side of the heat exchanger and the solar heating coil $\%$

The system provides six modes of operation:

- Direct heating from collectors

- Heating from storage

- Auxiliary heating (insufficient solar)

- Storage charging

- Continuous domestic hot water preheating

- Purging excess energy

\section{SYSTEM OPERATION}

When space heating is required and solar energy from the collectors is available, the collectors supply heat directly to the system. Energy transfer is through the heat exchanger then via the solar hot water coil in the heat pump indoor. section. Pump $P_{1}$ in the solar collector loop and $P_{2}$ in the water loop provide movement of the heat transport through valve $V_{2}$ to the heating coil. The blower moves the building air across this heating coil. Pumps $\mathrm{P}_{1}$ and $\mathrm{P}_{2}$ provide movement of the heat transport fluids to charge the storage tank. Storage charging occurs by circulating water from the tank bottom through the heat exchanger and returning the heated water to the top of the storage tank, thus taking advantage of stratification. During high solar insolation and low heating and storage demands, if surplus energy is collected, then valve $v_{1}$ diverts collector loop flow to the purge coil. The purge coil operates to maintain the system fluid temperatures below preselected values. 
When space heating is required and direct solar energy is not available, thermal storage supplies the heat. Pump $\mathrm{P}_{3}$ circulates the vater from the top of the tank through the solar hot water coil and returns the cooler water to the bottom of the storage tank, taking advantage of tank stratification. If the storage tank temperature is not high enough to provide space heating, the control subsystem activites auxiliary space heating to maintain a comfortable building temperature. Auxiliary space heating will be provided by the heat pump and by the electrical resistance heating coil.

A description of each mode of operation and a complete system checkout procedure is contained in Appendix A. 
SECTION 2

SOLAR HEATING SUBSYSTEMS AND COMPONENTS

The Solar Heating system consists of the following subsystems:

- Collector

$\therefore \therefore: \because ; \quad \because \because \because \cdots$

- Storage

- Auxiliary Energy and Space Heating

- Domestic Hot Water

- Energy Transport

- Control

- Site Data Acquisition Subsystem

A description of each subsystem is given in the following sections. Information on the major components within each subsystem is provided in the Appendices.

COLLECTOR SUBSYSTEM

The collector subsystem consists of 28 Lennox LSC 18-1 solar collectors, a purge, coil unit Lennox HRW-1-30, a diverting valve (V1), Honeywell Part Y534A, headers, supply/returns lines and isolation and balancing valves.

The solar collectors should operate without any special attention. However, excessive temperatures can be achieved if pumps $P_{1}$ and $P_{2}$ are in the of $f_{1}$ posi-. tion and direct solar energy is available. Pump $\mathrm{P}_{2}$ can be turned off and pump $P_{1}$. can be operated during daylight hours if flow is directed through the purge unit. Caution should be taken if pump $P_{1}$ is left running at night during below freezing conditions as the water in the tube side of the heat exchanger can be frozen and could rupture the unit. 


\section{Solar Collectors}

The LSC 18-1 is a double glass cover, flat plate collector. The tempered, lowiron glass has an acid etched surface to reduce reflection. The steel absorber plate has a special black chrome coating for high solar absorptivity. The absorber plate is formed around the copper. fluid tubes and is all encased in an insulated, formed, galvalume steel box.

\section{Purge Coil Unit}

The purge coil unit is a fin and tube coil and blower unit that is mounted outside the dwelling. It is used to evacuate excess heat energy from the collectors.

\section{Diverting Valve}

The diverting valve is a dual unit consisting of two valve bodies that are plumbed together. These are controlled by two powerheads that move each valve separately. This valve is used to divert the liquid coming from the solar collectors to the purge coil unit as required.

\section{Collector Plate Temperature Sensor}

A temperature sensor is mounted on the collector plate for control of the solar heating system.

\section{Incta11ation}

Se. Figures 2-1, 2-2, and 2-3 for installation of above components.

\section{Operation and Maintenance Data}

See Appendix B for details on these components. 


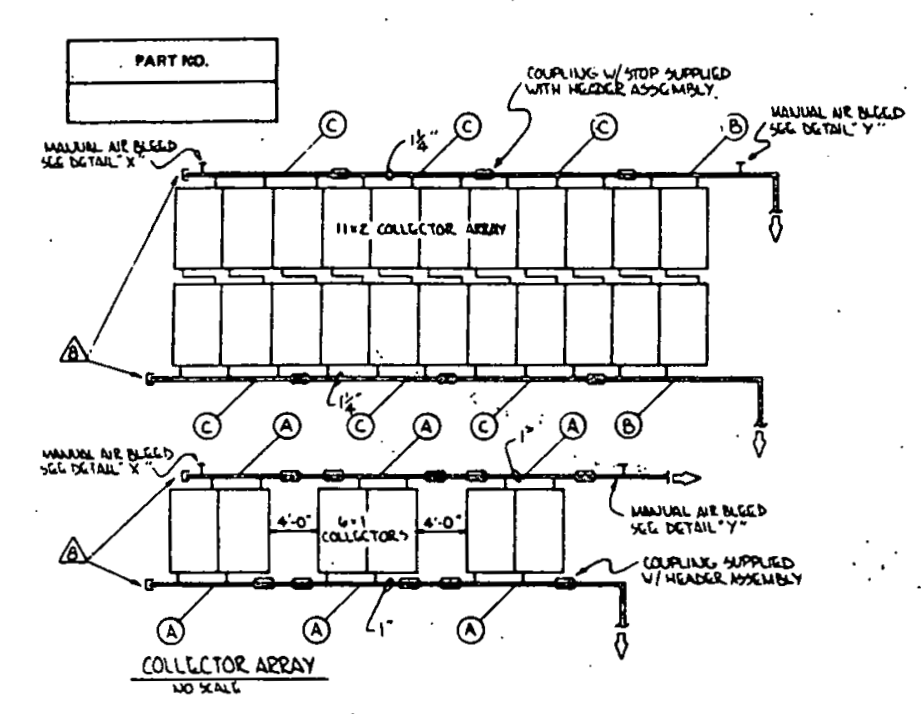

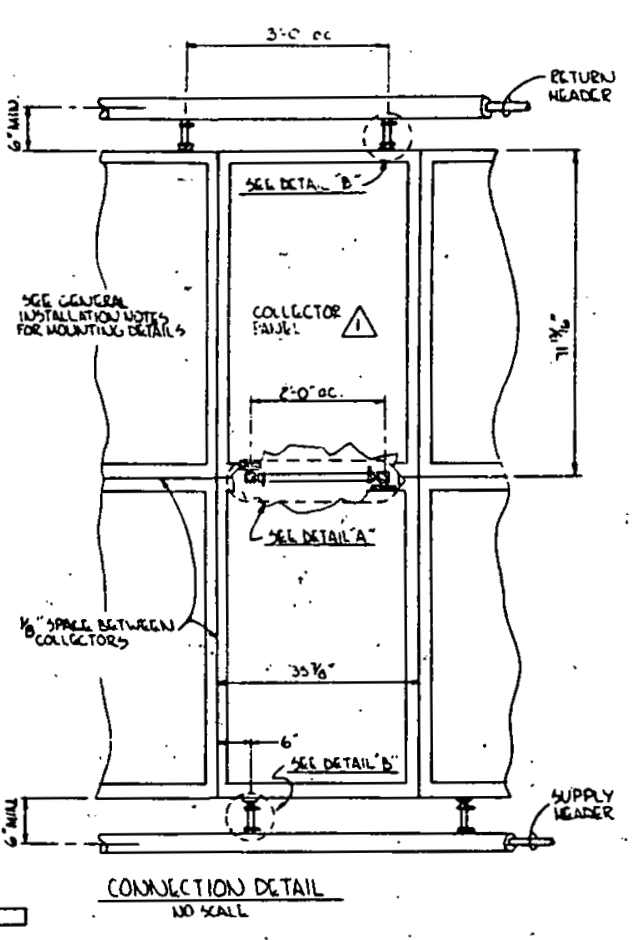

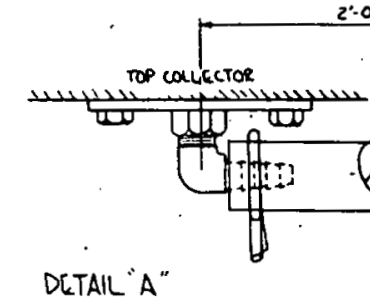

$\frac{\text { DLTAIL"A" }}{\text { WONG }}$

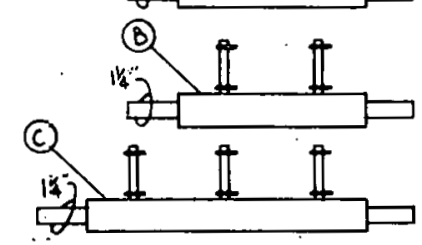

$\frac{\text { PRLASTEMBLLD CQLLCTOR NEADERS }}{\text { NO SCALC }}$

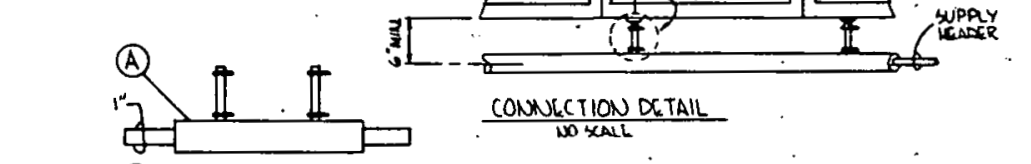

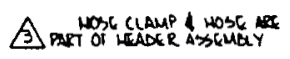
今s nomine

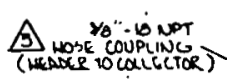
今 $\operatorname{ses}$ C Camp

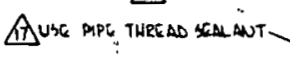

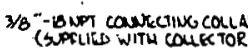
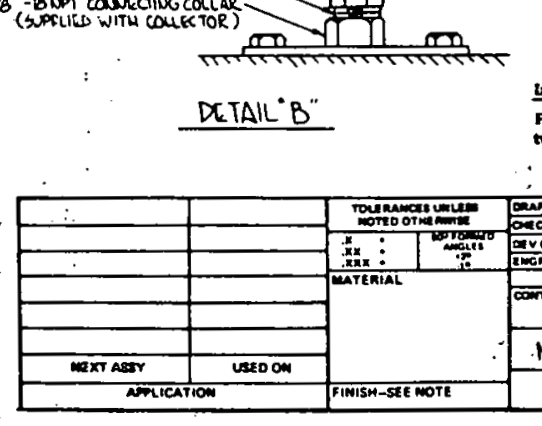

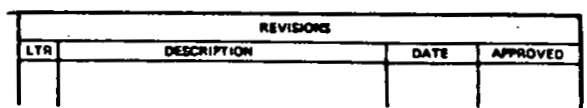

GENERAL. INST ALL LATION NOTES

\section{Single-Slack Collector Array}

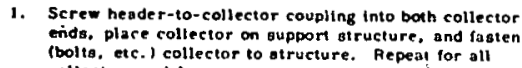

2. Connect pre-sssembled return header sectlons to tip $n$ at all jolints. Lubricate bead at end of coupling vith liguid cetergent soap (or equivalenti) prior to slipping hose over logether. Anoulape and weatherproot winculated aeccions ol header. Strap header to support structure.

3. Repeat iz for pre-desaembled supply heoder sections at
bottom of collector orray. Double-Stuck Collector Arrey

1. For bottom row collector screw heider-to-collector collector coupling into top end of collector. Place

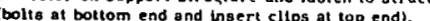

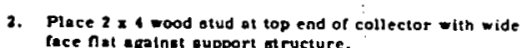

3. For eecond ouct collector aciè collector-to-collector

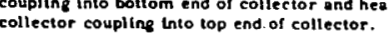

4. Lower collector dowin atructure untul it reats egatnat mood clompling each end to coupling: Lubricate bead at end of

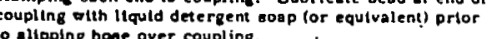

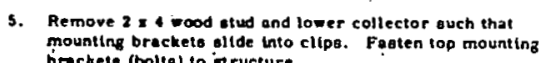

- Repeat ol - 15 tor entire collector array.

7. Connect pro-asuembled return header sections asme as
Oz for sunge-atuck erray.

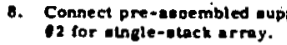

ineulation Noces

Art inculation tube around beader. Apply inoulastion adhesive in longi-

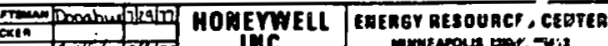
Ouxter

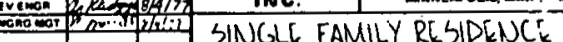
COLLCTOR SUBSYSTCM

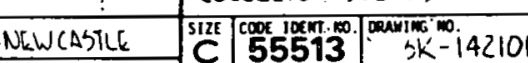
\begin{tabular}{l|l|l}
$C$ & 55513 & \\
\end{tabular} SCALE Mate L

Figure 2-1 


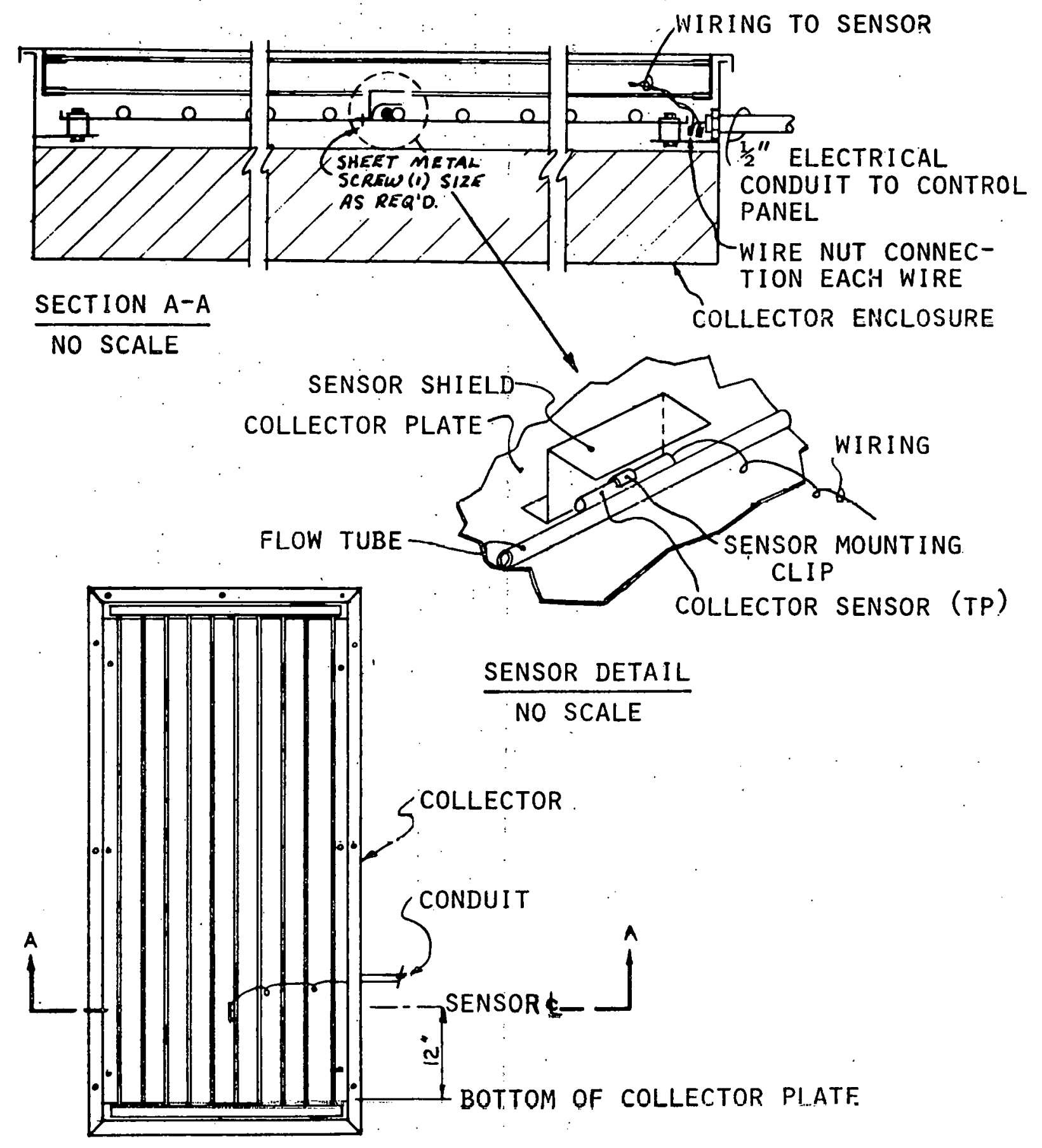

Figure 2-2. Collector Plate Sensor (Tp) Detail 


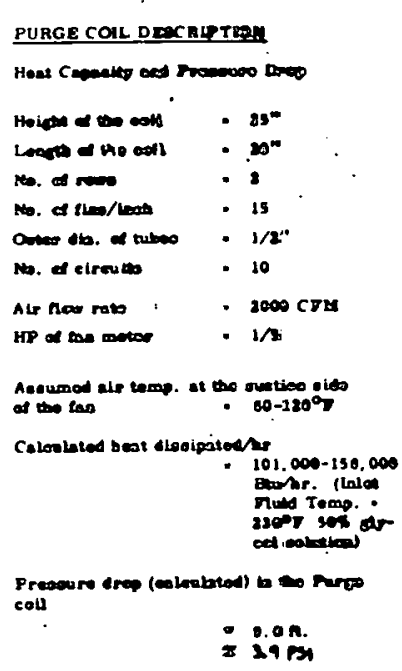

INSTALLATION MOT MBS

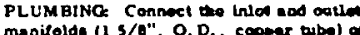

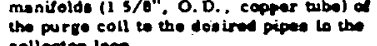

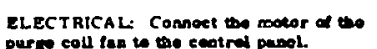

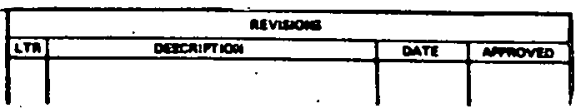

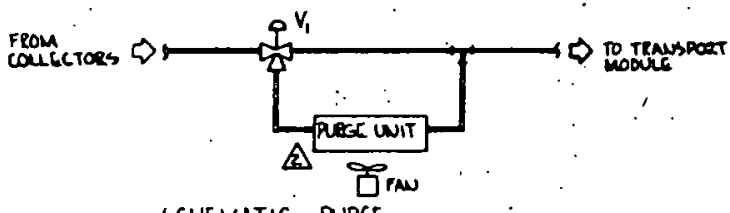
$\frac{\text { SCHEMATIC - PURGE }}{\text { SO XMG }}$
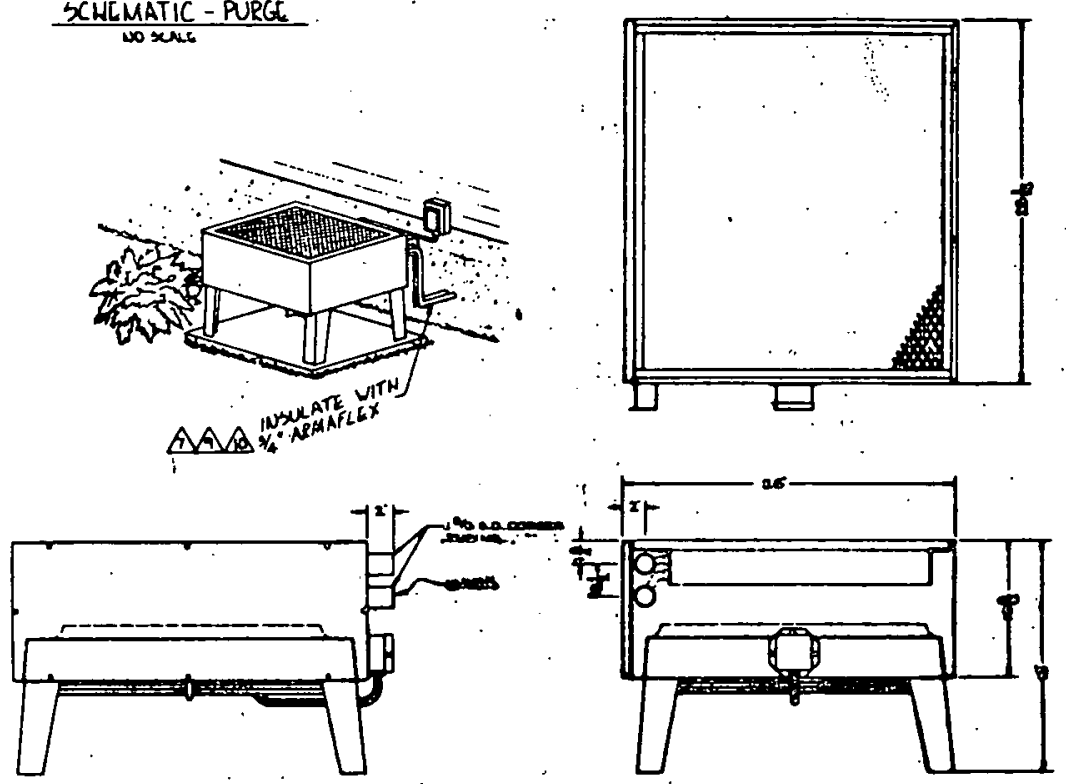

$\frac{\text { PURGE COIL UNIT }}{12^{2} \cdot I^{\circ} \cdot 0^{\circ}}$ (HEAT REJECTOR)

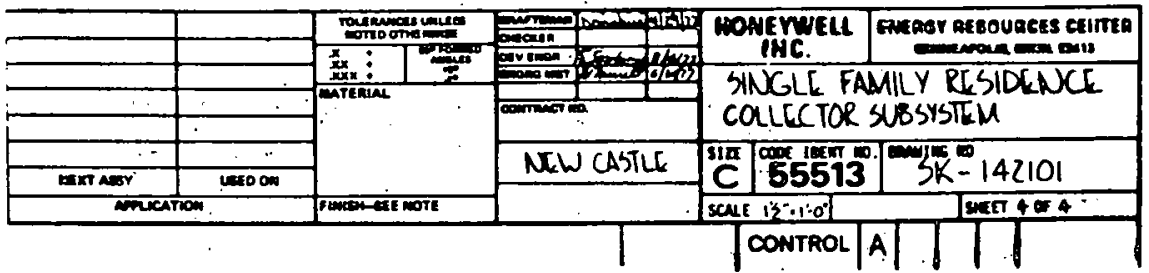

Figure 2-3. 
STORAGE SUBSYSTEM

The storage subsystem consists of a 1000-gallon lined steel tank. The tank is designed to operate at ambient pressure: and is vented to the space enclosing it. The water in the tank is neutralized with an inhibitor to reduce corrosion of system components.

The storage tank is filled to a level 6 inches from the top of the tank. Initial fill level is marked with a red band on the site glass. If the water level is more than 3 inches below this level, additional water should be added to the storage tank. This is accomplished by removing a manhole cover, using a hose connected to the domestic water system until. the level in the sight glass is up to the red band on the sight glass. Pumps $\mathrm{P}_{2}$ and $\mathrm{P}_{3}$ should be shut off during tank level checking and filling. For a description of the storage subsystem, see Figure 2-4.

\section{AUXILIARY ENERGY AND SPACE HEATING SUBSYSTEMS}

The Auxiliary Energy and Space Heating Subsystem consits of the Solar Heating System Space Heating Coil integrated with a conventional (non-solar assisted) electric-heat pump, and auxiliary electric heating coil.

The heat pump is a matched remote system consisting of an outdoor unit and an indoor unit. The space Heating Coil is insatlled between the separable halves of the heat pump indoor unit. 'The auxiliary electric heating coil is installed in the heat pump indoor unit.

Various blower speeds are available on the indoor unit fan. However, a new speed that is lower than the initial speed set by the installer should not be used as this can result in less solar energy utilized and consequently higher auxiliary electric energy consumption. 


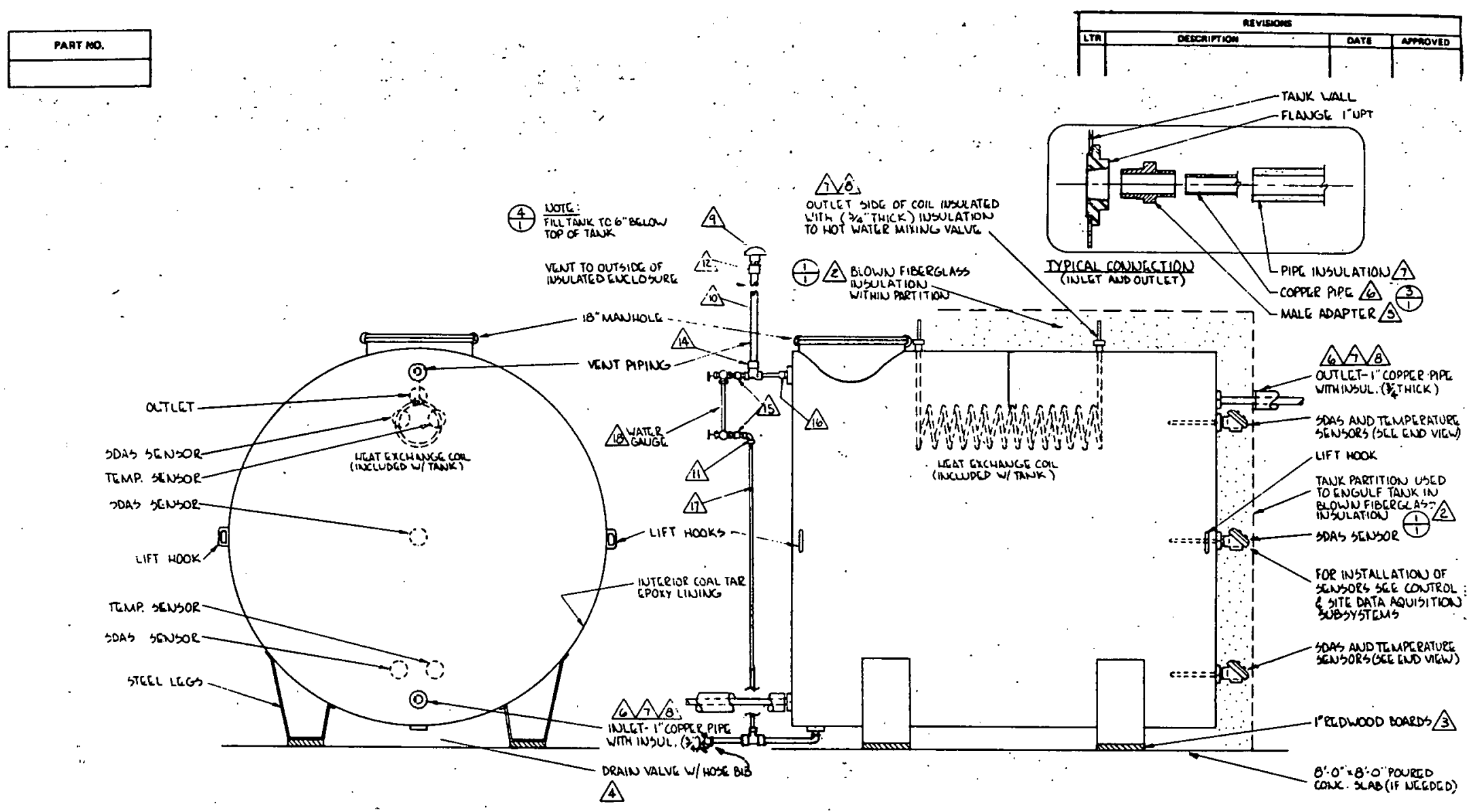

$\frac{\text { STORAGE TANK } \triangle 1}{1 \cdots 0^{\circ}}$ NOTE: FILL TANK APPROXIMATELY NALF FWL

000

\begin{tabular}{|c|c|c|c|c|c|}
\hline & & 势 & 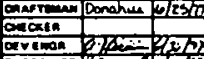 & $\begin{array}{l}\text { HOMEYWWELL. } \\
\text { IMC. }\end{array}$ & 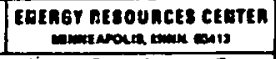 \\
\hline & & & 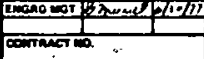 & SINGLE FA & $\begin{array}{l}\text { AMILY RESIDENCE } \\
\text {. }\end{array}$ \\
\hline 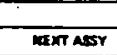 & yed on & & WLLIAM O'BRIEN & 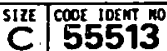 & SK- 142050 \\
\hline & & FINBSW-SEE WOTE & NEW CASTLE & 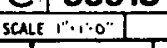 & Ishefy 2 of 2 \\
\hline
\end{tabular}


The subsystem schematic denoting the unit model number is shown in Figure 2-5. Operationand maintenance data for each component are shown in Appendix $C$. The control subsystem outdoor thermostat is:installed as shown.

DOMESTIC HOT WATER SUBSYSTEM:

The domestic hot water subsystem installation consists of a conventional hot water heater with its outlet (hot) connected to the dwelling hot water line and the inlet (cold) connected to the preheat coil. in the storage tank. This line should have a tempering valve installed in it. See Figure 2-6 for installation detall. The supply water (cold) is run to the preheat coil and the tempering valve. When hot water is utilized, make-up cold water from the domestic water supply flows through the preheat coil and undergoes an increase in temperature. If the storage tank temperature is below $150^{\circ}-160^{\circ} \mathrm{F}$, the preheated water will be below $140^{\circ}$. The water heater will maintain water temperature at $140^{\circ}$. If the storage tank temperature is greater than $160^{\circ} \mathrm{F}$, then the preheated water may be over $140^{\circ} \mathrm{F}$. In this case, the tempering valve then adds cold water to bring the water temperature down to $140^{\circ} \mathrm{F}$ before it enters the domestic hot water system.

l'he tempering valve setting should be kept at $140^{\circ} \mathrm{F}$. Operation and maintenance data is contained in Appendix D.

\section{ENERGY TRANSPORT SUBSYSTEM}

The Energy Transport Subsystem consists of the Energy Transport Module (ETM) and the piping between it and the collectors, storage and heating subsystems. The ETM is shown in Figure 2-7.

Pumps 1, 2, and 3, located in the bottom section of the ETM, provide the required flow rates in the collector, heating and storage loops. DO NOT RUN PUMPS WITHOUT FLUID IN SYSTEM. 


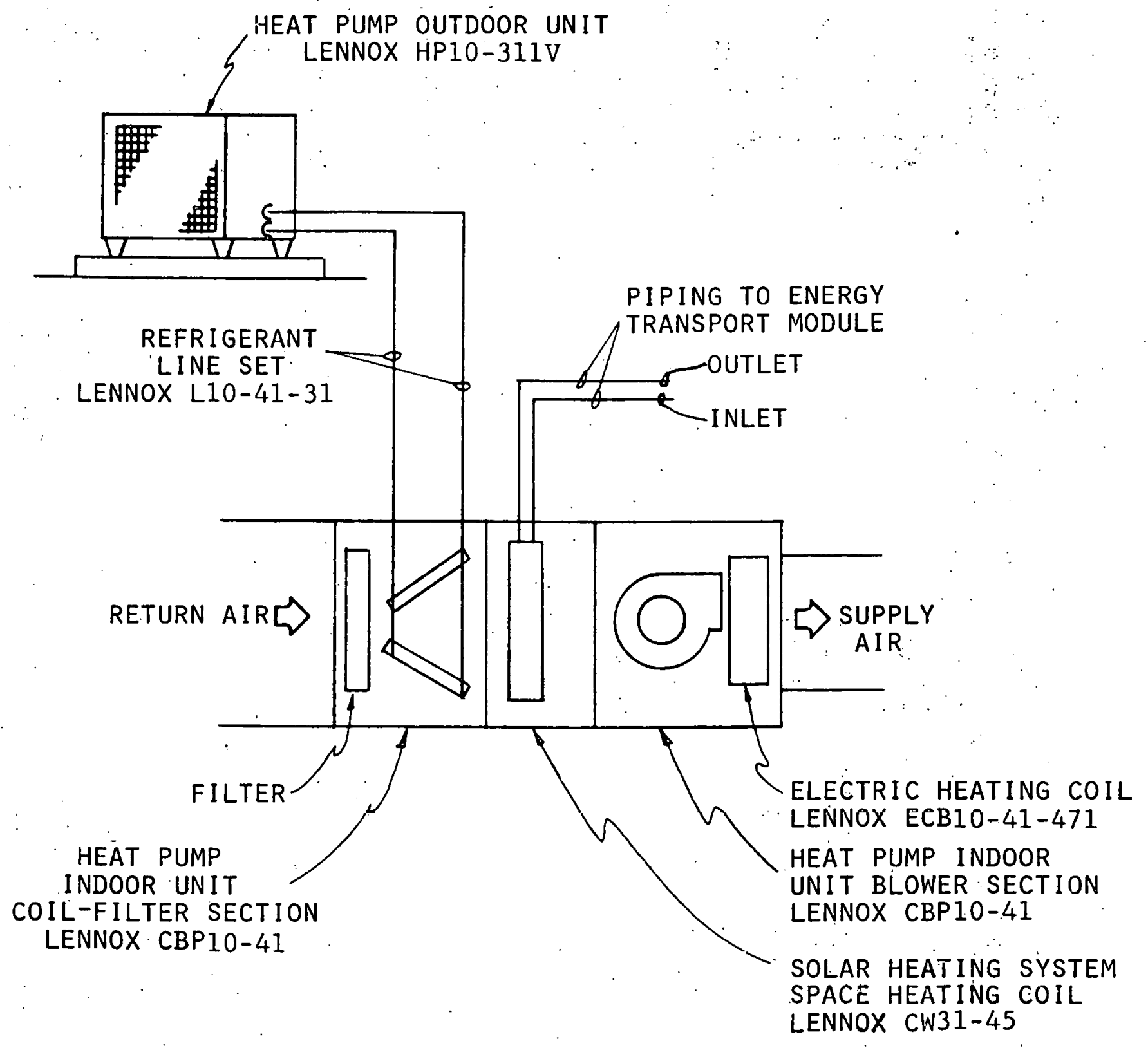

Figure 2-5. Auxiliary-Energy and Space Heating 
PART MO

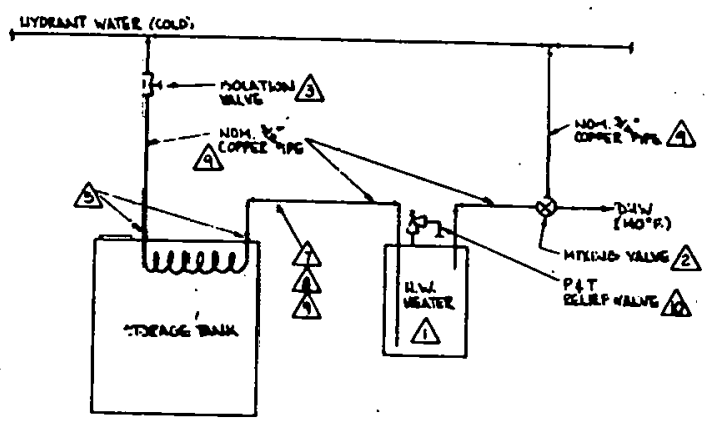

$\frac{\text { SCHQMATIC HW, sUROYSTEY. }}{10004}$
INGTALLA TION INF.JRMATION

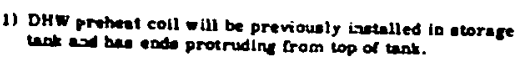

2) Tlentes atsper os comprestion fituine

3) Solder coll onte to copper tubing uaing coupling.

insULATION INFOEMATION

1) Goukew copper fubing trom atorage cint ouldet to bot

\begin{tabular}{|c|c|c|c|c|}
\hline \multicolumn{5}{|c|}{ MATERIAL SCHEDULC } \\
\hline $1 \pi\left[\mathrm{N}^{2}\right.$ & ITCM & IAANUFACTURER & TYPE / PART NC: & Q'JAN \\
\hline 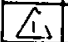 & HOT WATCR NGAE: \&R & LOCNIN'VAR & $=E$ Note - & 1 \\
\hline$\hat{2}$ & 3- NAY MIXING VANE & WATTS ESCULATOR CO. & $70 A-3 / 4$ & 1 \\
\hline$\hat{3 i}$ & SALL VALUE & Nisco & $3=80-Y_{4}^{\prime \prime}$ & 1 \\
\hline (4) & 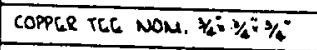 & GXID-IMPERIN Astinum & $11:-7 / 8$ & 1 \\
\hline S & 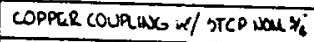 & GOULD-IMPERIAL GASTMAN & $100-1 / 8$ & 2 \\
\hline$\angle 6$ & COPPCR LLBOW :SOM. ${ }_{4}^{\circ}=\%_{4}^{\circ}$ & $\operatorname{coc} U 20-1.6$ & $007-5-7 \%$ & aseand \\
\hline$\hat{a}$ & INSULATION (3/4 iNICK) & AEMSTRONG CORK CO. & 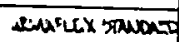 & $\sin 60^{\circ}$ \\
\hline 0 & INSURATION ADHESIVE & ALMBTRENG & 500 & ASECEOCO \\
\hline 4 & COPACR PIPE $3 / 4$ NOM. & RNERE & 4 & ASPCEO \\
\hline 10. & PRESSURC \& TEMP RULF VALVU & WhITS RUMBING SPRC. & $a_{C L}$ & 1 \\
\hline
\end{tabular}

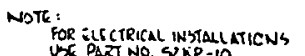

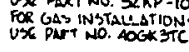

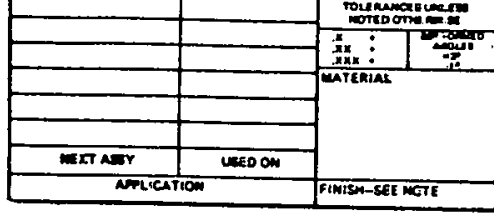

aivisomen

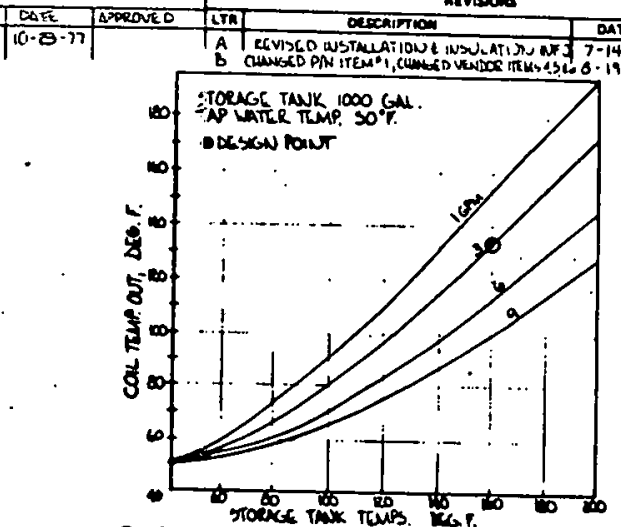

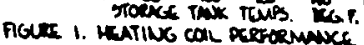

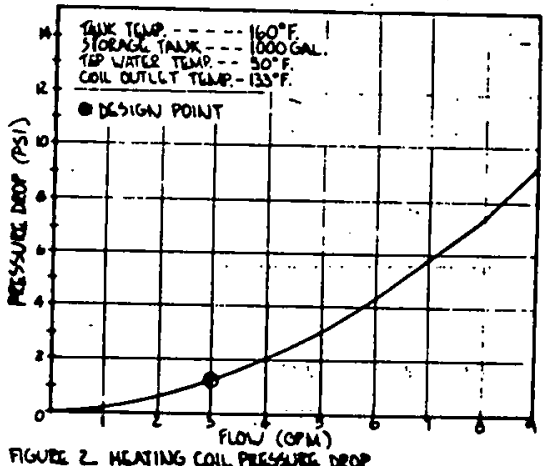

DONCSTIC HOT WATER (DHW)

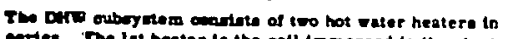

corres. The Lat water to the coll tommersed in the etora

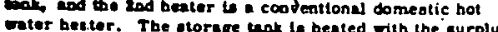

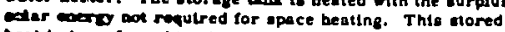

cot is transterred to clty water va a coll Ebich preheating

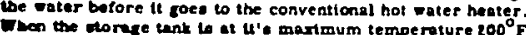

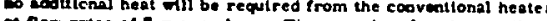

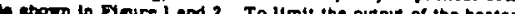

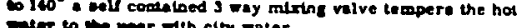

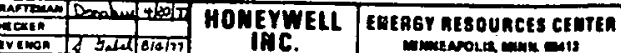

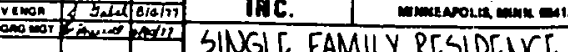

HOT WATCR SUBSYSTRM

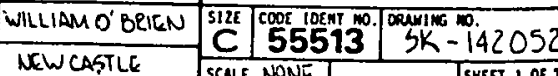
$\mid$ CONTROL $|A| T \mid$

Figure 2-6. 


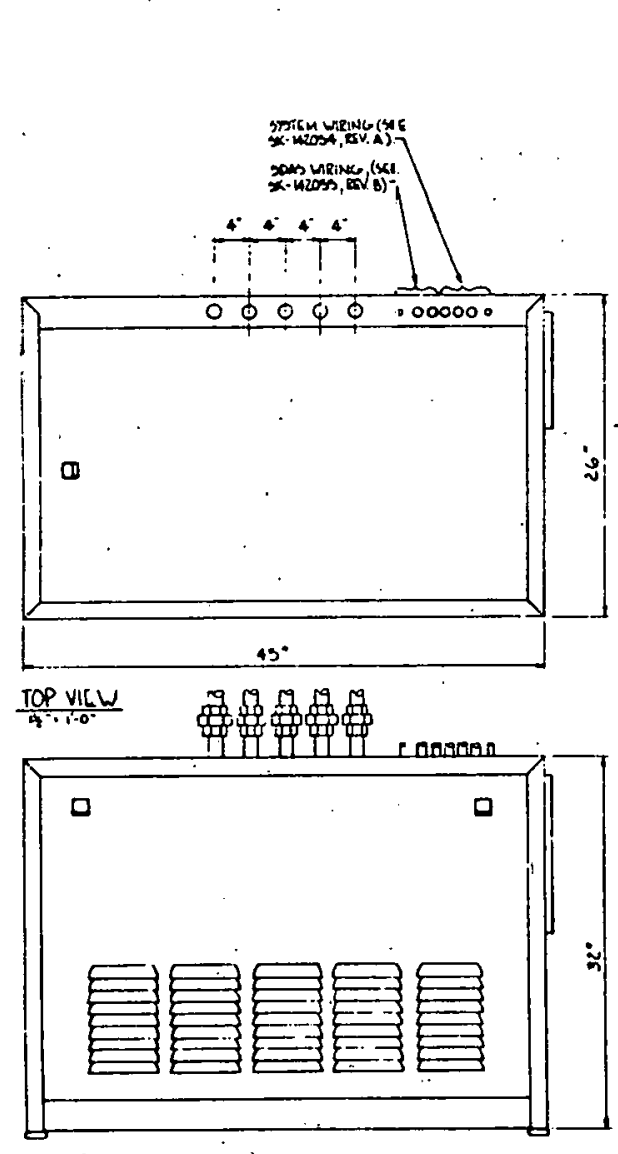

$\frac{\text { FRONT. VITW }}{\text { in: }: 1: 0^{\circ}}$

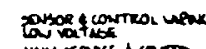

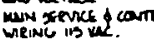

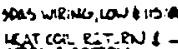

ardiexce roo

a.lictioe ripar

culctoceruen
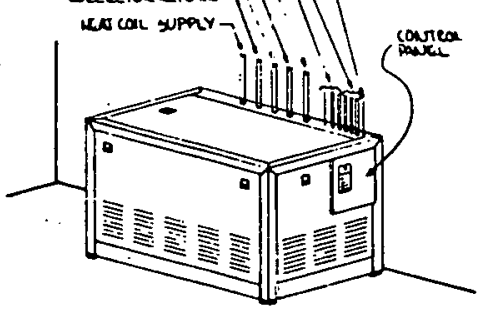

$\frac{\text { IYPLAL ASRICLIDN }}{\text { No Xanc }}$

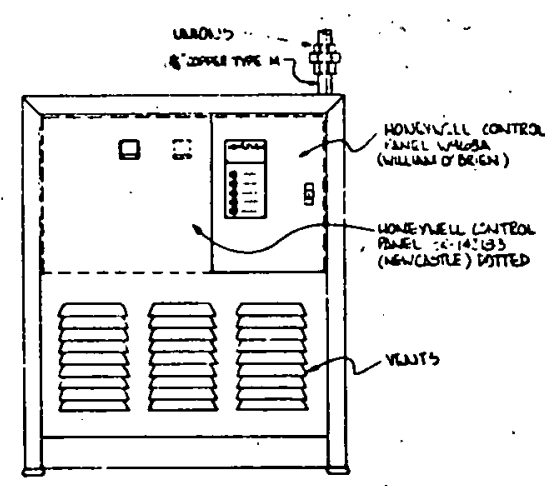

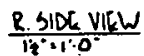

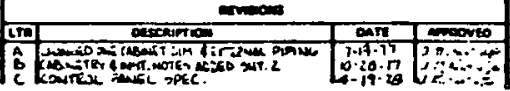

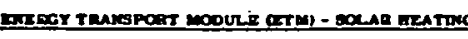

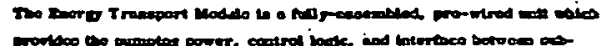

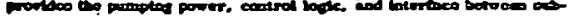

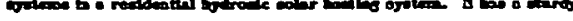

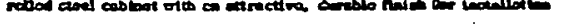

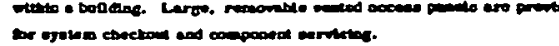

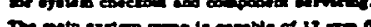

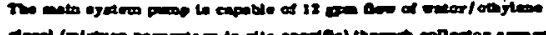
arcod Cis

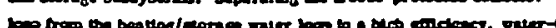

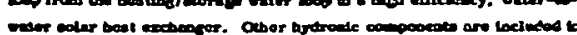

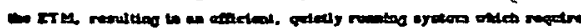

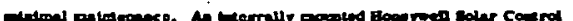

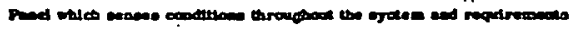

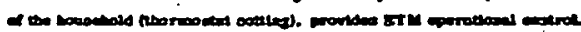
Appllestion

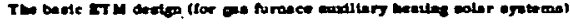

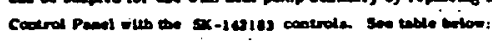

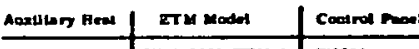

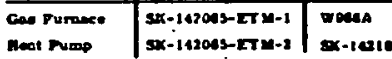

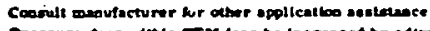

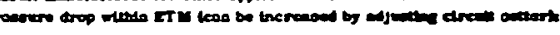

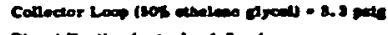

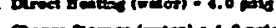

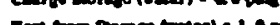

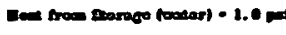

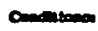

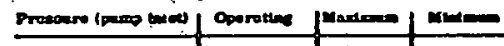

\begin{tabular}{|c|c|c|}
\hline 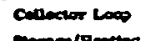 & $200-28$ note & sons \\
\hline
\end{tabular}

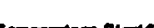

conosenos Los

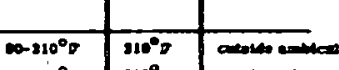

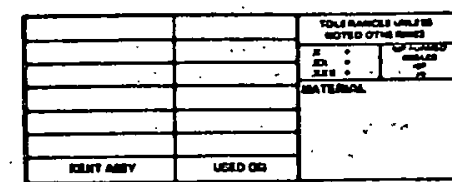

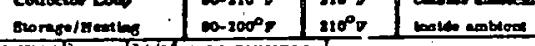

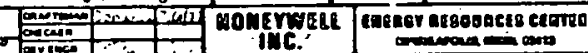

arcosiction

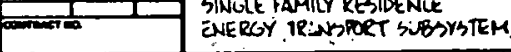

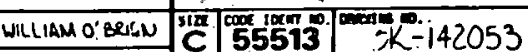

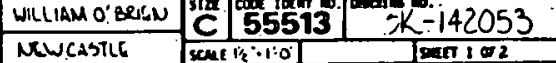

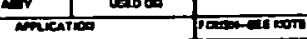
controus |A | |

Figure 2-7. Energy Transport Subsysțem 

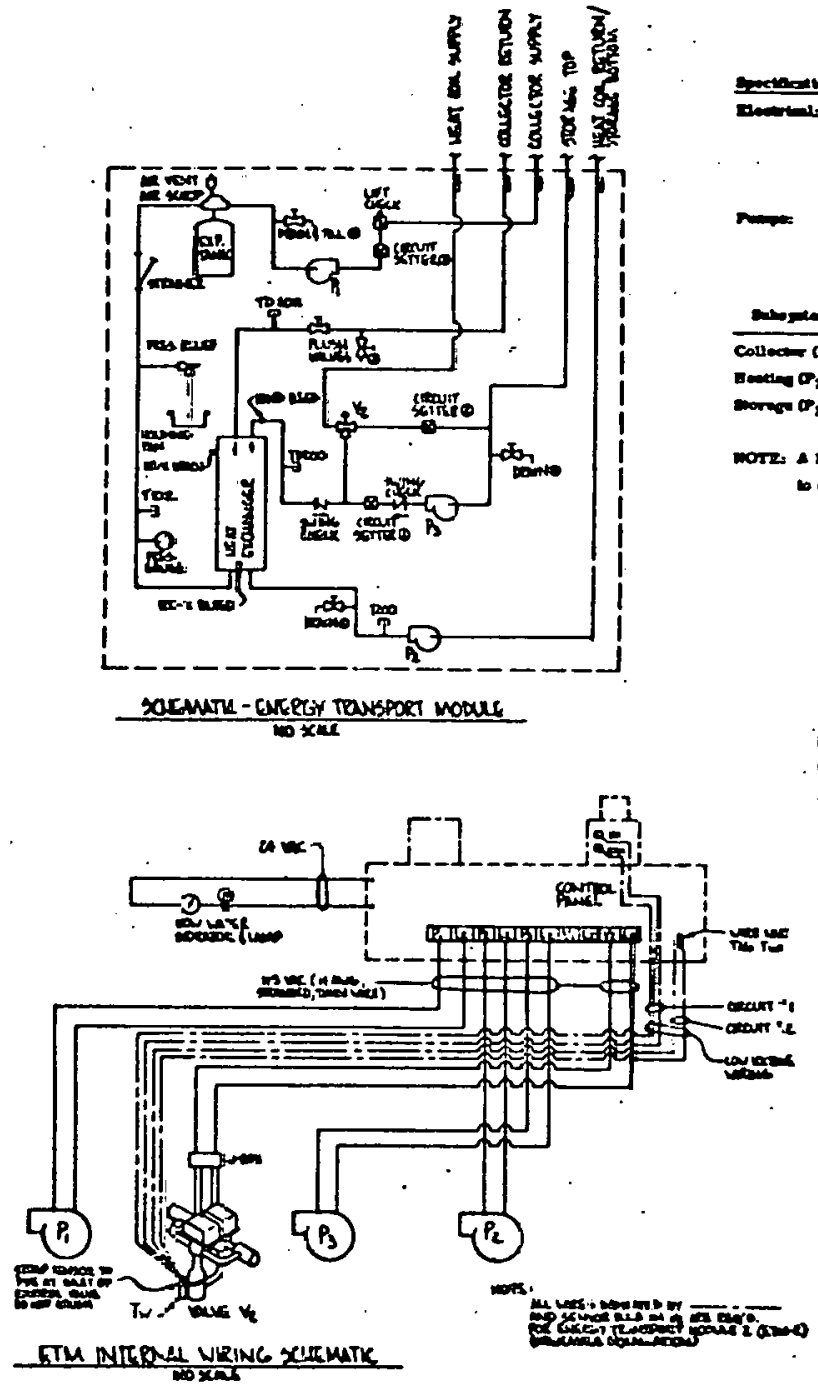

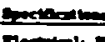

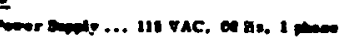

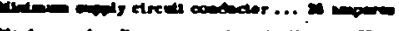

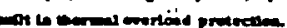

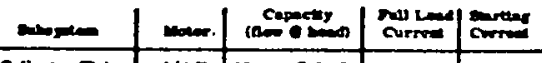

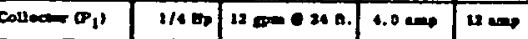

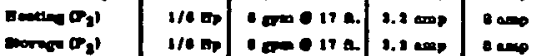

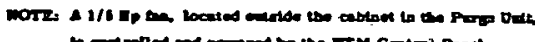

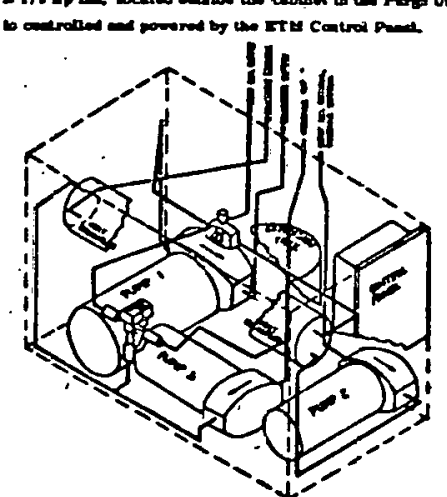

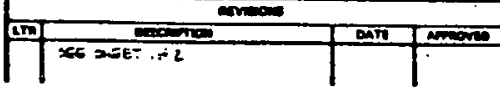

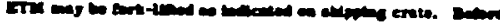

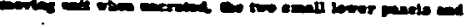

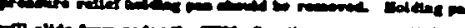
Co

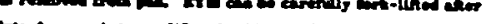

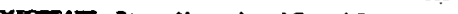

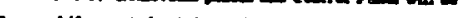

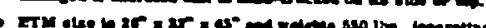

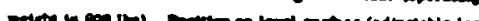
Com

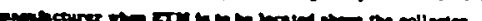
Trey -

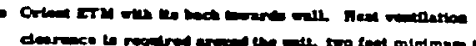

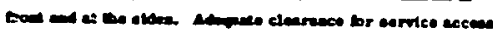

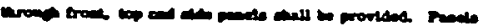

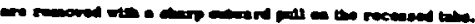

nemier canparapon

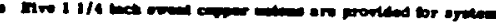

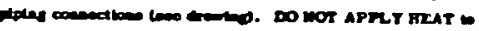

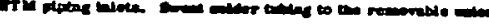

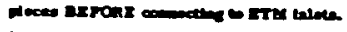

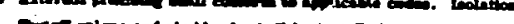

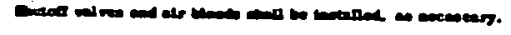

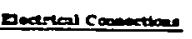

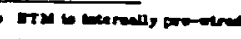

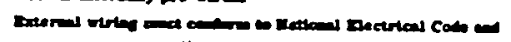

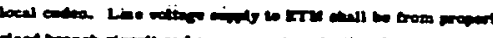
Are

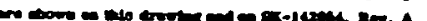

comber moperem

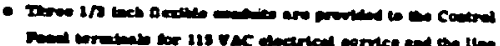

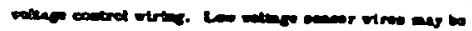

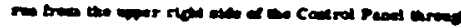

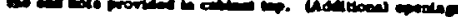

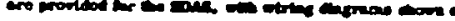

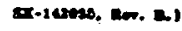

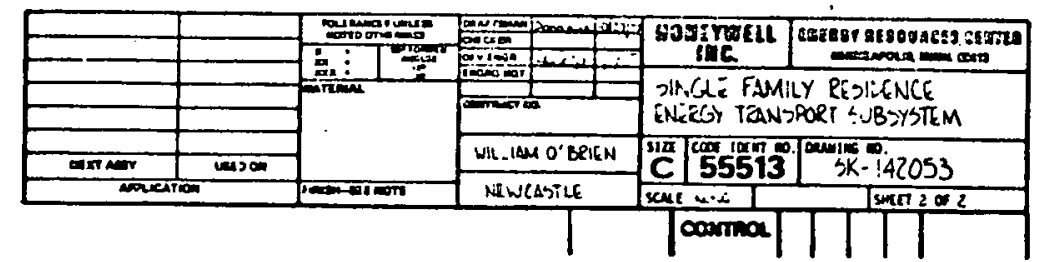

Figure. 2-7. Enerzy Transport Subsystem (concluded) 
The heat exchanger separates the freeze-protected collector loop from, and transfers energy to, the heating/storage water loop. Integrally plumbed and mounted into the top section of the ETM, it has no moving parts but is equipped with a manual air bleed and drain valve. Cleaning and flushing of the exchanger shell is possible, without contaminating the entire collector loop.

The diaphragm expansion tank absorbs the expansion of the transfer fluid from fili temperature $\left(50-60^{\circ} \mathrm{F}\right)$ to purge temperature $\left(210^{\circ} \mathrm{F}\right)$. It is mounted in the center of the ETM, with the charging air valve accessible on its bottom (relief) pan removal provides additional access to the valve). Tank air pressure should not drop below its initial 20 psi charge; it will increase as the system pressure increases. Removal of expansion tank is through the top panel, after removing the air separator and strainer.

Located in the upper section in the collector line is an air separator: With no moving parts, it separates entrapped air from the collector fluid as it circulates.

The automatic, float-type air vent attached to the air separator eliminates the purged air only. Then fluid fills the chamber, and the float closes the vent port. During system startup, this process may be expedited by removing the protective vent cap and manually depressing the vent stem. During operation, leave vent cap $2-1 / 2$ turns open.

Two air bleeds located in the top section allow manual venting of air from the ETM piping and heat exchanger during system startup. A catch basin should be used when venting the air/fluid mixture from plumbing.

A pressure relief valve located in the top section of the ETM protects the collector loop from overpressure during a system pump failure. When system. pressure reaches 45 psig, the valve will begin to open. The discharge is directed through the pressure relief line into the holding pan. DO NOT REMOVE ETM PANELS WHILE RELIEF VALVE IS FUNCTIONING. Fluid (water/ethylene glycol mixture) may be at $210^{\circ} \mathrm{F}$. 
The dual diverting control valve located in the lower section directs the water flow into various storage and heating modes. This electrically driven valve is controlled by the Solar Control Panel but does have manual override levers, one per powerhead. These levers should be in the unlocked position.

Three circuit setters located in the lower section are used to reduced flow rates to the correct level in the collector, charge storage, and heat from storage loops (there is no setter in the Direct Heating loop). The reduction is made by turning the large nut, thus adjusting the internal valve body. ETM is shipped with the setters in the "open" position; adjustment should be made during initial system startup. TURN PUMPS OFF AND SHIELD THEM AND THE ETM BASE FROM FLUID LEAKAGE WHEN CONNECTING OR DISCONNECTING PRESSURE METER FROM SETTER.

The lift check valve located in the collector supply line in the top section is used to prevent thermosyphoning (backward gravity flow) of cold collector fluid into the heat exchanger during cold, cloudy days. It is designed to prevent freezing of the heat exchanger water loop. During operation, the system pump ( $P_{1}$ ) pushes liquid through the check valve, lifting the mechanism off the seat. When flow stops (the protect mode), the valve mechanism drops by gravity onto the seat, thus not allowing flow in the reverse direction. DURING OPERATION, THE VALVE MUST BE FIRMLY SCREWED DOWN ONTO THE SEAT.

Located in the bottom section are two swing check valves (like hinged doors) that allow flow in only one direction. Reversed flow causes the valve to seat more firmly. Check valves are a part of the overall flow control in the heating and storage loops.

Four drain/fill valves located in the ETM are used to flush, clean, and fill the system. These valves are similar to the drain on a residentlal hot water heater and have a standard garden hose threaded outlet. ANY SPILLED GLYCOL SOLUTION SHOULD BE TMMEDIATELY WIPED UP. 
Located in the top section of the ETM (in the collector return line) is a ball valve, used during flushing of collector loop. The valve must be open (handle in-line) during system operation, thus allowing full flow through it. By opening and closing (handle perpendicular to supply line) the valve as stated in the operational instructions, the collector loop and heat exchanger shell can be independentiy flushed and cleaned.

A strainer located in the top section of the ETM (in the collector loop) removes most of the foreign matter from the fluid as it passes through the metal screen. Foreign material should be occasionally removed from the strainer. STRAINER SHOULD NOT BE OPENED PRIOR TO DRAINING OR ISOLATING THE COLLECTOR LOOP.

The low level indicator consists of an indicator lamp (mounted on the ETM) and the pressure gauge mounted in the top section of the ETM. After charging the system to 20 psig, the gauge contact pointer should be adjusted to the proper setting ( $17 \mathrm{psig}$ ). When the collector loop loses fluid, the pressure will drop from the nominal operating 20-36 psig to the 17 psig and the lamp will light. This indicates a. possible system pressure leak, i.e., loss of fluid.

The lamp may also light if all collector fluid becomes very cold and contracts sufficiently to cause a drop in system pressure. If the lamp remains lit when the system pump $\left(\mathrm{P}_{1}\right)$ is automatically turned on, check for a leak.

NOTE: The indicator actually detects a pressure loss, and not a liquid level.

The Solar Control Panel located on the right site of the ETM senses conditions throughout the system and requirements of the household (thermostat setting) and provides ETM operational control. When opening the Control Panel, care should be taken to avoid damage to the door or cabinet finish. Switches should remain in the "AUTO" position. Secure the door after closing it with the screw provided. 
The holding pan located on rails under the ETM is provided to catch and hold the overflow from the relief valve. The remove the pan, first disengage the relief line by twisting and sliding it up until it clears the holding pan. Then grasp the pan handles and pull from under the ETM.

Operation and maintenance of the Energy Transport Subsystem components are shown in Appendix E.

CONTROL SUBSYSTEM

The installation of the control subsystem consists of installing two aquastat controllers, the thermostat, a motorized valve, three temperature sensors, an outdoor thermostat, and a shield over the temperature sensor on the collector and connecting these units with the control panel on the ETM unit. The overall control system schematic is shown in Figure 2-8. A list of control subsystem components is shown in Table 2-1.

Fiectrical wiring from the control panel is shown in Figure 2-9:

Control subsystem checkout and a description of operating modes is described in the Solar-heat Pump Control Panel section of Appendix A.

Operation and maintenance data on all control subsystem components is described in Appendix A.

SITE DATA ACQUISITION SUBSYSTEM (SDAS)

To meet the data collection, performance evaluation, and data dissemination goals of the National Program for Solar Heating and Cooling, the solar heating system will include a comprehensive instrumentation subsystem. 


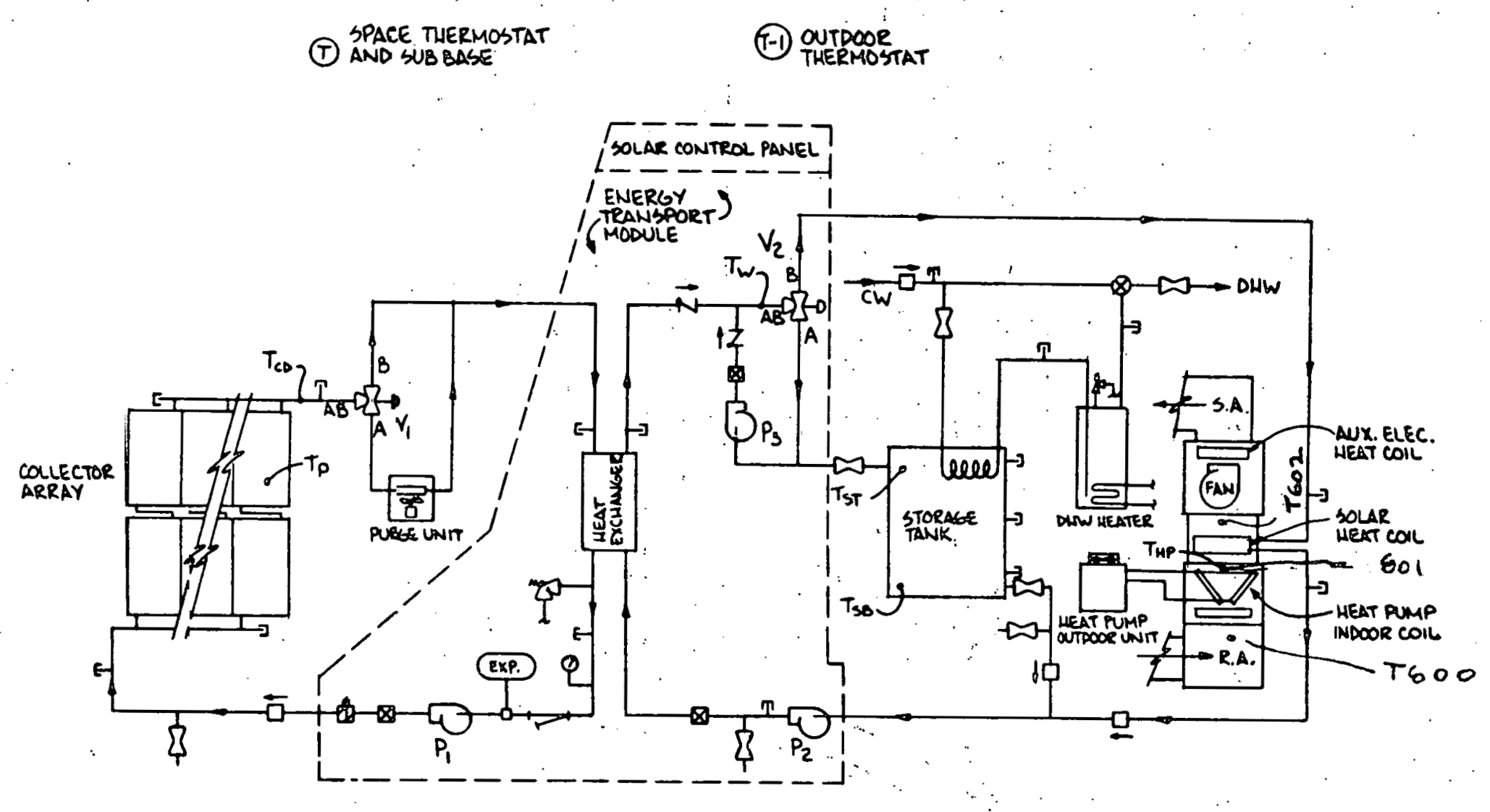

Figure 2-8. Solar Heating System Control 
Table 2-1. Control Components

FOR REFERENCE

ONLY, REMOUNTED

ON TRANSPORT MODULE SK142053

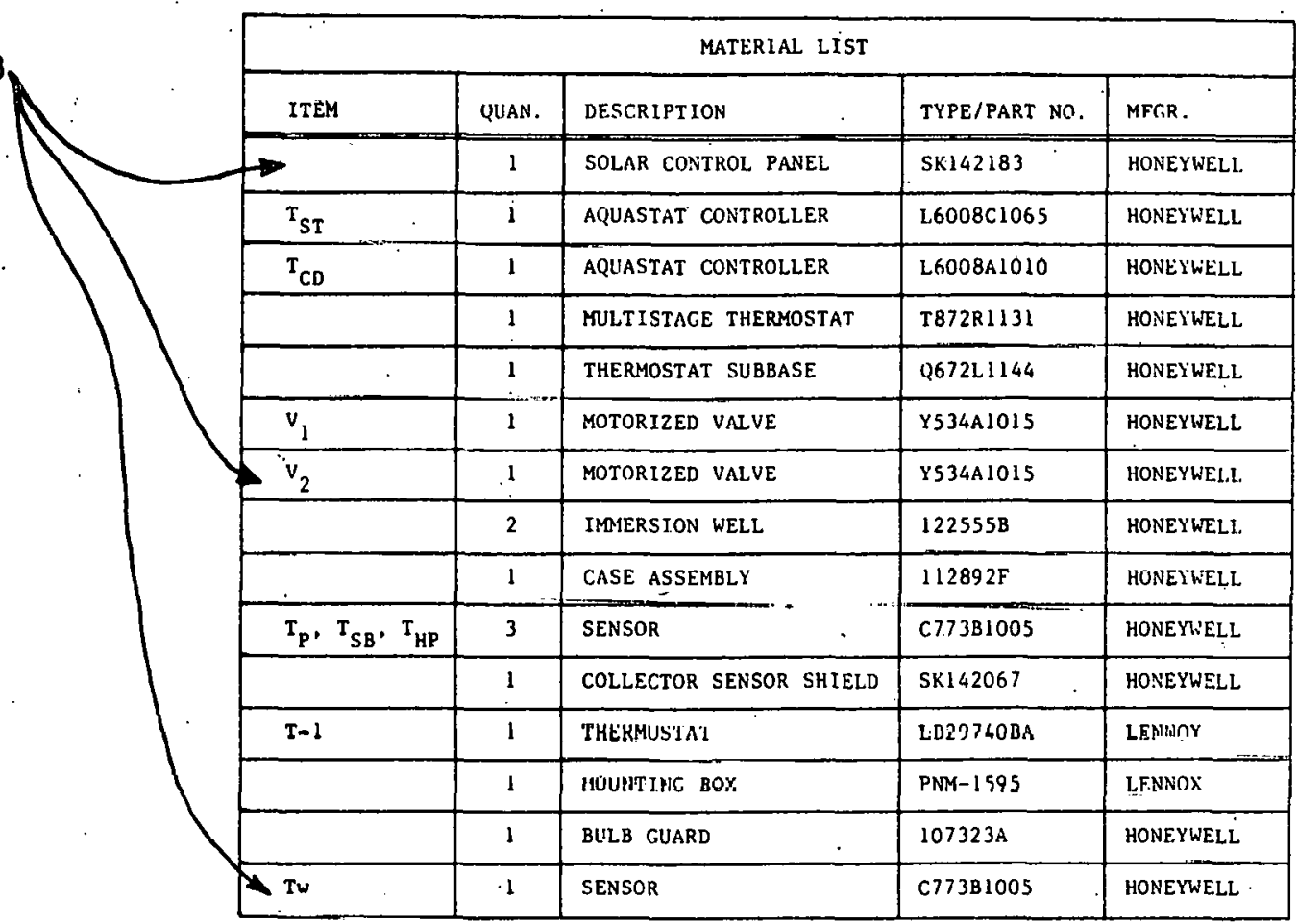




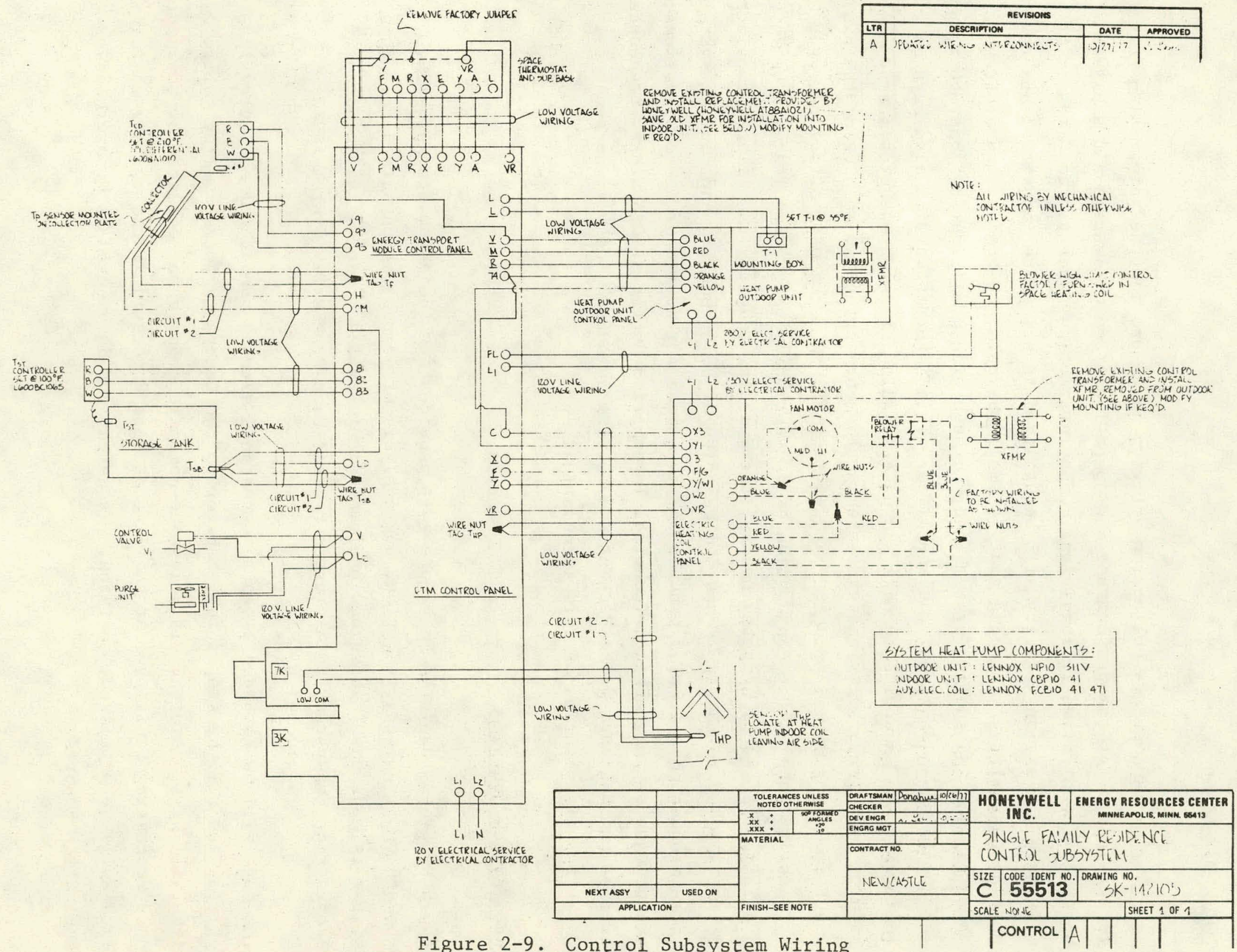




\section{Data Collection}

The goal of ERDA's data collection activity is to provide the information necessary for evaluation of the performance and operation of solar systems and subsystems under different climatic conditions. The information generated as a result of this data collection activity will be utilized to stimulate industrial and commercial capability, including that of small business, to produce and distribute solar heating and cooling systems and, through widespread applications, to reduce the demand on conventional fuel supplies. This information will also be used to improve the general knowledge and understanding of solar energy systems, to develop definitive solar energy system performance criteria, to provide the basis for component system improvement and to estimate the economics of solar energy systems in reducing the consumption of conventional fuels. Results will be available for use by property owners, the building industry and related sections of the economy to compare costs and benefits of solar heating and cooling systems. This information will also provide the data base for design of new applications in the private sector. ERDA's Technical Information Center at Oak Ridge, Tennessee, will be the National Solar Heating and Cooling Data Bank and will be the focal point for distribution of this information.

\section{Data System Uverview}

The Data System depicted in Figure 2-10 provides for the automatic gathering, conversion, transfer, reduction, and analysis of demonstration site data. This system is made up of three basic elements: installed sensors, a Site Data Acquisition Subsystem (SDAS), and a Central Data Processing System (CDPS).

The data will be gathered at each operational site at predetermined intervals of time and will be stored for transfer to the Central Processor. The collected data will be transferred via telephone communications upon request from the Central Data Processing Facility. At the Central Data Processing Facility, the collected datat will be processed, analyzed, evaluated, and documented as Perofmrance Evaluation Reports. 


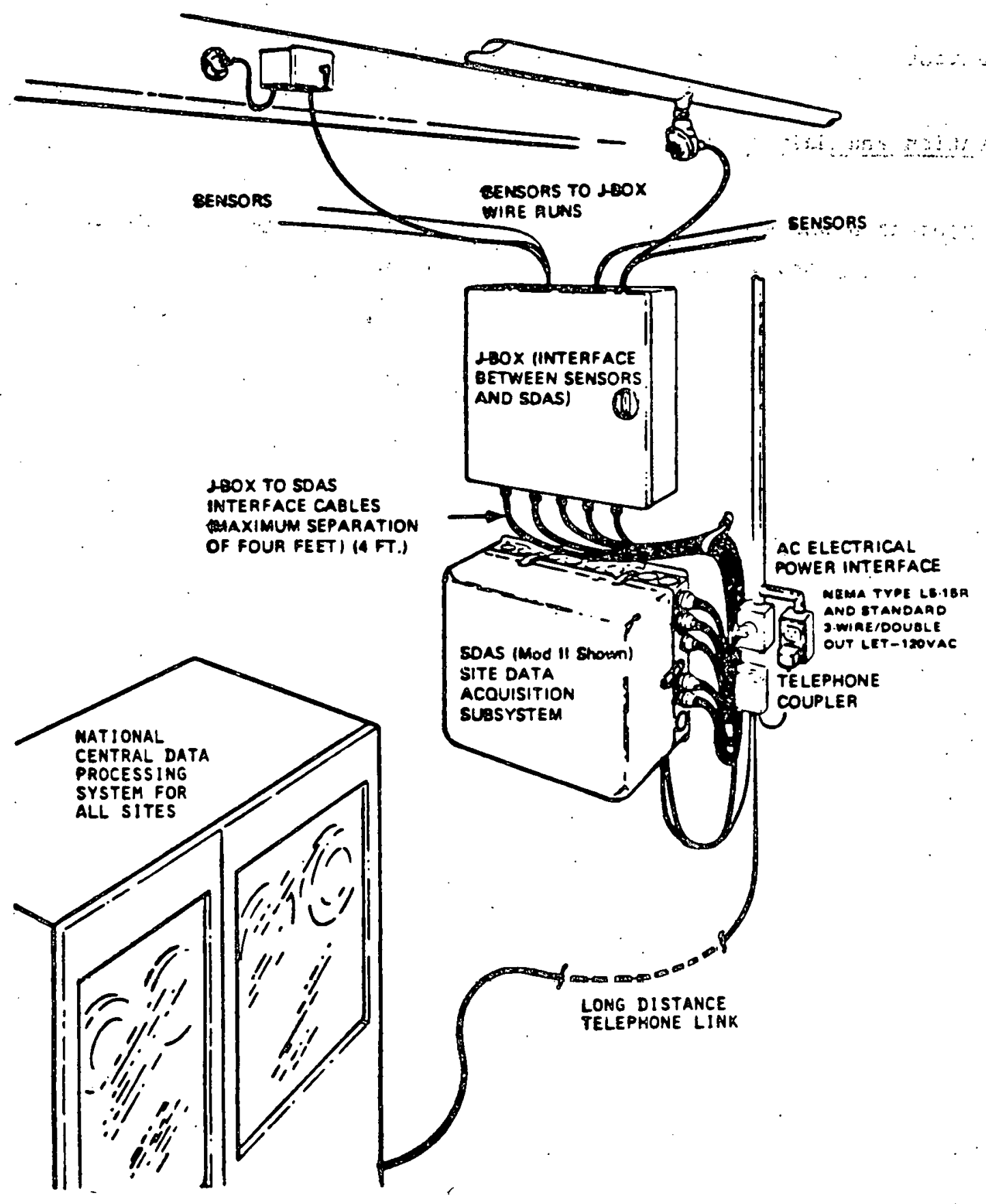

Figure 2-10. Site Instrumentation Interface Hardware 


\section{Sensor Locations}

Locations of all SDAS sensors are shown in Figure 2-11.

\section{Operation and Maintenance}

All operation and malntenance work for the Site Data Acquisition Subsystem will be the responsibility of ERDA or its appointed representative. 


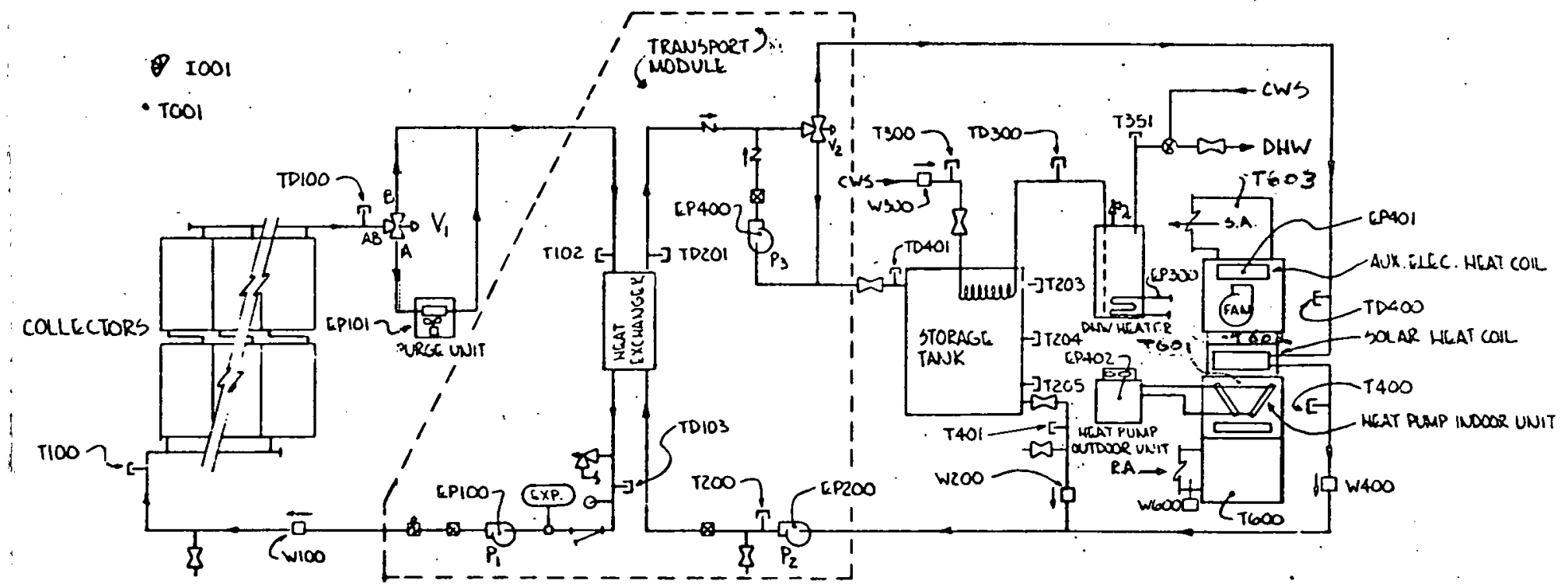

Figure 2-11. Site Data Acquisition Subsystem 


\section{SECTION $: 3$ \\ NEW CASTLE SYSTEM TEST AND FILLIÑG}

\section{TESTING}

As the hydronic loops are completed and before they are connected to the ETM, verify their integrity. Test piping and system as called, for in the construction specification.

FLUSHING AND CLEANING

After testing of the hydronic loops is completed, the following cleaning procedures should be used.

\section{CAUTION}

- DO NOT. run pumps when no liquid is present.

- Pressure should not exceed 40 psig. Maintain 20-3.5 psig during pump operation. Monitor pressure gauge periodically.

- With no isolation valves outside ETM, system must be drained before removing a.hydronic component.

- Lift check valve knob must be tumed clockwise to the fully-closed position for. HX freeze protection.

\section{Collector Loop}

The collector loop and the space heat/storage loop are controlled by the ETM. module.

- Fill valve 4 , drain valve 33 , and $\mathrm{HX}$ drain
Remove side panel

(oppusite control box) 
- Ball valve, lift check valve,

Remove top pane1 pressure gauge, and all

bleed valves

- Drain valves 非 1 and $\# 2$

Remove front panel

Flushing and draining the collector loop must be done through fill valve 非 and drain valve 3 . To clean collector loop:

a. Set all switches on control panel to STOP

b. Close ball valve and open balance vales in collector supply lines and air vents at collectors

c. Connect fill line from drum with 50 gal. of water mixed with $1 / 2 \mathrm{gal}$. trisodium phosphate to fill valve $\# 4$.

d. Open valve $\$ 4$ and, using external pump

e. Pump liquid into system.

f. A drain hose should be connected to flush valve $\|_{3}$ and run to a a large container (55-gal. drum) to catch the flushing fluid; open drain valve \#3.

g. Start pump by moving switch marked Pl to "ON."

h. Continue feeding flushing fluid until it flows freely from drain hose.

1. Close air vents at collector when air ceases to flow.

j. Energize valve VI (turn to ON position) and continue to feed fluid until it flows freely from drain hose.

k. Open ball valve and close drain valve \#3.

1. Continue to supply fluid until pressure gauge read 20 psig.

m. Bleed air from $\mathrm{HX}$ bleed valve, then

n. Close fill valve \#4. Shut external fluid supply and run system for 4 hours.

When cleaning is completed, drain total collector loop - HX fluid and measure volume so that correct amount of ethylene glycol can be mixed (see startup). 
To completely drain collector loop, the Lift Check Valve must be opened (turn knob counterclockwise till it stops). Insure knob is returned to the fully closed position.

After system is totally drained, remove drain.plug from HX to empty shell side and remove and clean strainer.

The collector loop should now be flushed with clean water for two hours. This may be accomplished using the water system. Caution: Insure supply pressure does not exceed 40 psi. It should be connected to fill valve No. 4. Pump $P_{1}$ need not be energized, but ball valve must be closed. A drain hose should be connected to drain valve No. 3 and run outside to an appropriate area.

The HX portion of the system should be flushed as follows:

a. Close ball valve and drain valve 3 .

b. Open HX drain and connect drain hose to it.

c. Pump fluid into fill valve $\$ 4$ and out of HX drain.

\section{Storage and Heating System Loop}

The storage and heating system loop should be flushed and cleaned prior to... filiing.

a. The storage tank should be flushed first. Connect hose to drain valve on bottom of tank and open valve. Drain hose should be run to appropriate floor drain. Remove manhole cover and, using hose connected to household water supply, flush interior of tank.

CAUTION: Do not enter tank with shoes as interior lining could be. domaged. 
To flush heat coil loop, connect a drain hose to drain valve 非 in ETM, open valve, and connect a hose from household cold water supply to drain valve $\$ 2$ in ETM. Close both isolation valves on inlet and outlet of storage tank. With control valve $V_{2}$ "OFF," turn water on, and let water flow for 30 minutes. Next, connect drain hose to drain $\left.\right|_{2}$ and connect water supply to drain \#1. With control valve $v_{2}$ "ON,": turn water on and let flow for 10 minutes.

b. When system is thoroughly flushed, shut off drain valve and fill tank to 6" below Lup of lank. Add inhibitor, 5 gallons $(1200 \mathrm{mg} / 1)$ of Norman Chemical product no. 284, 16.30 Carroll Ave., St. Paul, MN, or equal sodium nitrite based inhibitor.

\section{BALANCING}

Using a Bell and Gossett Delta Pressure readout kit or equivalent, adjust the Bell and Gossett Circuit Setter Balance Valves to the below listed values. Proceed per instructions included with readout kit and connect to Circuit Setter. 1 in ETM (heat from storage). Manually start P3. Adjust flow to 8 GPM.

Kepeat procedure with Circuit Setter $\# 2$ in ETM (storage charge loop). Run P2. Adjust flow to $8 \mathrm{GPM}$.

NOTE: If full flow is not attained through Circuit Setter 1, 2, and 3, ieave in open position (sero setting).

Repeat procedure with Circuit Setters in supply line to two-high collector array. (Not in ETM) with P-1 operating. Adjust flow to $9.5 \mathrm{GPM}$.

Repeat procedure with circuit setter flow balance valve in supply line to onchigh collector array (not in ETM) with P-1 running. Adjust flow to 2.5 GPM.

NOTE: Important to maintain the 9.5:2.5 ratio. 
STARTUP

Collector Loop (approximately 30 gallons total)

Fill the collector loop with an aqueous ethylene glycol solution, $40 \%$ Dowtherm SR1 ethylene glycol. Mix the glycol and water in a 55-gallon drum. Connect fill hose to fill valve \#4. Connect inlet of external pump to 55-gallon drum, open f11l valve \#4 and start pump. Open all air bleeds in the system and fill slowly. It is imperative not to fill the system too rapidly. Close air bleeds as they begin to leak. Precautions should be taken to prevent the glycol mixture from spilling onto the building or collector array.

\section{System Pressurization}

Once the system is full and purged of air, it may be pressurized to 20 psig as shown on low water/pressure gauge using external pump and 40/60 mixed solution. Energize the collector system pump $P_{1}$ manually. Air that is trapped will tend to be separated by the air separator as the fluid circulates. This will cause a decrease in the fluid level within the collector loop. It is important to watch this pressure level to see that it does not get too low. If it does, the low fluid warning light will come on. If the pressure gets low, add more fluid to the collector loop to maintain the 20 psig charge pressure. Low water/pressure gauge should be set to 15 psig. 


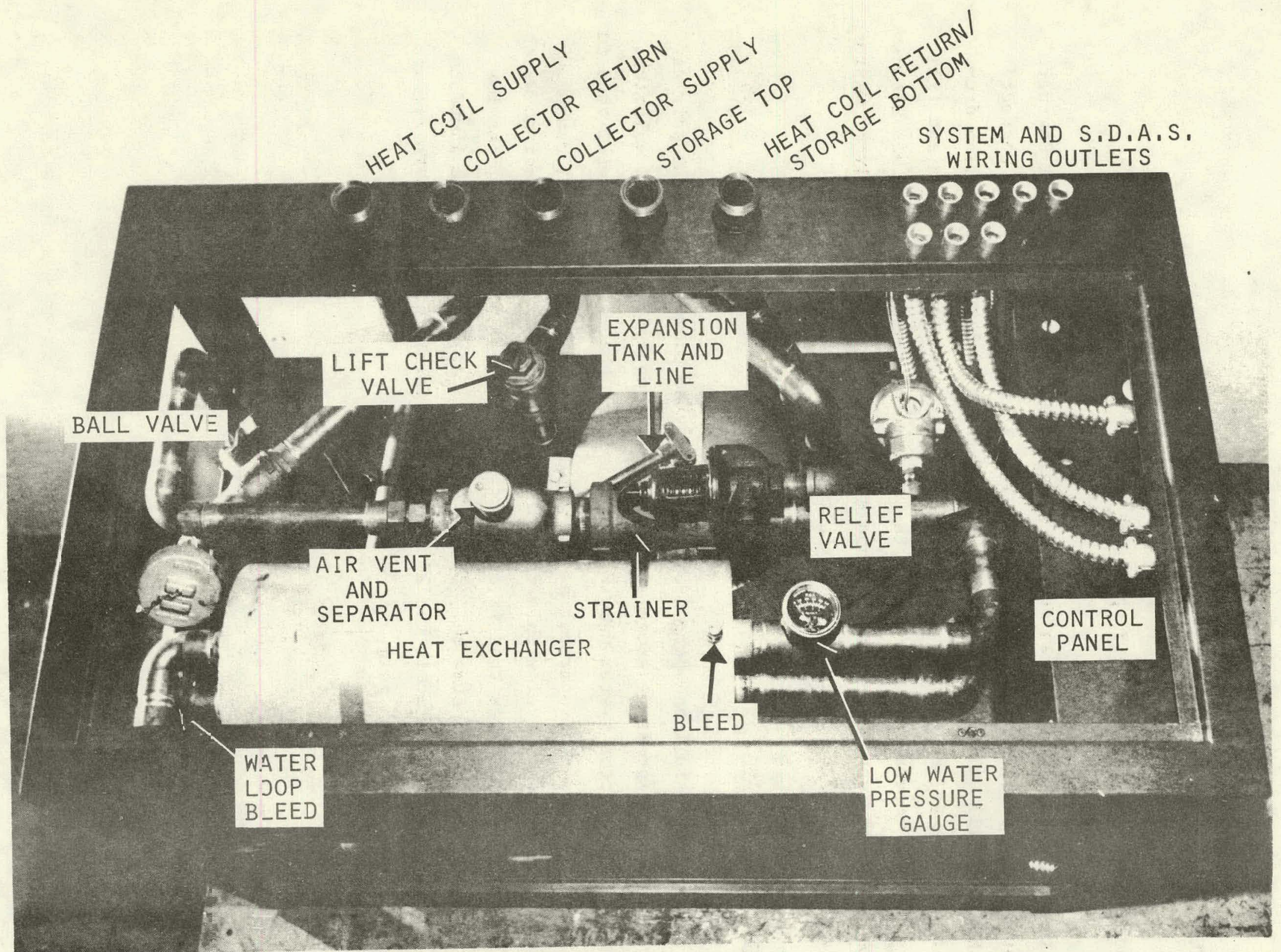

Figure 3-1. SK142065-ETM-2 Top View 


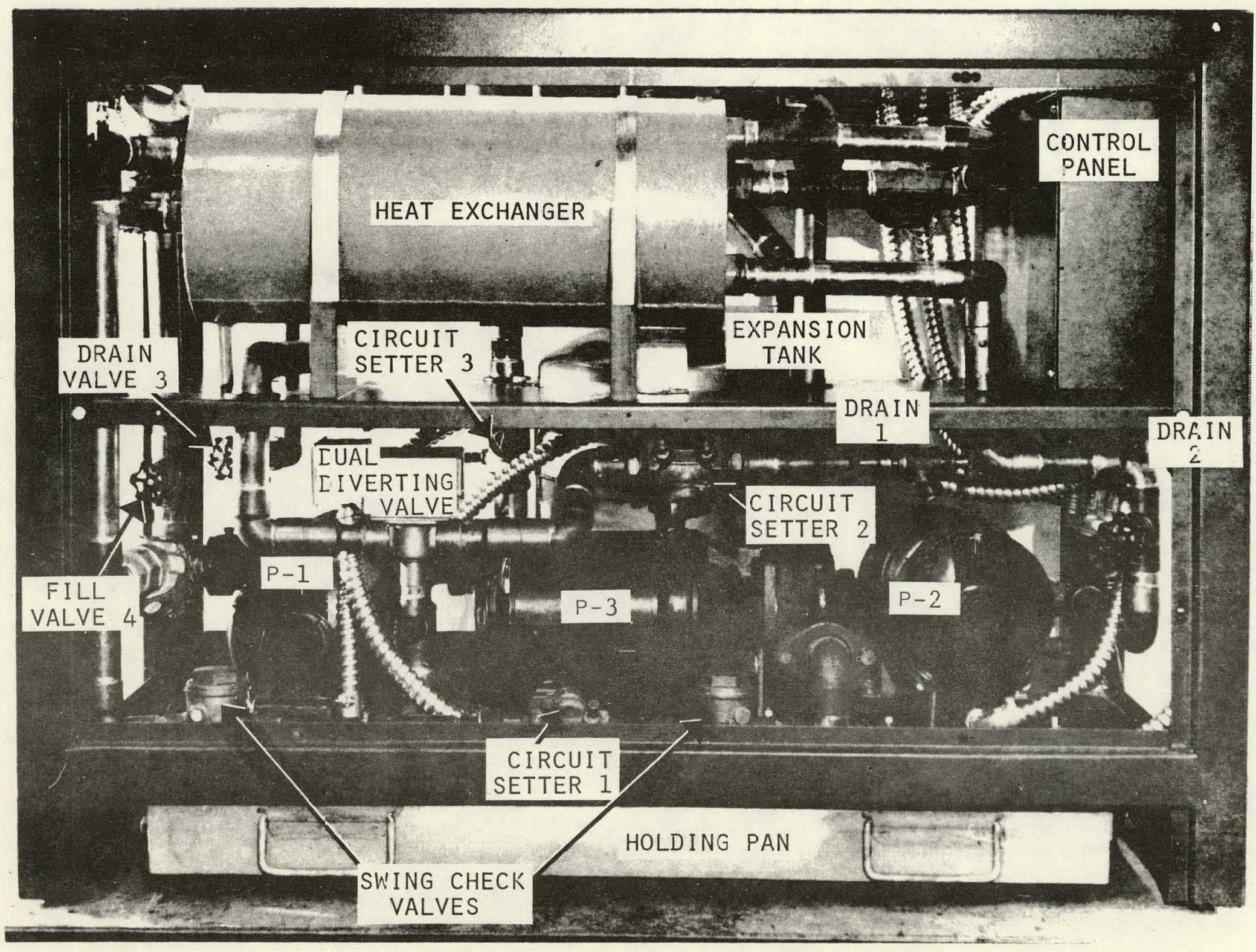

Figure 3-2. SK142065-ETM-2 Front View 


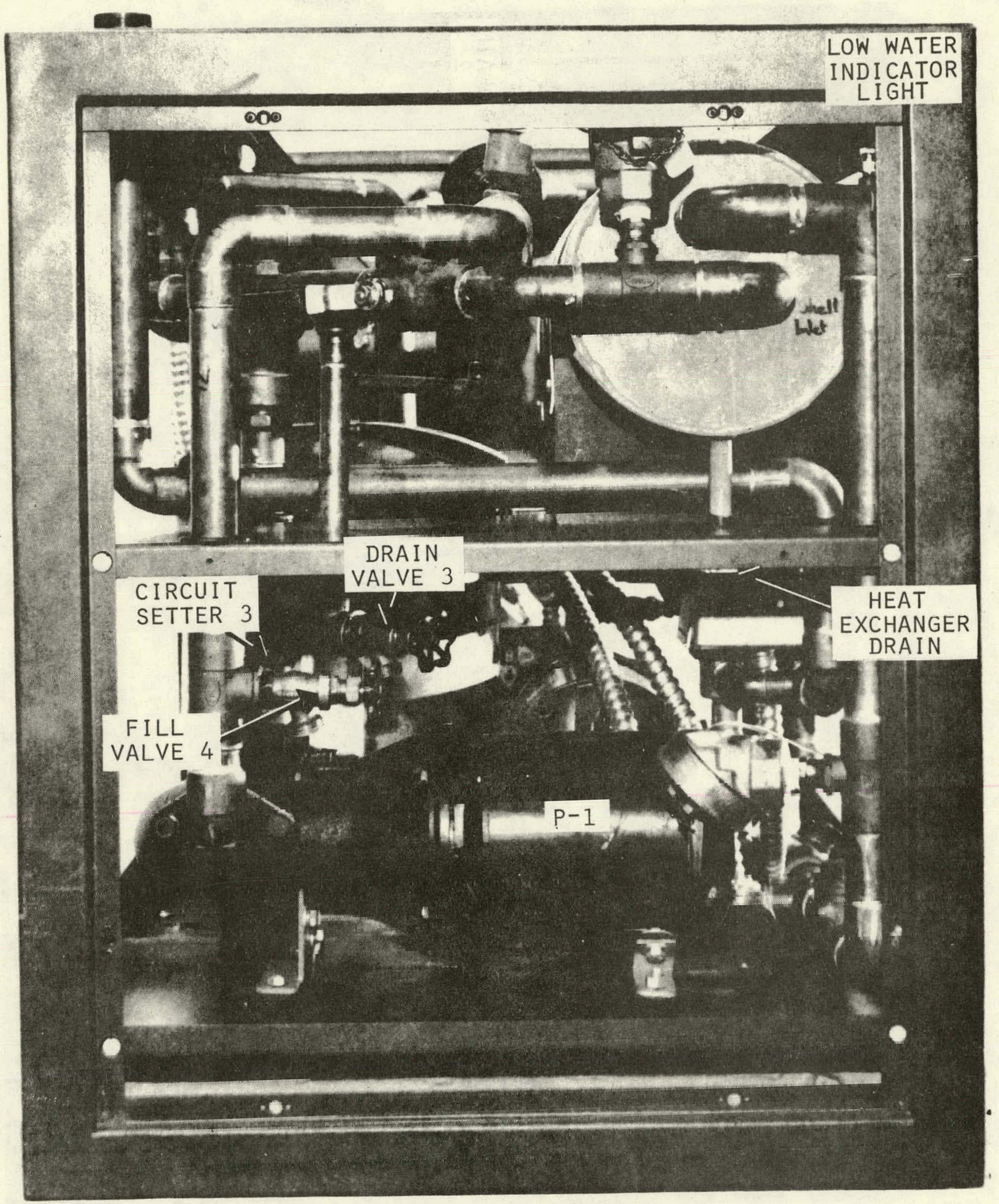

Figure 3-3. SK142065-ETM-2 Left Side View 


\section{Collector Loop Refilling Procedure}

1. Drain and Refill system at night or at dusk only.

2. Drain collector loop if necessary according to following steps:

a. Note: Ethylene glycol is a toxic fluid, do not dump in floor drain, sewer or storm sewer. Dispose of properly.

b. Connect a hose to drain valve \#3 and run into a 5 gallon pail.

c. Open drain valve \#3 to drain collectors and piping.

d. Operate control valve $\mathrm{V} 1$ to drain fluid from piping to .... ,,$\ldots$ Purge Unit.

e. Remove drain pan under Energy Transport Module (ET M) and empty fluid, dispose of properly.

3. Flush system with clean water by the following steps:

a. Note: Dispose of flushing water properly as above.

b. Leave hose on drain valve \#3, run to 5 gallon pail.

c. Open drain valve \#3

d. Connect another hose from cold water faucet in house to flll valve \#4.

e. Close ball valve in ETM (red handle).

f. Open cold water faucet, open fill valve \#4 and run pump P1 to flush system.

g. Flush for several minutes. 
h. Operate control valve V1 to flush piping to Purge Unit.

i. Flush for several minutes

j. Open ball valve in ETM (red handle)

k. Flush for several minutes

1. Flush as above until water coming out of hose is clean

m. Stop pump P1

n. Close cold water faucet. Close fill valve \#4 and remove hose.

4. Drain collector loop as in part 2 above.

5. Refill system with new ethylene glycol according to following steps:

a. Make new collector loop solution by mixing new ethylene glycol with clean water in a barrel or garbage can to a mixture of $45 \%$ to $50 \%$ ethylene glycol by volume. After filling system pressurize with clean water to provide a final solution of $40 \%$ ethylene glycol by volume (approx.). Procure at least 20 gallons of ethylene glycol to make the required 38 gallons of solution. Add ethylene glycol and water to barrel periodically during filling according to above instructions.

b. Close drain valve \#3.

c. Pump solution into collector lonp by either of following molhode:

1. Procure a positive displacement pump having an available pump head of 50 feet minimum. Place pump and barrel in basement and pump solution thru a hose into fill valve \#4.

$\underline{\mathrm{OR}}$ 
2. Procure a small submersible sump pump having an available pump head of 15 to 20 feet. Place solution barrel on second floor balcony of house, lower sump pump into barrel and run a hose from the pump discharge down to fill valve \# 4 in ETM.

d. Using a ladder climb up onto lower roof at lower bank of 6 solar collectors. Remove flashing over top collector header at left end of collector bank at point A. Open vent valve.

e. Using ladder climb up onto upper roof and climb up to the top of the upper bank of 22 solar collectors. Remove flashing over top collector header at left end of collector bank at point B. Open vent valve.

f. Monitoring vent valve at point $A$, open fill valve \#4 and start sump pump.

g. Operate control valve V1 periodically to fill piping to Purge Unit.

h. Vent air in ETM at air vent and heat exchanger periodically.

i. Leave vent valve at point $A$ open until solution starts coming out then close valve. Run pump P1 if necessary.

j. Run pump P1.

k. Monitor vent valve at point B. Leave open until solution starts coming out, then close valve. Open vent valve periodically to vent air in header.

1. Let system circulate for 20-30 minutes.

m. Vent air in system at vent valves periodically. 
n. Vent air in ETM at air vent and heat exchanger periodically.

o. Operate control valve V1 periodically to fill piping and remove air in lines to Purge Unit.

p. Repeat 1.-0. until system is full of solution and all air has been removed. The system should require 36 to 38 gallons of solution.

q. Close fill valve \#4.

r. Stop sump pump and remove hose

s. Connect a hose from cold water faucet to fill valve \#4

t. Open cold water faucet and fill valve \#4. Pressurize system to 25 psig on pressure gauge.

u. Close fill valve \#4, close cold water faucet and remove hose.

v. Run pump P1 and operate control valve V1 periodically to verify that the system is filled and all air has been removed.

w. Re-install flashing on roof at points A and B and re-caulk as required. 
SECTION 4

ROUTINE MAINTENANCE

The Solar Heating System requires on $1 y$ a small amount of routine maintenance. The elements requiring maintenance are broken down by subsyștems and.are described below.

COLLECTOR SUBSYSTEM

The collector subsystem components requiring routine maintenance are the solar collectors and the purge unit.

\section{Solar Collectors (LSC 18-1)}

Normal rainfall will usually suffice for cleaning. However, inspect spring and fall for dirty cover glass. Clean glass using a soft clean cloth, mild soap "or detergent and clean rinse water. Alkalies can stain the glass if allowed to remain in contact too long.

Purge Unit (HRW-1-30)

Inspect spring and fall for debris on coil. Clear debris from coil with brush unit may be flushed with water hose if necessary. Lubricate motor in accordance with guide on motor.

STORAGE SUBSYSTEM

The water in the storage tank should have the inhibitor and the water condition checked annually. If the tank water has a pungent.odor or dark discolorization, 
drain tank and refill with clean water adding inhibitor as called out in Section 3 .

The inhibitor $\mathrm{pH}$ level should be between 7:0 and 9.0. Draw a small amount of water from the storage tank drain valve. Using a $\mathrm{pH}$ test kit, dip a short piece of test paper in the fluid drainoff. Observe the color of the moistened portion and compare to color chart with kit. The desired $\mathrm{pH}$ is 8.0 or higher. If the $\mathrm{pH}$ is less than 8.0, add 5 gallons of Product No. 284 made by Normal Chemical Co., 1630 Carroll Ave., St. Paul; Minnesota, or equivalent to reach a value of 1200 $\mathrm{mg} / 1$. (1200 ppm) of nitrite base.

Adding inhibitor and filling tank may be done through the manhole in the tank top. Tank may be drained by connecting drain hose to tank drain on bottom of tank.

AUXILIARY ENERGY AND SPACE HEAT SUBSYSTEM

The heat pump indoor unit should have annual checks on the following:

- check and clean blower wheel

- lubricale bluwer mutor

- replace filter media*

- check unit operation

*Filter should be checked monthly during heavy operation and replaced as needed.

HOT WATER SUBSYSTEM

To assure long life and efficiency, the water heater tank should have a small amount of water drained periodically. Once very month or two the drain valve should be opened and the water allowed to run until it flows clean. This will help prevent sediment buildup on the bottom of the tank. 
ENERGY TRANSPORT SUBSYSTEM

The Energy Transport Module (ETM-1) has three pumps that should be lubricated every three months. Proper lubrication is the most important single factor in obtaining long life and trouble free operation. Each oil cup, two on motor and one on the pump, should be filled with \#20.nondetergent motor oil.

Transfer Fluid (SR-1), the ethylene glycol and water mixture, contains corrosion inhibitors. An annual test of the fluid is necessary to avoid plumbing decay. DO NOT ADD CHROMATE INHIBITORS TO SYSTEM. Using a standard pH test kit, dip a short piece of test paper in a small amount of fluid drawn from drain valve 非 in ETM. Observe the color of the moistened portion and compare to color chart with kit. The desired transfer fluid $\mathrm{pH}$ is 8 or higher. If the $\mathrm{pH}$ is less than 8 , acids are forming in the fluid. The dwelling owner should call the solar system man to add inhibitor to system. Use Figure.4-1 to determine the correct quantity of hibitor to be added. After 30 minutes of system operation, recheck $\mathrm{pH}$ level for proper value.

If the $\mathrm{pH}$ is less than 8 , the inhibitor is becoming depleted, "and "ading inhibitor to protect the system is recommended. Such inhibitor is readily available from the Dow Chemical Company in five-gallon lots. Since the inhibitors are specially designed for Dowtherm SR-1 heat transfer medium, other type inhibitors should never be mixed with this material.

CONTROL SUBSYSTEM

The control subsystem does not require any periodic maintenance. This subsystem can be used to check system operation, as shown in Appendix A. 


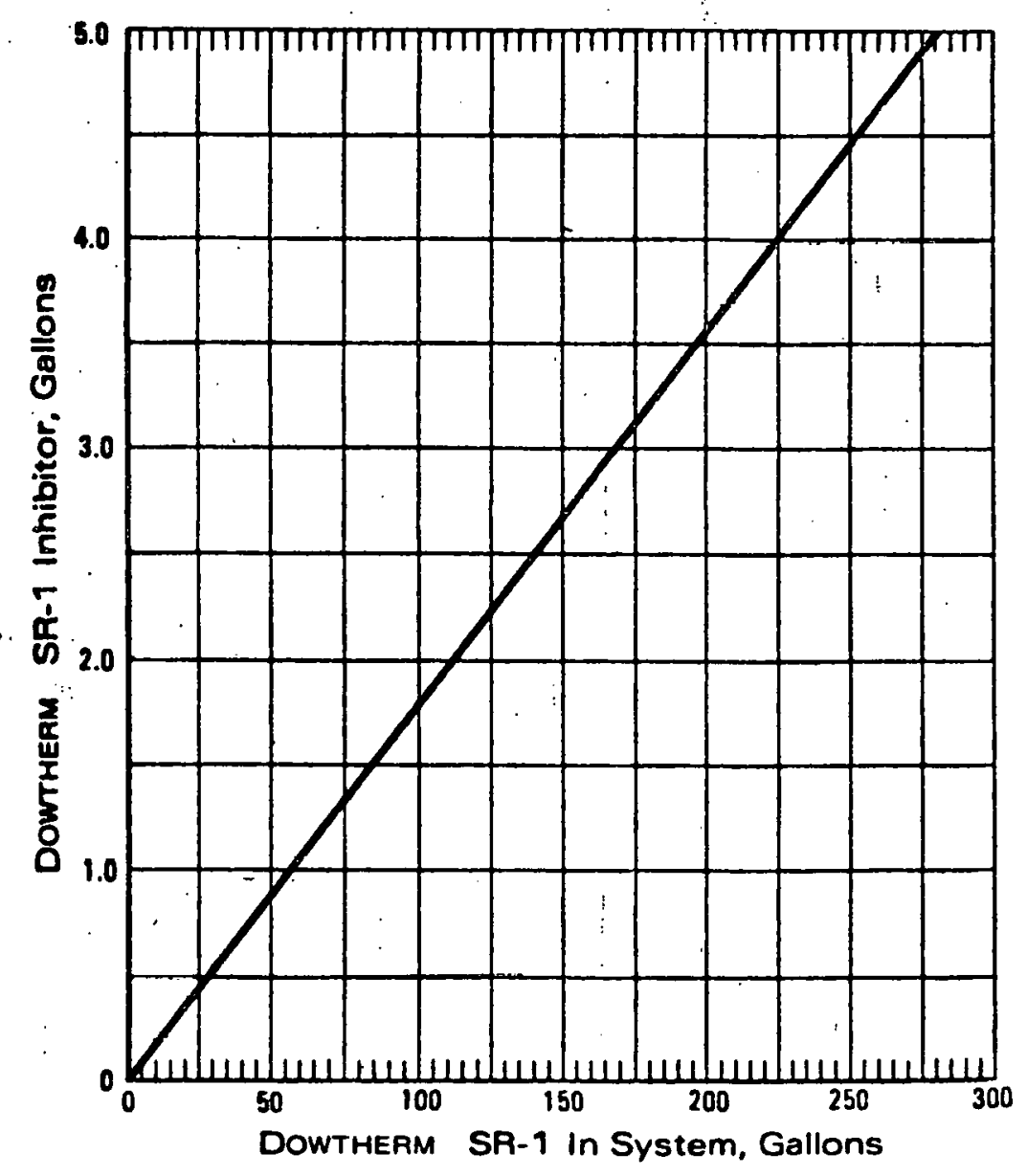

Figure 4-1. Quantities of Inhibitor for DOWTHERM to Recharge Syetcm Containing DOWTHERM 


\section{SECTION 5}

MAINTENANCE SCHEDULE

Table 5-1 outlines the routine maintenance required for the single-family Solar Heating System.

Table 5-1. Routine Maintenance

\begin{tabular}{|l|l|c|c|}
\hline \multirow{2}{*}{ Frequency } & \multicolumn{1}{|c|}{ Activity } & \multicolumn{2}{|c|}{ Reference } \\
\cline { 2 - 4 } $\begin{array}{l}\text { Quarterly } \\
\text { every 3 } \\
\text { monts }\end{array}$ & $\begin{array}{l}\text { Check heat pump indoor unit air filter } \\
\text { Hot water heater sediment drain } \\
\text { ETM pump lubrication }\end{array}$ & - & Appendix \\
\hline $\begin{array}{l}\text { Semi-Annual } \\
\text { or } \\
\begin{array}{l}\text { Seasonal } \\
\text { Annual }\end{array}\end{array}$ & $\begin{array}{l}\text { Clean Collector Glass } \\
\text { Clean purge unit }\end{array}$ & - & - \\
\hline Clean heat pump outdoor unit & $\begin{array}{l}\text { Storage tank fluid check } \\
\text { Service heat pump indoor unit } \\
\text { Solar collector fluid check }\end{array}$ & 4 & E \\
\hline
\end{tabular}


APPENDIX A

CONTROL SUBSYSTEM

Control Panel

Thermostat

Aquastàt Controllers 


\section{Honeywell}

\section{SOLAR-HEAT PUMP CONTROL PANEL}

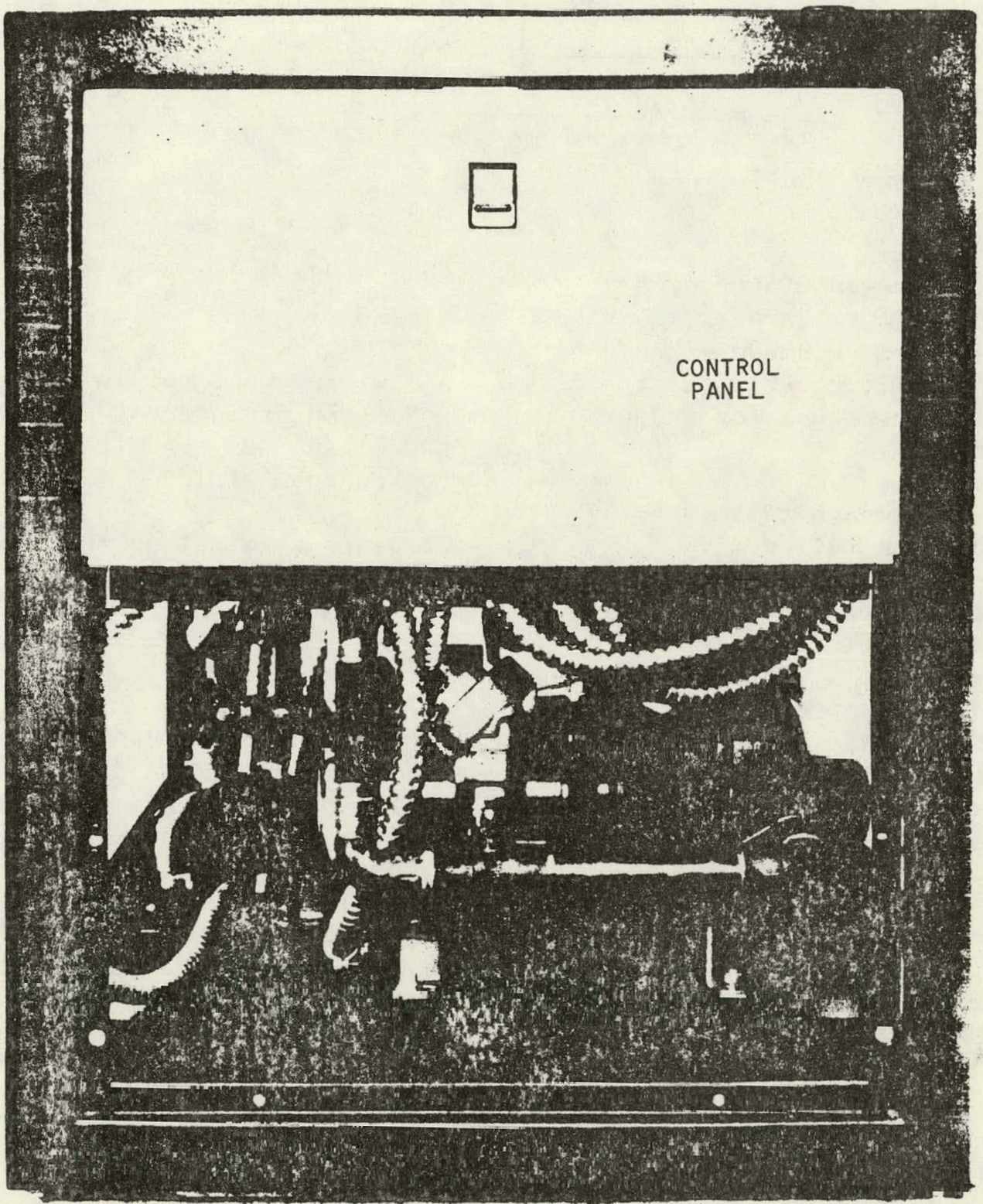




\section{*** * CAUTION * *}

1. Installer must be a trained, experienced service technician.

2. Disconnect power supply before connecting wiring.

3. Conduct thorough checkout when installation is complete.

4. Shield the collector with sensor against possible overtemperature conditions prior to system operation.

5. Wire additions to the leadwire must be capable nt withatanding a temperature of $450^{\circ} \mathrm{F}$ $\left(232^{\circ} \mathrm{C}\right)$.
Install C773 as a collector sensor using the mounting clip provided and No. 8 or 10 screw. Install collector sensor shield.

Temperatures in excess of $450^{\circ} \mathrm{F}$ $\left(232^{\circ} \mathrm{C}\right)$ will damage the sensor. Shield the collector with sensor against possible overtemperature conditions prior to system operation. Do not mount collector sensur to collector fluid channels.

\section{MOUNTING ELECTRONIC TEMPERATURE SENSORS}

Follow the system manufacturer's recommendations for the best location of the sensor. Each sensor should be located so that it experiences the most useful temperature for proper system operation.

Mount C773 in storage tank using an immersion well as follows:

1. Drain system fluid to a point below the sensor fitting.

2. Screw the well into the threaded fitting. Use an approved pipe dope or Teflnn tape to seal the threads.

3. Refill system and check for leaks.

4. Insert the sensor probe into the $i$ nersion well until it hottoms.

5. Attach retainer clamp groove on we11 spud. Fit wires in clamp groove and lightly tighten screw. Do not overtighten. If a remote sensor wiring compartment is used, secure the sensor with the spring clip instead of the retainer clamp.

\section{WIRING}

A11 wiring must comply with applicable codes and ordinances. The ETM has three $1 / 2$ inch conduit connections for control wiring. (See Figure 1.)

Pressure terminal connections are used for the wiring hookup.

If the amount of electronic temperature sensor cable used exceeds 100 feet $(30.5 \mathrm{~m})$, use No. 14 wire and givunded metallic conduit or shielded cable. Connect the shield to ground at the panel. Grounded metallic conduit and shielited cable (such as Belden 8762 or equivalent) minimize possible radio frequency signal interference. Wire additions to the leadwires must be capable of withstanding maximum collector stagnation temperatures if installed within the collector. 


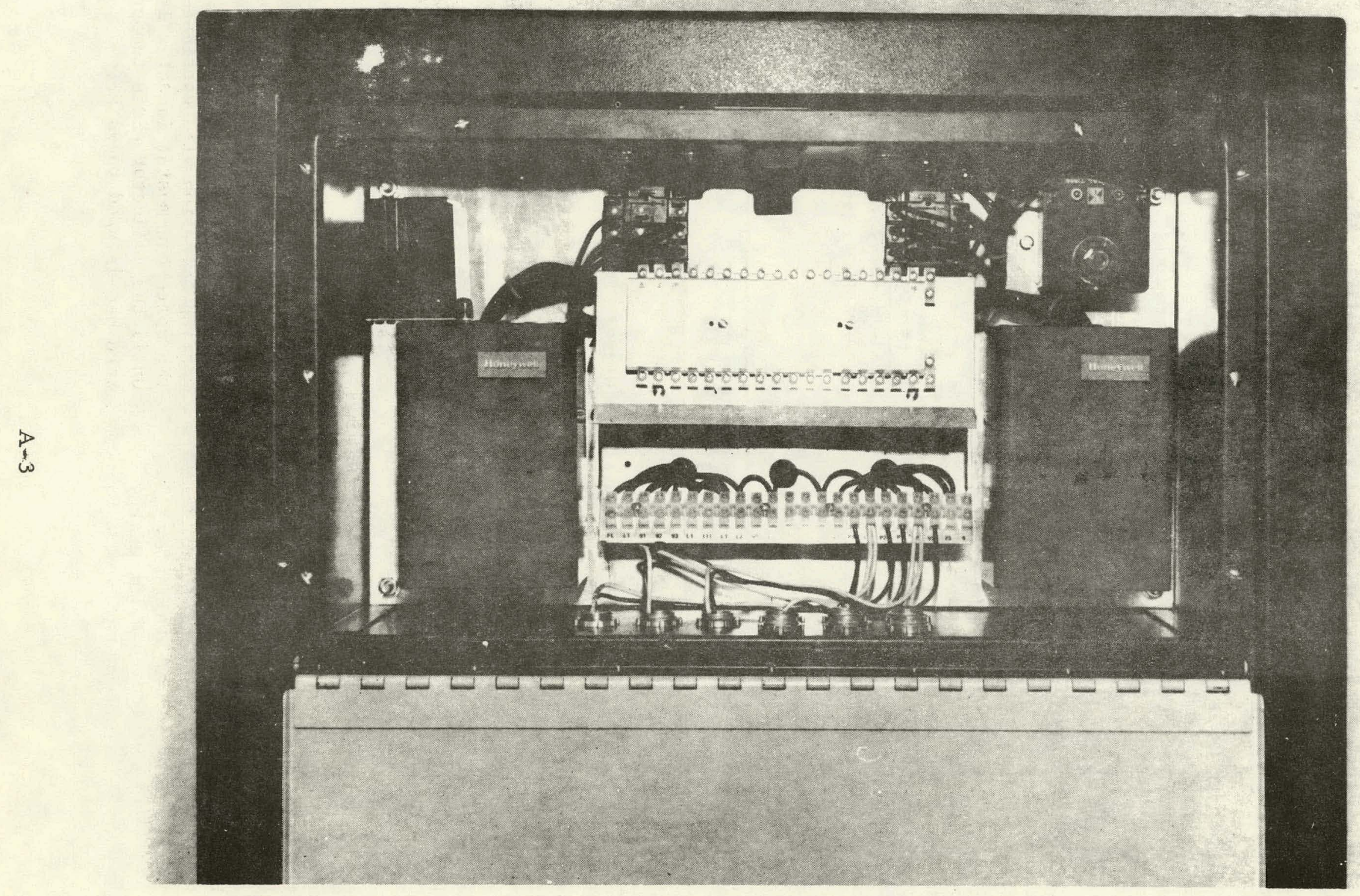

Figure 1. Control Panel Installed in Energy Transport Module 
ADJUSTMENTS

AUTO-STOP-ON SWITCHES: For normal operation, the panel switches should remain in the AUTO position. The ON and STOP positions of these switches are useful during installation and calibration of the heating system. They may also be used for manually operating the system if necessary.

\section{COLLECTOR SETPOINT POTENTIOMETER.}

The collector setpoint potentiometer establishcs the minimum fluid temperature that the heating system will accept from the collector for direct heating of the house. Set the collector setpoint potentiometer to the desired setting; $105^{\circ} \mathrm{F}\left(40^{\circ} \mathrm{C}\right)$ is the recommended setting.

\section{CHECKOUT}

AUTO-STOP-ON SWITCHES: One by one, set the AUTO-STOP-ON switches in the ON position to check that the pumps and control valve have been wired correctly and that they are operating properly. Set to AUTO position for system checkout.

HEAT PUMP: Complete all electrical power wiring to heat pump outdoor unit, heat pump indoor unit and clectric coil. Complete all cuntrul wiring to control panel.

PROCEDURE: Follow instructions in Table 1 for checkout of all modes of operation.

\section{OPERATION}

\section{OPERATION}

Space heating is controlled by a twostage heating thermostat. First-stage heating utilizes solar energy if available, while second-stage heating will supply auxiliary energy. The system control logic is as follows:

- Coilect solar energy when availablc. Store energy under no-load conditions.

- Provides energy directly to load on demand. Use direct solar energy before stored energy.

- Use storage energy when direct solar energy is not available.

- Use direct or stored solar energy before auxiliary energy.
TTREC:T HEATING FROM COLLECTORS

Whenever the collector plate temperature $\mathrm{T}_{\mathrm{p}}$ is greater than $105^{\circ} \mathrm{F}$ (adjustable) and there is a call for heating from the space thermostat, pumps $\mathrm{P}_{1}$ and $P_{2}$ are activated. Valve $V_{2}$ is positioned to direct flow to the heating coil. 'lhe heat pump indoor unit fan is activated to provide warm air to the space.

An overtemperature limit on the heat pump indoor unit fan will cause valve $\mathrm{V}_{2}$ to direct flow to the storage tank if the heating coil leaving air temperature exceeds $140^{\circ} \mathrm{F}$. Direct heating operation will continue until the space thermostat is satisfied or until the collector plate temperature has dropped to $90^{\circ} \mathrm{F}$. 
Table 1. Control Subsystem Checkout Procedure

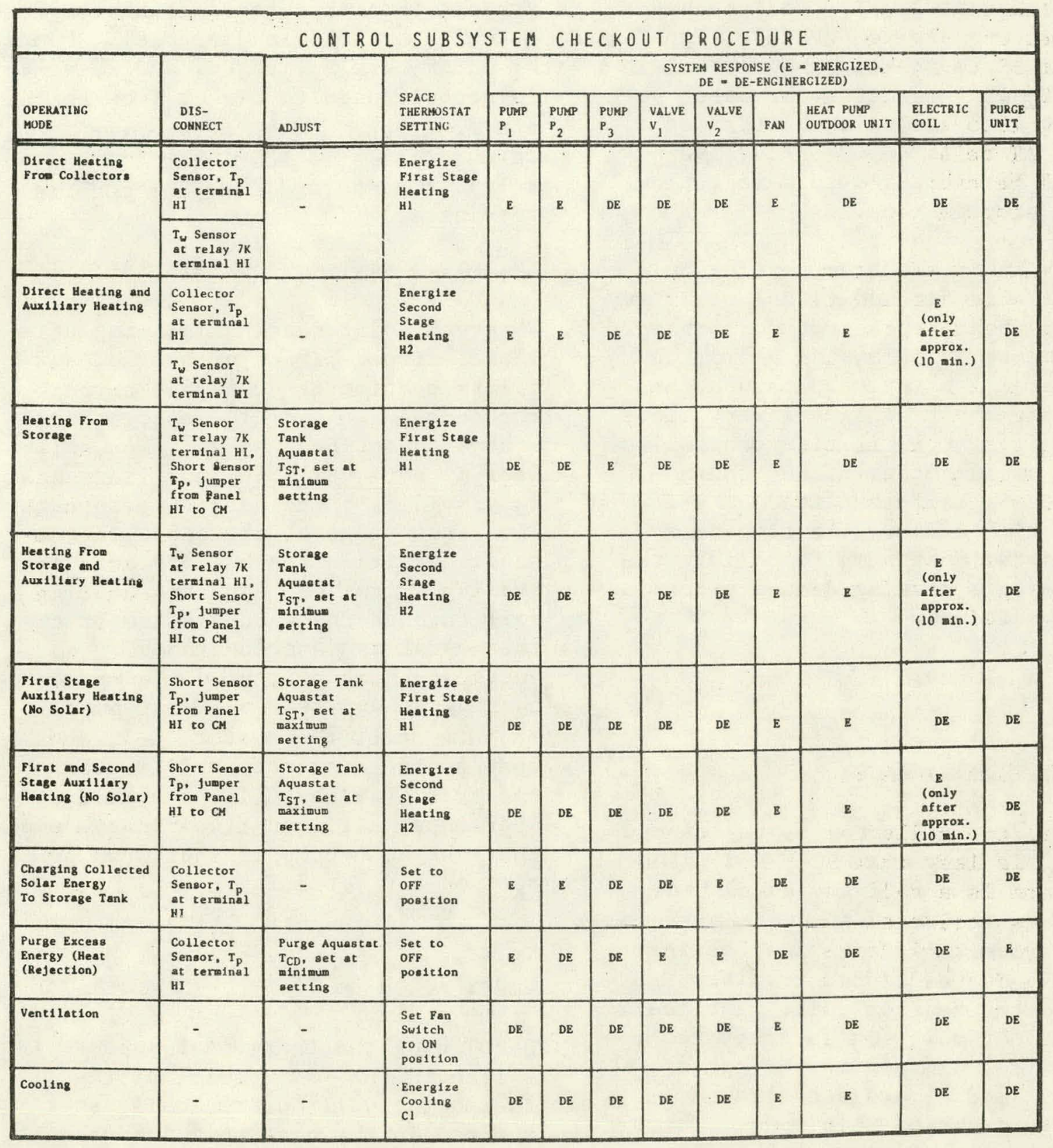


On a second stage call for heat, the heat pump is energized to provide additional heat to the space. A differential temperature controller senses the solar heating coil inlet water temperature, $\mathrm{T}_{\mathrm{W}}$, and the heat pump leaving air temperature, $\mathrm{T}_{\mathrm{HP}}$. - If that $\Delta \mathrm{T}$ is greater than $10^{\circ} \mathrm{F}$, valve $V_{2}$ will permit solar water to flow thru the solar heating coil. If the $\Delta \mathrm{T}$ falls below $5^{\circ} \mathrm{F}$, valve $v_{2}$ will be energized to divert flow to the storage tank.

The auxiliary electric heating coil is available for additional auxiliary heating whenever the outdoor ambient temperature is below the normal heat pump balance point temperature, in this case $35 \%$ F. The auxiliary electric heating coil is also controlled by the second stage of the thermostat and is energized after a $9-1 / 2$ minute time delay. The time delay enables the heat pump to satisfy the second-stage heating demand under most conditions.

\section{HEATING FROM STORAGE}

Whenever the collector plate temperature $\mathrm{T}_{\mathrm{p}}$ is less than $90 \mathrm{~F}$ (adjustable), and there is a call for space heat, pump 3 is activated to use heat from the storage tank for space heating. Valve $V_{2}$ is positioned to direct flow to the heating coil. The heat pump indoor unit fan is activated to provide warm air to the space. Pumps $P_{1}$ and $P_{2}$ are not allowed to operate during this mode. The high temperature limit located on the fan functions as previously described.

The second stage of the thermostat controls auxiliary heat from the heat pump and the electric heating coil as described above.

\section{STORAGE CHARGING}

Storage charging is accomplished whenever there is no call for heat and the collector plate temperature $\mathrm{T}_{\mathrm{p}}$ is greater than the storage tank temperature $\mathrm{T}_{\mathrm{SB}}$ by $18^{\circ} \mathrm{F}$ (adjustable). Pumps $\mathrm{P}_{1}$ and $\mathrm{P}_{2}$ are activated, and valve $\mathrm{V}_{2}$ is repositioned to direct flow to the storage tank. If this temperature difference falls to less than $3^{\circ} \mathrm{F}$ (adjustable), the storage charging mode is terminated.

\section{AUXTLIARY HEATING}

Whenever solar heating is being utilized, either dirert or stored, auxiliary heating is available through the second stage of the space thermostat as described above. When solar heat is not available, auxiliary heat is provided by the heat pump through the first stage of the space thermostat. Additional auxiliary heat is available from the electric heating coil through the second stage of the thermostat as described above. An energency heat switch on the space thermostat bypasses the heat pump balance point thermostat, $\mathrm{T}-1$, and enables the system to utilize the electric heating coil for alliliary heat under all conditions in the event that the heat pump is shut down or removed for servicing.

\section{VENTILATION}

By placing the thermostat subbase fan switch in the "ON" position, the Lhermostat will automatically energize the fan in the heat pump indoor unit.

\section{COOLING}

Conventional direct expansion cooling is provided by the heat pump as controlled by the cooling section of the space thermostat. 


\section{HEAT REJECTOR}

A purge control aquastat $\mathrm{T}_{C D}$ on the discharge of the collectors allows pump $\mathrm{P}_{2}$ to run in direct heating or storage charging modes if there is no overtemperature condition. If the temperature of the collector loop fluid rises above $210^{\circ} \mathrm{F}$ (adjustable), pump $P_{2}$ is shut of $f$, and valve $V_{1}$ is energized, diverting flow through the purge unit. The purge unit fan is energized forcing outdoor air across the purge coil to cool the collector fluid.

\section{DOMESTIC HOT WATER HEATING}

Whenever domestic hot water is drawn from the water heater, it is replaced by preheated water from a coll in the storage tank. A thermostatic mixing valve is used to regulate the hot water supply from the water heater to $140^{\circ} \mathrm{F}$.

\section{TROUBLESHOOTING}

When the Control Panel does not appear to be operating properly, the following steps may be taken to troubleshoot system problems:

1. Determine the temperatures at the differential temperature controller and solar aquastat controller sensors. For the differential tempeature controller, use a high resistance ohmmeter to measure the resistance across the remote sensors. Refer to Figure 2 to convert the resistance measurement to a temperature reading.

Determine the temperature that the solar aquastat is experiencing by adjusting the set points with a screwdriver and listening for the relays to operate when the relay in the aquastat changes state. Observe temperature scale for temperature reading.

2. Read the OPERATION section to determine which mode(s) the heating system should be operating in based on sensor temperatures and the space temperature.

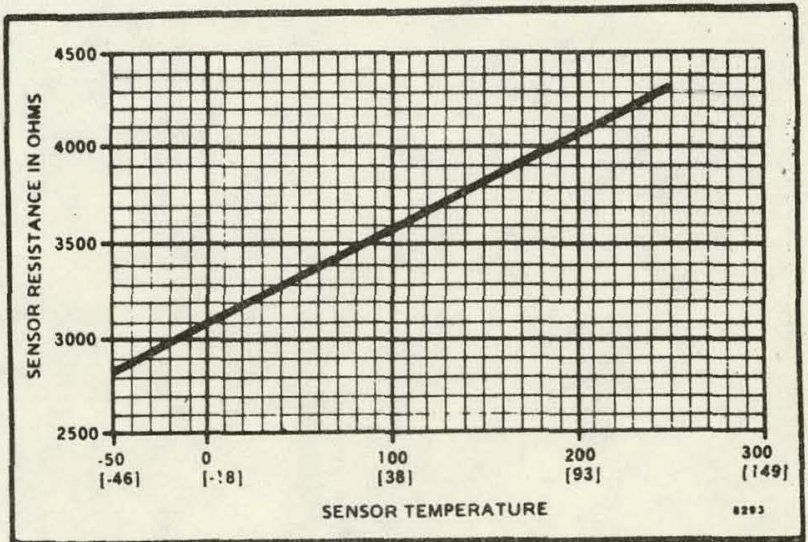

Figure 2. Converting Sensor Resistance into Degrees F (C).

3. Check the location of the sensors for the differential temperature controller and solar aquastat controller. Make certain that each sensor is located so as to measure the most appropriate temperature for proper system operation. If the sensors are not providing correct temperature readings, change the 10cation and mount properly. 
4. Check that the solar aquastat is operating properly by adjusting the control point of the aquastat limit controller and listening for the relays to operate. Reset to the proper temperature.

5. Check that the differential temperature controller relay is operating properly by disconnecting the wire to high temperature terminal HI. Relay should pull in. Reconnect sensor wire to high-temperature terminal HI and disconnect wire to low- temperature terminal L0. Relay should drop out. Reconnect sensor wire to low-temperature terminal LO.

6. Check system operation on a mode-by-mode basis using the procedures of Table 1 .

7. If necessary, check for proper relay operation. See Figure 3 for internal wiring schematic of control panel.

8. For replacement parts list, see Figure 4.

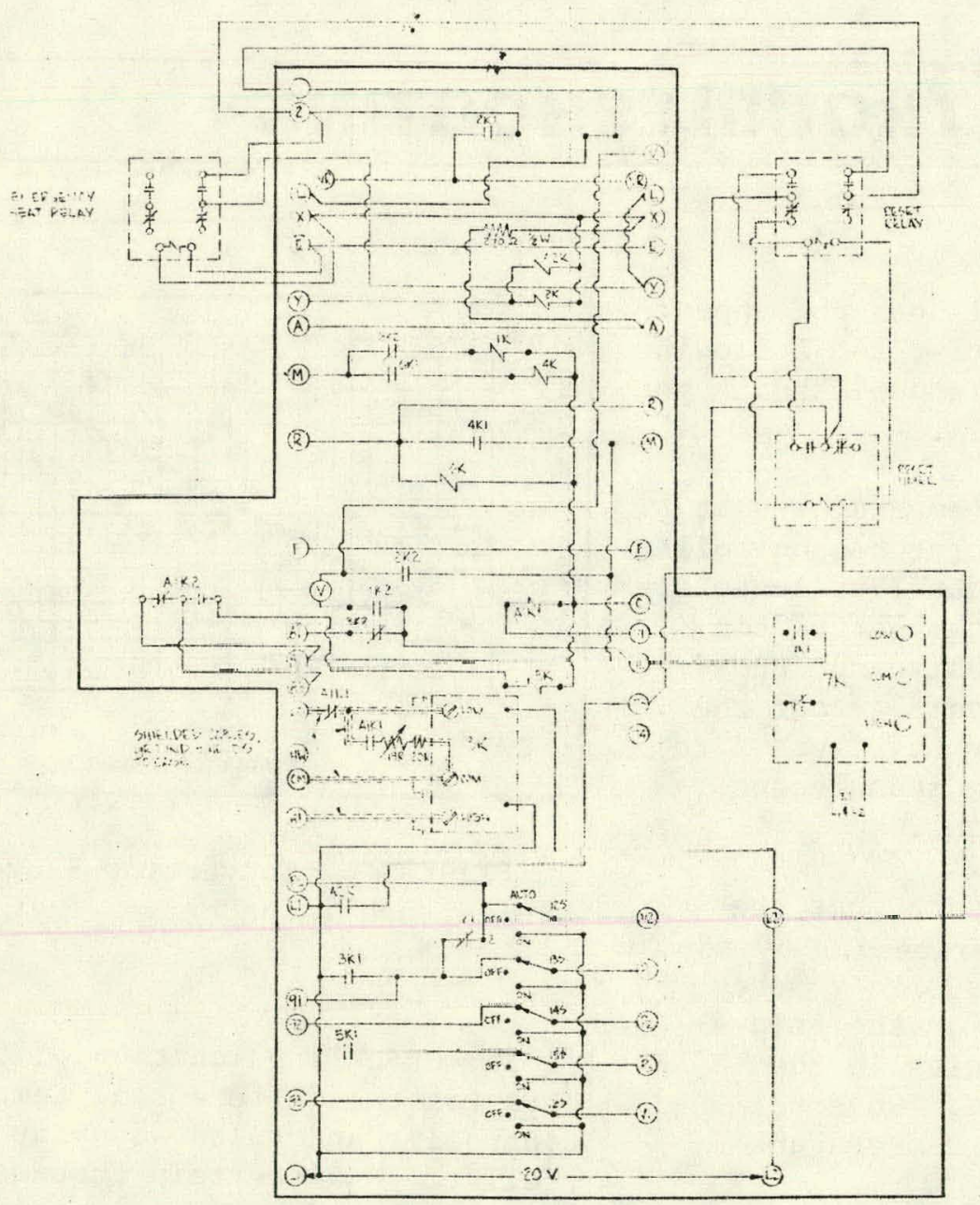

Figure 3. Control Panel Wiring Schematic 


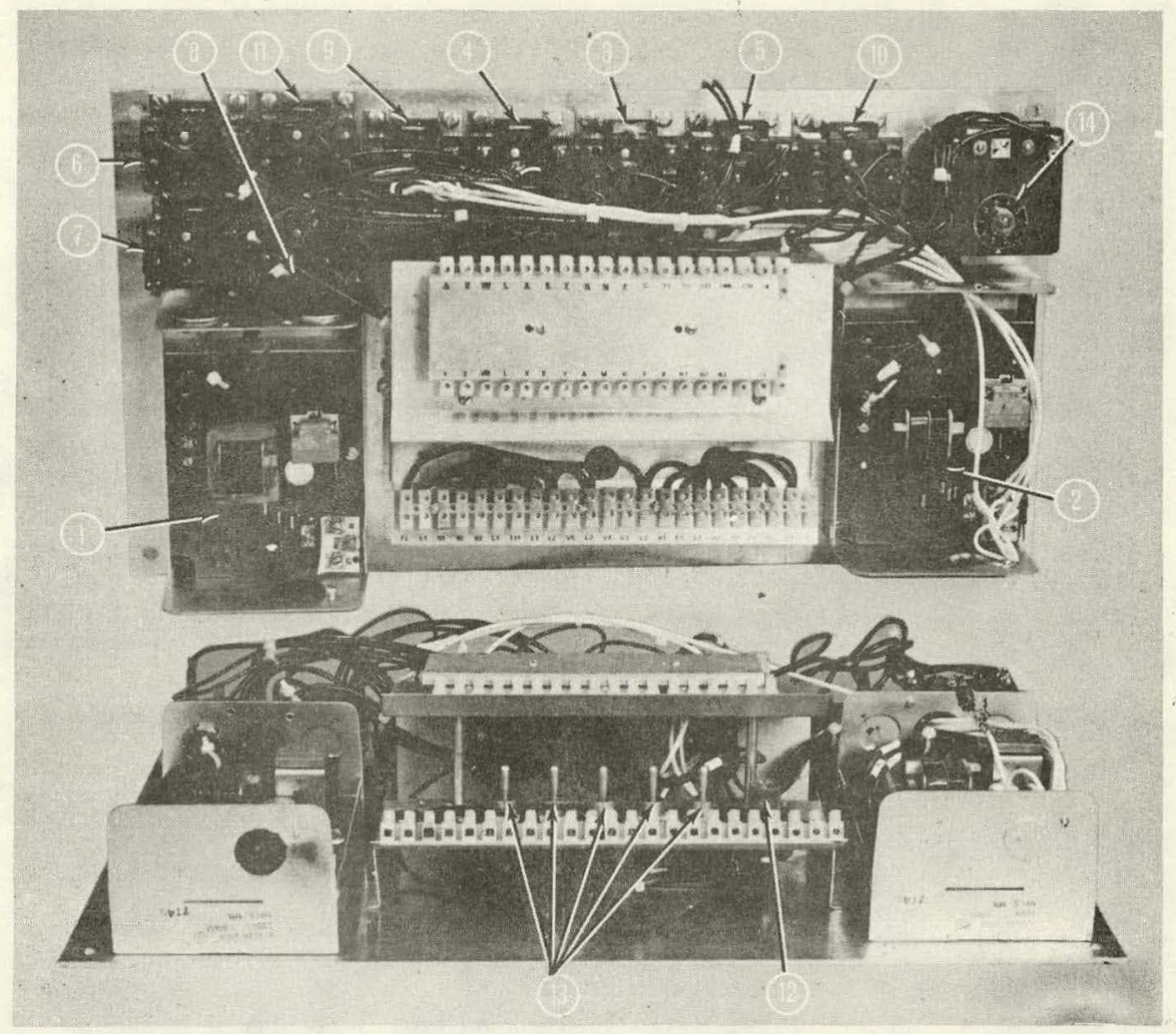

\begin{tabular}{|c|c|c|c|c|}
\hline LOCATION & SYMBOL & DESCRIPTION & PART NO. & MANUFACTURER \\
\hline 1 & $7 \mathrm{~K}$ & $\begin{array}{l}\text { Differential Temperature } \\
\text { Controller }\end{array}$ & $\mathrm{R} 7412 \mathrm{~A} 1012$ & Honeywe11 \\
\hline 2 & $3 \mathrm{~K}$ & Diff. Temp. Controller & R7412A1012 & Honeywel1 \\
\hline 3 & $I \mathrm{~K}$ & Switching Relay & $\mathrm{R} 8222 \mathrm{~V} 1003$ & Honeywe11 \\
\hline 4 & $\mathrm{~A} 1 \mathrm{~K}$ & Switching Relay & R8222N1011 & Honeywe11 \\
\hline 5 & $2 \mathrm{~K}$ & Switching Relay & R8222N1011 & Honeywell \\
\hline 6 & $\mathrm{~A} 2 \mathrm{~K}$ & Switching Relay & R8222B1067 & Honeywel1 \\
\hline 7 & $4 \mathrm{~K}$ & Switching Relay & R8222N1011 & Honeywe11 \\
\hline 8 & $5 K$ & Switching Relay & R8222B1067 & Honeywe11 \\
\hline 9 & $6 \mathrm{~K}$ & Switching Relay & R8222N1011 & Honeywell \\
\hline 10 & RESET & Switching Relay & $\mathrm{R} 4222 \mathrm{~N} 1002$ & Honeywel1 \\
\hline 11 & EM. HT & Switching Relay & R8222N1011 & Honeywell \\
\hline 12 & $19 \mathrm{R}$ & Potentiometer & $105364 \mathrm{~F}$ & Honeywe11 \\
\hline 12 & $20 \mathrm{R}$ & Resistor & $802139 D D C B$ & Honeywell \\
\hline 13 & -- & Manual Switch & 113700 & Honeywel1 \\
\hline 14 & TIMER & Reset Timer & DA21004 & General Time \\
\hline
\end{tabular}

Figure 4. Replacement Parts List 
SOLAR-HEAT PUMP

CONTROL PANEL

SK-142183

INTERNAL WIRING CHECKOUT

If the control panel has been disconnected for relay replacement, trouble-shooting, etc., the Internal wiring of the control panel can be checked out by the following procedure:

1.) Disconnect all ficld wiring to control panel.

2.) Provide two separate 24-volt AC, 40VA transformers and connect to control panel as called for in checkout procedure.

3.) Connect $120 \mathrm{~V}$ power to Ll (line) and L2 (ground) as called for in checkout procedure.

4.) Check out each mode of operation as described in following checkout procedure. 
SET-UP all switches in AUTO position, $120 \mathrm{~V}$ to L1 and L2 $24 \mathrm{~V}$ between $\underline{V}$ and $C$, separate $24 \mathrm{~V}$ between VR and $\underline{X}$

NOTE: Disconnect all power after each test

1. DIRECT HEATING

a.) Jumper $\underline{V}$ to $M$

b.) CM and HI open, Jumper CM to LO

c.) Jumper COM to LO on $7 \mathrm{~K}$

d.) Jumper 91 to 92

e.) OPERATION $-\mathrm{P}_{1}$ and $\mathrm{P}_{2}$ should run

f.) Proceed to next test

2. FAN HIGH LIMIT

a.)-d.) Same as 1a-d above, (simulate direct heating)

e.) OPERATION $-\mathrm{P}_{1}$ and $\mathrm{P}_{2}$ should run

f.) Jumper FL to L1

g.) OPERATION $-V_{2}$ should operate

h.) Remove jumper from FL to L1.

i.) Proceed to next test

3. DIRECT HEATING WITH HEAT PUMP AND ELEC. HEAT ON SECOND STAGE CALL FOR HEAT
a.
b. Same as 1a, b, c, d above
d.
e.) OPERATION - $P_{1}$ and $P_{2}$ should run
f.) Jumper $\underline{L}$ to $L$
g.) .Tumper $\mathrm{VR}$ to $\mathrm{Y}$
h.) OPERATION $-24 \mathrm{~V}$ between $\mathrm{M}$ and $\mathrm{C}$
- Reset timer runs,
- After $91 / 2$ minutes (approx.) $24 \mathrm{~V}$ between $\underline{Y}$ and $\underline{X}$

i.) Remove all jumpers for next test

4. HEAT FROM STORAGE
a.) Jumper $\underline{V}$ to $M$
b.) Jumper CM to $\mathrm{HI}$
c.) Jumper COM to $\mathrm{LO}$ on $7 \mathrm{~K}$
d.) Jumper 81 to 83
e.) OPERATION $-\mathrm{P}_{3}$ should run
f.) Proceed to next test 
5. HEAT FROM STORAGE, HEAT PUMP COMES ON (SECOND STAGE)

AND STORAGE WATER TEMP. TOO LOW; HEAT FROM STORAGE IS SHUT-OFF

a. -d.) Same as 4 a-d. above

e.) OPERATION $-\mathrm{P}_{3}$ should run

f.) Jumper $\underline{\mathrm{VR}}$ to $\mathrm{Y}$

g.) OPERATION $-24 \mathrm{~V}$ between $\mathrm{M}$ and C

h.) Remove jumper COM to LO on $7 \mathrm{~K}$

i.) Jumper COM to HIGH on $7 \mathrm{~K}$

j.) OPERATION $-\mathrm{P}_{3}$ should stop

k.) Remove all jumpers for next test

6. STORAGE CHARGING

a.) Jumper CM to LO

b.) Jumper 91 to 92

c.) OPERATION $-\mathrm{P}_{1}, \mathrm{P}_{2}$ and $\mathrm{V}_{2}$ should operate

d.) Proceed to next test

7. PURGE

a.)-b.) Same as 6 a, b above, (simulate storage charging)

c.) OPERATION $-P_{1}, P_{2}$ and $V_{2}$ should operate

d.) Remove jumper 91 to 92

e.) Jumper 91 to 93

f.) OPERATION - $\mathrm{P}_{2}$ should stop

- $P_{1}$ and $V_{2}$ should continue to operate

- $120 \mathrm{~V}$ between V1 and L2

g. ) Remove all jumpers for next test

8. HEAT PUMP ON FIRST STAGE HEAT (NO SOLAR AVAILABLE)
a.) Jumper $\underline{V}$ to $M$
b.) Jumper CM to HI (COM to HIGH on $3 \mathrm{~K}$ )
c.) Jumper 81 to 82
d.) OPERATION - $24 \mathrm{~V}$ between $\underline{\mathrm{M}}$ and C
e.) Proceed to next test

9. HEAT PUMP ON FIRST STAGE HEAT (NO SOT,AR A VAILABLE) SECOND STAGE CALL FOR HEAT IS ELEC. HEAT

a.)-c.) Same as 8-c. above

d.) OPERATION $24 \mathrm{~V}$ between $\mathrm{M}$ and $\mathrm{C}$

e.) Jumper $\mathrm{L}$ to $\mathrm{L}$

f.) Jumper $\overline{\mathrm{VR}}$ to $\mathrm{Y}$

g.) OPERATION - after $91 / 2$ minutes (approx.) between $\underline{Y}$ and $X$

h.) Remove all jumpers

TESTING OF ETM CONTROL PANEL IS COMPLETE 


\section{Honeywell}

THESE THERMOSTATS AND SUBBASES PROVIDE LOW/VOLTAGE CONTROL OF MULTISTAGE HEATING AND COOLING SYSTEMS INCLUDING HEAT PUMP SYSTEMS.

口 T872 Thermostat requires a Q672 Subbase.

Q672 Subbase provides system and fan switching, wiring terminals, and mounting base for T872 Thermostat.

T872 Thermostat has silent dust-free mercury switches operated by coiled bimetal elements.

$\square$ Q672 Subbase mounts on wall or horizontal outlet box.

Adapter plate available for mounting Q672 Subbase on vertical outlet box.

口 Ileat anticipator(s) are adjustablc or fixed; cooling anticipator(s) are fixed.

- External levers and scale for temperature setting located on top of thermostat case.

马 Cover thermometer on most T872 Thermostat models.

Locking cover and locking lever screws available for T872 Thermostats.

Plastic thermostat guards available for T872 Thermostats.

Key lock cover with tumbler lock available for T872 Thermostats.

MULIIBTIBEE
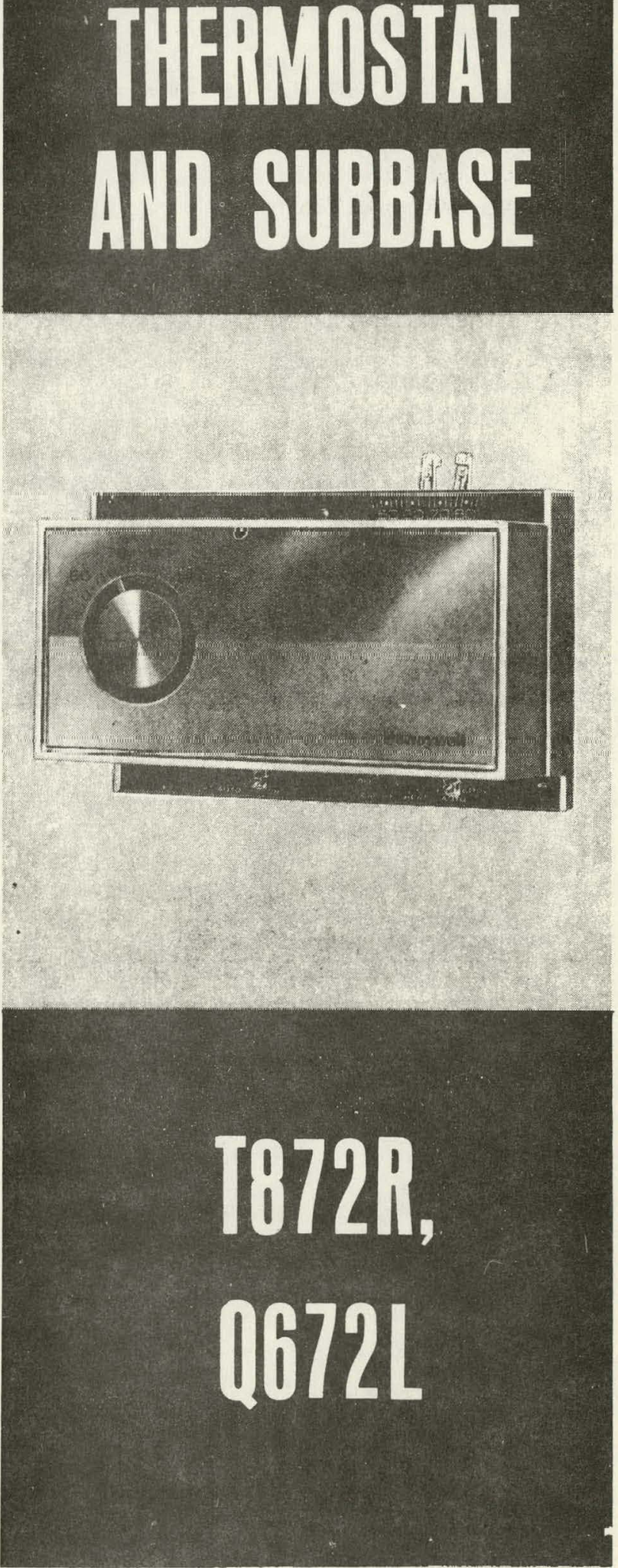


\section{T872 THERMOSTATS}

ELECTRICAL RATING: 24 to $30 \mathrm{~V}$ ac.

SWITCHING: Coiled bimetal elements operate mercury switches.

TEMPERATURE ADJUSTMENT: Heating and cooling setting lever, with common scale located on top of thermostat base. Common lever for heating and cooling on T872R.

TEMPERATURE SCALE RANGE: 44 to $86 \mathrm{~F}$ [ 7 to $30 \mathrm{Cl}$, standard; optional ranges available.

THERMOMETER RANGE: 52 to $98 \mathrm{~F}$ [11 to $36 \mathrm{C}$ ].

CHANGEOVER DIFFERENTIAL: $3 \mathrm{~F}$ [2 C] minimum between heating and cooling.

\section{INTERSTAGE DIFFERENTIAT:}

Standard Models-mechanical differential is $1 \mathrm{~F}$ $[0.6 \mathrm{C}]$ between heating or cooling stages; operating differential is approximately $1.9 \mathrm{~F}\left[\begin{array}{ll}1 & \mathrm{C}\end{array}\right]$ between stages in heating or cooling.
FINISH: Silver bronze.

MOUNTING MEANS: T872 Thermostat mounts on Q672 Subbase. Subbase mounts horizontally on wall or outlet box. Mounts on vertical outlet box with optional 130821 A Adapter Plate Assembly.

(See Fig. 1)

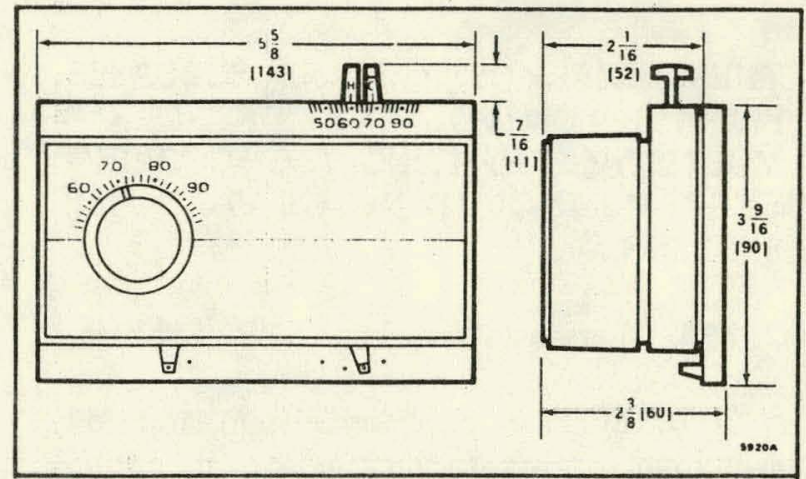

FIG. 1-DIMENSIONS OF T872 THERMOSTAT MOUNTED ON 0672 SUBBASE.

\section{INSTALLATION}

\section{CAUTION}

1. Installer must be a trained, experienced serviceman.

2. Disconnect power supply to prevent electrical shock and equipment damage.

3. Do NOT short across coil terminals on relay. This may burn out the heat anticipator.

4. Run wires as close to the subbase as possible. To prevent interference with the thermostat linkage, keep wire length to a minimum, and make certain wires do NOT protrude outward beyond standoffs (Fig. 4). Push excess wire back into the hole, and plug hole to prevent drafts from affecting thermostat operation.

5. Do NOT overtighten thermostat captive mounting screws. This may damage the threads in the subbase.

6. Always conduct a thorough checkout when installation is complete.

\section{IMPORTANT}

Thermostats are calibrated at the factory using subbases mounted at true level. Inaccurate subbase leveling will cause thermostat control deviation.

\section{LOCATION}

Locate the thermostat about 5 fect [ 1.5 metre] above the floor in an area with good air circulation at average temperature.

Do not mount the thermostat where it may be affected by-

-drafts, or dead spots behind doors and in corners.

-hot or cold air from ducts.

-radiant heat from the sun or appliances.

- concealed pipes and chimneys.

-unheated (uncooled) areas behind the thermostat.

\section{SUBBASE MOUNTING}

The subbase is designed for mounting on a wall or horizontal outlet box. (Adapter assembly, Part No. $130821 \mathrm{~B}$, with cover plate only is available for covering wall marks from old thermostat.) An adapter assembiy, Part No. $130821 \mathrm{~A}$, with adapter ring and cover plate is available for mounting on a vertical outlet box. Tc mount subbase, proceed as follows:

1. At the location selected, prepare an opening for the thermostat wires.

2. Run low voltage thermostat wires to the location, and pull about 4 inches [ 100 millimetres] through the wall opening.

NOTE: Use color-coded thermostat cable for proper wiring.

3. If mounting the subbase on a vertical outlet box (Fig. 2), install the adapter ring with the 2. screws provided. 


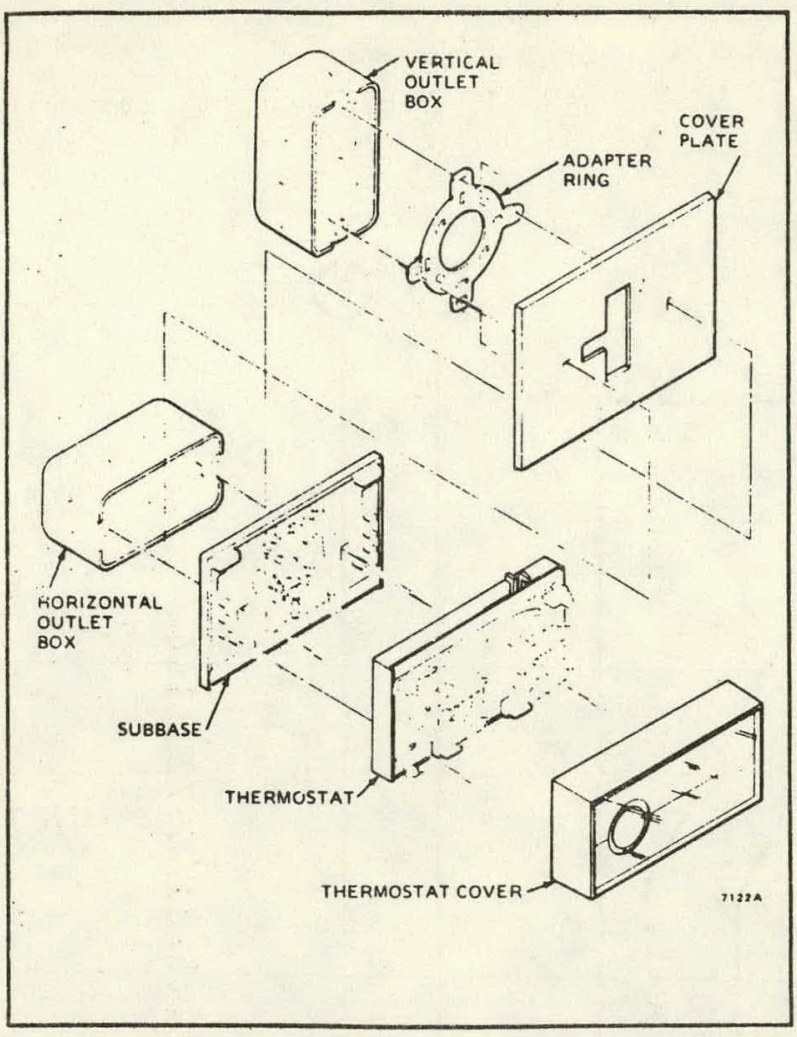

FIG. 2-INSTALLATION OF 0672 SUBBASE ON OUTLET BOX.

4. Pull thermostat cable through cover plate (if used) and subbase opening. Secure the cover plate and subbase with the 2 screws provided, but do not tighten.

Thermostats are calibrated at the factory using subbases mounted at true level. Inaccurate subbase leveling will cause thermostat control deviation.

5. The subbase mounting slots provide for minor out of level adjustments. Level the subbase using a spirit level, as shown in Fig. 3 and tighten subbase mounting screws.

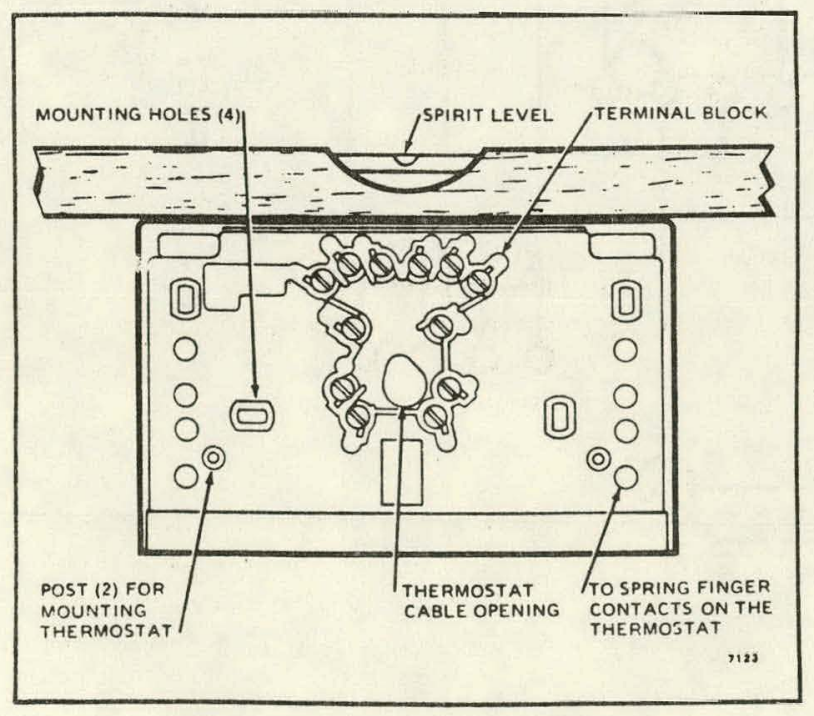

FIG. 3-LEVELING THE SUBBASE.

\section{WIRING}

All wiring must comply with local electrical codes and ordinances.

A letter code is near each terminal for easy identification. Typical terminal designation and wiring connections are listed in Tables 1 and $\mathbf{2}$

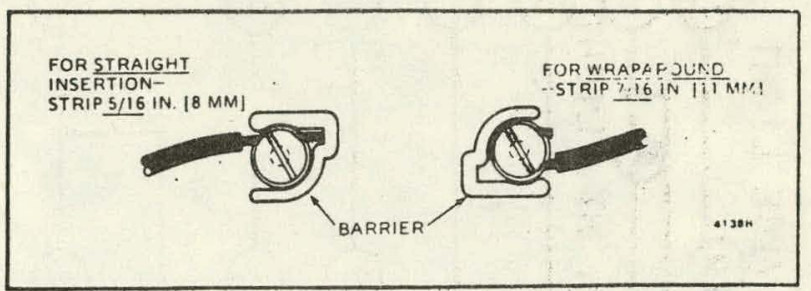

FIG. 4-BARRIER CONFIGURATION.

TABLE 1-TERMINAL DESIGNATIONS

\begin{tabular}{c|l}
\hline TERMINAL & \multicolumn{1}{|c}{ TYPICAL CONNECTION } \\
\hline$B$ & $\begin{array}{l}\text { Heating damper motor: changeover valve } \\
\text { (if used). }\end{array}$ \\
\hline$E$ & Emergency heat relay. \\
\hline$G$ & Fan relay coil. \\
\hline$O$ & $\begin{array}{l}\text { Cooling damper motor: changeover valve } \\
\text { (if used). }\end{array}$ \\
\hline$R$ & $\begin{array}{l}\text { Power connection to transformer lin- } \\
\text { ternally connected for cooling and } \\
\text { heating). }\end{array}$ \\
\hline$R_{C}$ & Power connection to cooiing transformer. \\
\hline$R_{H}$ & Power connection to heating transformer. \\
\hline$W_{1}$ & Stage 1 heating control. \\
\hline$W_{2}$ & Stage 2 heating control. \\
\hline$Y_{1}$ & Stage 1 cooling control. \\
\hline$Y_{2}$ & Stage 2 cooling control. \\
\hline$X \cdot X_{1} \cdot X_{2} \cdot C$ & Clogged filter switch. \\
\hline
\end{tabular}

TABLE 2-ALTERNATE CONTROL CIRCUIT TERMINAL DESIGNATIONS

\begin{tabular}{c|c|c|l}
\hline $\begin{array}{c}\text { ALTERNATE } \\
\text { DESIG- } \\
\text { NATIONS }\end{array}$ & $\begin{array}{c}\text { STANDARD } \\
\text { DESIG- } \\
\text { NATION }\end{array}$ & \multicolumn{1}{|c}{$\begin{array}{c}\text { TYPICAL } \\
\text { CONNECTION }\end{array}$} \\
\hline V & V & R & 24 volt power supply \\
\hline H1 & - & W1 & First stage heating \\
\hline H2 & Y & W2 & Second stage heating \\
\hline C1 & M & Y1 & First stage cooling \\
\hline C2 & - & Y2 & Second stage cooling \\
\hline F & F & G & Fan \\
\hline- & - & B & Heating changeover \\
\hline- & R & O & Cooling changeover \\
\hline
\end{tabular}

The shape of the terminal barrier permits insertion of straight or conventional wrap-around (Fig. 4) wiring connections. Either method is acceptable. When making connections, strip wire to the length specified in Fig. 5.

Follow the equipment manufacturer's wiring instructions, if available, when wiring the subbase. Figure 5 shows internal wiring schematic for this unit. 


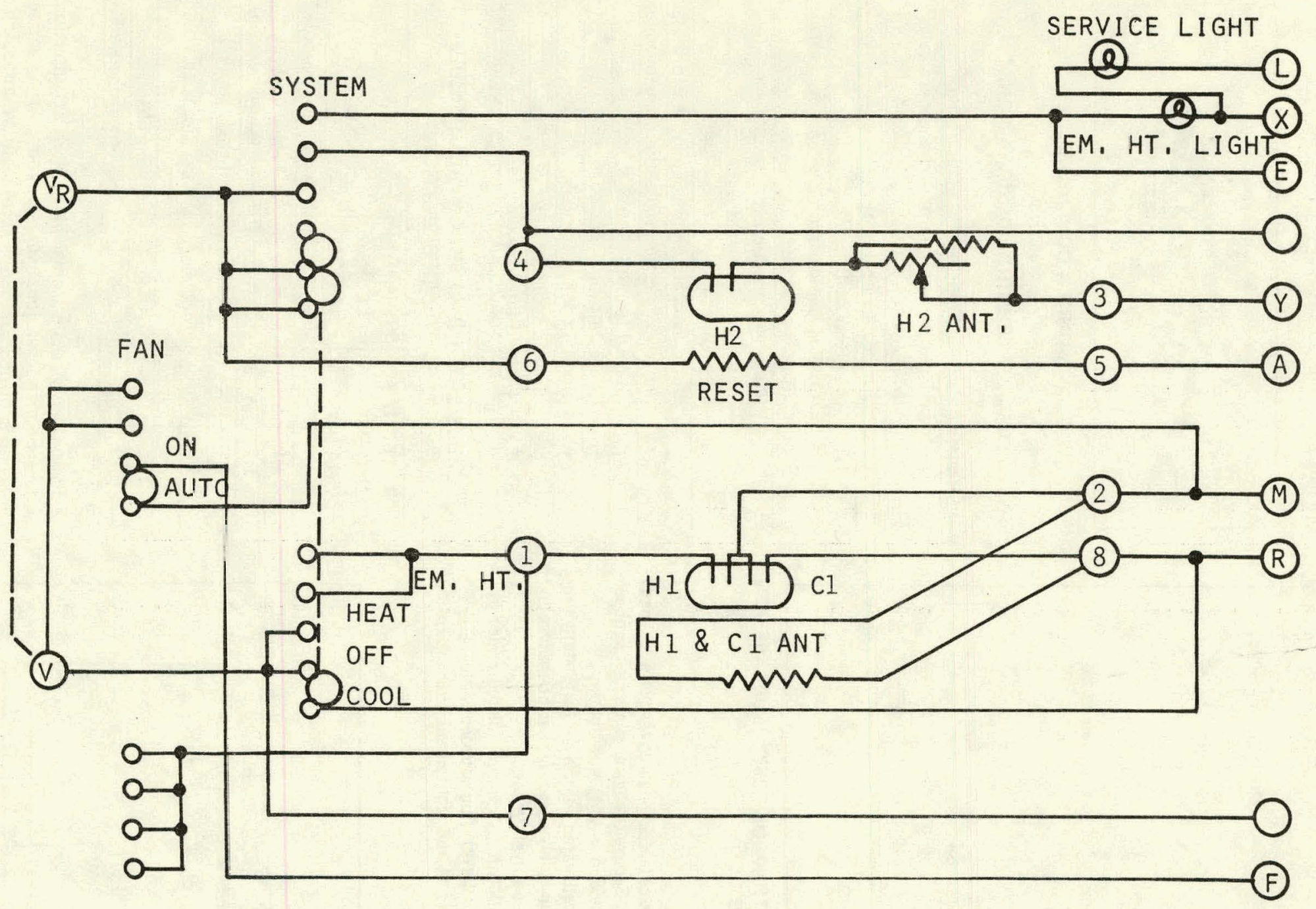

FIG, 5 - INTERNAL SCHEMATIC T872R1131/Q672L1144 
Run wires as close to the subbase as possible. To prevent interference with the thermostat linkage, keep wire length to a minimum, and make certain wires do NOT protrude outward beyond standoffs, (Fig. 6). Push excess wire back into the hole, and plug hole to prevent drafts from affecting thermostat operation.

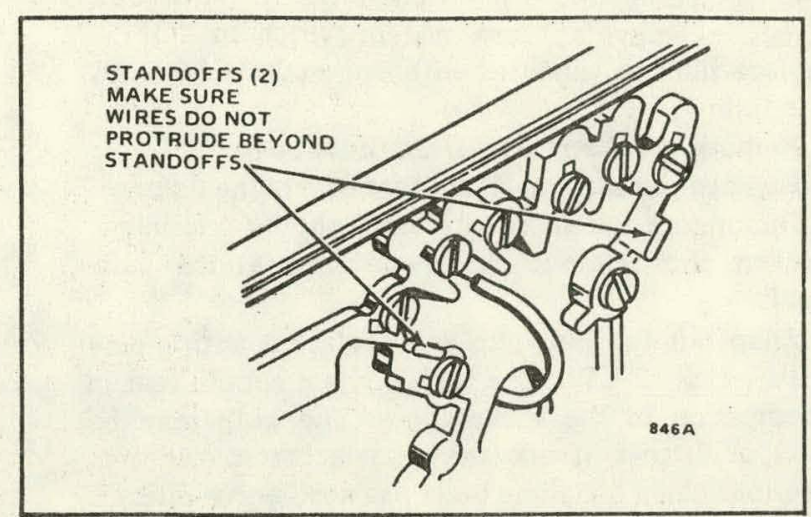

FIG. 6-INDIVIDUAL SCREW WIRING FOR 0672 SUBBASE.

\section{HEAT ANTICIPATOR SETTING}

Set the heat anticipator scale to match the primary control rating. When using a T872 Thermostat with 2 stages of heating, set both heat anticipators to match their respective primary control rating. If the primary control nameplate has no rating or if further adjustment is necessary, use the following procedure to determine the current draw of each stage.

The current draw of each heating stage must be measured with the thermostat removed.

1. Connect an ac ammeter of appropriate range between the heating terminals of the subbase-

Stage 1-not applicable

Stage 2 -between $\mathrm{Y}$ and VR

2. Move the system switch to HEAT or AUTO.

3. After 1 minute, read the ammeter and record the reading.

Stage $1-N / A$

Stage 2-

amp.

4. After mounting the thermostat (see Thermostat Mounting, next paragraph), set the adjustable heat anticipator to match the respective reading measured in step 3.

5. For Solar-Heat Pump system set Stage 2 heat anticipator at $0.4 \mathrm{amp}$.
If equipment cycles too fast, set the anticipator to a higher current rating, not more than $1 / 2$ division at a time, and recheck cycle rate. Most conventional 2-stage heating equipment is designed to operate at 3 cycles per hour, and 1-stage heating equipment at 6 cycles per hour, at 50 percent load conditions. When using a T872 Thermostat in heat pump systems, set the heat anticipator at $140 \%$ of the actual primary control current draw to reduce the cycling rate.

Most heat pump systems should cycle $2-1 / 2$ to 3 times per hour.

\section{THERMOSTAT MOUNTING}

1. Remove the thermostat from the polystyrene shipping container.

2. Remove the thermostat cover by pulling the bottom edge of the cover upward until it snaps free of the locking springs.

NOTE: The cover is hinged at the top and must be removed by pulling up at the bottom.

3. Carefully remove and discard the polystyrene packing insert which protects the mercury switches during shipment.

4. Turn the thermostat base over and note the spring fingers which engage the subbase contacts. Make sure the spring fingers are NOT bent preventing proper electrical contact with the subbase.

5. Set the heat anticipator indicator(s), Fig. 7, to the respective current setting of each stage. See Heat Anticipator Setting.

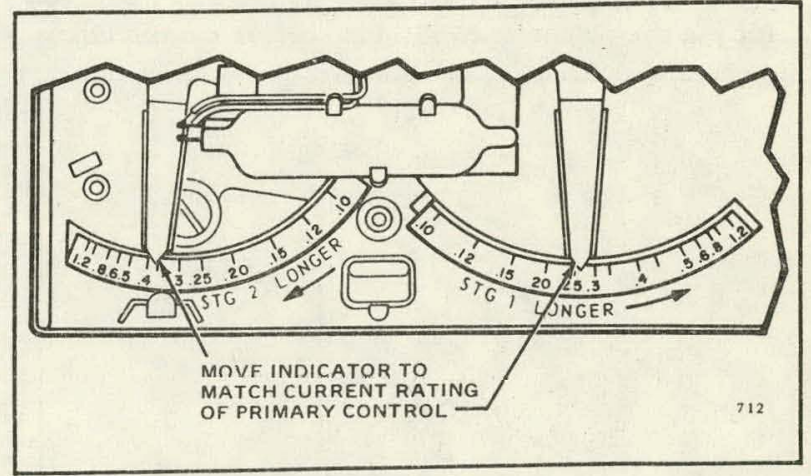

FIG. 7-ADJUSTABLE HEAT AN TICIP.ATOR SCALES. 


\section{SERVICE}

\section{CAUTION}

Before servicing, disconnect power supply to prevent electrical shock or equipment damage.

\section{THERMOSTAT}

T872 Thermostats are accurately calibrated at the factory; THEY DO NOT HAVE PROVISION FOR FIELD CALIBRATION.

\section{THERMOMETER}

To calibrate the thermometer:

1. Remove thermostat cover by pulling up from the bottom until it clears the locking springs. If cover has optional locking screws, these must be backed out before cover can be removed.

2. Set the cover on a table near an accurate thermometer.

3. After allowing 5 or 10 minutes for stabilization, compare the readings. If they are the same, replace cover and put system into operation. If they are different, recalibrate the thermostat thermometer, step 4.

4. Insert a small screwdriver in the thermometer shaft (Fig. 8 ) and turn it until the thermometers read the same. When thermometer is calibrated, replace cover and place system and fan switches for desired operation.

NOTE: Hand heat will offset the thermometer reading. After making each adjustment, wait 5 or 10 minutes for the thermometer to stabilize before comparing.

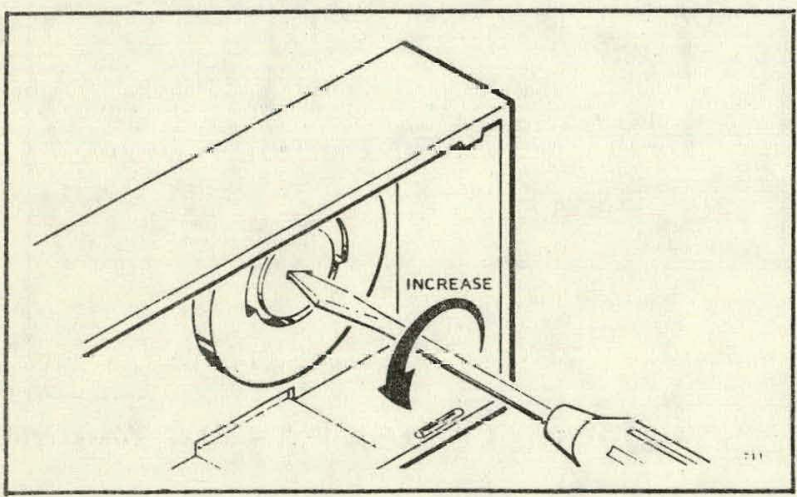

FIG. 8-THERMOMETER CALIBRATION.

\section{BULB REPLACEMENT}

Before replacing bulb, shut off the power supply to prevent shorting out the transformer at the bulb terminals, or move subbase system switch to "OFF."

Replace bulb in subbases with optional malfunction light as follows.

1. Remove the thermostat from the subbase.

2. Remove the snap-on shield that covers the light.

3. Disconnect the field wire from the " $X$ " terminal to prevent shorting out the transformer at the bulb terminals.

4. Snap out the old bulb and replace it with a new bulb, Part No. 129571. The bulb contact should seat in the depression in the socket base. The bulb may be screwed in farther, if necessary, for a better electrical connection. When installing bulb, use needlcnose pliers.

5. Reconnect the field wire to terminal "X."

6. Replace the shield and mount the thermostat. 


\section{Honeywell}

AQUASTAT CONTROLLERS ARE IMMERSION TYPE DEVICES FOR LIMITING OR REGULATING THE TEMPERATURE OF LIQUIDS IN BOILERS, STORAGE TANKS, AND OTHER APPLICATIONS WHERE TEMPERATURE CONTROL OF LIQUIDS IS REQUIRED. AS THE TEMPERATURE OF THE CONTROLLEDMEDIUMRISESTOTHE SET POINT, EXPANSION OF THE FLUID IN THE SENSING ELEMENT OPERATES THE - INTERNAL SWITCH OR SWITCHES.

The L4006, 7, and 8 provide spst switching for high or low limit control of a burner.

The L4006G model has two spst switches that make and break in sequence to provide boiler sequencing.

The L6006 and 8 provide spdt switching for low limit and circulator control.

$\square$ Models which break contact on a temperature rise to the set point are calibrated for high limit use. They are also suitable for low limit control if a separate high limit control is used.

$\square$ Ambient compensated models are available to prevent control-point shift caused by temperature fluctuation at the case.

$\square$ Visible control point scale and external adjustment screw permit easy setting.

$\square$ Models are available for either horizontal or vertical insertion of the sensing element. The sensing element may be directly immersed or placed in an immersion well.

$\square$ Remote bulb models are available if the controller must be mounted at a location away from the sensing element.

Remote bulb models may also be used to sense air temperature in ducts and in outside air sensing applications.

Totally enclosed Micro Switch snap-acting switches are used in all models.

S.K.

7-75
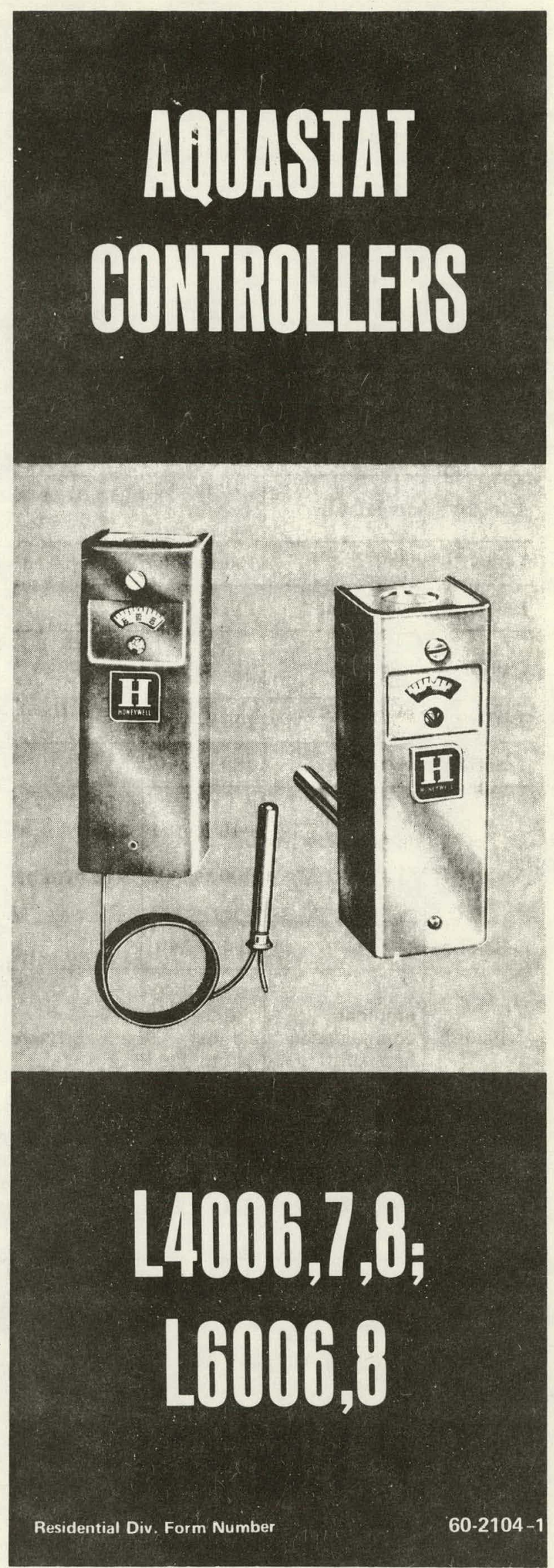
SPST MODELS:

\begin{tabular}{|c|c|c|c|c|c|c|}
\hline MODEL & APPLICATION & RANGE (F) & $\begin{array}{c}\text { MIDSCALE } \\
\text { DIFFERENTIAL } \\
(\mathrm{F})\end{array}$ & INSER TION ${ }^{\mathrm{a}}$ & \begin{tabular}{|l|} 
SWITCHING \\
ON TEMP. \\
RISE \\
\end{tabular} & AVAILABLE OPTICNS \\
\hline L4006A & $\begin{array}{l}\text { high or low } \\
\text { limit }\end{array}$ & $\begin{array}{r}40 \text { to } 180 \\
100 \text { to } 240\end{array}$ & $\begin{array}{l}2 \text { or } 5 \text { fixed or } \\
5 \text { to } 30 \text { adj. }\end{array}$ & horizontal & breaks & $\begin{array}{l}\text { Tradeline models which in- } \\
\text { clude well and tube of heat } \\
\text { conductive compound. Plas- } \\
\text { tic shield for covering well } \\
\text { in water heater applications. } \\
3 / 4 \text { in. NPT brass spud. } \\
\text { Centigrade scale markings. } \\
\text { Factory set stops at } 160 \mathrm{~F} \text {, } \\
185 \mathrm{~F}, 190 \mathrm{~F}, 200 \mathrm{~F} \text {, or } \\
220 \mathrm{~F} \text {. Dial marked WARM, } \\
\text { NORMAL, HOT. Insulation } \\
\text { depths of } 1-1 / 2,3 \text {, or } 5 \\
\text { inches. }\end{array}$ \\
\hline L4006B & circulator & $\begin{array}{c}40 \text { to } 180 \\
\text { or } \\
100 \text { to } 240\end{array}$ & $\begin{array}{l}5 \text { fixed or } \\
5 \text { to } 30 \text { adj. }\end{array}$ & horizontal & makes & $\begin{array}{l}3 \text { inch insulation depth. } 3 / 4 \\
\text { inch NIT brass spuul. }\end{array}$ \\
\hline L4006C & $\begin{array}{l}\text { high or low } \\
\text { limit }\end{array}$ & 100 to 240 & 2 or 5 fixed & \begin{tabular}{|l|}
$\begin{array}{l}\text { horizontal } \\
\text { direct }\end{array}$ \\
\end{tabular} & breaks & $\begin{array}{l}10 \text { in. element. Factory } \\
\text { set stop at } 205 \mathrm{~F} \text {. }\end{array}$ \\
\hline $\mathrm{L} 4006 \mathrm{~Eb}$ & high limit & 110 to 250 & $\begin{array}{l}\text { manual } \\
\text { reset }\end{array}$ & \begin{tabular}{|l|} 
horizontal \\
or vertical \\
\end{tabular} & breaks & $\begin{array}{l}3 / 4 \text { in. NPT brass spud. } 3 \\
\text { in. insulation depth. } \\
\end{array}$ \\
\hline L4006G & sequencing & 100 to 240 & \begin{tabular}{|l}
5 fixed \\
interstage \\
$3-10 \mathrm{~F}$ adj.
\end{tabular} & $\begin{array}{l}\text { horizontal } \\
\text { or vertical }\end{array}$ & \begin{tabular}{|l|} 
breaks \\
two \\
switches \\
\end{tabular} & \\
\hline L4007A & \begin{tabular}{|l|} 
high or low \\
limit \\
\end{tabular} & 100 to 240 & $\begin{array}{l}2 \text { or } 5 \text { fixed, } \\
5 \text { to } 30 \text { adj. }\end{array}$ & vertical & breaks & Centigrade scale markings. \\
\hline L4007B & circulator & 100 to 240 & \begin{tabular}{|l|}
5 fixed or \\
5 to 30 adj. \\
\end{tabular} & vertical & makes & . \\
\hline $\mathrm{L} 4008 \mathrm{~A}^{\mathrm{a}}$ & $\begin{array}{l}\text { high or low } \\
\text { limit }\end{array}$ & $\begin{array}{c}40 \text { to } 180 \\
\text { or } \\
100 \text { to } 240\end{array}$ & $\begin{array}{l}2 \text { or } \\
5 \text { fixed, } \\
5 \text { to } 30 \text { adj. }\end{array}$ & $\begin{array}{l}\text { remote } \\
\text { bulb }\end{array}$ & breaks & $\begin{array}{l}5 \mathrm{ft} .6 \text { in., } 8 \mathrm{ft} .6 \text { in. or } 10 \mathrm{ft} \text {. } \\
\text { remote capillary. Factory } \\
\text { set scale stop at } 120 \text { or } \\
200 \mathrm{~F} \text {. External adjusting } \\
\text { knnh. Centigrade scalc } \\
\text { markings. }\end{array}$ \\
\hline L4008Ba & circulator & 100 to 240 & \begin{tabular}{|l|}
5 fixed or \\
5 to 30 adj. \\
\end{tabular} & $\begin{array}{l}\text { remote } \\
\text { bulb }\end{array}$ & makes & $8 \mathrm{ft} .6$ in. capillary. \\
\hline L $4008 C^{a}$ & $\begin{array}{l}\text { ambient } \\
\text { eompensated } \\
\text { high limit }\end{array}$ & $\begin{array}{c}0 \text { to } 70 \\
\text { or } \\
40 \text { to } 180\end{array}$ & 2 or 5 fixed & $\begin{array}{l}\text { remote } \\
\text { bulb }\end{array}$ & breaks & $\begin{array}{l}7 \mathrm{fl} .6 \mathrm{ln}, \text {, } 20 \mathrm{ft} . \text { capillary } \mathrm{nr} \\
\text { fast response element. } \\
\text { External adj. knob. } 150 \mathrm{va} \\
\text { rating at } 120,240 \mathrm{v} \text { ac. } \\
\text { High limit stamped on case } \\
\text { scale lock. }\end{array}$ \\
\hline
\end{tabular}

L4008 models continued on page 3

Copper well or fitting is supplied with all models except remote bulb type. When ordering, specify boiler tapping size $(1 / 2$ or $3 / 4$ inch) and insulation depth.

bManual reset (trip-free) - Switchbreaks circuit and locks out when controlled medium reaches set point. Controlled temperature must drop 20 degrees below set point before contacts can be manually reset.

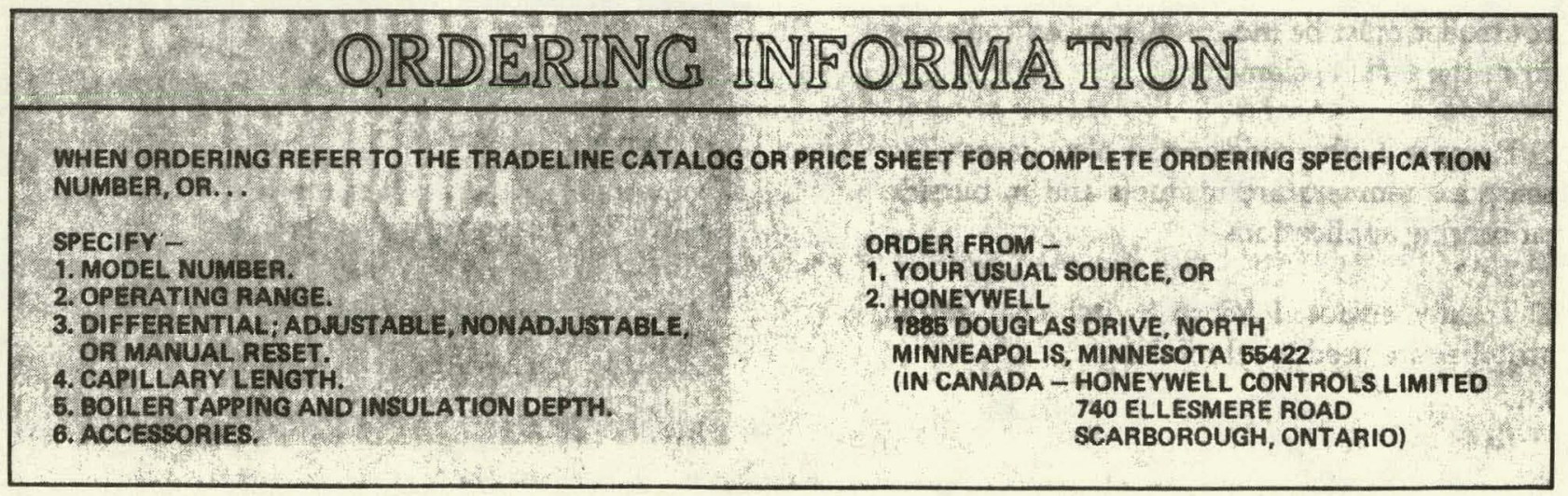




\begin{tabular}{|c|c|c|c|c|c|c|}
\hline MODEL & APPLICATION & RANGE (F) & $\begin{array}{c}\text { MIDSCALE } \\
\text { DIFFERENTIAL } \\
\text { (F) }\end{array}$ & INSERTION & $\begin{array}{l}\text { SWITCHING } \\
\text { ON TEMP. } \\
\text { RISE } \\
\end{array}$ & AVAILABLE OP'TIONS \\
\hline $\mathrm{L} 4008 \mathrm{D}^{\mathrm{a}}$ & $\begin{array}{l}\text { ambient } \\
\text { compensated } \\
\text { circulator }\end{array}$ & $\begin{array}{l}0 \text { to } 70 \\
\text { or } \\
40 \text { to } 180\end{array}$ & 2 or 5 fixed & $\begin{array}{l}\text { remote } \\
\text { bulb }\end{array}$ & makes & $\begin{array}{l}\text { Tradeline model available. } \\
\text { Centigrade scale markings. } \\
\text { Hot tinned } 8 \mathrm{ft} . c a p i l l a r y . \\
\text { Electrical rating: } 2.3 \mathrm{amp} \\
\text { at } 120-240 \mathrm{v} \text { ac, full load. } \\
\text { Fast response, } 10 \mathrm{ft} . a r- \\
\text { mored capillary with } 3 \mathrm{ft} \text {. } \\
\text { bulb. External adjustment } \\
\text { knob. Factory set scale } \\
\text { stops at } 120,220 \text {, or } 250 \mathrm{~F} \text {. } \\
\text { Plastic shield for covering } \\
\text { well in water heater } \\
\text { applications. }\end{array}$ \\
\hline $\mathrm{L} 4008 \mathrm{E}^{\mathrm{ab}}$ & high limit & $\begin{array}{c}40 \text { to } 80 \\
\text { or } \\
110 \text { to } 290\end{array}$ & $\begin{array}{l}\text { manual } \\
\text { reset }\end{array}$ & $\begin{array}{l}\text { remote } \\
\text { bulb }\end{array}$ & breaks & $\begin{array}{l}\text { Factory set scale stop at } \\
250: \mathrm{F} . \quad 8 \mathrm{ft} .6 \text { in. capillary. }\end{array}$ \\
\hline $\mathrm{L} 4008 \mathrm{~J}^{\mathrm{a}}$ & high limit & 100 to 240 & 5 fixed & $\begin{array}{l}\text { remote } \\
\text { bulb }\end{array}$ & breaks & $\begin{array}{l}\text { All models less case and } \\
\text { cover. } 18 \text { in. capillary' and } \\
1 / 2 \text { in. well assy. Factory } \\
\text { set scale stop at } 220 \mathrm{~F} \text {. }\end{array}$ \\
\hline $\mathrm{L} 4008 \mathrm{~K}^{\mathrm{a}}$ & circulator & 40 to 180 & 5 fixed & $\begin{array}{l}\text { remote. } \\
\text { bulb }\end{array}$ & makes & All models less cover. \\
\hline
\end{tabular}

SPDT MODELS:

\begin{tabular}{|c|c|c|c|c|c|}
\hline MODEL & APPLICATION & RANGE (F) & $\begin{array}{c}\text { MIDSCALE } \\
\text { DIF FERENTIAL (F) }\end{array}$ & INSERTION $^{\mathrm{a}}$ & AVAILABLE OPTIONS \\
\hline $\mathrm{L} 6006 \mathrm{~A}^{\mathrm{a}}$ & $\begin{array}{l}\text { circulator } \\
\text { and low } \\
\text { limit or } \\
\text { high limit }\end{array}$ & $\begin{array}{l}100 \text { to } 240 \\
\text { or } \\
110 \text { to } 290\end{array}$ & $\begin{array}{l}5 \text { fixed or } \\
5 \text { to } 30 \text { adj. }\end{array}$ & horizontal & $\begin{array}{l}\text { Tradeline model which includes } \\
\text { well adapter and tube of heat con- } \\
\text { ductive compound. } 3 / 4 \text { in. NPT } \\
\text { brass spud. } 3 \text { in. insulation } \\
\text { depth. Horizontal or vertical } \\
\text { mount available on same models. }\end{array}$ \\
\hline L6006B & $\begin{array}{l}\text { circulator } \\
\text { and low } \\
\text { limit or } \\
\text { high limit }\end{array}$ & 100 to 240 & $\begin{array}{l}5 \text { fixed or } \\
5 \text { to } 30 \text { adj. }\end{array}$ & horizontal & $\begin{array}{l}3 / 4 \text { in. brass bulb compression } \\
\text { fitting. }\end{array}$ \\
\hline $\mathrm{L} 6008 \mathrm{~A}^{\mathrm{a}}$ & $\begin{array}{l}\text { circulator } \\
\text { and low limit } \\
\text { cooling }\end{array}$ & $\begin{array}{l}100 \text { to } 240 \\
-30 \text { to } 70\end{array}$ & $\begin{array}{l}5 \text { fixed or } \\
5 \text { or } 30 \text { adj. }\end{array}$ & $\begin{array}{l}\text { remote } \\
\text { bulb }\end{array}$ & $\begin{array}{l}\text { Tradeline model with } 5 \mathrm{ft} . \text { cap- } \\
\text { illary. Range of }-30 \text { to } 70 \mathrm{~F} \text {. With- } \\
\text { Centigrade scale markings. Withe } \\
\text { out cover. }\end{array}$ \\
\hline $\mathrm{L}, 6008 \mathrm{c}^{\mathrm{a}}$ & $\begin{array}{l}\text { dual fuel } \\
\text { changeover }\end{array}$ & $\begin{array}{l}0 \text { to } 70 \\
40 \text { to } 180\end{array}$ & 2 or 5 fixed & $\begin{array}{l}\text { remote } \\
\text { bulb. } \\
\text { May be } \\
\text { duct. mounted. }\end{array}$ & $\begin{array}{l}\text { Tradeline model. } 150 \text { va switch } \\
\text { rating. Centigrade scale } \\
\text { markings. } 7 \mathrm{ft} .6 \text { in. armored } \\
\text { capillary. External adjustment } \\
\text { knob. Lock type cover. } 20 \mathrm{ft} . \\
\text { element. Averaging element. }\end{array}$ \\
\hline $\mathrm{L} 6008 \mathrm{E}^{\mathrm{a}}$ & $\begin{array}{l}\text { ambient } \\
\text { compensated }\end{array}$ & 40 to 180 & 5 fixed & $\begin{array}{l}\text { remote } \\
\text { bulb }\end{array}$ & $\begin{array}{l}\text { All models less enclosure. Front } \\
\text { mounted. }\end{array}$ \\
\hline
\end{tabular}

acopper well or fitting is supplied with all models except remote bulb type. When ordering, specify boiler tapping size $(1 / 2$ or $3 / 4$ inch) and insulation depth.

${ }^{b}$ Manual reset (trip-free)-Switch breaks circuit and locks out when controlled medium reaches set point. Controlled temperature must drop 20 degrees below set point before contacts can be manually reset.

NOTE: The following specifications are standard. Variances, available as options, are noted in the preceding table.

ELECTRICAL RATING (AMPS):

Models with $2 F$ fixed differential-

\begin{tabular}{l|c|c}
\hline & $120 \mathrm{v} \mathrm{ac}$ & $240 \mathrm{v} \mathrm{ac}$ \\
\hline FULL LOAD & 2.6 & 1.3 \\
\hline LOCKED ROTOR & 15.6 & 7.8 \\
\hline
\end{tabular}

Models with $5 \mathrm{~F}$ differential

\begin{tabular}{l|c|r}
\hline & $120 \mathrm{v}$ ac & $240 \mathrm{v} \mathrm{ac}$ \\
\hline FULL LOAD & 8 & 5,1 \\
\hline LOCKED ROTOR & 48 & 30.6 \\
\hline INDUCTIVE CURRENT & .25 at $1 / 4$ to $12 \mathrm{v} \mathrm{dc}$ \\
\hline
\end{tabular}


PRESSURE RATING:

Capillary bulb (direct immersion) -200 psi.

Immersion well-255 psi.

SENSING BULB MATERIAL: Copper.

SENSING BULB FULL: Liquid. Toluene or Silicone.

CAPILLARY LENGTH (including bulb): Remote bulb models -60 inches.

SENSING BULB DIMENSIONS (inches): 2-7/8 long, $3 / 8$ diameter.

INSERTION DEPTH: $3-3 / 8$ inches.

INSULATION: Brass. $1-1 / 2$ or 3 inches. Specify when ordering.

PROVISION FOR WIRING: Screw terminals.

MOUNTING: Horizontal and vertical models mount directly to an immersion well installed in a boiler fitting. Remote bulb models have 3 mounting holes rear of case for screw mounting to a vertical surface.

FINISH: Gray.

INSTTALLA TION DIMEN3ION3. Bee Figs, 1 and \&.

IMMERSION WELL DIMENSIONS: See Fig. 3.

BOILER FITTING AND BULB DIMENSIONS: See Fig. 4.

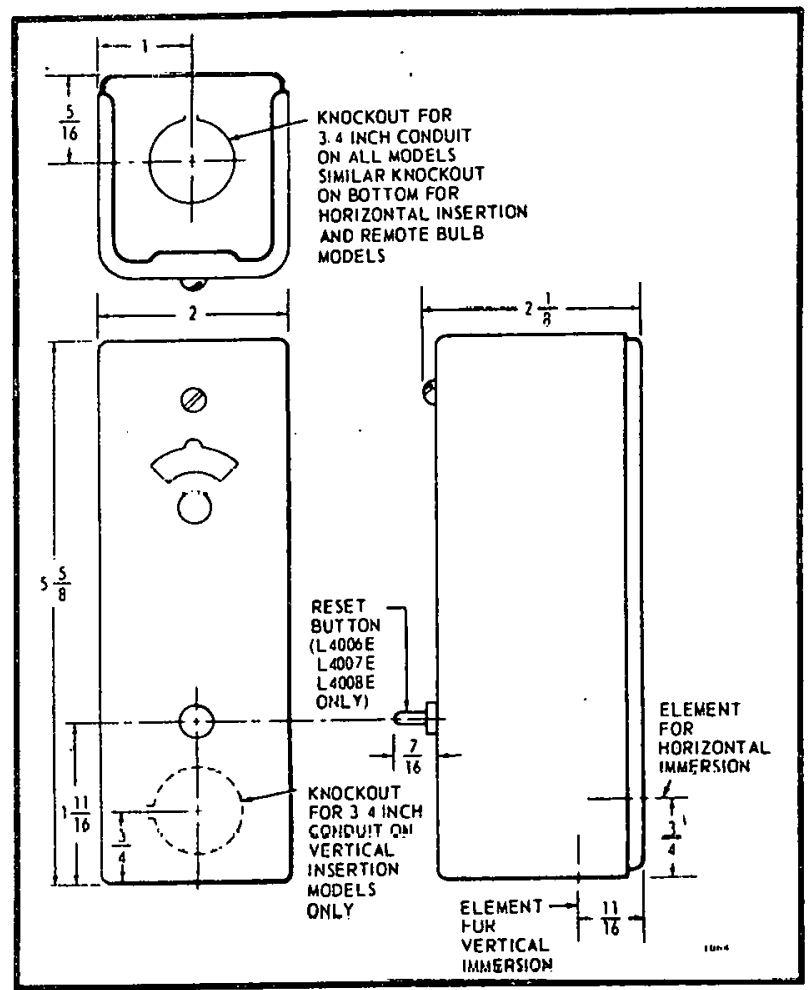

FIG. 1-INSTALLATION DIMENSIONS.

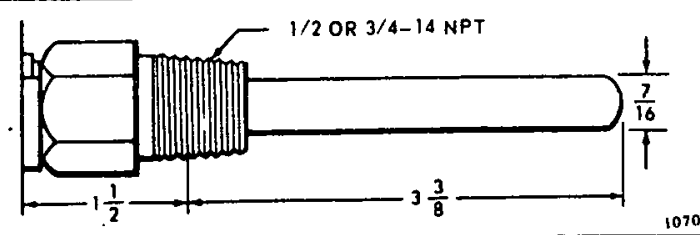

FIG. 3-IMMERSION WELL DIMENSIONS FOR ALL MODELS EXCEPT L4006C, L4007D, AND L6006B.
ACCESSORIES:

Weatherproof enclosure-Q615.

Immersion wells -

Copper, 1/2 NPT, 1-1/2 inch insulation-Part No. $121371 \mathrm{~A}$.

Copper, 1/2 NPT, 3 inch insulation-Part No. $121371 \mathrm{~L}$.

Copper, 3/4 NPT, 1-1/2 inch insulation-Part No. $121371 \mathrm{~B}$.

Copper, 3/4 NPT, 3 inch insulation-Part No. $121371 \mathrm{M}$.

Copper, 3/4 NPT, 1-1/2 inch insulation, plastic sleeve-Part No. $12131 \mathrm{~K}$.

Copper, 3/4 NPT, 3 inch insulation, plastic sleeve-Part No. $121371 \mathrm{~N}$.

Stainless steel, 1/2 NPT, 1-1/2 inch insulation - Part No. 121371E.

Stainless steel, 3/4 NPT, 1-1/2 inch insulation - Part No. 121371F.

Bulb Compression Fittings (see Fig. 6) -

Brass, 1/2 NPT plug. $1-1 / 2$ inch insulationPart No. 104486B.

Brass, 3/4 NPT plug. 1-1/2 inch insulationPart No, 104486C.

Capillary Compreasion Fittings (cee Fig. 7)-

Copper, 1/2 NPT, plug. 1-1/2 inch insulationPart No. $104484 \mathrm{C}$.

Copper, 3/4 NPT plug. 1-1/2 inch insulationPart No. 104484B.

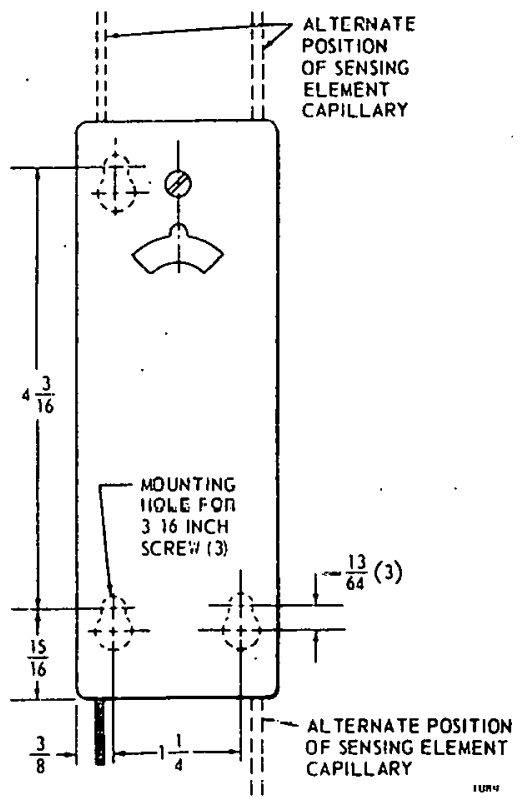

FIO. 2-INGTALLATION DIMENSIONS FOR REMOTE BULB MODELS. OTHER DIMENSIONS SAME AS FIG. 1.

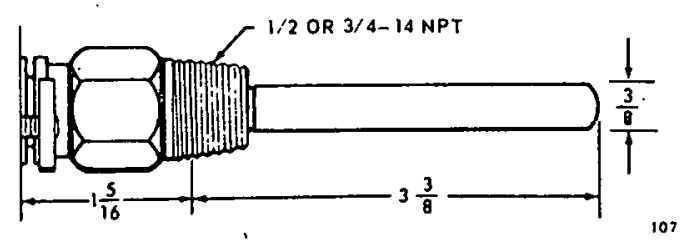

FIG. 4-BOILER FITTING AND BULB DIMENSIONSFOR L4006C. L4007D, AND L6006B. 


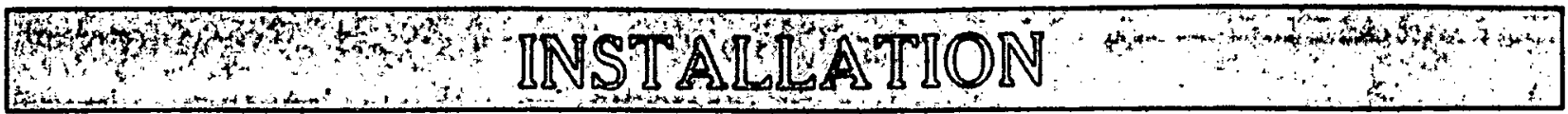

The manufacturer usually provides a tapping for insertion of the controller's sensing element. This tapping is located at a point where typical water temperature can be measured. Depending on model, the element is inserted in an immersion well, through a boiler fitting, or directly immersed.

Installation should be made by a qualified serviceman. Follow the instructions furnished by the system manufacturer, if available. Otherwise, refer to appropriate procedure listed below.

\section{IMPORTANT̃}

Controller may be used with or without immersion well. Well, if used, must fit sensing bulb snugly for good thermal responoc. Ingert bulb until it rests against bottom of well, then hold it there while tightening the tubing clamp.

\section{MOUNTING REMOTE BULB MODELS}

The remote temperature-sensing bulb can either be installed in an immersion well (Fig. 5) that extends into the boiler or tank, or it can be directly immersed in the liquid. For installations not using a well, secure the remote bulb with a bulb compression fitting (Fig. 6), or capillary compression fitting (Fig. 7).

Well, bulb compression fitting or capillary compression fitting must be ordered separately. Sizes available: $1 / 2$ in. , $3 / 4$ in. NPT spud. Well, if used, must fit sensing bulb snugly for good thermal response. Insert bulb until it rests against bottom of well, then hold it there while tightening the tubing clamp. (See Fig. 5.)

The boiler manufacturer generally provides a tapping for the insertion of the Aquastat controller's sensing element. This tapping should be located at a point where typical water temperature can be measured. The bulli or prolecting immersion well must never be located close to a hot or cold water inlet or a steam coil.

If the system is filled, drain system to a point below the boiler tapping, or wherever the sensing bulb is to be installed.

The bulb can also be installed in the supply line of an indirect water heater, in the direct water heater itself, or in the feed riser, about 6 in. above the boiler. If the riser is valved, the bulb can be installed between the boiler and the valve.

NOTE: Avoid making sharp bends or kinks in the capillary. Bends should be no sharper than 1 inch radius.

After installing, carefully coil excess capillary at the bottom of the controller case.

\section{IMMERSION WELL MOUNTING}

1. Screw the well into the boiler, tank, or pipe tapping.

2. Insert bulb in well, pushing tuhing until bulb bottoms in well.
3. Attach retainer clamp to end of well spud. Loosen draw nut and spread jaws of clamp with screwdriver if necessary.

4. With retainer clamp attached to well spud (be sure jaws of clamp hook over ridge at end of spud, as shown at points "A"), adjust tubing to fit through retainer clamp groove, as shown at point "B,"

5. Tighten draw nut so that retainer clamp is firmly attached to well spud and tubing is held securely in place.

CAUTION $n$ not secure drap nut on tightly that retalner clamp
could collapse tubing.

could collapse tubing.

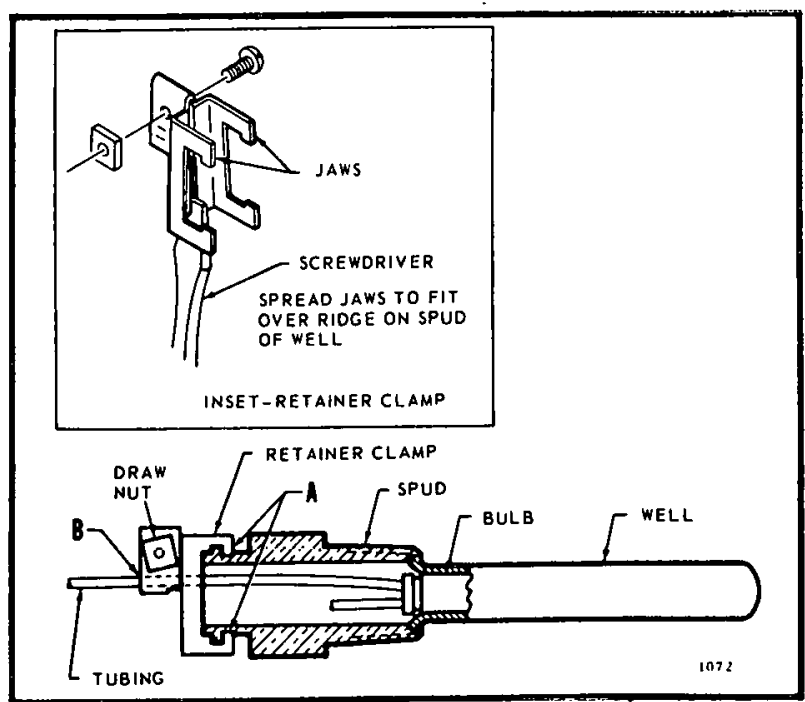

FIG. 5-IMMERSION WELL FITTING.

\section{MOUNTING WITH BULB COMPRESSION FITTING}

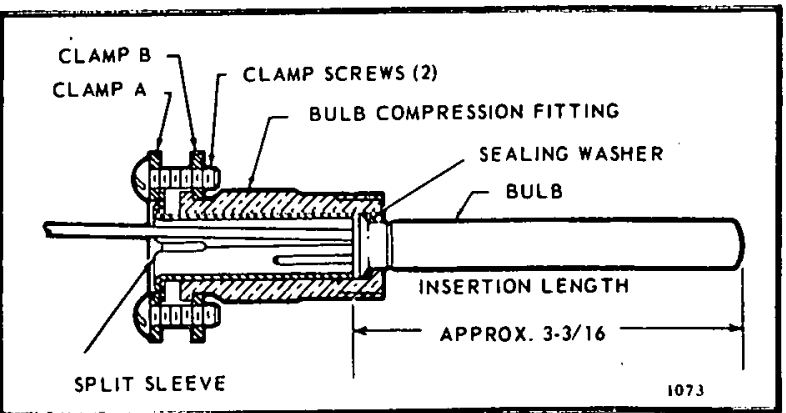

FIG. 6-BULB COMPRESSION FITTING. USE WITH MODEL L4008A,B,E,J, OR L6008A.

1. Screw the fitting into boiler or pipe tapping.

2. Slide sealing washer onto bulb.

3. Insert bulb into boiler fitting until bulb bottoms.

4. Slide split sleeve into fitting.

5. Place clamps A and B on assembly so that sleeve is drawn into fitting when screws are tightened. Note: make sure that nub on clamp $A$ engages space between sleeve and clamp.

6. Tighten clamp screws evenly. 


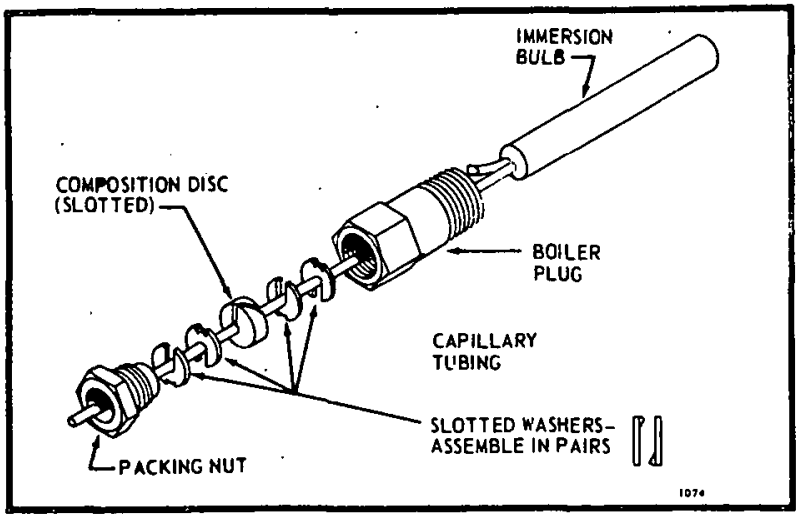

FIG. 7-CAPILLARY COMPRESSION FITTING. USE WITH MODEL L4008C,D,K, OR L6008C,E.

1. Screw fitting into boiler or pipe tapping.

2. Place packing nut on tubing.

3. Slide bulb completely through fitting.

4. Place composition disc and 4 slotted brass washers on tubing in the order shown in Fig. 7. Turn brass washers so that slots are 180 degrees apart.

5. Slide seal assembly into fitting and tighten packing mat.

\section{DUCT MOUNTING}

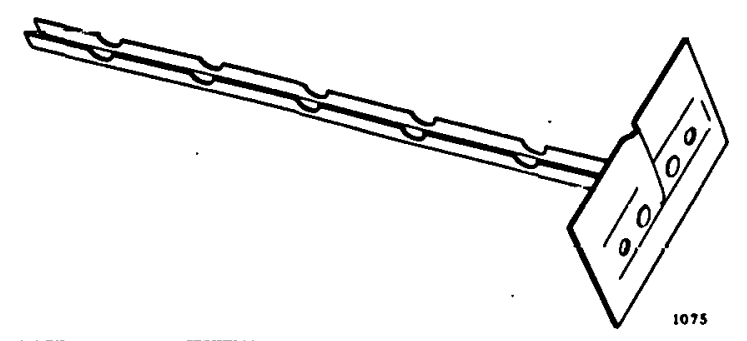

FIG. 8-BULB SUPPPORT.

1. Drill a $3 / 4$ inch hole in the duct wall large enough to admit the sensing bulb into the holder.

2. Using the holder as a template, mark and drill holes for bulb holder mounting screws.

3. Break holder to desired length (Fig,9).

NOTE: Holder must be long enough to hold sensing bulb in freely circulating air away from duct wall. Neatly coil excess capillary at controller case or at bulb holder.

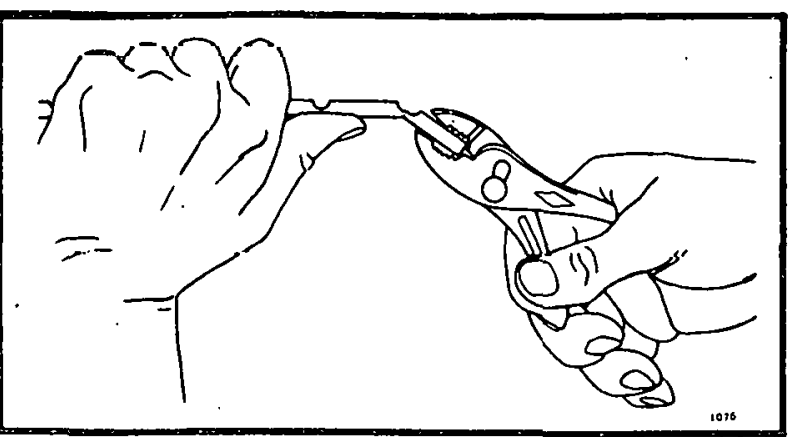

FIG. 8-REMOVING EXCESS BULB SUPPORT.
4. Place capillary in bulb holder channel. Pinch top edges of holder together at each segment (Fig. 10).

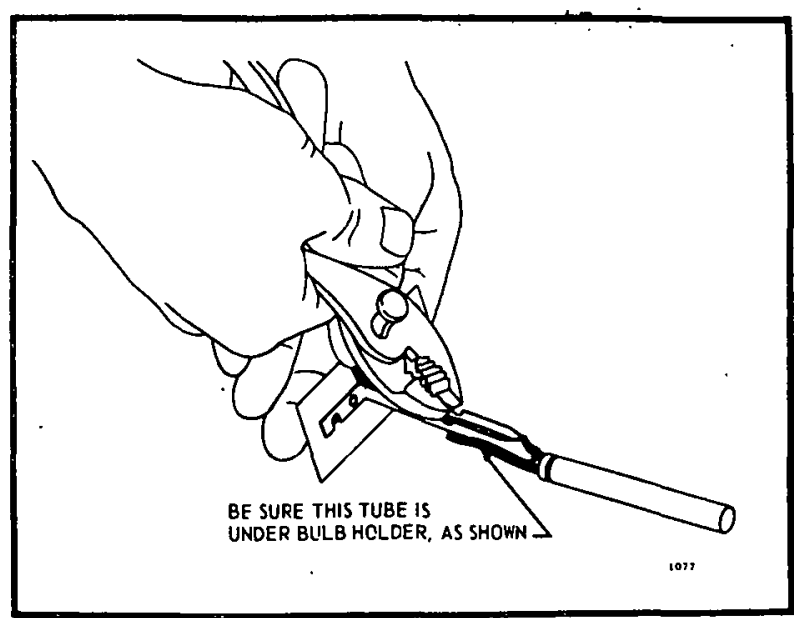

FIG. 10-SECURING CAPILLARY IN BULB HOLDER.

5. Insert bulb holder into controlled area through hole prepared in step 1 above.

6. Fasten bulb holder to duct wall with screws furnished.

\section{MOUNTING DIRECT IMMERSION MODELS}

\section{FOR MODELS USING AN IMMERSION WELL}

The well of the Aquastat controller must always be exposed to circulation of the medium under control, but must never be located close to a hot or cold inlet ur sleuul cuil. Where the tapping ie on the side of the boiler, use an Aquastat controller with horizontal well. Where the tapping is on top of the boiler, use a model with a vertical well.

\section{INSTALLING THE IMMERSION WELL}

On existing installations, shut off the power and remove the old control. If the old immersion well appears suitable, and if the adapter clamp on the Aquastat controller fitis the old well siall, the well nced not be replaced.

1. If the system is filled, drain system to a point below the boiler tapping.

2. Remnve plug (or old woll) from boiler tapping.

3. Install the No. 121371 Immersion Well included with the controller. If boiler tapping is greater than $1 / 2$ inch a reduction fitting must be used to adapt the boiler opening to the $1 / 2$ inch threads that are standard with the wcll or fitting. Fittings with $3 / 4$ inch threads are also available.

4. Fill the system. Make sure that the well is screwed in tightly enough to prevent leakage. Do NOT tighten or apply force to case after controller is secured to well. 


\section{INSTALLATION OF SENSING BULB IN IMMERSION WELL}

a. Loosen screw (at top of case, above scalesetting), and remove cover. Loosen two screws that secure adapter clamp. See Fig. 11. well.

b. Insert the sensing element into the immersion

c. Fasten the case of the Aquastat controller to the well with the adapter clamp. Make certain that the clamp is properly positioned over the groove of the well spud. Also be sure the flange at the opening of the well fits snugly into the opening of the case. The sensing element bulb must bottom in the well,

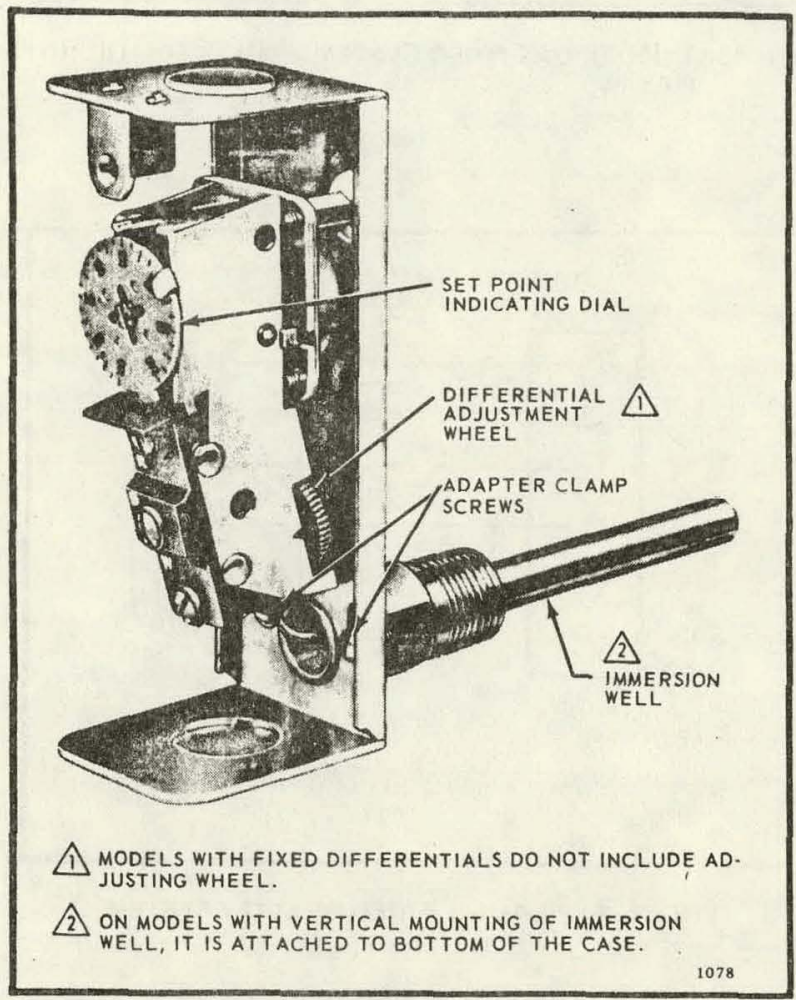

FIG. 11-INTERNAL VIEW OF L6006A.

\section{MODELS DESIGNED FOR DIRECT IMMERSION (WITHOUT WELL)}

Some models, which provide direct immersion of the sensing element into the boiler, include a No. 104486 bulb compression fitting assembly instead of an immersion well. Install fitting in boiler tapping. Be sure sealing washer is in place as shown in Fig. 12. Make sure that spud of bulb cumpression fitting is screwed in tightly enough to prevent leaking. Insert immersion bulb (sensing element) through bulb compression fitting. Adjust the adapter clamp so that it fits over the groove at the opening of the bulb compression fitting. Tighten adapter clamp screws so that Aquastat controller is firmly attached to bulb compression fitting.

\section{MOUNTING DUAL FUEL CHANGEOVER MODELS}

These mudels have a five foot capillary. This capillary establishes the maximum distance between the case and the outdoor mounting.

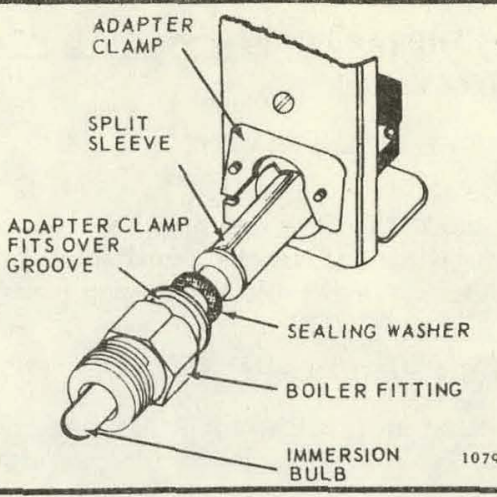

FIG. 12-DIRECT IMMERSION MODEL WITH BULB COMPRES. SION FITTING PARTIALLY REMOVED.

The bulb should be installed on the outside of the building in the shield provided (see Fig. 13) where it will be exposed to representative air temperature, but not to direct sunlight. It should be mounted high enough so that accumulated snow, leaves, or other debris cannot obstruct circulation of air around it, and where children cannot reach it. Avoid vents from the building.

Install the case at the indoor location selected, fastening with screws through holes in back of the case. Bring the bulb and tubing out through a $3 / 4$ inch hole in the outside wall. In uncoiling the tubing, carefully avoid sharp bends or kinks. Excess tubing should be left coiled near the case. Do not make sharp bends near the case or bulb.

Slip the bulb through the supports in the shield. Pinch the split supporting clip until it holds the bulb firmly in position. If the seal-off tube protrudes from under the shield, it may be bent under as shown in Fig. 13.

Hold the shield over the mounting position and form a small-radius bend in the tubing. Place the split plug around the tubing and move the shield into mounting location as a unit. Push the split plug into the hole until it is wedged securely in place. Fasten the shield in place on the wall with the screws provided.

NOTE: If the tubing is properly shaped and the split plug installed as directed, the shield will cover the split plug, and the hole in the wall will be hidden from sight.

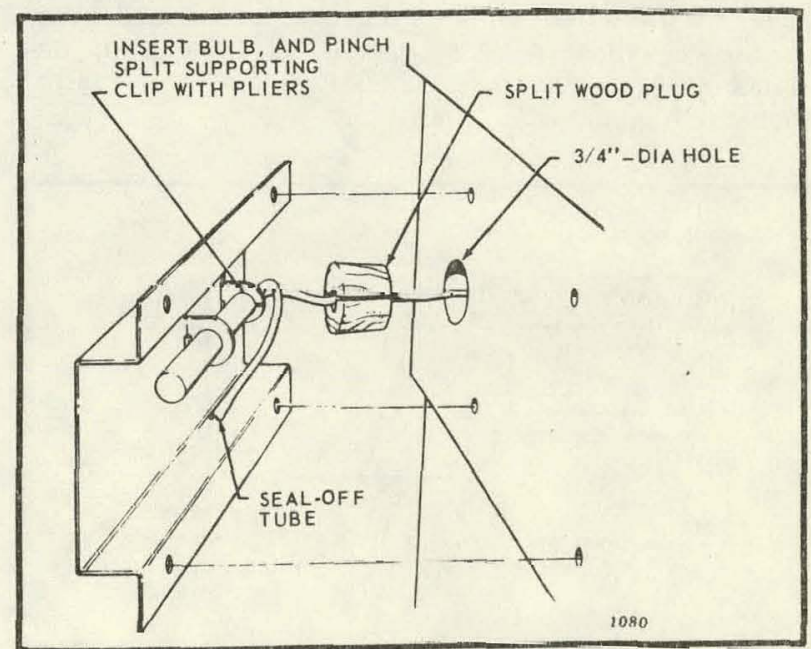

FIG. 13-MOUNTING BULB IN SHIELD OUTSIDE BUILDING. 


\section{MOUNTING THE L6008A REMOTE BULB COOLING THERMOSTAT}

\section{MOUNTING WITH GUARD BRACKET}

Mount the bulb in the guard bracket as shown in Fig. 14. Locate the bulb and bracket combination in freely circulating air in the controlled area. With screws provided, fasten the bracket in place.

\section{MOUNTING ON SUCTION LINE}

1. In cooling units with more than one suction line, sensing bulb should be placed on the common line.

2. Make certain the bulb is at least 2 feet from the point at which the suction line leaves the cooler. This will prevent the outside temperature from being transmitted to the remote bulb through the copper tubing of the suction line.

3. Place the remote sensing bulb on the side of the horizontal suction line between the coil and trap (not on the trap).

4. Attach the sensing bulb to the suction line with clips or straps.

5. Coil the excess length of capillary tubing near the L6008A case.

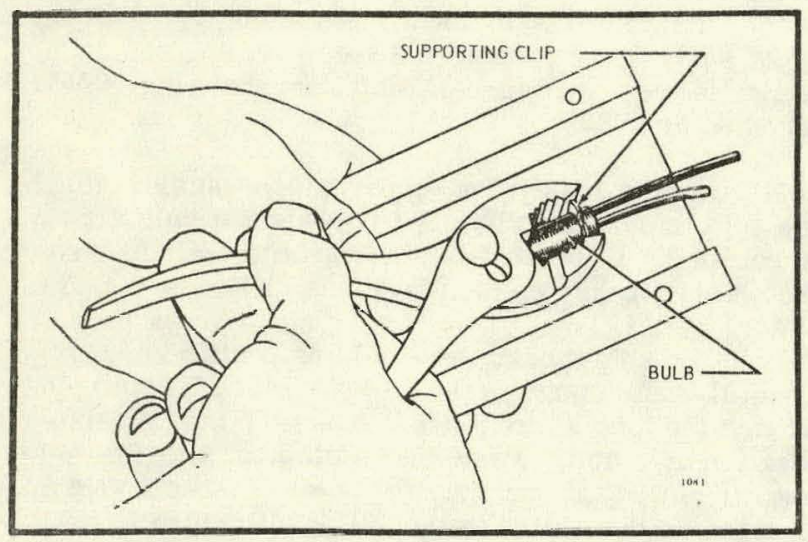

FIG. 14-SECURING REMOTE BULB IN CLIP.

\section{WIRING}

All wiring must comply with local codes and ordinances regarding wire size, type of insulation, enclosure, etc. Figures 16 through 23 show typical hook-up diagrams.

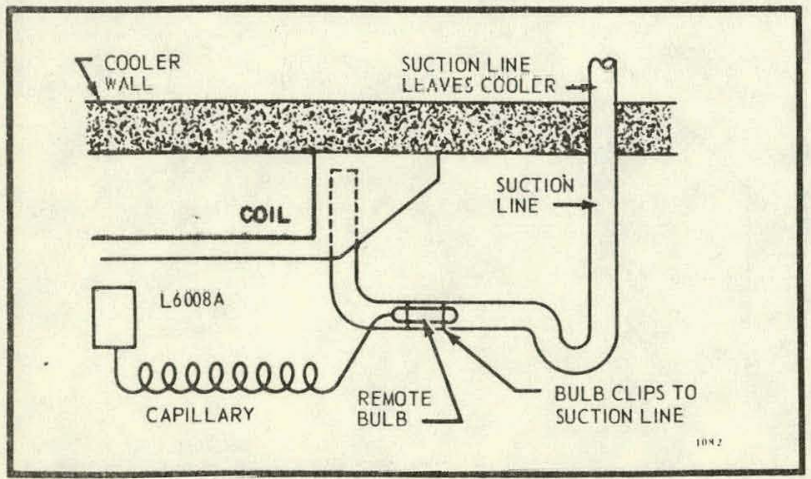

FIG. 15-ATTACHING REMOTE BULB TO HORIZONTAL SUCTION LINE.

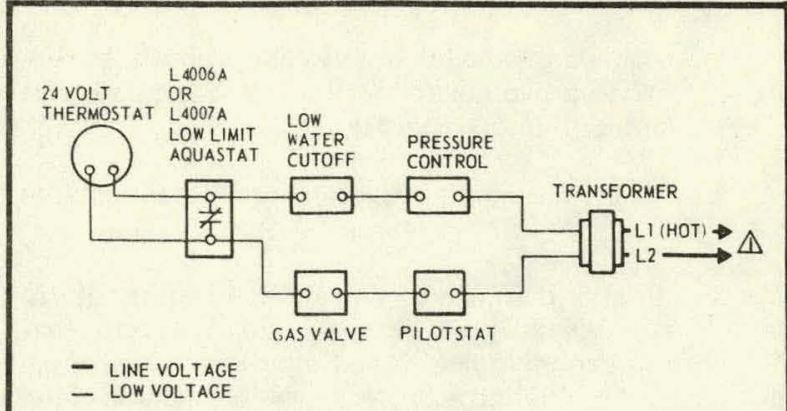

1. PROVIDE DISCONNECT MEANS AND OVERLOAD PROTECTION AS REQUIRED.

FIG. 16-TYPICAL GAS-FIRED SYSTEM WITH DOMESTIC HOT WATER.

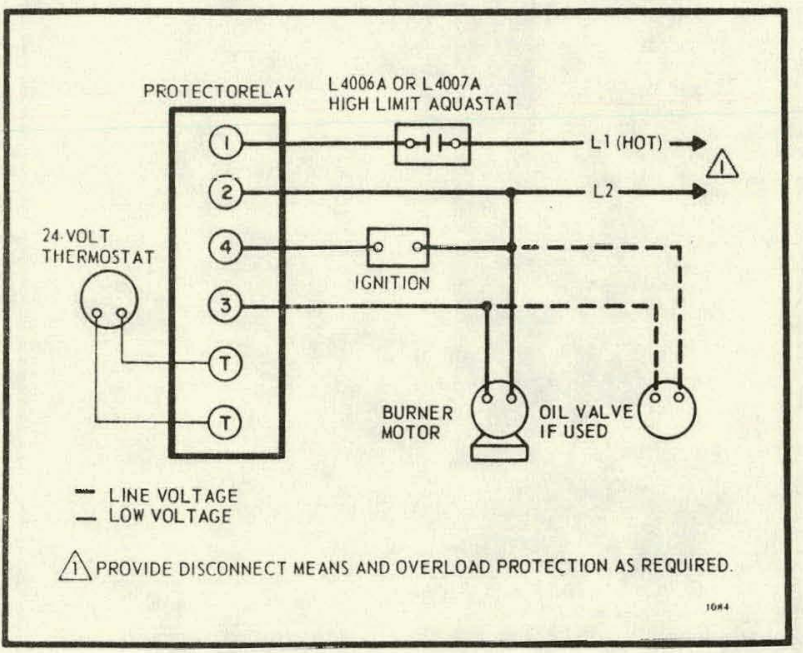

FIG. 17-TYPICAL OIL-FIRED GHAVIIY SYSTEM.

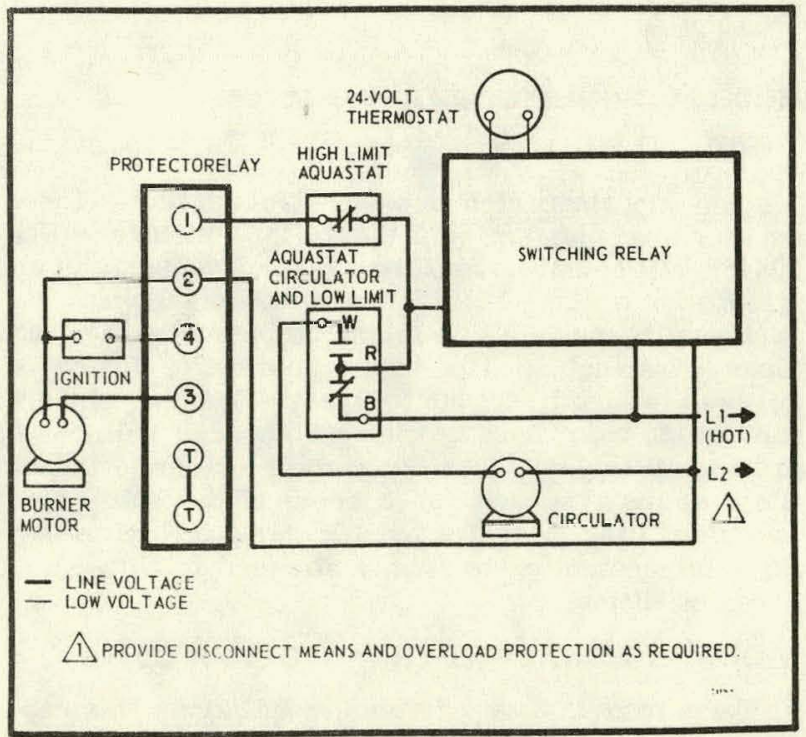

FIG. 18-TYPICAL OIL-FIRED HYDRONIC SYSTEM WITH DOMESTIC HOT WATER. 


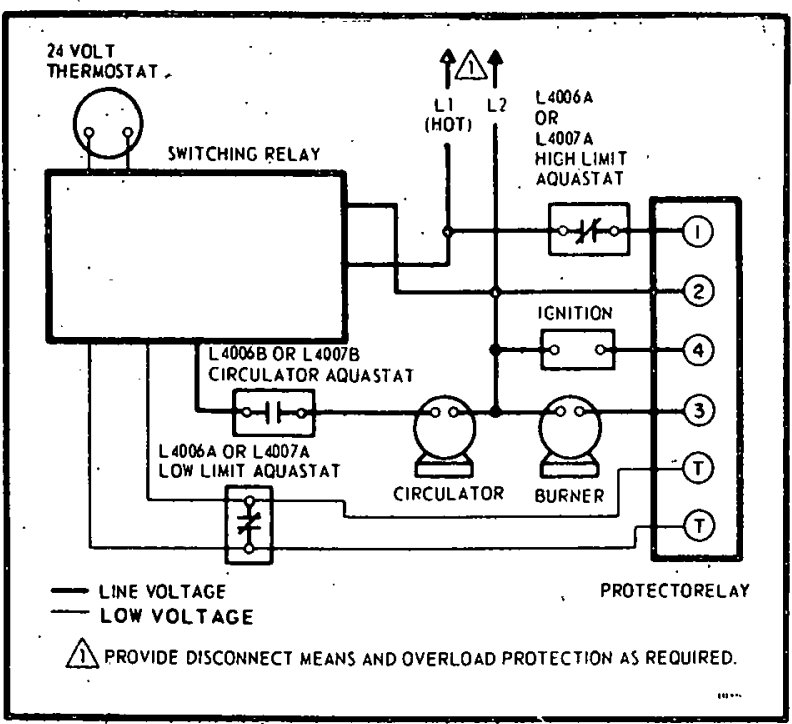

FIG. 19-OIL-FIRED SUMMER.WINTER HYDRONIC SYSTEM WITH DOMESTIC HOT WATER.

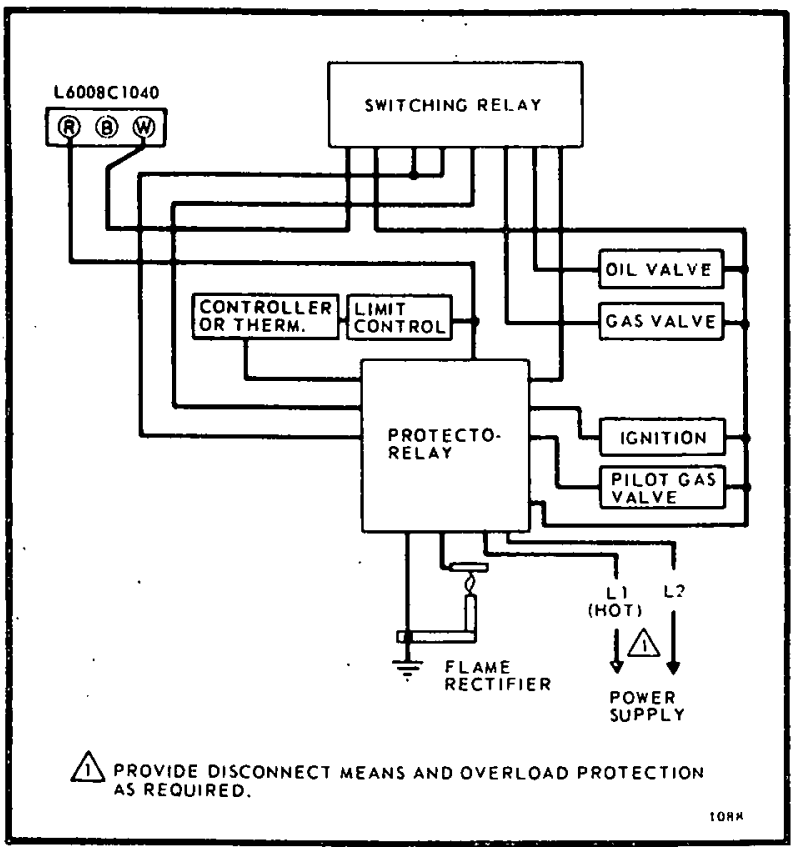

FIG. 20-TYPICAL WIRING DIAGRAM FOR L6008C1040 USED TO SWITCH FROM GAS TO OIL ON TEMPERATURE DROP.

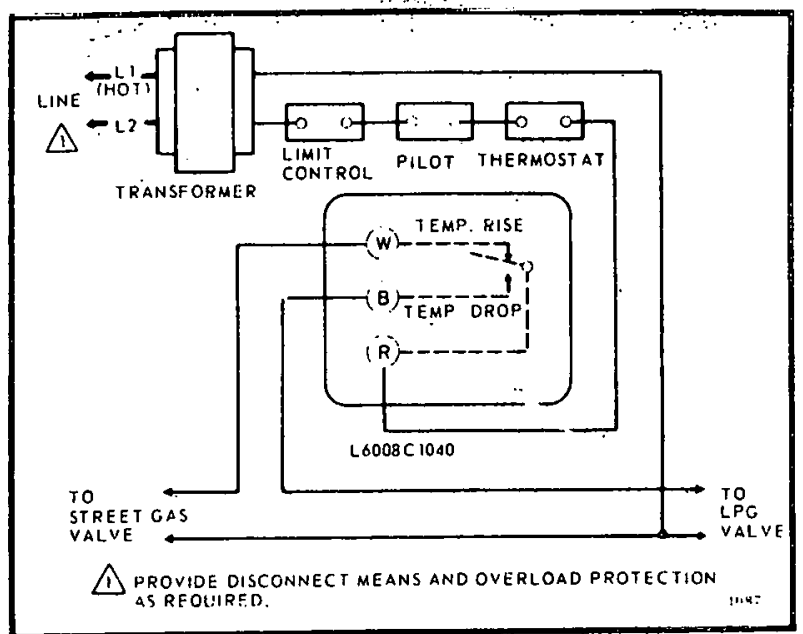

FIG. 21-TYPICAL WIRING DIAGRAM FOR L6008C1040 USED TO SWITCH STREET GAS TO LPG ON TEMPERATURE DROP.

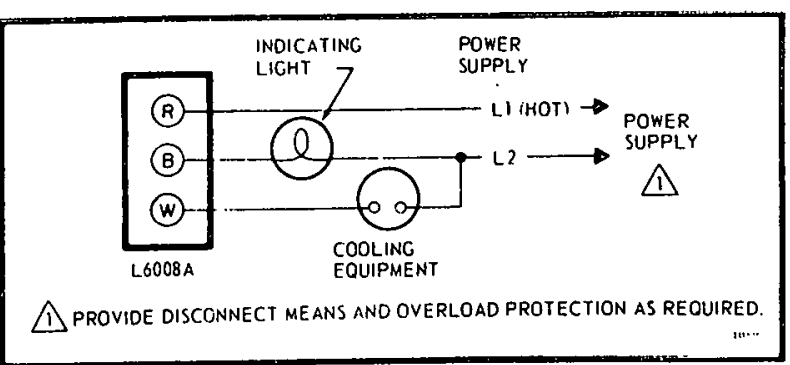

FIG. 22-L6008A USED TO CONTROL COOLING EQUIPMENT AND INDICATING LIGHT.

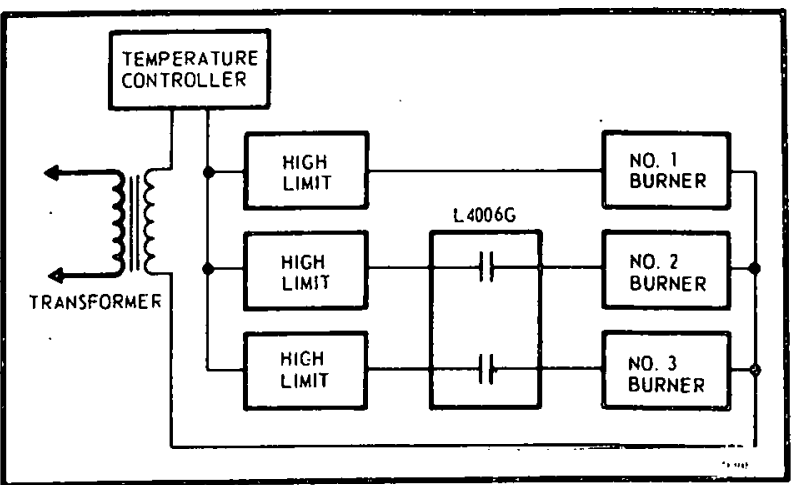

FIG. 23-TYPICAL HOOKUPFOR L4006G BOILER SEQUENCING AQUASTAT.
For proper selection of settings, follow the boiler manufacturer's recommendations.

\section{HIGH LIMIT CONTROLLER}

Shuts off burner if water temperature exceeds high limit setting. Burner restarts when temperature drops to high limit setting, less differential.

NOTE: On manual reset models, the reset button on

the front of the case must be pushed in to allow the

burner to operate after a high limit shutdown.

\section{LOW LIMIT CONTROLLER}

Maintains minimum boiler temperature for domestic hot water. Turns on boiler at temperature setting, minus differential.

\section{CIRCULATOR CONTROLLER}

Prevents circulation of water that is below the desired heating temperature. Breaks circulator circuit on temperature drop below setting minus differential, remakes on rise to setting. 
Set the differential to correspond with the boiler manufacturer's recommendations. To adjust models with adjustable differential, rotate the wheel on the back of the snap switch until the desired reading is aligned with the " $V$ " notch in the frame. The wheel provides an adjustment from 5 to $30 \mathrm{~F}$. Replace the cover on the Aquastat controller.

Adjust the control point to correspond with the boiler manufacturer's recommendations. To adjust, insert a screwdriver in the slotted screw-type head located beneath the window in the cover. Turn the scale to the desired control point.

\section{L6008A LOCATION DIFFERENTIAL CALIBRATION}

The L6008A1093 is calibrated for applications with both the bulb and case located in the room in which the temperature is being controlled. A correction will be necessary if the temperature of the case is different from the desired dial setting.

1. If the case is at a higher temperature than the desired dial setting, raise the desired dial setting by the correction determined from the table at right.
2. If the case is at a lower temperature than the desired dial setting, lower the desired dial setting by the correction determined from the table below.

\begin{tabular}{c|c}
\hline $\begin{array}{c}\text { Temperature difference between } \\
\text { desired room temperature and } \\
\text { case temperature (F) }\end{array}$ & $\begin{array}{c}\text { Correction } \\
\text { (Degrees F) }\end{array}$ \\
\hline 0 & 0 \\
\hline 5 & $3 / 4$ \\
\hline 10 & $1-1 / 2$ \\
\hline 15 & 2 \\
\hline 20 & $2-3 / 4$ \\
\hline 25 & $3-1 / 2$ \\
\hline 30 & $4-1 / 4$ \\
\hline 35 & 5 \\
\hline 40 & $5-3 / 4$ \\
\hline 45 & $6-1 / 2$ \\
\hline 50 & 7 \\
\hline 55 & 8 \\
\hline 60 & $8-1 / 2$ \\
\hline 70 & 10 \\
\hline 80 & $11-1 / 2$ \\
\hline
\end{tabular}

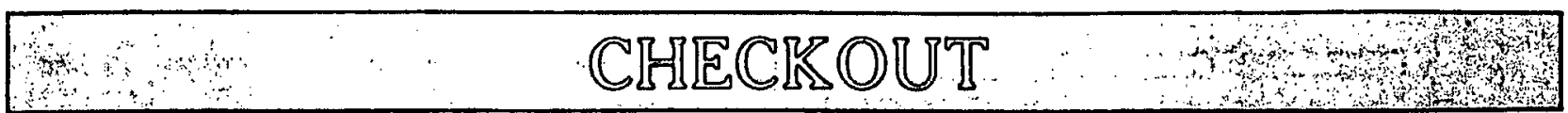

Check to make certain that the Aquastat controller has been installed and adjusted properly. Put the system into operation and observe the action of the device through several cycles to make certain that it provides proper control of the system as described under OPERATION. Further adjustments then can be made to meet more exact comfort requirements. 
APPENDIX B

COLLECTOR SUBSYSTEM

$\begin{array}{ll}\text { LSC18-1 } & \text { Solar Collectors } \\ \text { HRW-1-30 } & \text { Purge Unit } \\ \text { Y534A } & \text { Diverting Valve }\end{array}$




\section{operation maintenance and installation instructions}




\section{PARTS ARRANGEMENT}

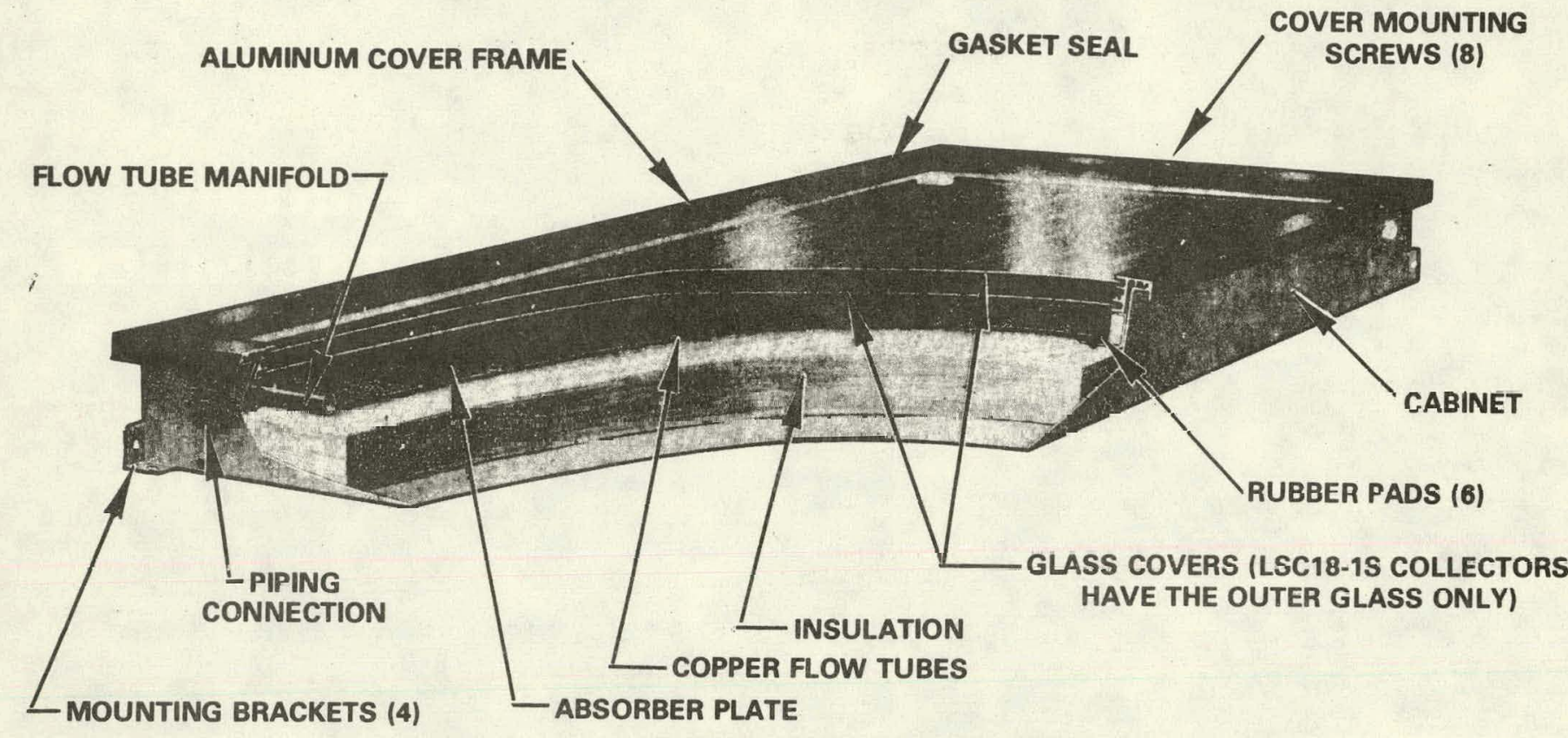

\section{SOLAR COLLECTOR DIMENSIONS}

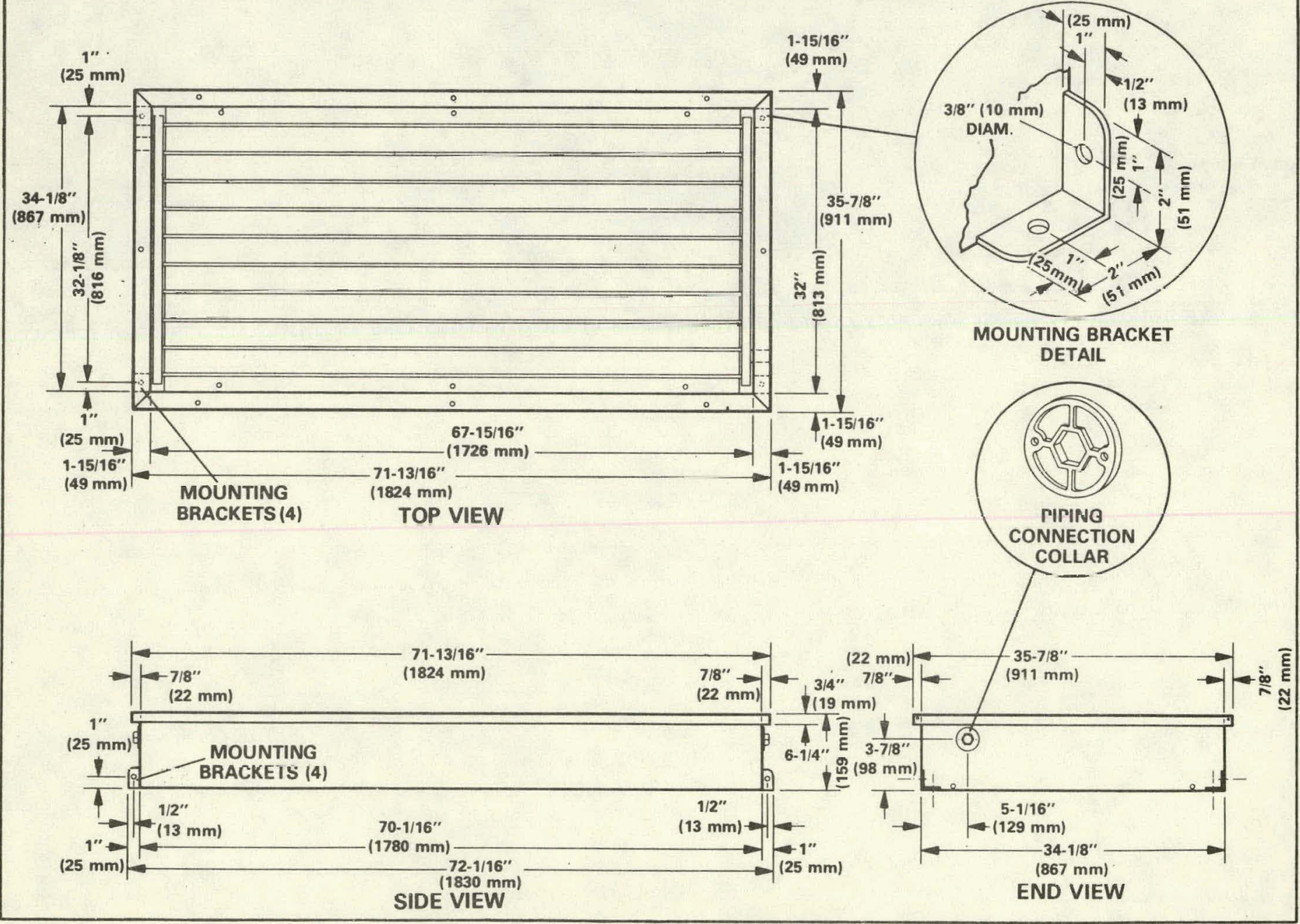




\section{FRAMING - FLASHING - COLLECTOR MOUNTING}

I - SHIPPING AND PACKING LIST

Package 1 of 1 Contains

1 - Assembled solar collector

\section{II - SHIPPING DAMAGE}

Check unit for shipping damage. Contact the last carrier immediately if any damage is found.

\section{III - GENERAL}

These instructions are intended as a general guide and do not supersedelocal codes. Authorities having jurisdiction should be consulted before installation.

\section{IV - APPLICATION}

The consulting engineer, architect or dealer must determine the solar collector application including number required, placement,

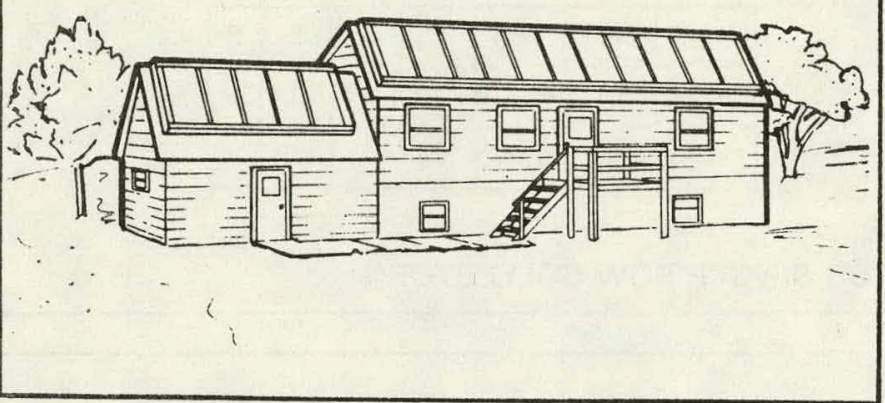

FIGURE 1 mounting angle and piping sequence. This instruction outlines one typical method of framing and installing the solar collectors. Other designs can be substituted if the basic guidelines within the instruction are followed.

Figure 1 illustrates a typical residential application.

\section{V - SOLAR COLLECTOR}

The collectors must mount on a watertight roof. Roof construction must be adequate to support the collectors and mounting frame. Solar collectors must be installed with the flow tubes in the vertical

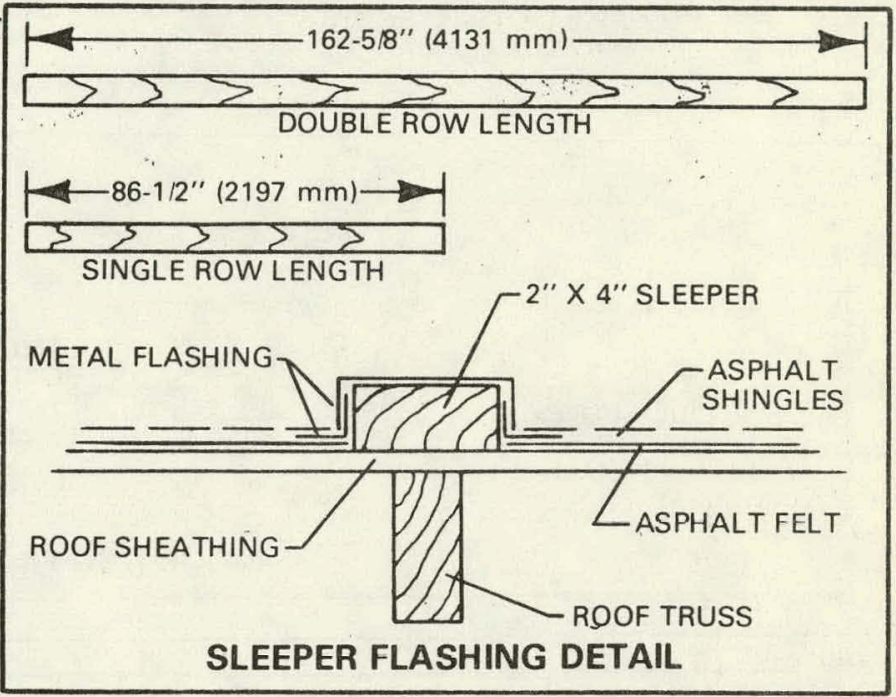

FIGURE 3

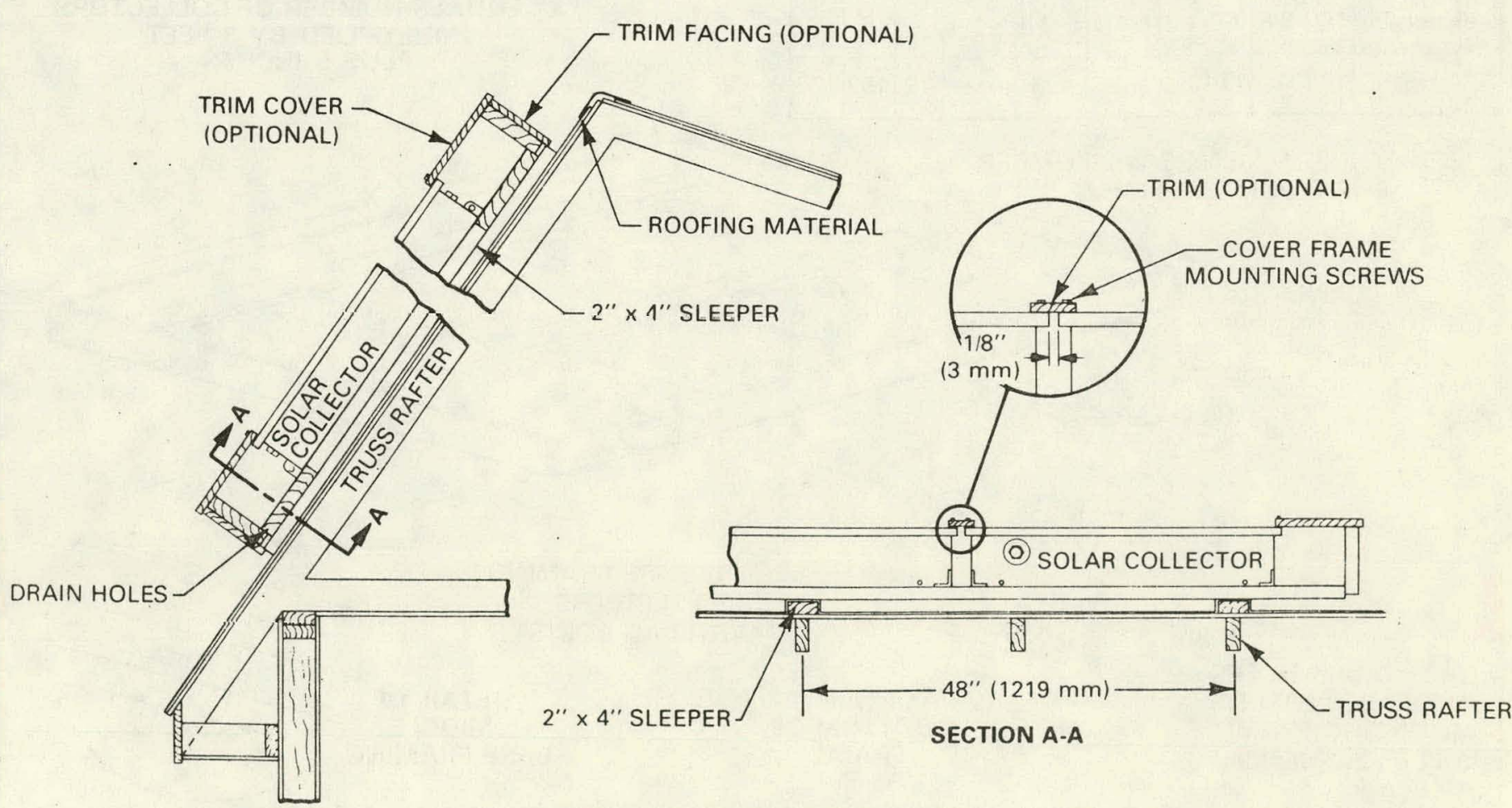

TYPICAL MOUNTING DETAIL 
position. Figure 2 illustrates details for a typical mounting frame. Install the frame and solar collectors as follows:

1 - Center sleepers over trusses and secure to roof. Figure 3 shows the sleeper flashed into the roof.

a - Length of sleepers required for a single row of collectors is $86-1 / 2$ inches. $b$ - Length of sleepers required for two rows of collectors is $162-5 / 8$ inches.

2 - Figure 4 illustrates typical framing construction for one row of collectors. Figure 5 illustrates construction for two rows of collectors. $2^{\prime \prime} \times 8$ " dimentional lumber is utilized.

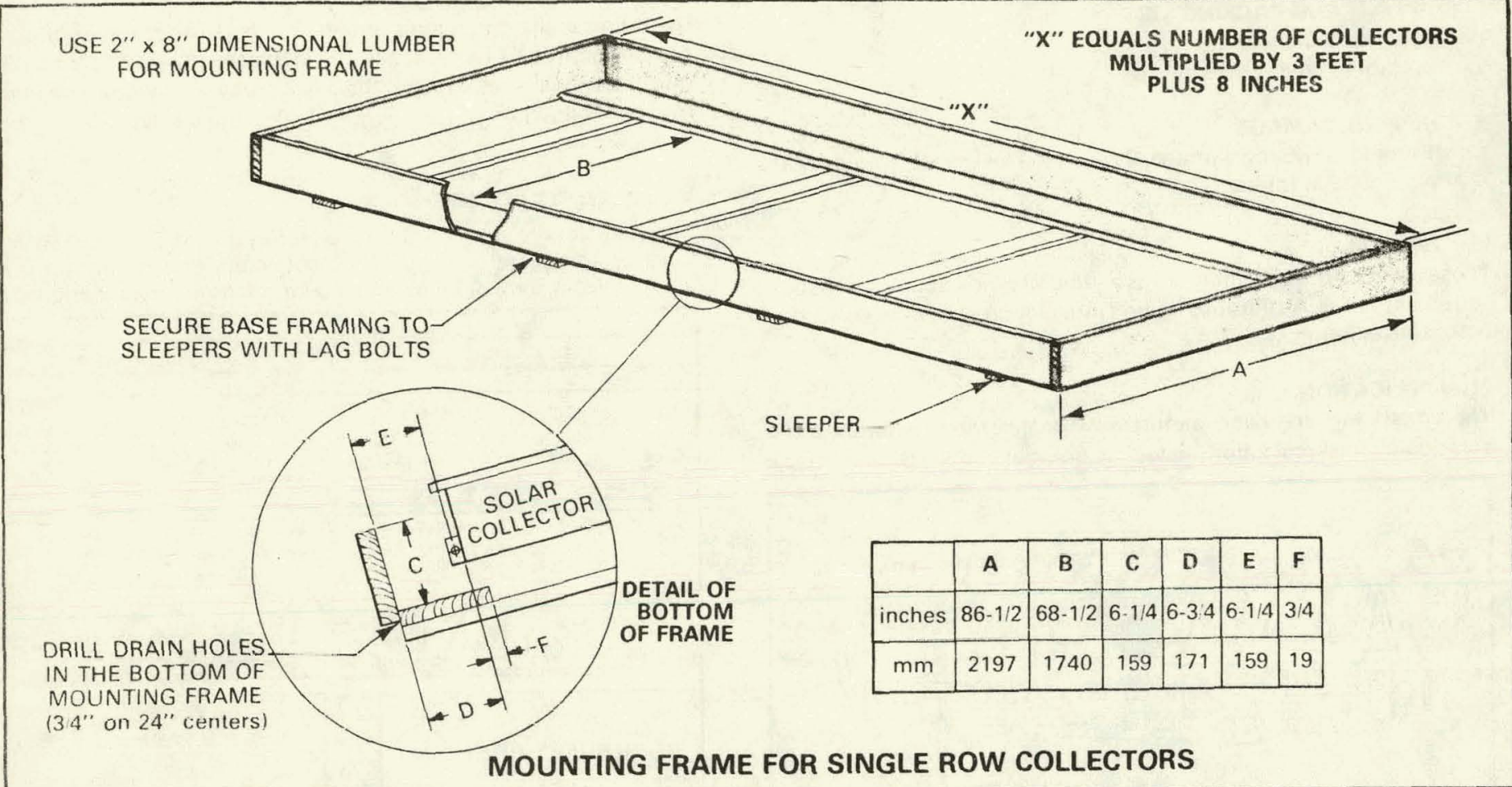

FIGURE 4

\begin{tabular}{|c|c|c|c|c|c|c|c|c|}
\hline & A & B & C & D & E & F & G & H \\
\hline inches & $162-5 / 8$ & $68-1 / 2$ & $6-1 / 4$ & $6-3 / 4$ & $6-1 / 4$ & $3 / 4$ & 6 & 5 \\
\hline $\mathrm{mm}$ & 4131 & 1740 & 159 & 171 & 159 & 19 & 152 & 127 \\
\hline
\end{tabular}

" $X$ " EQUALS NUMBER OF COLLECTORS MULTIPLIED BY 3 FEET PLUS 8 INCHES

USE 2" $\times$ 8" DIMENSIUNAL LUMBER FOR MOUNTING FRAME

DRILL DRAIN HOLES IN THE BOTTOM OF MOUNTING FRAME (3/4" on $24^{\prime \prime}$ centers)

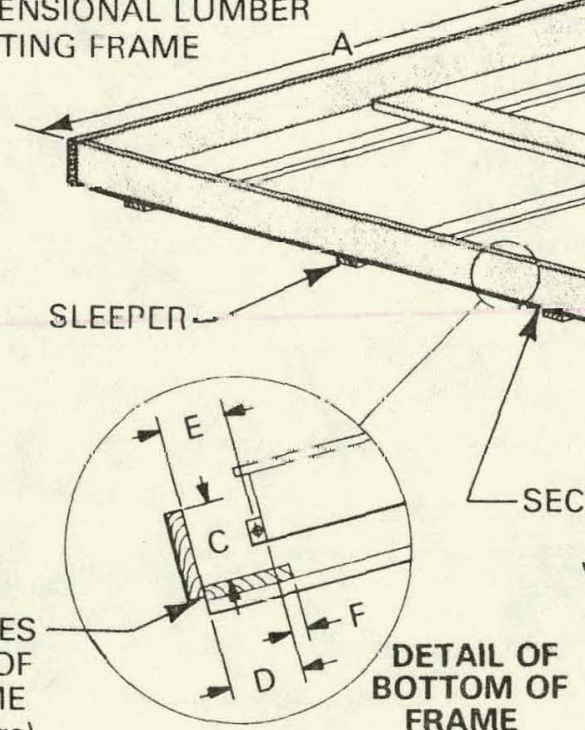

MOUNTING FRAME FOR DOUBLE ROW COLLECTORS

FIGURE 5 
3 - Position first collector 4-78 inches from end of frame and then maintain $1 / 8$ inch between remainder of collectors. Refer to Figure 6 . Secure collectors to frame with lag bolts ( 4 per collector). If desired the inside spacing could enclose the supply and return header runs where they penetrate through roof.

NOTE - Solar collectors can be piped individually as they are set or if working area permits, piped after all collectors are set.

4 - The temperature control system has a sensor which secures directly to one absorber plate. Remove the collector frame from desired collector and install the sensor in the center of absorber plate. Refer to manufacturer's installation instructions. Drill a hole through collector cabinet and route wiring to sensor.

5 - After the system has been leak tested and the insulation has been installed on outdoor piping, flash the frame and solar collectors as illustrated in Figure 7. This flashing prevents air flow around collectors minimizing convection losses. This trim can bolt directly to the collector frame.
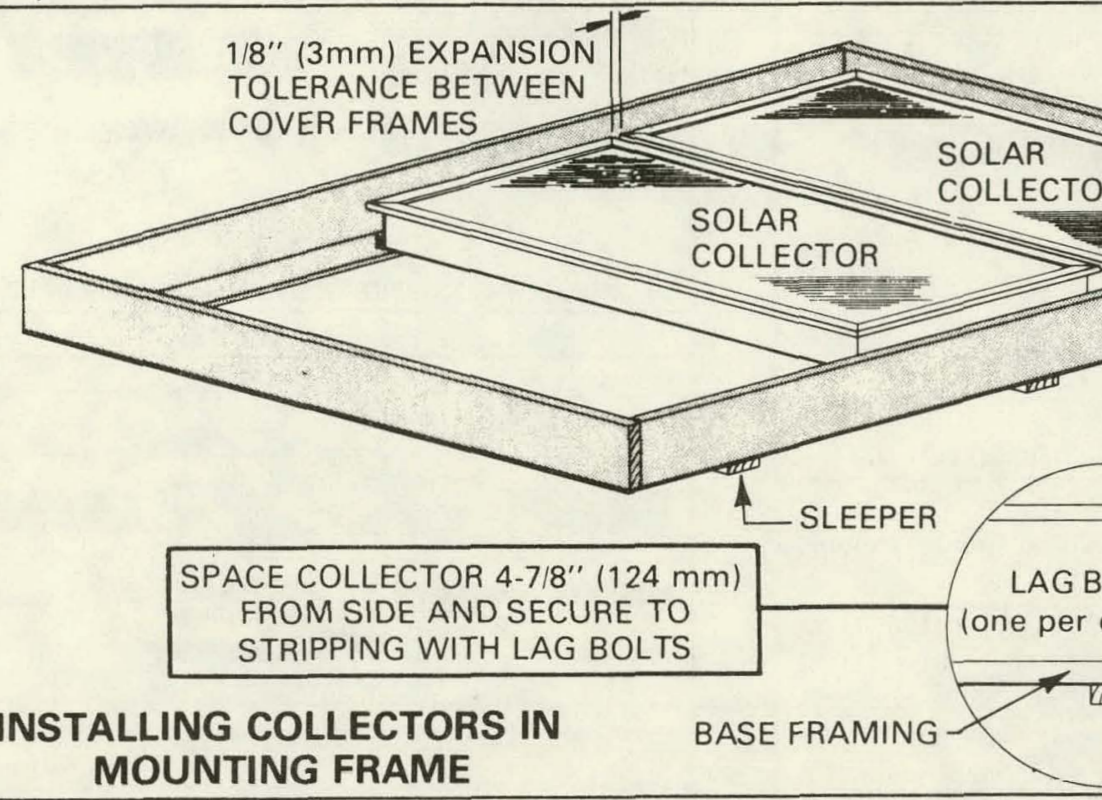

SOLAR COLLECTOR COLLECTOR
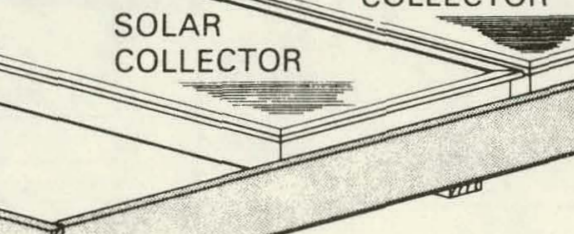

SLEEPER

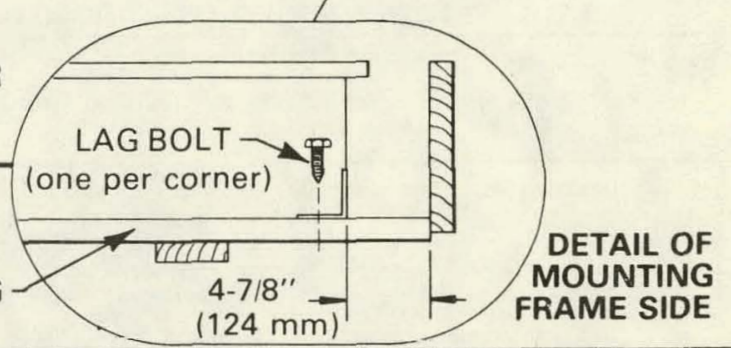

FIGURE 6

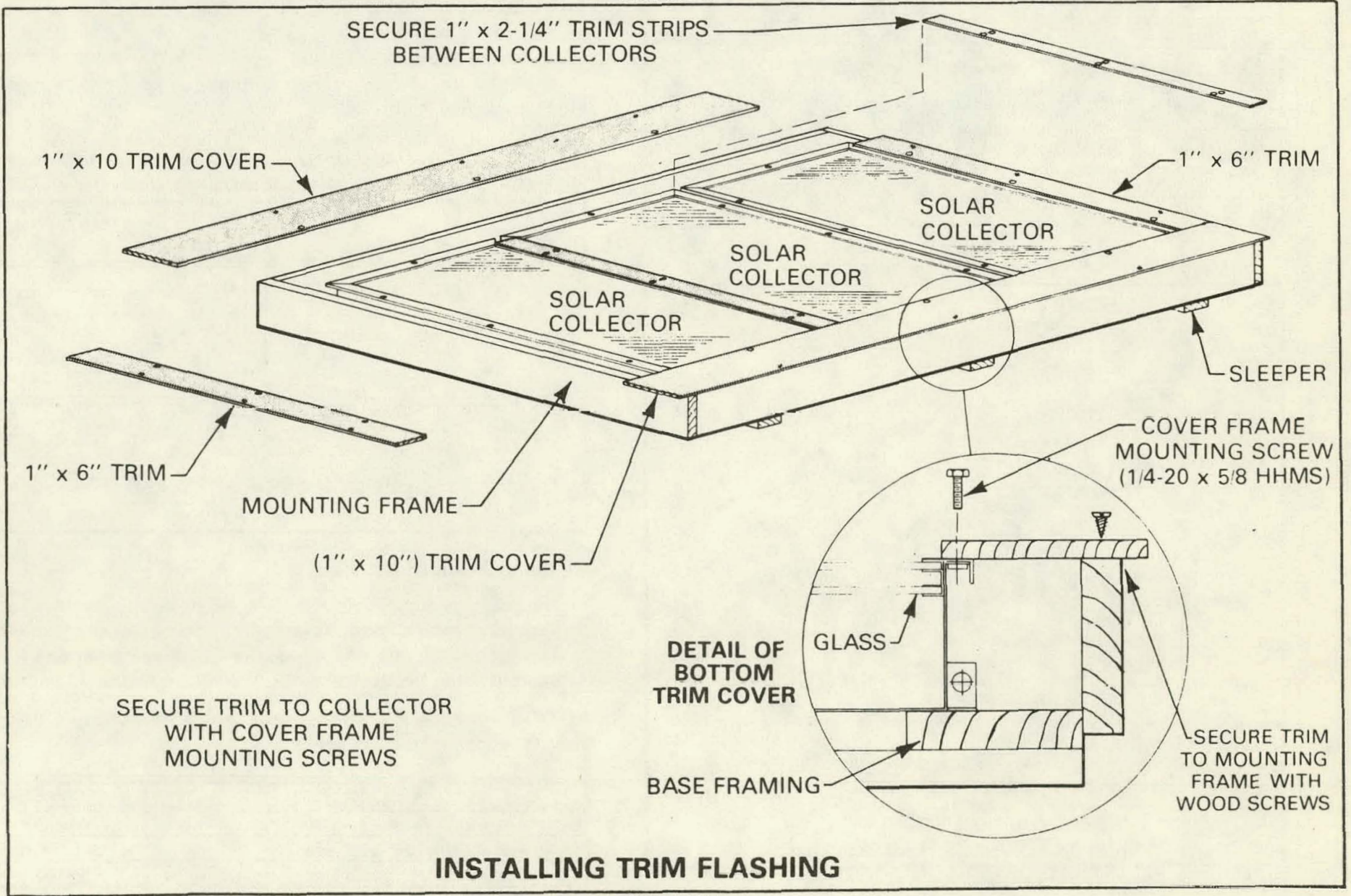

FIGURE 7 


\section{PIPING}

\section{VI - PIPING FOR SOLAR COLLECTORS}

A - Basic Piping Fundamentals

1 - Flared Connections

a - Cut pipe to size with a roller type tubing cutter. See Figure 8.

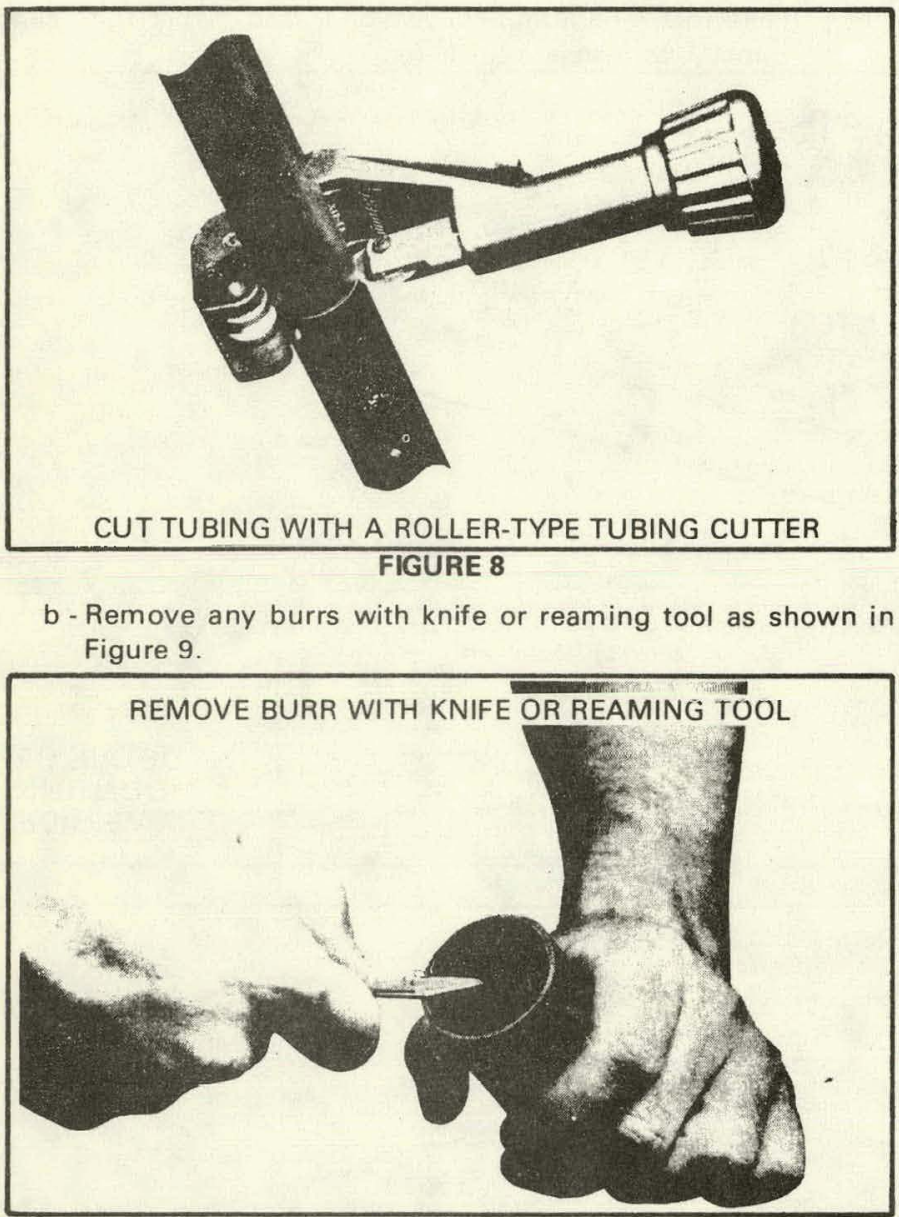

FIGURE 9

c- Flare tubing with a flaring tool as illustrated in Figure 10.

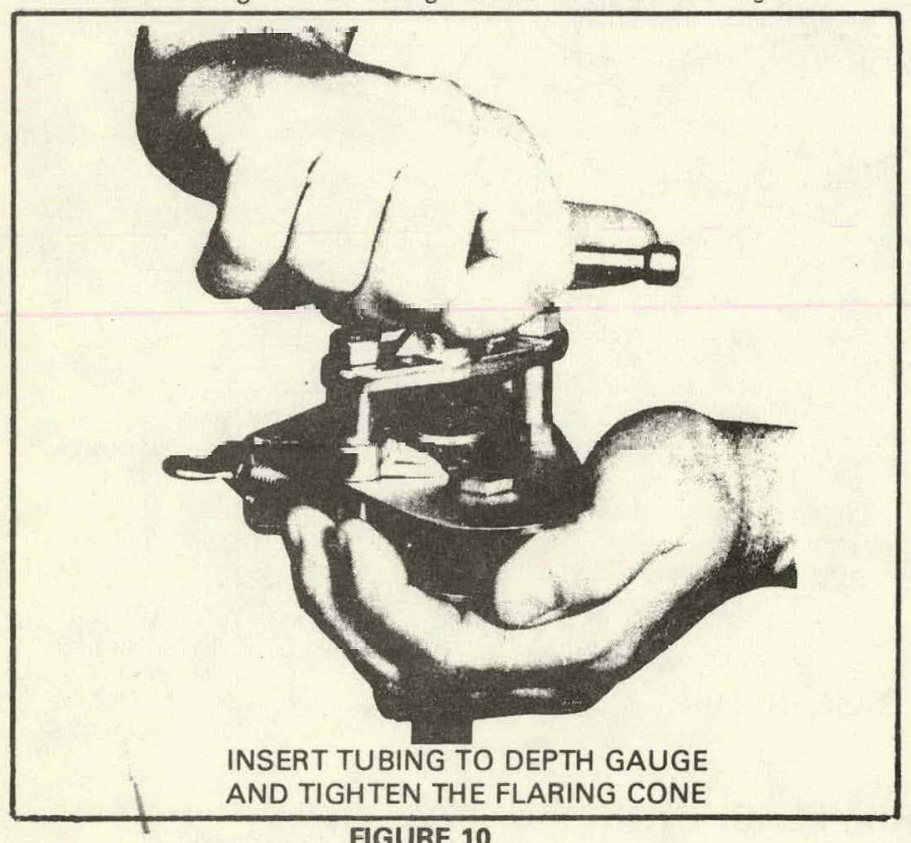

FIGURE 10
d-Align parts as shown in Figure 11 and tighten using two wrenches to prevent twising lines. Figure 12 shows cutaway of flared connections.

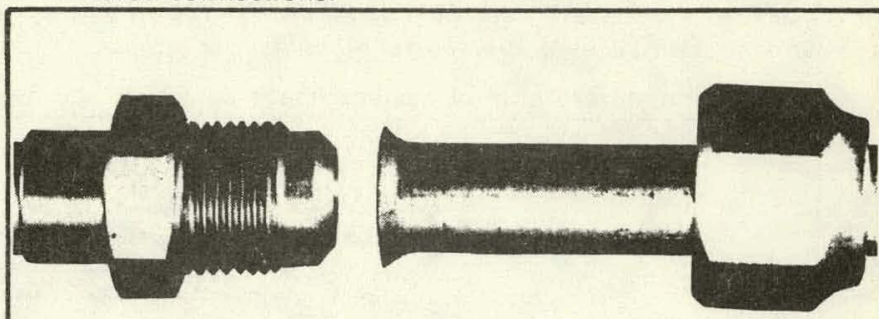

ALIGN PARTS AND THEN PUSH FLARE ONTO FITTING

FIGURE 11

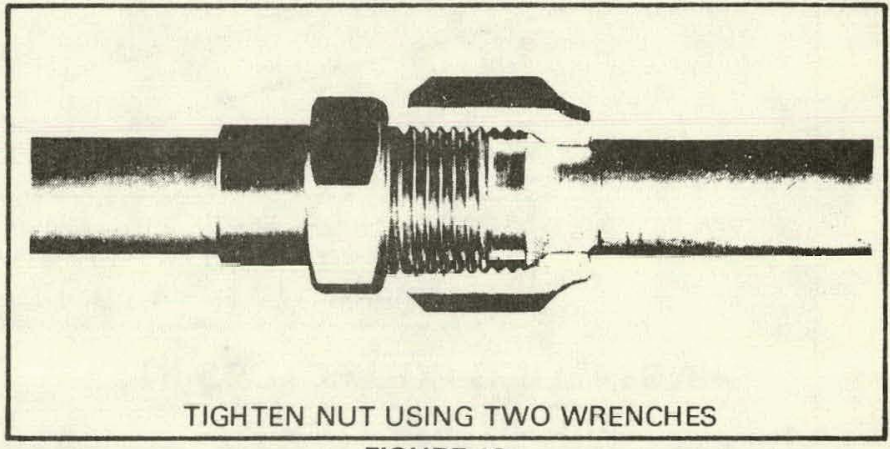

FIGURE 12

2 - Soldered Connections

a - Cut the pipe to size.

b - Remove burr.

c - Fit tubing into coupling maintaing a tight and proper clearance. See Figure 13.

d - Use minimum 95-5 rated solder

c - Make joint using proper amount of heat to draw solder in joint.

$f$ - Cool and clean the joint with wet cloth.

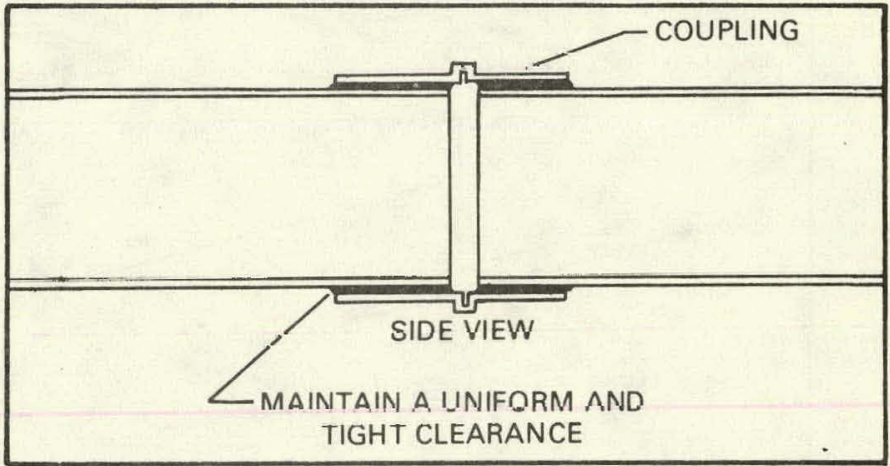

B - General Guidelines

\section{FIGURE 13}

1 - The solar collectors can be assembled in parallel, series or seriesparallel combinations. Figure 14 illustrates various sequencing arrangements. The supply header is always positioned at the bottom side of collectors while the return header is on the top.

NOTE - For residential applications, no more than two collectors should be connected in series.

TABLE 1

\begin{tabular}{|l|c|}
\hline \multicolumn{1}{|c|}{ APPLICATION } & SIZE \\
\hline Single family heating and heating/cooling & $1-1 / 4^{\prime \prime}(38 \mathrm{~mm})$ \\
\hline Multi-family heating and heating/cooling & $3^{\prime \prime}(76 \mathrm{~mm})$ \\
\hline Commercial heating and heating/cooling & $4^{\prime \prime}(102 \mathrm{~mm})$ \\
\hline
\end{tabular}


2 - Table 1 lists information for sizing headers.

3 - Avoid dissimilar metals. Where copper piping connects to dif- ferent piping materials, dielectric insulating couplers should be used to prevent corrosion.

\section{TYPICAL PIPING ARRANGEMENTS}
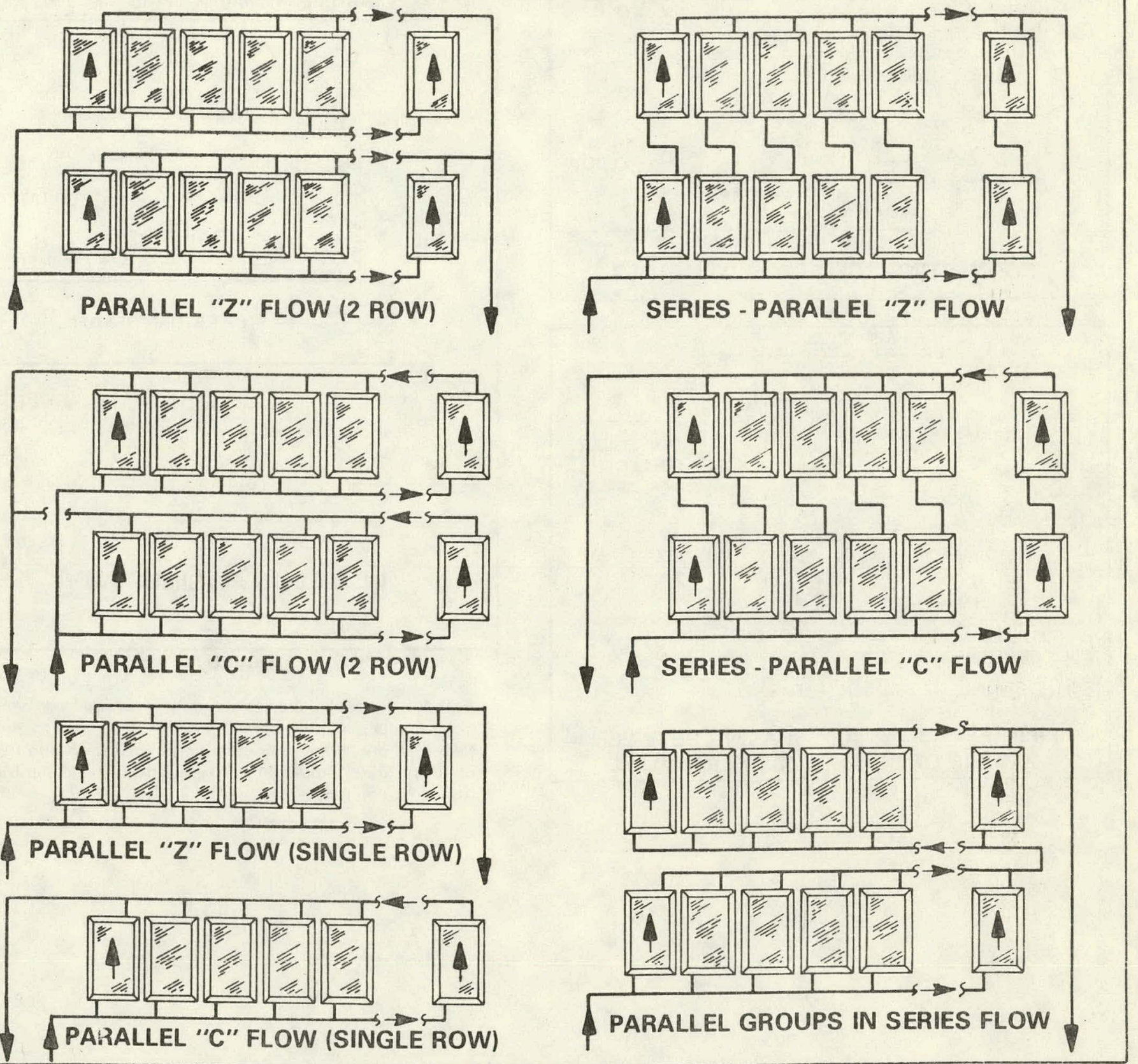

C - Installation of Piping

1 - Remove the plug from each end of solar collector.

2 - The collector either pipes to another collector or into a header. The 1/2 inch copper tubing must be field provided.

a - Figure 15 illustrates two solar collectors piped in series. Install a flare male elbow at the bottom collector and a flare male straight connection at the top collector.

b - A 3/8 inch sweat to $1 / 2$ flare fitting must be soldered into each header at 36 inch intervals. Install a flare male elbow at the collector and connect piping as shown in Figure 16. In a two row parallel application, the return and supply headers can be piped according to Figure 17 to minimize collector spacing.

3 - Route the supply and return headers into the interior of building and then flash completely to waterproof the opening.

\section{FIGURE 14}

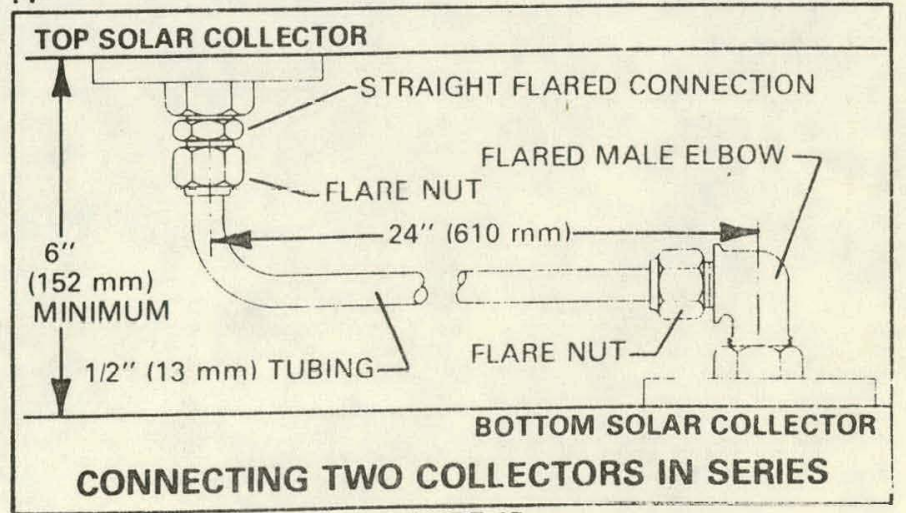




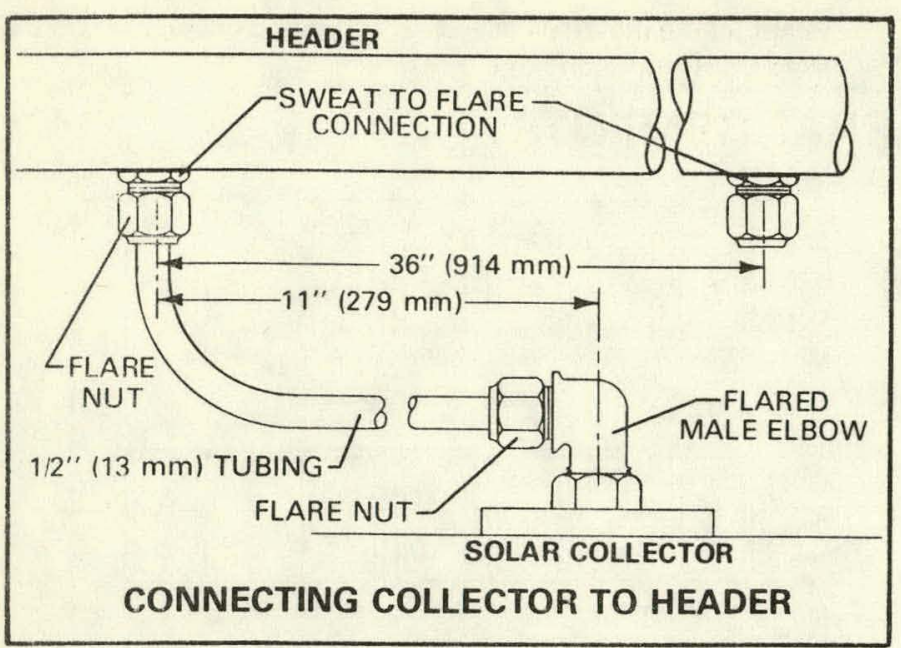

FIGURE 16

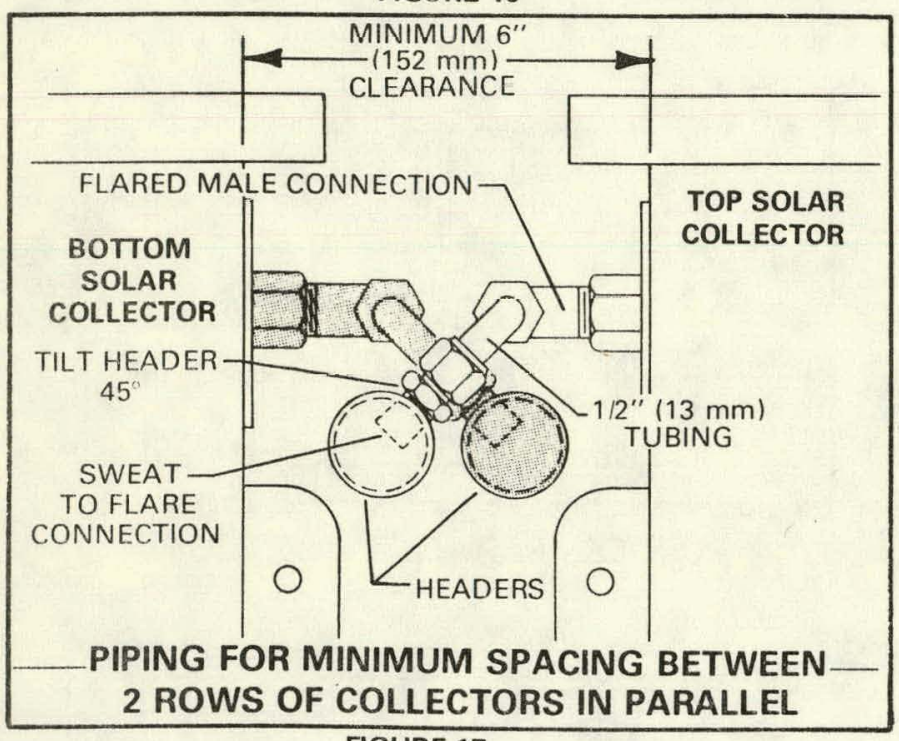

FIGURE 17
4 - An air bleed valve must be installed at each end of the return header for the top row of collector cells. Solder a sweat to flare fitting into the ends of return header. Connect a short length of 38 inch tubing to flared connection and then secure to a " $B$ " valve with a nut and ferrule. Refer to Figure 18.

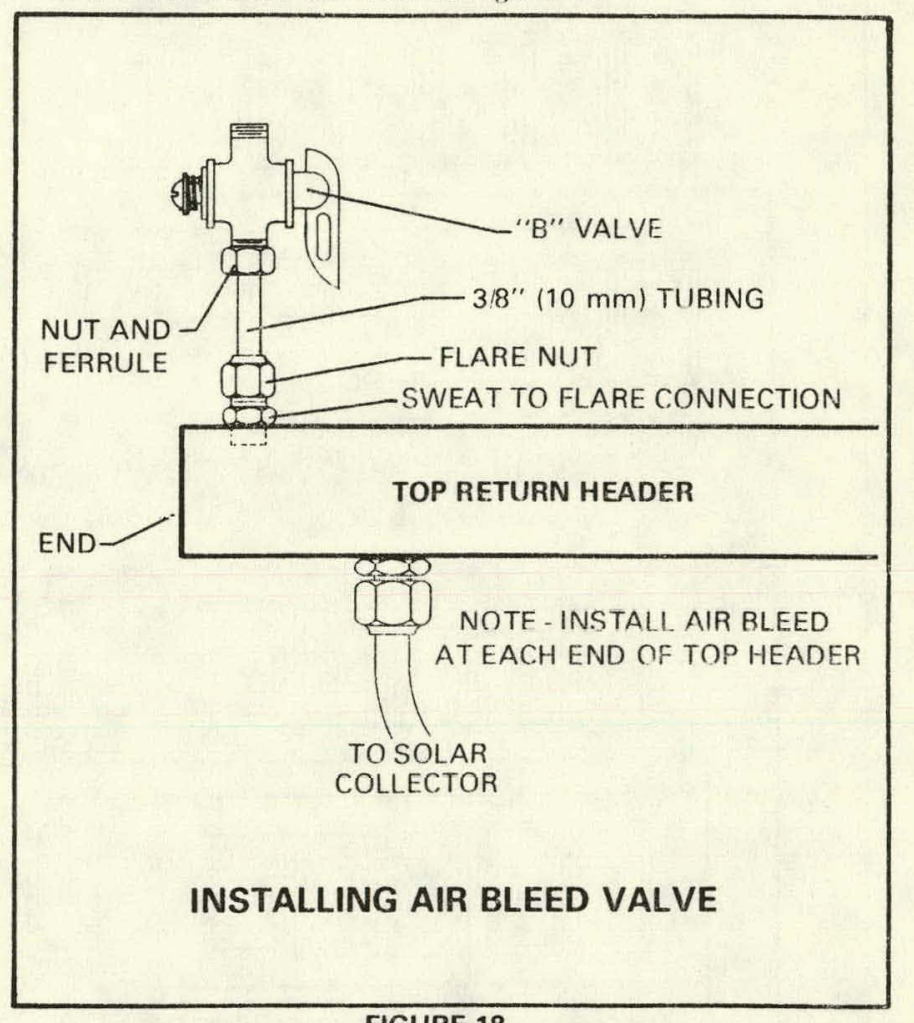

FIGURE 18

5 - Leak test the installation thoroughly and make any needed repairs. Insulate all outdoor piping with $3 / 4$ inch thick foamed plastic insulation. Waterpoof outdoor pipe insulation with two coats of plastic finish reinforced with glass mesh. Install per manufacturer's recommendations. 


\section{MAINTENANCE}

VII - MAINTENANCE

1 - If the glass cover becomes dirty, clean the glass using a soft clean cloth, mild soap or detergent and clean rinse water. Alkalies can stain the glass if allowed to remain in contact too long.

NOTE - The collector surface temperature can burn. Handle solar collector with caution.

2 - Use rubber gloves when handling solar collector to avoid finger prints on glass.

3 - To replace the glass, remove the collector as shown in Figure 19 and dismantle according to Figure 20. To re-assemble frame, insert the glass sheets and new gaskets into side pieces making sure the glass is centered and the ends are even. Next insert the glass into the end pieces and secure with existing screws. Use sealer compound on corner joints.

4 - To replace an absorber plate refer to following sequence and Figure 21.

a - Drain collector.

b - Remove collector frame.

c-Remove plate seal and gasket on each end of collector.

d - Disconnect flare fitting on each end of collector.

e-Remove 6 screws securing absorber and left plate from cabinet. Avoid touching coating on plate.

$\mathrm{f}$ - When re-assemblying absorber plate, tighten screws between $10 \mathrm{lbs}$ and $15 \mathrm{lbs}$ torque.

5 - The ethylene glycol/water mixture should be checked once a year by your Lennox service organization for proper freeze protection and inhibitor level.
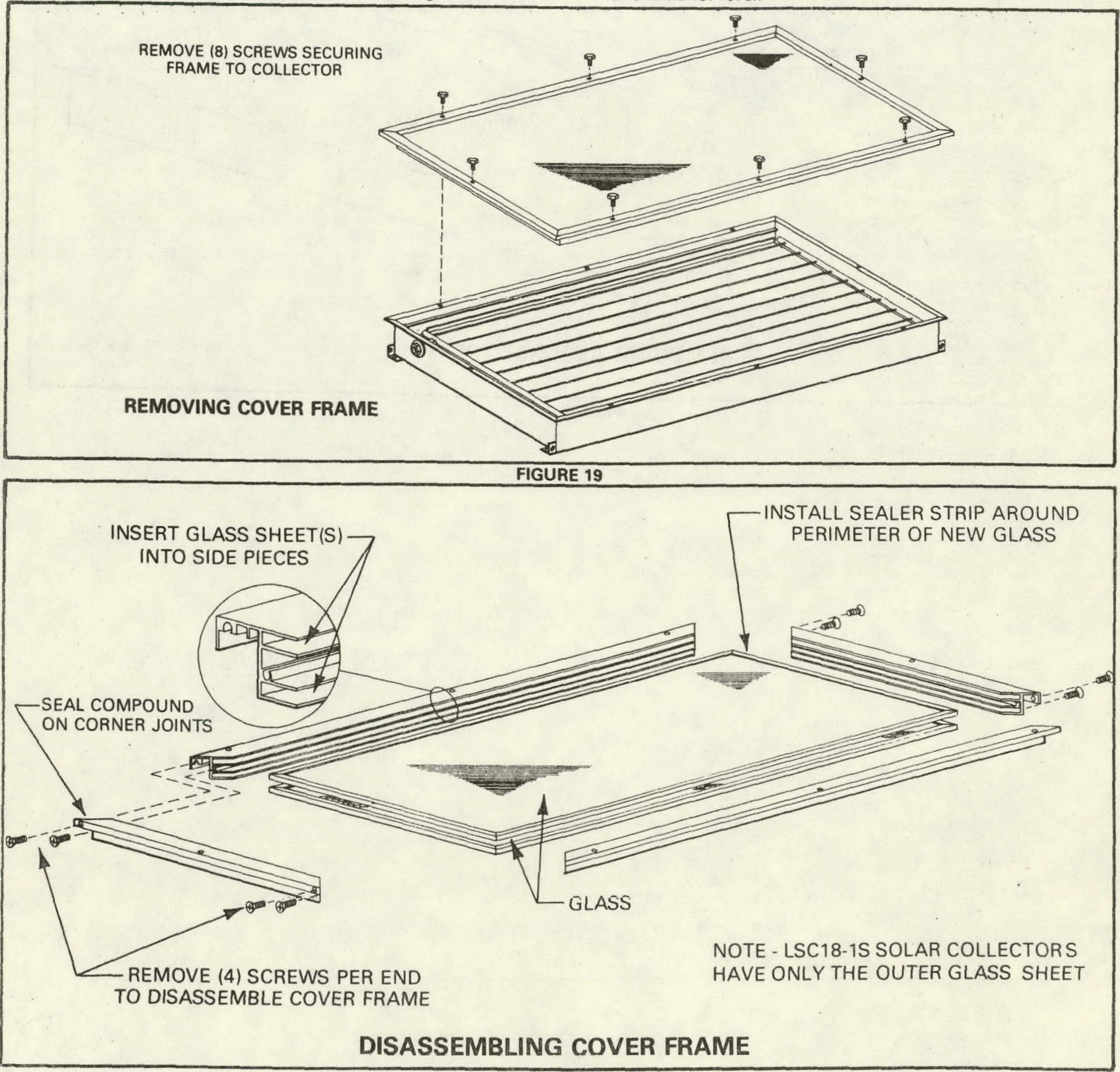

FIGURE 20 


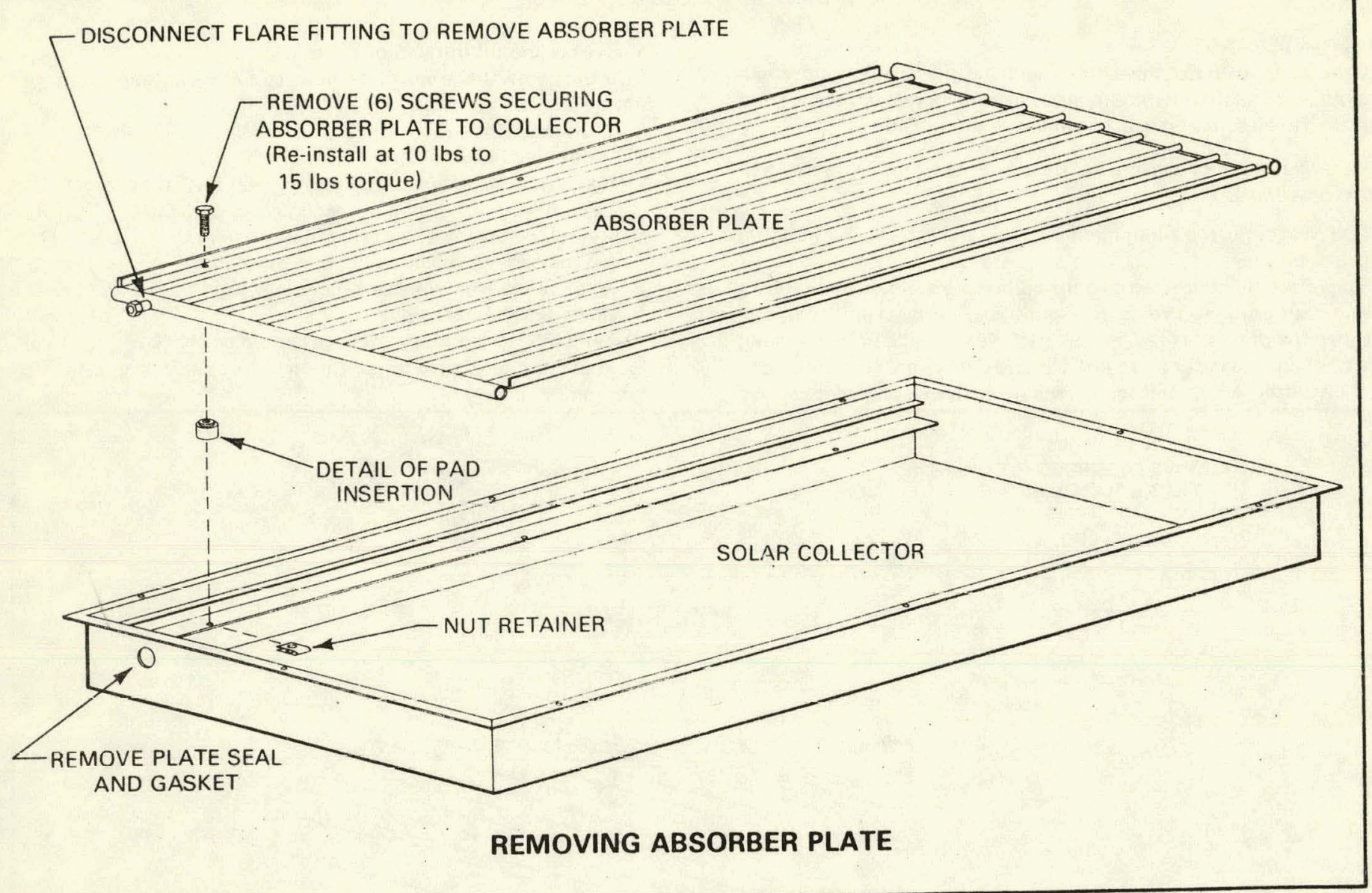

FIGURE 21 


\section{PURGE UNIT HRW-1-30}

The HRW-1-30 is an air to water heat exchanger. The finred tube coil and the blower are mounted in a cabinet designed for outdoor installation. The air is drawn in through the bottom and exhausted out the top of the unit. When connected to the collector outlet line, the purge unit will lower the fluid temperature. The unit is rated at 2000 CFM and should dissipate 100,000 Btu's per hour.

\section{Maintenance}

At the beginning of each heating or cooling season the system should be cleaned as follows:

A. HRW-1-30 Unit

1. Clean and inspect both sides of coil. Coil may be flushed with water hose if necessary.

2. Oil outdoor fan motor: always relubricate motor according to manufacturers lubrication instructions on each motor. If no instructions are provided, use the following as a guide.

a. Motors With Oiling Ports - Prelubricated for an extended period of operation. For extended bearing life, relubricate with a few drops of SAE No. 10 non-detergent oil once every two years.

b. Motors Without Oiling Ports - Prelubricated and sealed. No further lubrication required.

3. Visually inspect all connecting lines, joints and coils for evidence of fluid leaks.

4. Check all wiring for loose connections.

5. Check for correct voltage at unit (unit operating). 
THE Y534A DUAL DIVERTING VALVE ASSEMBLY CONSISTS OF TWO VALVE BODIES WHICH ARE SWEATED TOGETHER AND TWO POWERHEADS WHICH CONTROL EACH VALVE BODY SEPARATELY. WHEN ASSEMBLED, THE Y534A OFFERS FLOW CHARACTERISTICS WHICH ARE COMPATIBLE WITH SOLAR ENERGY SYSTEMS.

$\square$ Available for line or low voltage applications (specify when ordering).

$\square$ Assembly provides a flow capacity of $14 \mathrm{Cv}$ [12 kv].

$\square$ Sweat copper end connections may be installed without disassembling the valve.

$\square$ Manual opener for valve operation on power failure. Valve returns to automatic position when power is restored.

․ Complete powerhead may be removed without breaking the line connections.

$\square$ Motor actuator may be replaced without removing the valve body or draining the system.
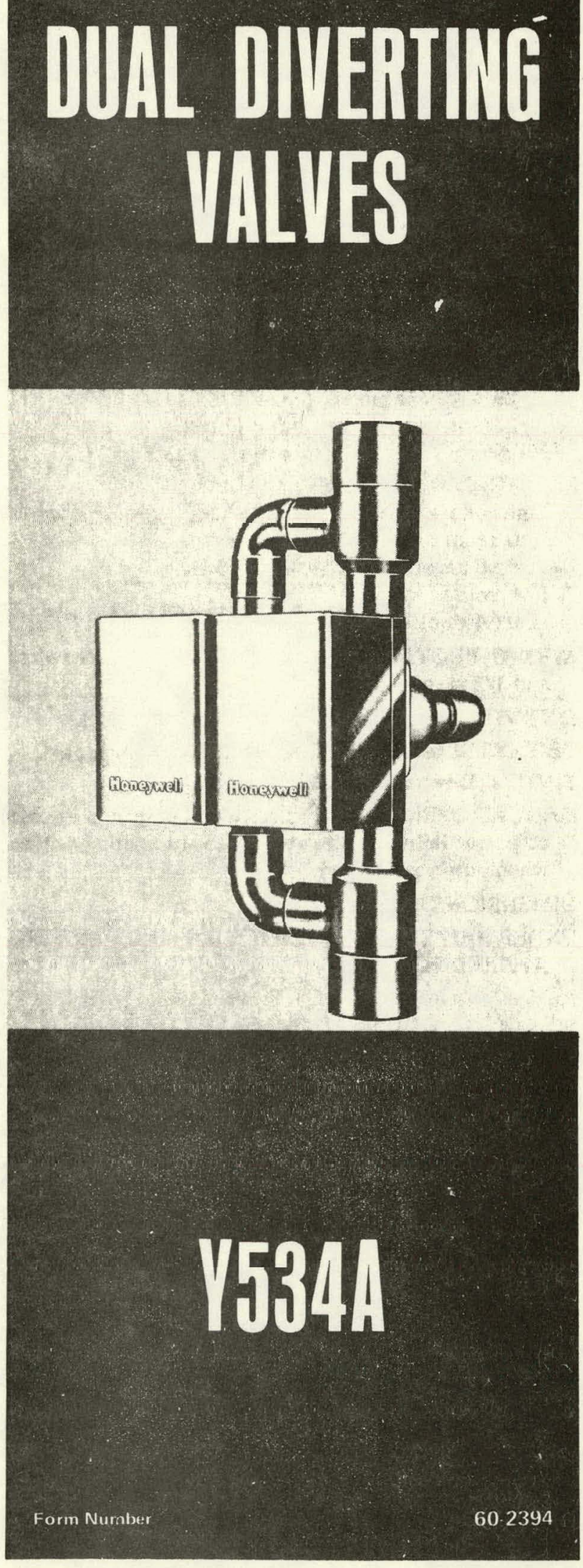
THE SPECIFICATIONS GIVEN IN THIS PUBLICATION DO NOT INCLUDE NORMAL MANUFACTURING TOLERANCES. THEREFORE, THIS UNIT MAY NOT MATCH THE LISTED SPECIFICATIONS EXACTLY. ALSO, THIS PRODUCT IS TESTED AND CALIBRATED UNDER CLOSELY CONTROLLED CONDITIONS, AND SOME MINOR DIFFERENCES IN PERFOR. MANCE CAN BE EXPECTED IF THOSE CONDITIONS ARE CHANGED.

MODEL:

Y534A-2-position dual diverting valve. The two powerheads must be assembled to the two valve bodies which are shipped sweated together. Available for line or low voltage applications.

TEMPERATURE AND FLOW RATINGS:

Capacity Rating-14 Cv [12 kv].

Maximum Closeoff Pressure-10 psi [ $69 \mathrm{kPa}$ ].

Static Pressure Rating-125 psi [ $862 \mathrm{kPa}$ ].

Maximum Fluid Temperature--

Line voltage model $-200 \mathrm{~F}$ [ $93 \mathrm{C}]$.

Low voltage model-240 F [115 C].

Maximum Ambient Temperature-125 F [52 C].

ELECTRICAL RATINGS:

Line voltage models-

0.16 amps at $120 \mathrm{~V} \mathrm{ac}, 60 \mathrm{~Hz}$.

0.08 amps at $220 / 240 \mathrm{~V}$ ac, $50 \mathrm{~Hz}$.

Low voltage model-

0.64 amps at $24 \mathrm{~V}$ ac, $50 / 60 \mathrm{~Hz}$.

WIRING PROVISIONS: 18 in. [457.2 $\mathrm{mm}$ ] leadwires and $1 / 2$ in. conduit openings.

LINE FITTINGS: $1-1 / 4$ in. sweat (1-3/8 in. O.D.).

DE-ENERGIZED POSITION: Port A normally closed.

TIMING: Diverts flow in 30 seconds.

MANUAL OPENER: Allows valve to be opened in case of power failure. Valve returns to automatic position when power is restored.

DIMENSIONS: See Fig. 1.

UNDERWRITERS LABORATORIES INC. LISTING APPLIED FOR.
REPLACEMENT PARTS:

O-ring-Part No. 802344.

Powerhead-

Line voltage model-Part No. 130441 ARG.

Low voltage model-Part No. 130441 ARA.

DETERMINATION OF WATER FLOW CHARACTERISTICS: The pressure drop in psi [ $\mathrm{kPa}$ ], equivalent feet [metres] of pipe, or feet of water [ $\mathrm{kPa}$ ] may be determined by calculating the flow rate, referring to Fig. 2, and using the following procedures.

Pressure drop in psi $[\mathrm{kPa}]-$

1. Locate the flow rate at the bottom of the graph in Fig. 2.

2. Draw a line upward from the flow rate until it intersects the curve on the graph.

3. Draw a line from the intersection to the lefthand edge of the graph and read the pressure drop in psi [ $\mathrm{kPa}]$.

Pressure drop in equivalent feet [metres] of pipe-

1. Locate the flow rate at the bottom of the graph in Fig. 2.

2. Draw a line vertically to the top of the graph. Read the pressure drop in equivalent feet [metres] of pipe on the $3 / 4$ in. pipe scale.

Pressure drop in feet of water $[\mathrm{kPa}]-$

1. Locate the flow rate at the bottom of the graph in Fig. 2.

2. Draw a line upward from the flow rate until it intersects the curve on the graph.

3. Draw a line from the intersection to the righthand edge of the graph and read the pressure drop in feet of water $[\mathrm{kPa}]$.

\section{ORDERING INFORMATION}

WHEN PURCHASING REPLACEMENT AND MODERNIZATION PRODUCTS FROM YOUR TRADELINE WHOLESALER OR YOUR DISTRIBUTOR, REFER TO THE TRADELINE CATALOG OR PRICE SHEETS FOR COMPLETE ORDERING NUMBER, OR SPECIFY-

1. Order number (specify line voltage or low voltage model).

2. Heplacement part, if required.

IF YOU HAVE ADDITIONAL QUESTIONS, NEED FURTHER INFORMATION, OR WOULD LIKE TO COMMENT ON OUR PRODUCTS OR SERVICES, PLEASE WRITE OR PHONE:

1. YOUR LOCAL HONEYWELL RESIDENTIAL DIVISION SALES OFFICE (CHECK WHITE PAGES OF PHONE DIRECTORY).

2. RESIDENTIAL DIVISION CUSTOMER SERVICE HONE YWELL INC., 1885 DOUGLAS DRIVE NORTH MINNEAPOLIS, MINNESOTA 55422 (612) $542-7500$

(IN CANADA-HONEYWELL CONTROL.S LIMITFN, 7AN ELLESMERE ROAD, SCARBOROUGH, ONTARIO MIP 2V9) INTERNATIONAL SALES AND SERVICE OFFICES IN ALL PRINCIPAL CITIES OF THE WORLD. 

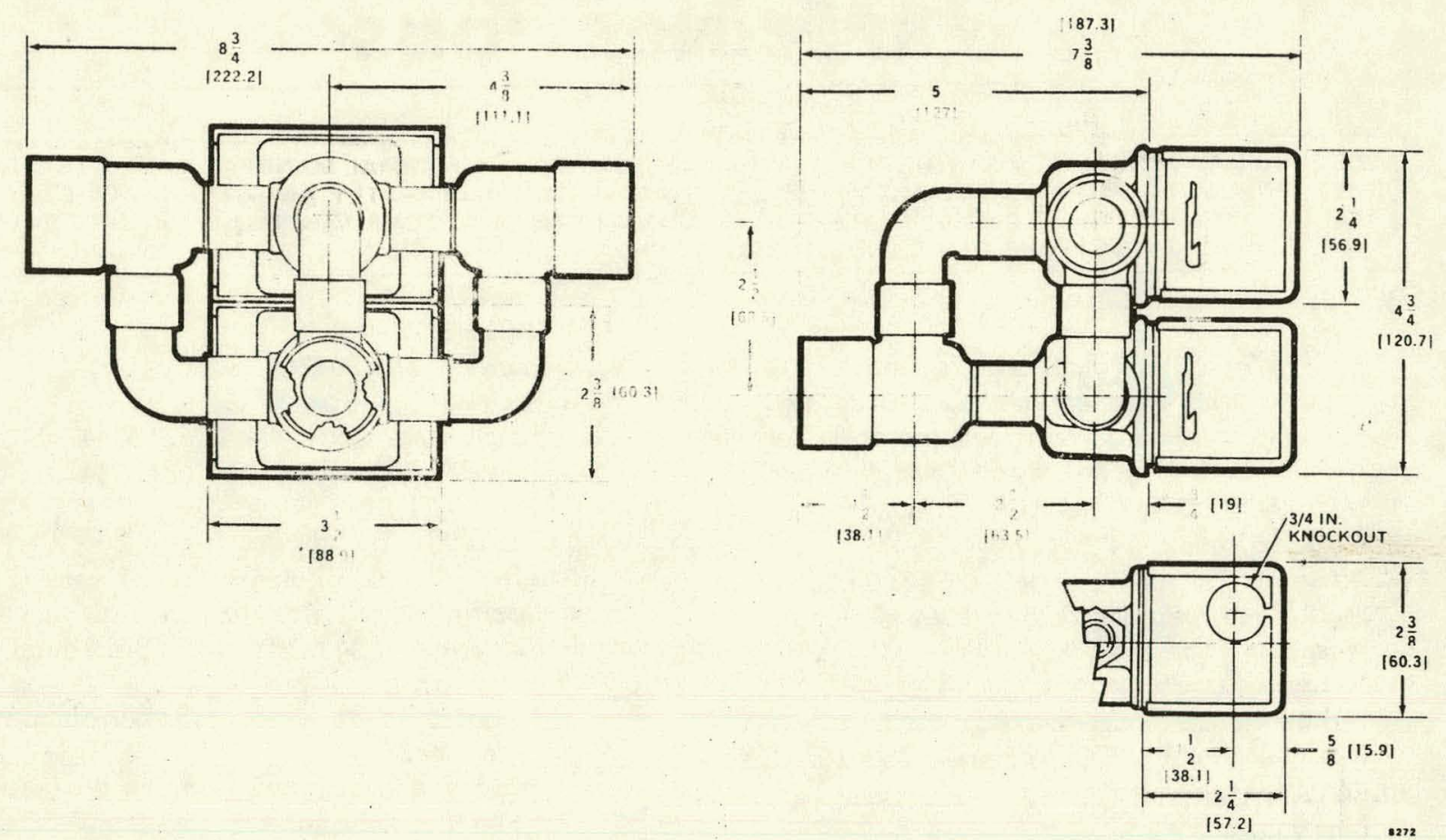

FIG. 1- 534A DIMENSIONS IN INCHES MIIZIMETRES IN BRACKETS].

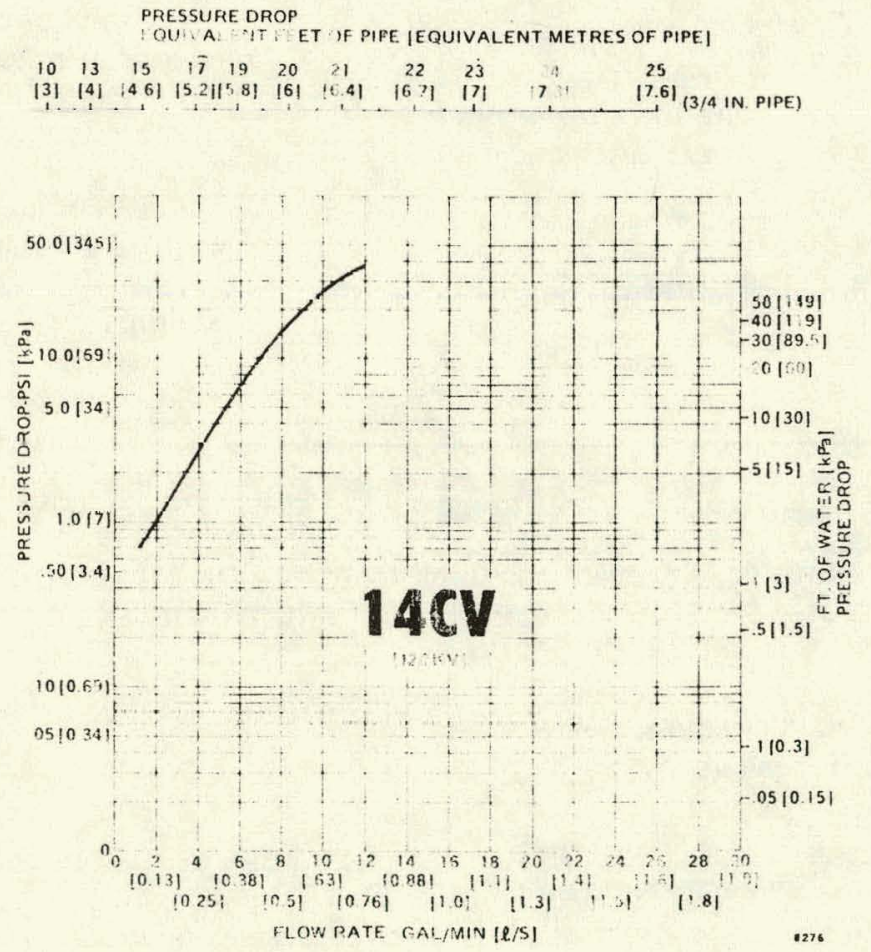

FIG. 2-FLOW CHARACTERISTICS OF Y534A DUA!. DIVERTING VALVES. 


\section{CAUTION}

1. Installer must be a trained, experienced service technician.

2. Disconnect power supply before connecting wiring to prevent electrical shock and equipment damage.

3. Always conduct a thorough checkout when installation is complete.

\section{ASSEMBLY}

Each powerhead controls each valve body separately. To assemble a powerhead to a valve body, place an O-ring in the circular slot on the top of the valve body (Fig. 3). Assemble the powerhead to the valve body by placing the manual opening lever on the powerhead in the MAN. OPEN position.

Align the powerhead by fitting the hex head screw on the bottom of the powerhead into the hole on the top of the valve body. The guide pins and the positioning pin in the powerhead should fit the holes in the valve body. Tighten securely and repeat this procedure for the other powerhead and valve body.

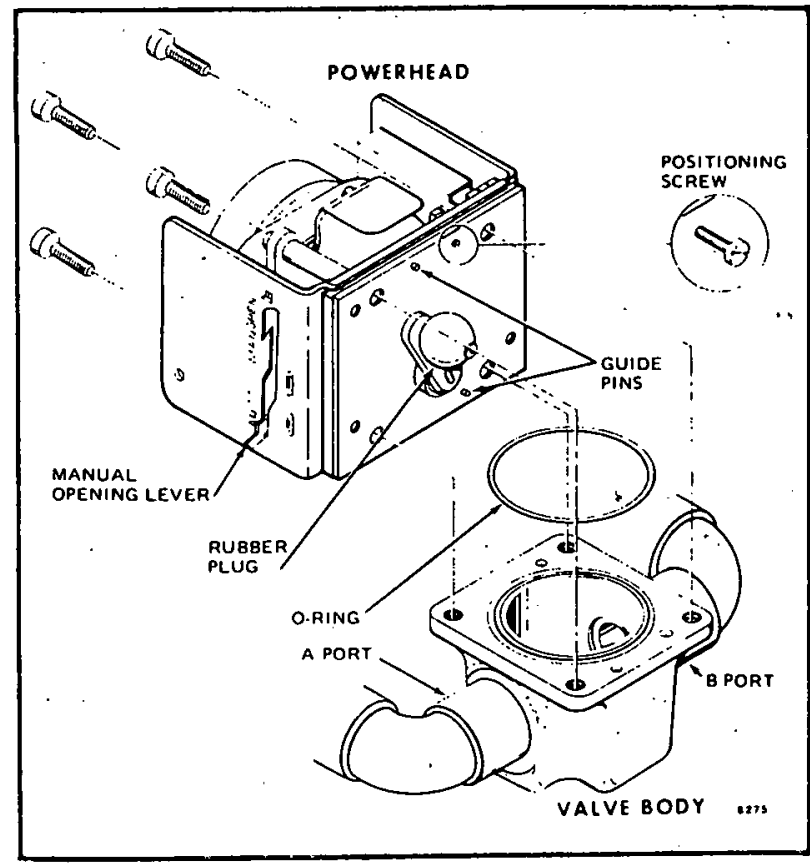

FIG. 3-POWERHEAD MUST BE ALIGNED SO THAT THE GUIDE PINS AND THE POSITIONING PIN IN THE POWERHEAD FIT THE HOLES IN THE VALVE BODY.

\section{MOUNTING}

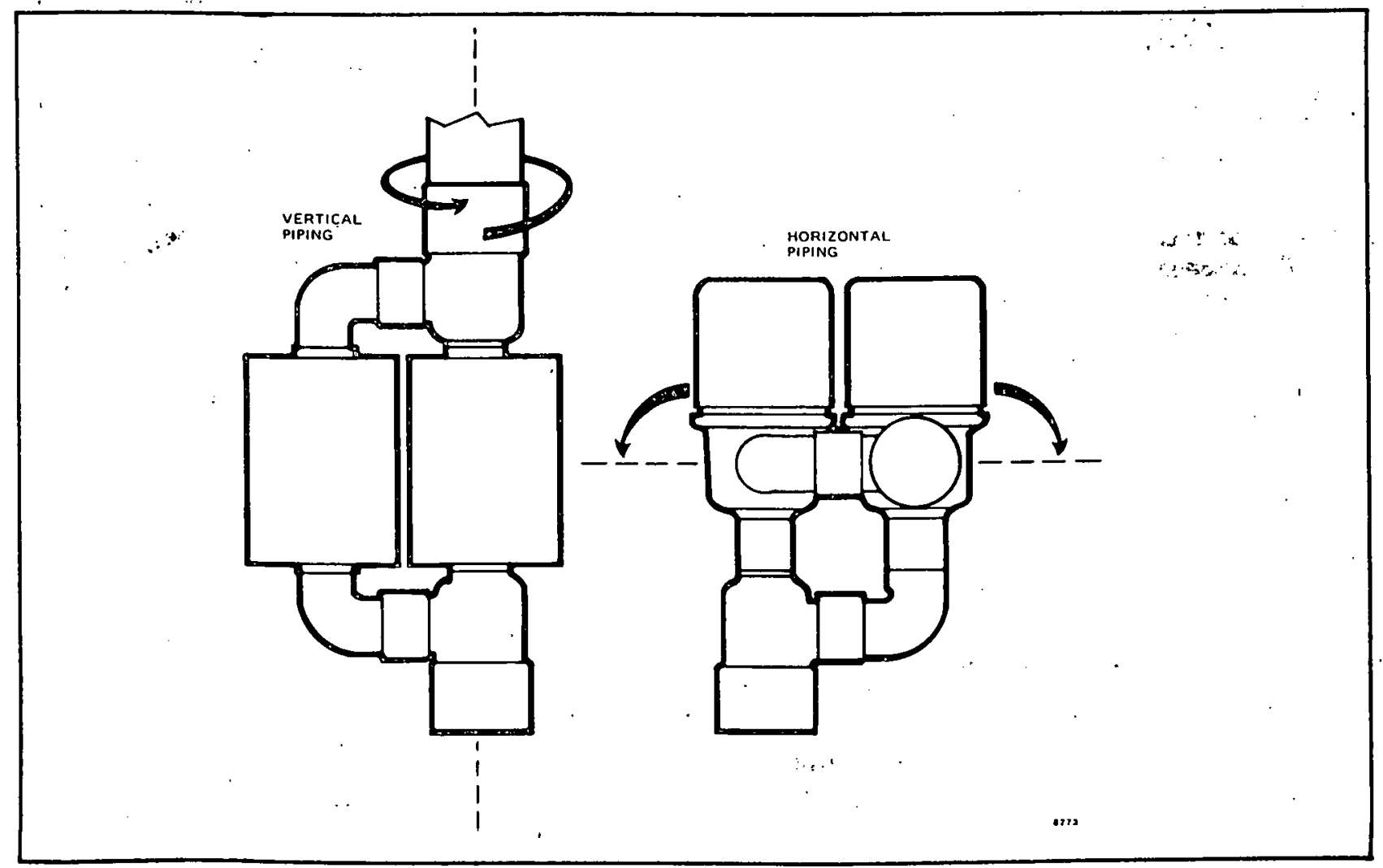

FIG. 4-MOUNTING POSITIONS. 
The valve may be mounted in any position on a vertical line. If valve is mounted horizontally, the powerhead must be even with or above the center line of the piping. Make sure that enough room is provided above the powerhead to remove the cover for servicing. See Fig. 4.

The 3 fittings or ports of the dual diverting valves are labeled on the bottom of the valve body castings. Port $A$ is connected to the purge coil piping and is closed when the valve is deenergized. Port $B$ is connected to the system bypass and is open when the valve is de-energized. Port $A B$ is the inlet and is open at all times. See Fig. 4.

\section{SWEAT COPPER MODELS}

1. Use new, properly reamed pipe, free from dents or corrosion.

2. Place valve onto the pipe. Set the manual opener lever to MAN. OPEN before applying heat. This will protect the plug inside the valve by removing it from the heat.

3. Sweat joints keeping the outer surface free from solder. DO NOT use silver solder because of the hiqh melting temperatures required.

\section{TO INSTALL REPLACEMENT POWERHEAD}

\section{IMPORTANT}

Installation of new powerhead does not require the removal of the valve body from the pipe line. It is, however, necessary to drain the water from the system before beginning the installation.

1. Disconnect the valve from the electrical power source and remove the conduit connections if fitted.

2. Place the manual opening lever on the old power. head in the MAN. OPEN position.

3. With the cover off, remove the 4 screws securing the powerhead to the valve body. Remove the old O-ring from the valve body.
4. Place the new O-ring in the circular slot on the top of the value body.

5. Install the new powerhead-

-Place the manual opening lever on the new powerhead in the MAN. OPEN position.

-Align the powerhead by fitting the hex head screw on bottom of powerhead into the hole on top of valve body (see Fig. 3).

6. Reconnect electrical connections.

Inspect the powerhead installation and the valve body to insure that all connections and adjustments have been correctly made. Adjust the thermostat or controller connected to the valve so the valve runs through its cycle. Make sure the valve runs smoothly and positively from closed to open to closed again.

\section{WIRING}

All wiring must agree with local codes and ordinances. See Fig. 5 for a typical wiring hookup.

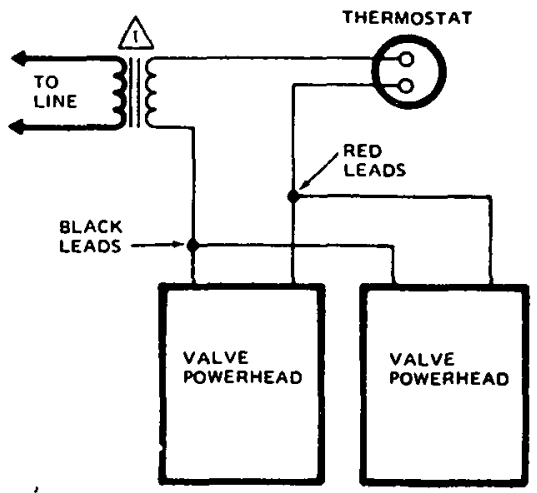

(14V TRANSFORMER USED ONLY WITH LOW VOLTAGE POWERHEAD.

121.

FIG. 5-TYPICAL WIRING FOR Y534 DUAL DI. VERTING VALVES.

\section{OPERATION AND CHECKOUT}

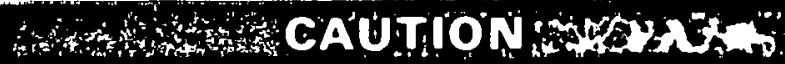

On 24 volt systems, never jumper the valve coil terminals, even temporarily. This may burn out the heat anticipator in the thermostat.

\section{OPERATION}

\section{AUTOMATIC OPERATION}

When the valve is energized, port $B$, the bypass, closes and port $A$ opens. Port $A$ closes by integral spring return when the valve is de-energized. 
MANUAL OPERATION

The motorized dual diverting valves (two with each assembly) can be opened manually by lifting the manual opener lever over the stop and pushing slowly and firmly to the MAN. OPEN position. The stop permits the valve to be locked in the open position. The valve will return to automatic position when the valve is energized.

\section{CHECKOUT}

1. Lower the set point of the high limit controller below the temperature of the collector fluid.

2. Observe that port $A$ of the valve should be open and port $B$ of the valve should be closed.

3. Raise the set point of the high limit controller above the collector fluid temperature.

4. Observe that port $A$ of the valve should close and port $B$ of the valve should be open.

\section{SERVICE}

This valve should be serviced by a trained, experienced service technician.

1. If the valve is leaking, check to see if the O-rings need to be replaced.

2. If the gear train is damaged or the motor is burned out, it is necessary to replace the entire powerhead assembly. See INSTALLATION.

NOTE: Honeywell zone valves are designed and tested for silent operation in properly designed and installed systems. However, water noises may occur as a result of excessive water velocity or piping noises may occur in high temperature (over $212 \mathrm{~F}$ [100 C]) systems with insufficient water pressure. 


\author{
APPENDIX $C$ \\ AUXILIARY ENERGY AND SPACE HEATING SUBSYSTEMS \\ HP10 Heat Pump Outdoor Unit \\ CBP10 Heat Pump Indoor Unit \\ ECB10 Electric Heating Coil \\ CW31-45 Solar Heating Coil \\ Outdoor Thermostat Kit
}




\section{INSTALLATION OF HPIO SERIES UNITS}

\section{PARTS ARRANGEMENT}

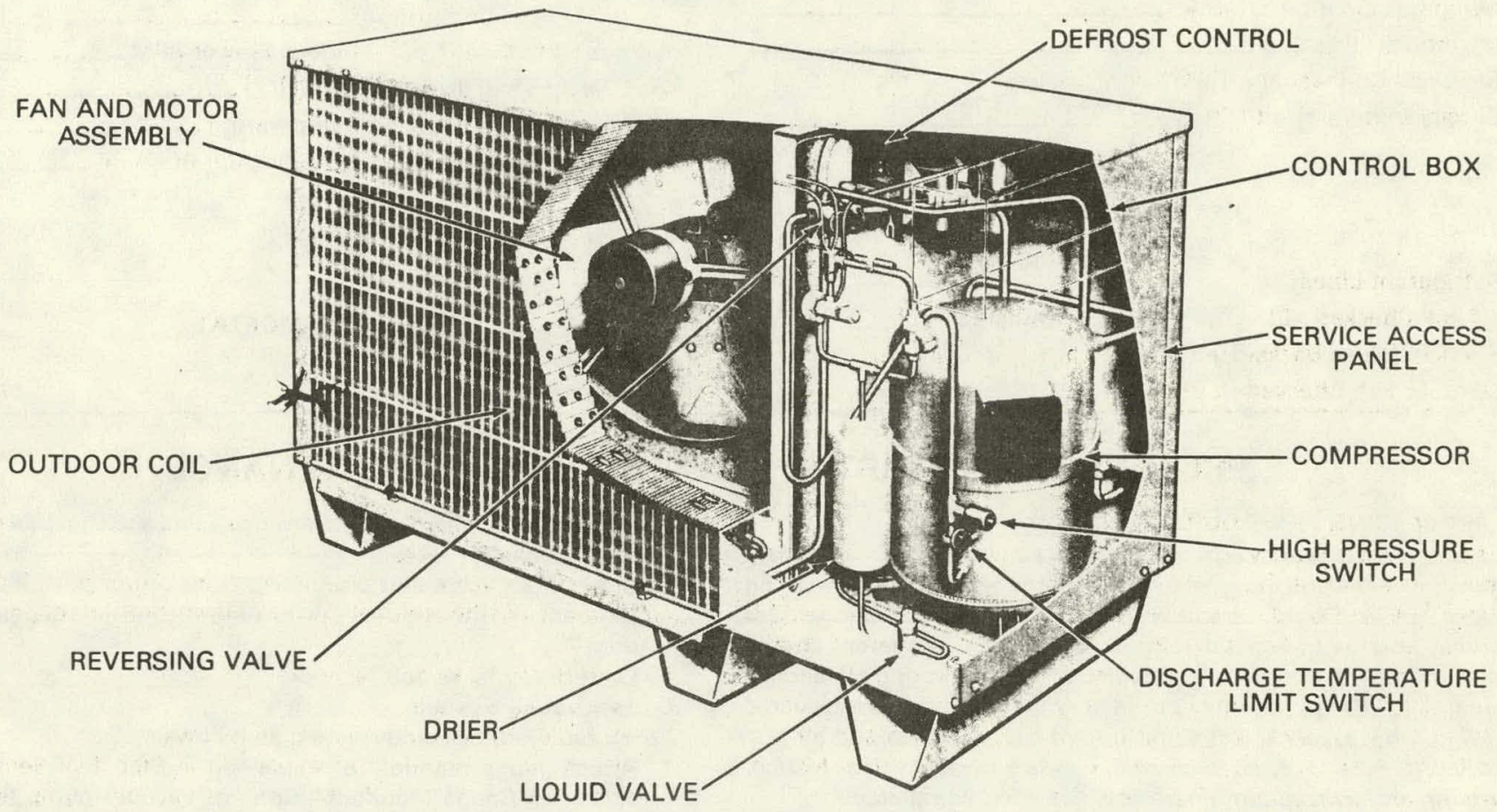

\section{UNIT DIMENSIONS}
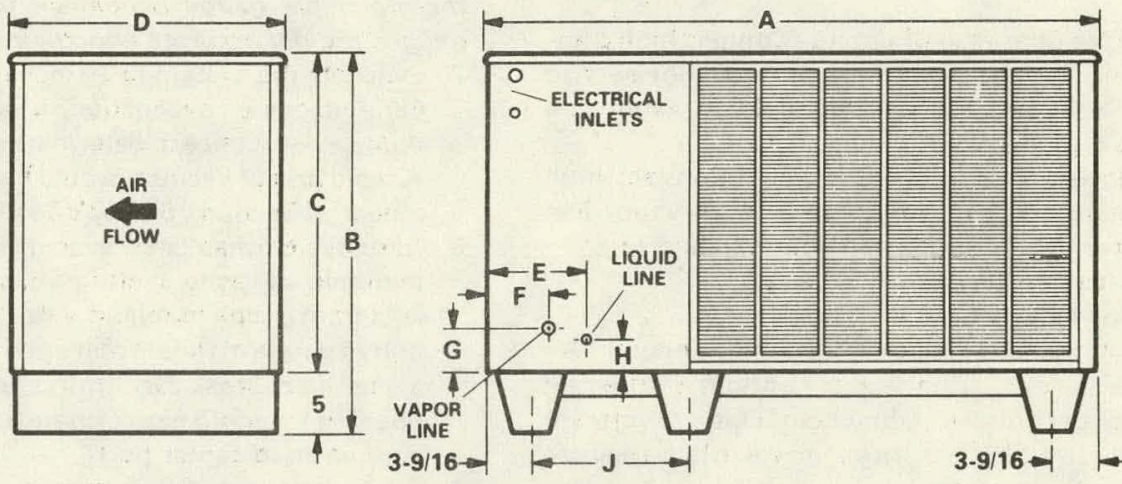

UNIT DIMENSIONS

\begin{tabular}{|c|c|c|c|c|c|c|c|c|c|c|c|c|c|c|c|c|c|c|}
\hline \multirow{2}{*}{$\begin{array}{l}\text { UNIT MODEL } \\
\text { NUMBER }\end{array}$} & \multicolumn{2}{|c|}{ A } & \multicolumn{2}{|c|}{ B } & \multicolumn{2}{|c|}{ C } & \multicolumn{2}{|l|}{ D } & \multicolumn{2}{|c|}{$\mathbf{E}$} & \multicolumn{2}{|c|}{$\mathbf{F}$} & \multicolumn{2}{|c|}{ G } & \multicolumn{2}{|c|}{ H } & \multicolumn{2}{|l|}{ 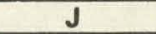 } \\
\hline & in & $\mathrm{mm}$ & in & $\mathrm{mm}$ & in & $\mathrm{mm}$ & in & $\mathrm{mm}$ & in & $\mathrm{mm}$ & in & $\mathrm{mm}$ & in & $\mathrm{mm}$ & in & $\mathrm{mm}$ & in & $\mathrm{mm}$ \\
\hline HP10-311V & $48-1 / 8$ & 1222 & $30-1 / 2$ & 775 & $25-1 / 2$ & 648 & $21-3 / 8$ & 543 & 7 & 178 & 4 & 102 & $3-1 / 4$ & 83 & $2-1 / 2$ & 64 & $12-1 / 2$ & 318 \\
\hline HP10-410V & $48-1 / 8$ & 1222 & $30-1 / 2$ & 775 & $25-1 / 2$ & 648 & $21-3 / 8$ & 543 & 8 & 203 & 5 & 127 & $3-1 / 4$ & 83 & $2-1 / 2$ & 64 & $12-1 / 2$ & 318 \\
\hline HP10-510V & 59 & 1499 & $35-1 / 2$ & 902 & $30-1 / 2$ & 775 & $27-1 / 16$ & 687 & 17 & 432 & 15 & 381 & 2 & 51 & $1-3 / 8$ & 35 & 15 & 381 \\
\hline
\end{tabular}




Job Name
Job Location
Installer
Unit Model No.
Nameplate Voltage
Minimum Circuit Ampacity
Maximum Fuse Size
Electrical Connections Tight?
Supply Voltage (Unit Off)

Job No.

City

City

Serial No.
Date

State

State

Serviceman

Voltage with Compressor Operating

Amps:

Supply Outdoor Fan Compressor

Indoor Filter Clean? $\square \quad$ Indoor Blower RPM

S.P. Drop Over Indoor Coil (Dry)

Outdoor Coil Entering Air Temperature

Discharge Pressure

Suction Pressure

HEAT PUMP SECTION

Refrigerant Lines:

Leak Checked

Properly Insulated

THERMOSTAT

Service Valves Backseated

Outdoor Fan Checked $\square$

$\square$

Calibrated

Level

\section{PROCESSING - START-UP - OPERATION - MAINTENANCE}

\section{PROCESSING PROCEDURE}

The HP10 unit is factory charged with the amount of R-22 refrigerant indicated on the unit rating plate. This charge is based on a matching indoor coil and outdoor coil with a 25 foot $(7,62 \mathrm{~m})$ line set. For varying lengths of line set refer to Table 1 for refrigerant charge adjustment. A blank space is provided on the unit rating plate to list actual field charge. All units are factory leak tested and evacuated making it necessary to keep unit free of dirt, moisture and air.

WARNING - Do not open (back-seat) valves on unit until leak testing, purging, and evacuating of line sets has been completed.

A - Attaching Gauge Manifold

1 - Leak Testing, Purging or Evacuating - Connect high pressure side of gauge manifold to gauge port on liquid line service valve. Connect suction side of gauge manifold to gauge port on vapor line service valve.

2 - Cooling Cycle, Checking Charge or Charging - Connect high pressure side of gauge manifold to gauge port on liquid line service valve. Connect suction side of gauge manifold to vapor line gauge port. Refer to Figure 1.

3 - Heating Cycle, Checking Charge or Charging - Connect high pressure side of gauge manifold to gauge port on vapor line service valve. Connect suction side of gauge manifold to compressor suction service port. Refer to Figure 2.

B - Leak Testing Installed Line Set

1 - Attach gauge manifold as explained in Step 1 of Section "A Attaching Gauge Manifold." Connect an upright refrigerant (R-22) drum to center port of gauge manifold. Open refrigerant drum valve and manifold high pressure gauge valve to pressurize line set and indoor coil of system.

TABLE 1

\begin{tabular}{|c|c|c|}
\hline \multicolumn{2}{|c|}{ Line Set Dia. } & $\begin{array}{c}\text { Ounce per foot adjustment * } \\
\text { from } 25 \text { foot line set }\end{array}$ \\
\hline Suction & Liquid & 1 ounce \\
\hline $7 / 8$ & $3 / 8$ & 1 ounce \\
\hline $3 / 4$ & $3 / 8$ & $1-3 / 4$ ounce \\
\hline $1-1 / 8$ & $1 / 2$ & . \\
\hline
\end{tabular}

*NOTE - If line set length is greater than 25 feet, add this amount. If line set length is less than 25 feet subtract this amount.
2 - Close manifold high pressure gauge valve and check all lines and connections for leaks.

3 - Close drum valve and disconnect from center port. Release refrigerant into the atmosphere through suction side of gauge manifold.

4 - Correct any leaks and recheck.

C - Evacuating System

When required, evacuate system as follows:

1 - Attach gauge manifold as explained in Step 1 of Section "A Attaching Gauge Manifold." Connect vacuum pump (with vacuum gauge) to center port of gauge manifold. With both manifold service valves open, start pump and evacuate indoor coil and refrigerant lines.

NOTE - A temperature vacuum gauge, mercury vacuum (U tube), or thermocouple gauge should be used. The usual Bourdon tube gauges are rot accurate enough in the vacuum range.

2 - Evacuate the system to 29 inches $(737 \mathrm{~mm}$ ) vacuum. During the early stages of evacuation, it is desirable to stop the vacuum pump at least once to determine if there is a rapid loss of vacuum. A rapid loss of vacuum would indicate a leak in the system and a repeat of Section "B - Leak Testing" would be necessary.

3 - After system has been evacuated to 29 inches $(737 \mathrm{~mm})$, close manifold valves to center port, stop vacuum pump, and disconnect from gauge manifold. Attach an upright R-22 drum to center port of gauge manifold and open drum valve slightly to purqe line at manifold. Break vacuum in system with refrigerant pressure by opening manifold high pressure valve. Close manifold high pressure valve to center port.

4 - Close drum valve and disconnect from gauge manifold center port. Purge refrigerant from system through suction side of gauge manifold.

5 - Reconnect vacuum pump to gauge manifold center port. Evacuate system through manifold service valves until vacuum in system does not rise above 29.7 inches $(754 \mathrm{~mm}$ ) mercury (5 $\mathrm{mm}$ absolute pressure) within a 20 minute period after stopping vacuum pump.

6 - After evacuation is completed, close manifold service valves, disconnect vacuum pump from gauge manifold center port, and connect refrigerant drum. Pressurize system slightly with refrigerant to break vacuum. 


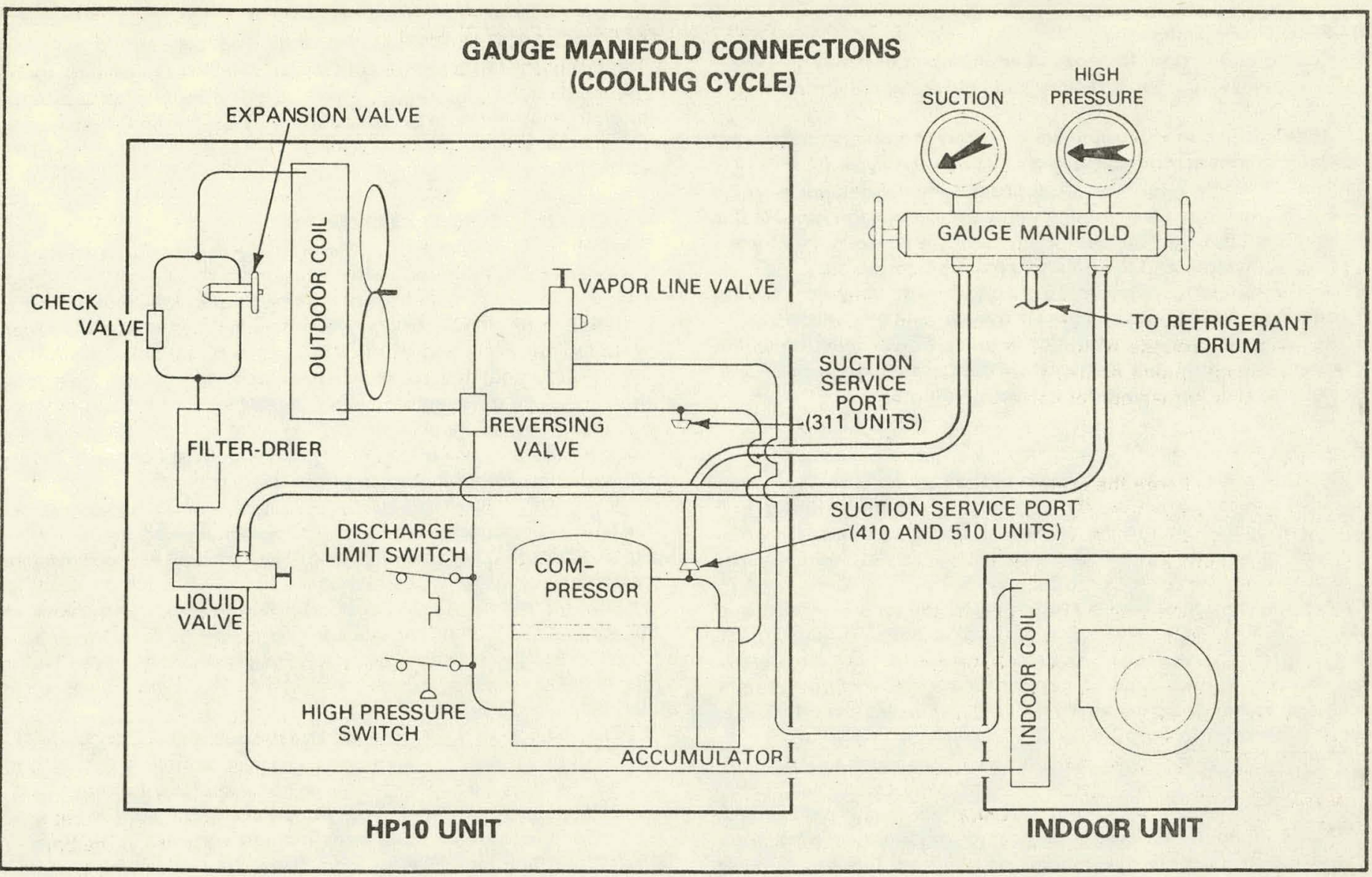

FIGURE 1

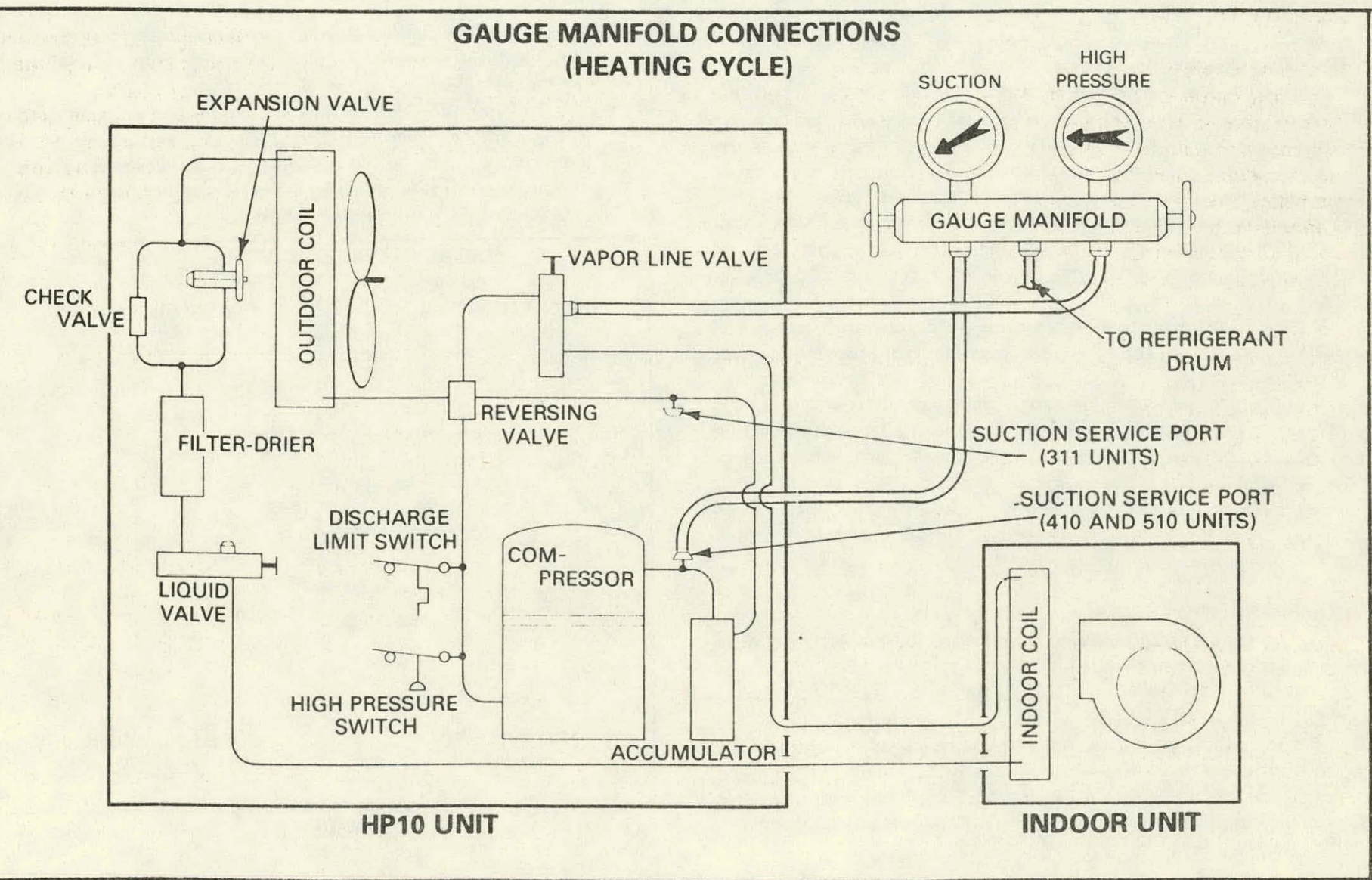

FIGURE 2

C -3 
D - Start-Up Procedure

1 - Rotate fan to check for frozen bearings or any binding.

2 - Inspect all wiring (both factory and field installed) for loose connections.

3 - Open liquid and vapor line service valves to release refrigerant charge (confined in heat pump unit) into the system.

4 - Check voltage supply at disconnect switch; voltage must be within the range listed on unit nameplate. If voltage is not in this range, do not start the equipment until the power company has been consulted and the voltage condition corrected.

5 - Set thermostat for a demand. Turn on power to indoor coil blower and close heat pump disconnect switch to start unit.

6 - Recheck unit voltage with unit running. Power must be within range shown on unit nameplate. Check amperage draw of unit. Refer to unit nameplate for correct running amps.

\section{E - Charging}

It is desirable to charge the system in the cooling cycle if weather conditions permit. However, if the unit mut be charged in the heating cycle, the charge should be re-checked in the cooling cycle when outdoor conditions permit. This assures a complete and efficient charge.

If system is completely void of refrigerant, the recommended and most accurate method of charging is to weigh the refrigerant into the unit according to the total amount shown on the unit nameplate. Refer to the "Lennox Cooling Service Handbook" for procedure. If weighing facilities are not available or if unit is just low on charge, use the following procedure:

1 - Connect gauge manifold as explained in Step 2 or Step 3, depending upon season, of Section "A - Attaching Gauge Manifold." Connect an upright R-22 drum to center port of gauge manifold.

2 - Start unit, open drum valve, and charge a quantity of refrigerant gas into the system through the suction port. Close refrigerant drum valve and allow unit to run for a few minutes to stabilize operating pressures.

\section{F - Checking Charge}

Refrigerant charge is checked by the use of a "Normal Operating Pressure Curve" that is mounted on each HP10 unit and also appears on pages 5 and 6 in this instruction. Liquid pressure is read at the liquid line service valve during the cooling cycle and vapor pressure at the vapor line service valve during the heating cycle.

1 - Three factors are needed to use the pressure curve: (1) outdoor coil entering air temperature, (2) suction pressure, and (3) liquid pressure during cooling cycle or vapor pressure during heating cycle.

2 - Read curve from correct suction pressure, over to outdoor coil entering air temperature and then down to liquid pressure (vapor pressure).

3 - A liquid pressure (vapor pressure) gauge reading within 3 psig $(21 \mathrm{kPa})$ of the table value indicates a properly charged unit. When pressure is not within 3 psig $(21 \mathrm{kPa})$ unit is not properly charged. Refer to Section "E - Charging."

4 - When system is operating properly, make sure all service valves are open (back-seated) and disconnect gauge manifold. Replace all gauge port caps and tighten. Set thermostat at desired sefting.

\section{II - COMPRESSOR OIL CHARGE}

Refer to "Lennox Cooling Service Handbook" for correct procedure to check and add compressor oil.

\section{III - HIGH PRESSURE SWITCH}

All units are equipped with a high pressure switch (manual reset type) mounted on the compressor discharge line. This switch has a "cut-out" point of $410 \mathrm{psig}(2827 \mathrm{kPa})$ and must be manually reset when discharge pressure drops below 180 psig (1241 kPa).

\section{IV - DISCHARGE TEMPERATURE LIMIT SWITCH}

The discharge temperature limit switch is a factory installed option mounted on the compressor discharge line. It shuts off the system if discharge temperature exceeds $260^{\circ} \mathrm{F}\left(127^{\circ} \mathrm{C}\right)$. The limit switch must be manually reset when discharge temperature drops to $225^{\circ} \mathrm{F}$ $\left(107^{\circ} \mathrm{C}\right)$ or below.

\section{V - DEMAND DEFROST SYSTEM}

The HP10 unit utilizes an air pressure differential defrost system. A pressure sensor mounted on the division panel between the outdoor coil and the orifice panel senses the buildup of static air pressure, caused by coil icing, across the outdoor coil. Refer to Figure 3 . When static buildup exceeds .5 in. w.c. ( $12.7 \mathrm{~mm}$ w.c.) set point, the defrost cycle is activated; this stops condenser fans and activates the reversing valve. The temperature sensor bulb, located near the outdoor coil distributor, terminates the defrost cycle when liquid refrigerant temperature increases to $65^{\circ} \mathrm{F}\left(18^{\circ} \mathrm{C}\right)$. The defrost control is factory set and should not be adjusted from these points.

IMPORTANT - It is important that the placement and cleanliness of the defrost pressure sensor be maintained for proper unit operation. Inspect both sides of the outdoor coil periodically and remove any y'dss, leaves, or other obstructions.

The defrost system may be checked for proper operation by blocking the air flow through the outdoor coil on the outlet side. The defrost cycle should be activated when approximately $85 \%$ of the coil is hlocked. The following procedure should be used when checking the defrost control system.

A - Field Checking Air Pressure Defrost Control (Heating Cycle)

1 - Cut a piece of cardboard to cover approximately $85 \%$ of outdoor coil surface and remove front condenser guard.

2 - Mark position of defrost termination sensing bulb on refrigerant line; remove bulb from line and immerse in ice bath.

3 - Start unit by adjusting room thermostat to call for heat.

4 - Block coil inlet with cardboard from Step 1. Unit should start defrost cycle.

5 - After unit starts defrost cycle, remove sensing bulb from ice bath and warm bulb by holding in hand or immersing in warm water bath. Unit defrost cycle should terminate.

6 - After termination of defrost cycle, re-mount sensing bulb on refrigerant line in original location and secure clamp. Use caution to avoid damaging sensing bulb when installing.

7 - If defrost control fails to operate properly, remove entire mntrol and replace with a new control.

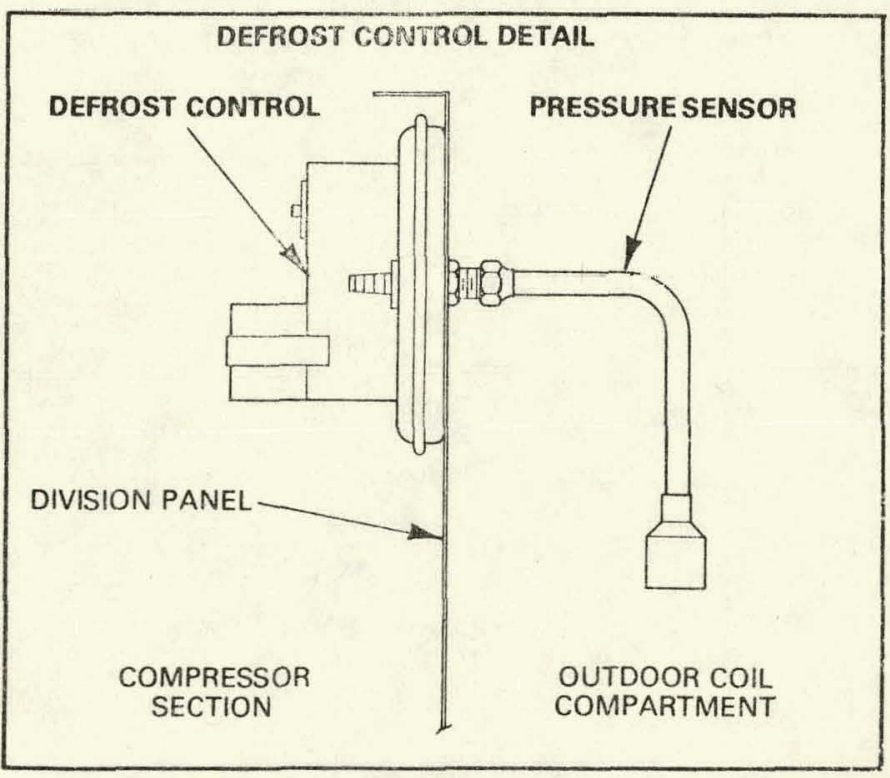

FIGURE 3 


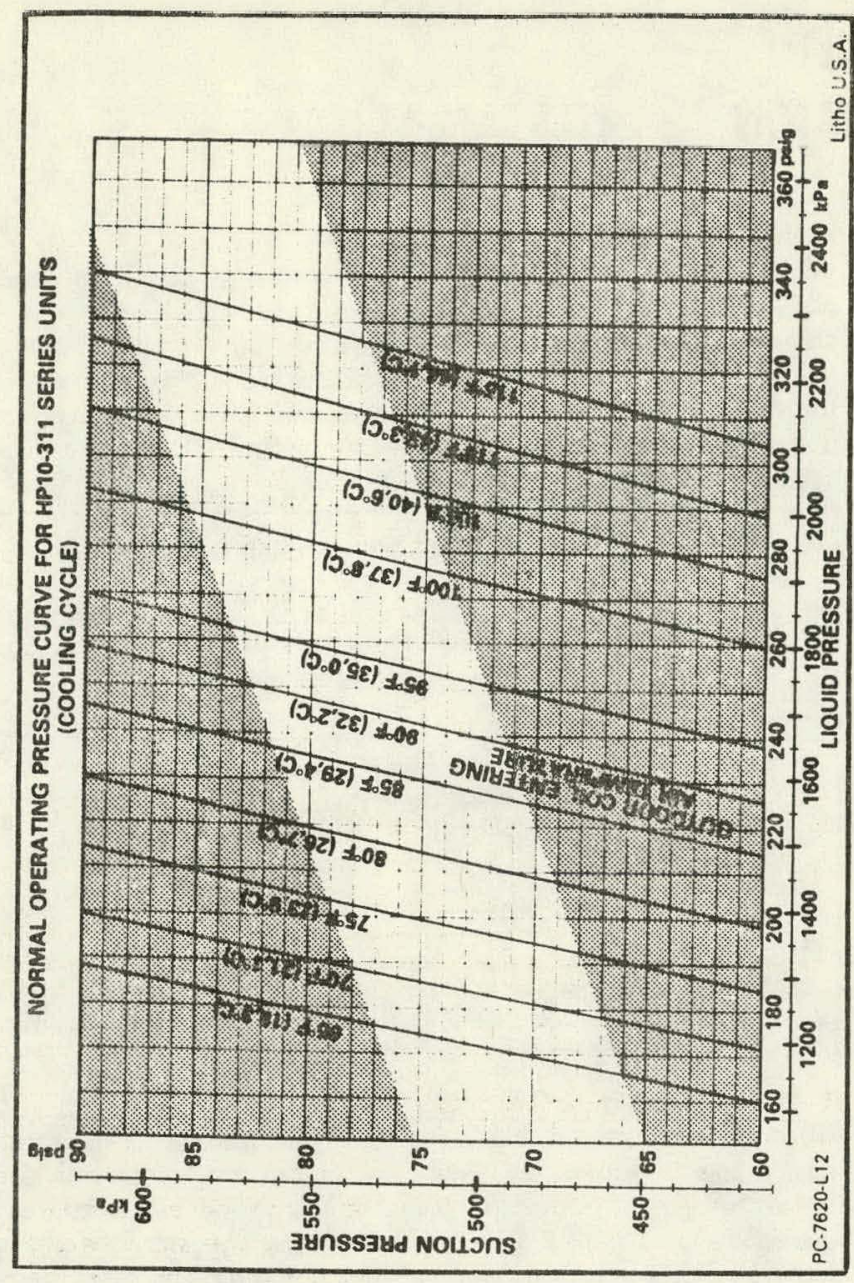

\section{VI - CRANKCASE HEATERS}

All units are provided with crankcase heaters (oil rectifiers). This heater must always be energized to prevent compressor damage as a result of slugging. A warning sticker (provided with instructions) should be applied to the main disconnect switch at the time of installation.

\section{VII - FILTER-DRIER}

CAUTION - The refrigerant filter drier in this system has two way flow (refrigerant flows in either direction depending upon unit operating mode). If replacement is required, the filter drier should only be replaced with one of like design and capacity. Order from Lennox Part Center.

\section{VIII - MAINTENANCE}

At the beginning of each heating or cooling season the system should be cleaned as follows:

\section{A - HP10 Heat Pump Unit}

1 - Clean and inspect both sides of outdoor coil. Coil may be flushed with water hose if necessary.

2 - Clean and inspect defrost pressure sensors.

3 - Oil outdoor fan motor: always relubricate motor according to manufacturers lubrication instructions on each motor. If no instructions are provided, use the following as a guide.

a-Motors With Oiling Ports - Prelubricated for an extended period of operation. For extended bearing life, relubricate with a few drops of SAE No. 10 non-detergent oil once every two years.

b-Motors Without Oiling Ports - Prelubricated and sealed. No further lubrication required.

4 - Visually inspect all connecting lines, joints and coils for evidence of oil leaks.

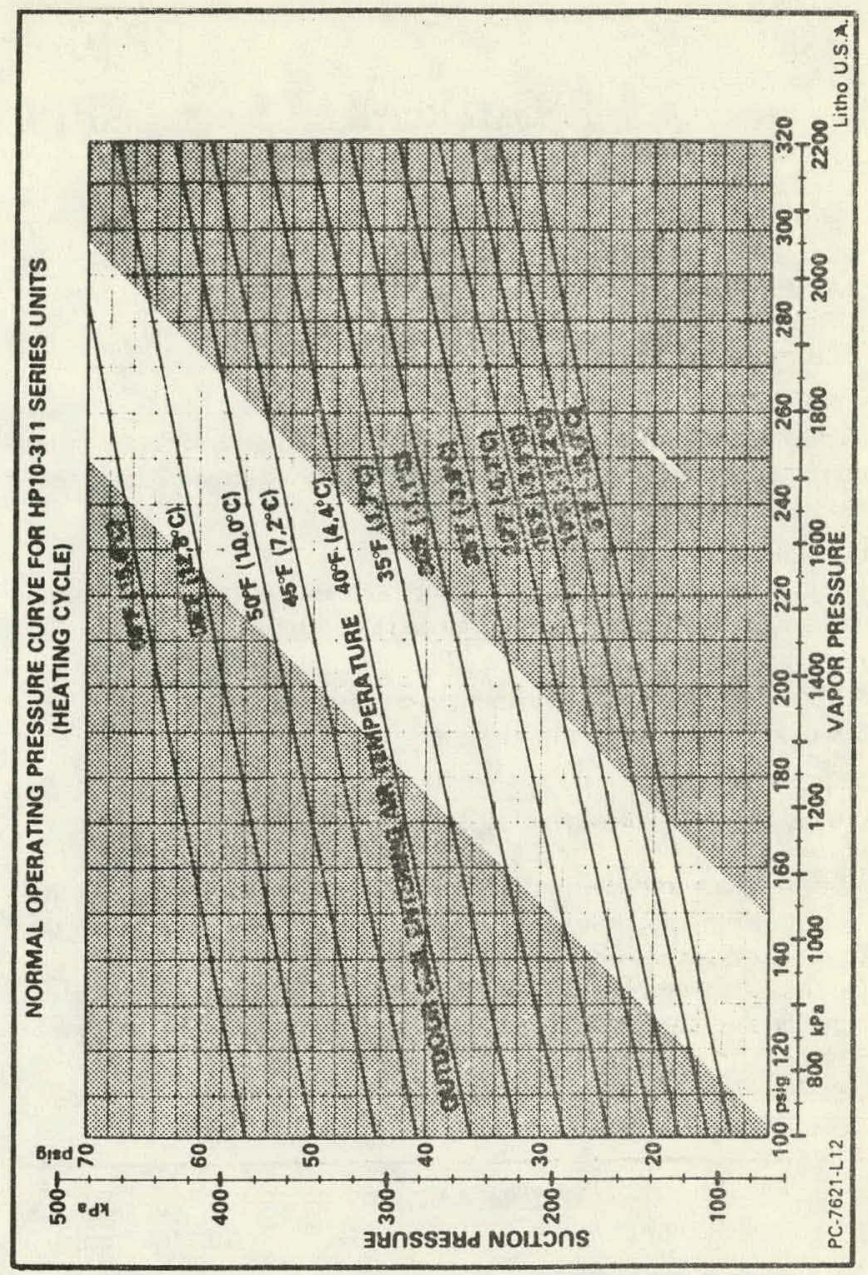

5 - Check all wiring for loose connections.

6 - Check for correct voltage at unit (unit operating).

7 - Check amp - draw on heat pump fan motor.

Unit nameplate Actual

NOTE - If insufficient heating or cooling occurs, the unit should be gauged and refrigerant charge checked.

B - Indoor Coil

1 - Clean coil if necessary.

2 - Check connecting lines, joints and coil for evidence of oil leaks.

3 - Check condensate line and clean if necessary.

C - Indoor Unit

1 - Clean or change filters.

2 Lubricate blower motor:

Always relubricate motor according to manufacturers lubrication instructions on motor. If no instructions are provided, use the following as a guide.

a - Motors Without Oiling Ports - Prelubricated and sealed. No further lubrication required.

b - Direct Drive Motors With Oiling Ports - Prelubricated for an extended period of operation. For extended bearing life, relubricate with a few drops of SAE No. 10 non-detergent oil once every two years. It may be necessary to remove blower assembly for access to oiling ports.

3 - Adjust blower speed for cooling. The pressure drop over the coil should be checked to determine the correct blower CFM. Refer to the "Lennox Cooling Service Handbook" for pressure drop tables and procedures.

4 - Check all wiring for loose connections.

5 - Check for correst voltage at unit.

6 - Check amp draw on blower motor. Motor nameplate. Actual 


\section{HP 10 - 311V \\ REQUIREMENTS - APPLICATION - INSTALLATION}

\section{I - SHIPPING AND PACKING LIST}

Package 1 of 1 contains:

1 - Assembled unit

1 - Thermostat

1 - Compressor Warning Sticker

\section{II - GENERAL}

These instructions are intended as a general guide and do not supersede local codes in any way. Authorities having jurisdiction should be consulted before installation.

\section{III - SHIPPING DAMAGE}

Check unit for shipping damage. The receiving party should contact last carrier immediately if any damage is found.

\section{IV - APPLICATION}

HP10-311V, 410V and 510V units are mated to CBP10 indoor coils with matching Lennox L10 line sets.

\section{$V$ - CLEARANCES}

Refer to Figure 1 and provide service and air flow clearances as tollows:

1 - Coil inlet - A minimum of 18 inches $(457 \mathrm{~mm}$ ) should be provided between the coil inlet and any building surfaces, fences or other vertical obstructions.

2 - Coil outlet - Provide at least 4 feet $(1.22 \mathrm{~mm})$ between the coil outlet and any building surfaces, fences or other vertical obstructions.

3 - Service access - Allow a minimum of 3 feet $(0.91 \mathrm{~m})$ clearance on the service access end of unit.

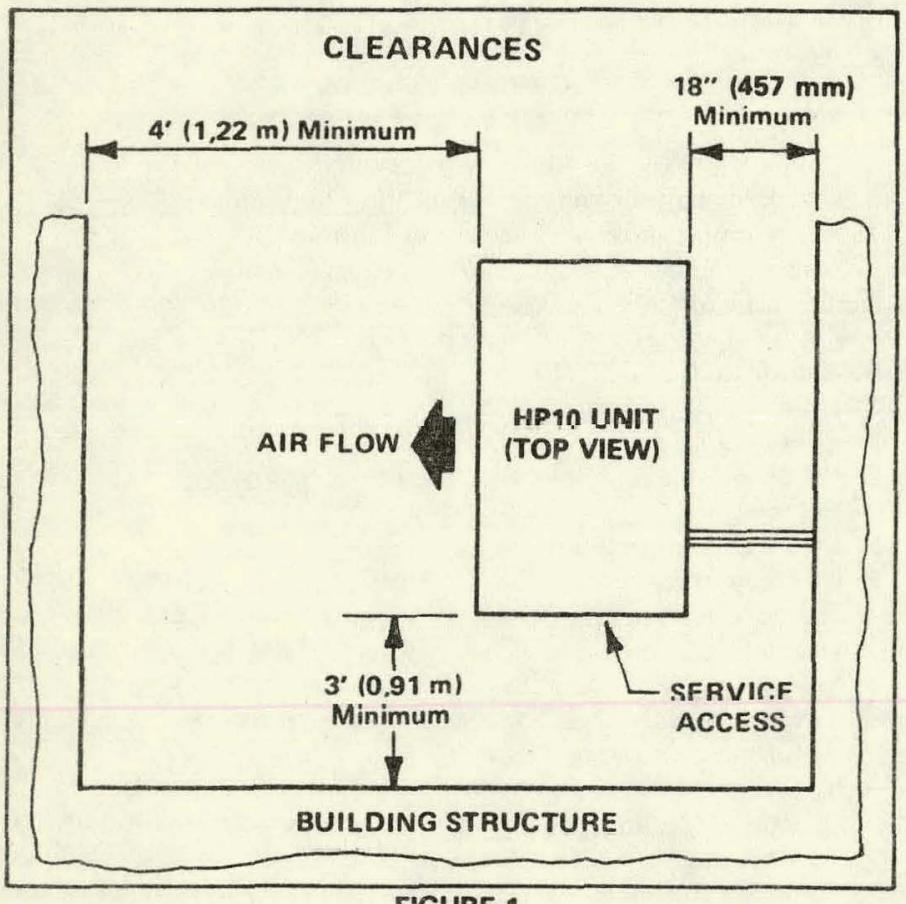

FIGURE 1

\section{VI - SETTING THE UNIT}

A sound absorbing material, such as isomode, should always be used under unit if installed in a position or location that will transmit sound or vibration to the living area or adjacent buildings.

\section{A - Slab Mounting}

When installing unit at grade level, mount on a slab high enough above the grade to allow adequate drainage of water. Top of the slab should be located so run-off water from higher ground will not collect around unit. Slab should have a slope tolerance away from the building of 2 degrees or 2 inches per 5 feet $(51 \mathrm{~mm}$ per 1,5 meters). This will prevent ice build-up under the unit during a defrost cycle. Refer to Figure 2.

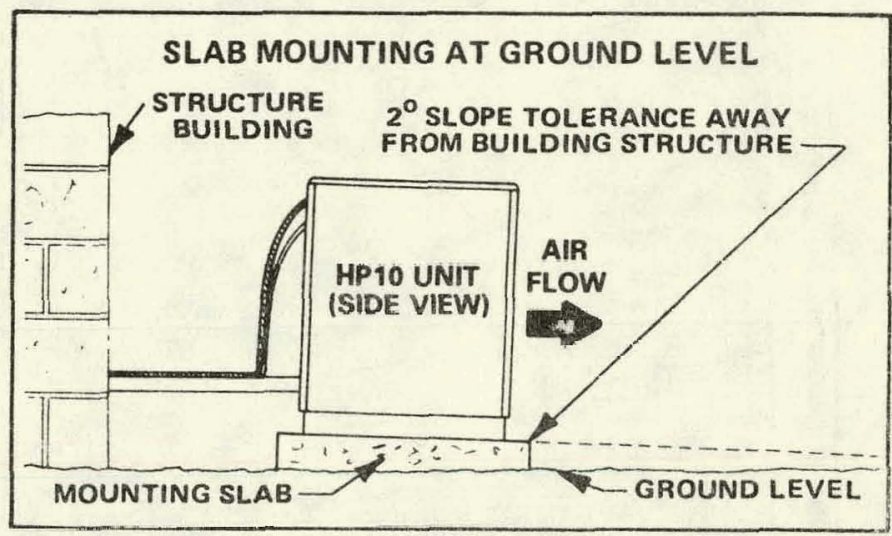

FIGURE 2

\section{B - Roof Mounting}

When unit is installed in areas where low ambient temperatures exist. it should he plared sn winter prevailing winds are not in direct line with the heat pump coil. If this is not possible, a wind barrier should be constructed. Size barrier at least the same height and width as unit and mount barrier 24 inches $(610 \mathrm{~mm})$ from the coil inlet side of unit in the direction of prevailing winds. Refer to Figure 3 .

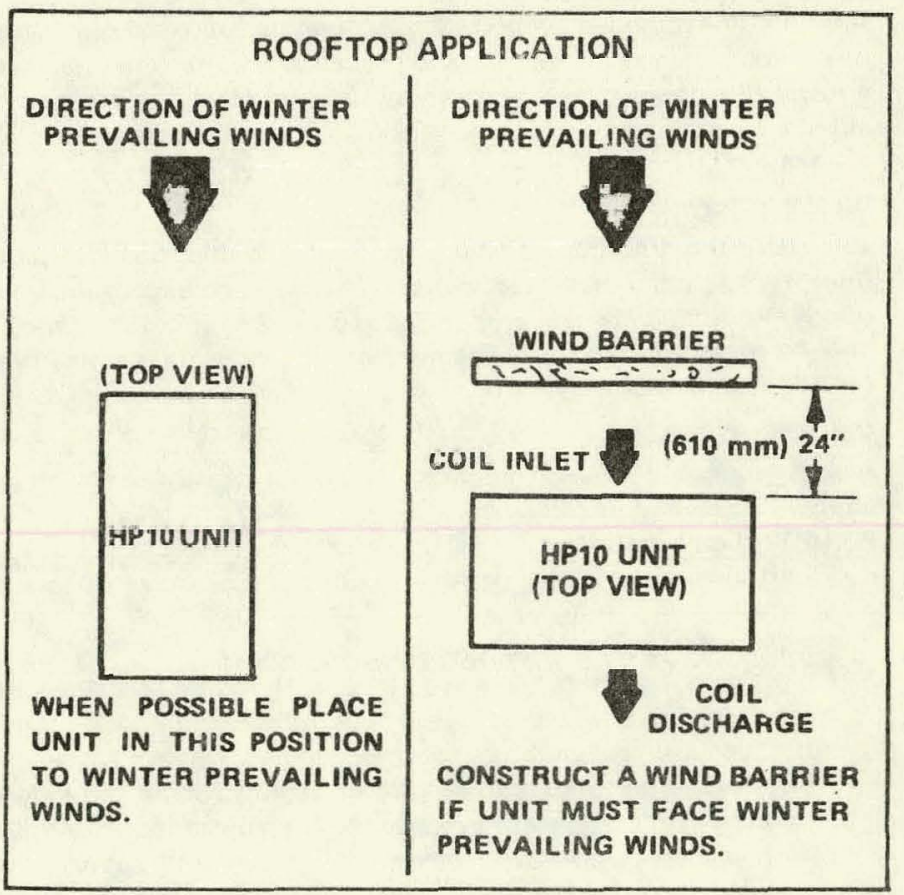

FIGURE 3 


\section{VII - ELECTRICAL}

Wiring must conform to the National Electric Code (NEC) and local codes. Application diagrams are included at the back of this instruction and in indoor unit instructions.

Refer to unit rating plate for minimum circuit ampacity and maximum fuse size.

1 - Provide line voltage power supply to HP10 unit from a properly sized disconnect switch.

WARNING - Be sure line voltage connections are made as shown in this instruction. Do not close disconnect switch or apply power to this unit until advised to do so by these instructions.

2 - Install room thermostat (provided with HP10 unit) in the conditioned area. Locate where it will not be effected by sunlight, drafts, or vibration. Do not install on an outside wall. A position approximately 5 feet $(1.5 \mathrm{~m})$ from the floor and near the center of the conditioned area is most desirable.
3. Provide low voltage wiring from HP10 to indoor unit and from thermostat to indoor unit as indicated on the field wiring diagram in this instruction.

4-Ground unit either through supply wiring or with an earth ground.

5 - Mount compressor warning sticker on unit disconnect box.

VIII- REFRIGERANT PIPING

Field refrigerant piping consists of liquid and vapor lines from the HP10 unit to the indoor coil. Use applicable Lennox L10 series line sets as shown in table. These line sets may be shortened in the field when necessary.

A - Piping Connections at Outdoor Unit

HP9 units are equipped with stub type connections and field installer will determine connection type to use.

B - Piping Connections at Indoor Coil

Refer to indoor coil installation instructions for proper refrigerant line connection procedure.

TABLE 1

\begin{tabular}{|c|c|c|c|c|c|c|c|c|c|c|c|}
\hline \multirow{4}{*}{$\begin{array}{c}\text { Outdoor } \\
\text { Unit } \\
\text { Model }\end{array}$} & \multicolumn{11}{|c|}{ L10 LINE SETS } \\
\hline & \multirow{3}{*}{$\begin{array}{l}\text { Line } \\
\text { Sot } \\
\text { Numbers }\end{array}$} & \multirow{2}{*}{\multicolumn{2}{|c|}{ Length }} & \multicolumn{4}{|c|}{ Suction Line Connections } & \multicolumn{4}{|c|}{ Liquid Line Connections } \\
\hline & & & & \multicolumn{2}{|c|}{ Outdoor Unit (Stub) } & \multicolumn{2}{|c|}{ Indoor Coil } & \multicolumn{2}{|c|}{ Outdoor Unit (Stub) } & \multicolumn{2}{|c|}{ Indoor Coil (Flare) } \\
\hline & & $f t$ & $m$ & $\ln$ & $\mathrm{mm}$ & In & $\mathrm{mm}$ & In & $\mathrm{mm}$ & In & $\mathrm{mm}$ \\
\hline \multirow{4}{*}{$\begin{array}{l}\text { HP10-311 } \\
\text { HP10-410 }\end{array}$} & L10-41-20 & 20 & 6.1 & $3 / 4$ & 19.1 & $3 / 4$ & 19.1 & $3 / 8$ & 9.5 & $3 / 8$ & 9.5 \\
\hline & L10-41-30 & 30 & 9.1 & $3 / 4$ & 19.1 & $3 / 4$ & 19.1 & $3 / 8$ & 9.5 & $3 / 8$ & 9.5 \\
\hline & $L 10-41-40$ & 40 & 12.2 & $3 / 4$ & 19.1 & $3 / 4$ & 19.1 & $3 / 8$ & 9.5 & $3 / 8$ & 9.5 \\
\hline & $L 10-41-50$ & 50 & 15.2 & $3 / 4$ & 19.1 & $3 / 4$ & 19.1 & $3 / 8$ & 9.5 & $3 / 8$ & 9.5 \\
\hline \multirow{3}{*}{ HP10-510 } & L10-65-30 & 30 & 9.1 & $7 / 8$ & 22.2 & $3 / 4^{*}$ & 19.1 & $3 / 8$ & 9.5 & $3 / 8$ & 9.5 \\
\hline & L10-65-40 & 40 & 12.2 & 718 & 22.2 & $3 / 4^{*}$ & 19.1 & $3 / 8$ & 9.5 & $3 / 8$ & 9.5 \\
\hline & L10-65-50 & 50 & 15.2 & $7 / 8$ & 22.2 & $3 / 4^{*}$ & 19.1 & $3 / 8$ & 9.5 & $3 / 8$ & 9.5 \\
\hline
\end{tabular}

*The $L 10-65$ series of line sets must have the $3 / 4 \mathrm{in} .(19,1 \mathrm{~mm})$ reduction removed before matching to the $1-1 / 8 \mathrm{in}$. $(28,6 \mathrm{~mm})$ stub fitting on the indoor coil. 
8. SHPPING ANO PACKING LIST

Packsge 1 of 2 contains:

9-Assembled blower cabinet

Peckage 2 of 2 contelns:

1 - Assembled coil cabinet

1 - Drip shield (C10-51/65 only - taped to coil)

3 - Drive cleats

1 - Roll gaskating

3. Rubber drain plugs

1. $90^{\circ}$ Adapter fitting (C10 \& CP10-41 refrig. piping only)

\section{SHIPPING DAMAGE}

Check contents for shipping damage. If damage is found, contact last carrier immediately.

\section{III - GENERAL}

These instructions are intended as a general guide and do not supersede local codes. Authorities having jurisdiction should be consulted before installation.

\section{IV - REQUIPEMENTS}

Installation of Lennox blower coil units with electric heat must con- form with standards in National Fire Protection Association (NFPA) "Standard for Installation of Air Conditioning and Ventilating Systems NFPA No. 90A," "Standard for the Installation of Residence Type Warm Air Heating and Air Conditioning Systems NFPA No. 90B," Manufacturer's installation instructions and local municipal building codes. Unit is approved for installation at clearance to combustible materials as listed below:

$$
\begin{aligned}
& 0^{\prime \prime} \text { to cabinet } \\
& 1^{\prime \prime} \text { to plenum and outlet duct within } 3 \text { ' of unit }
\end{aligned}
$$

Accessibility and service clearances must take precedence over combustible material clearances.

\section{V-APPLICATION}

These units are designed for indoor installations only. CBP10 units are designed for installation with matching HP10 heat pump units. Units may be installed for up-flo, down-flo or horizontal air discharge. Refer to Figure 1 for stacking arrangement. Units are intended for use with specific Lennox sections of heat pumps.

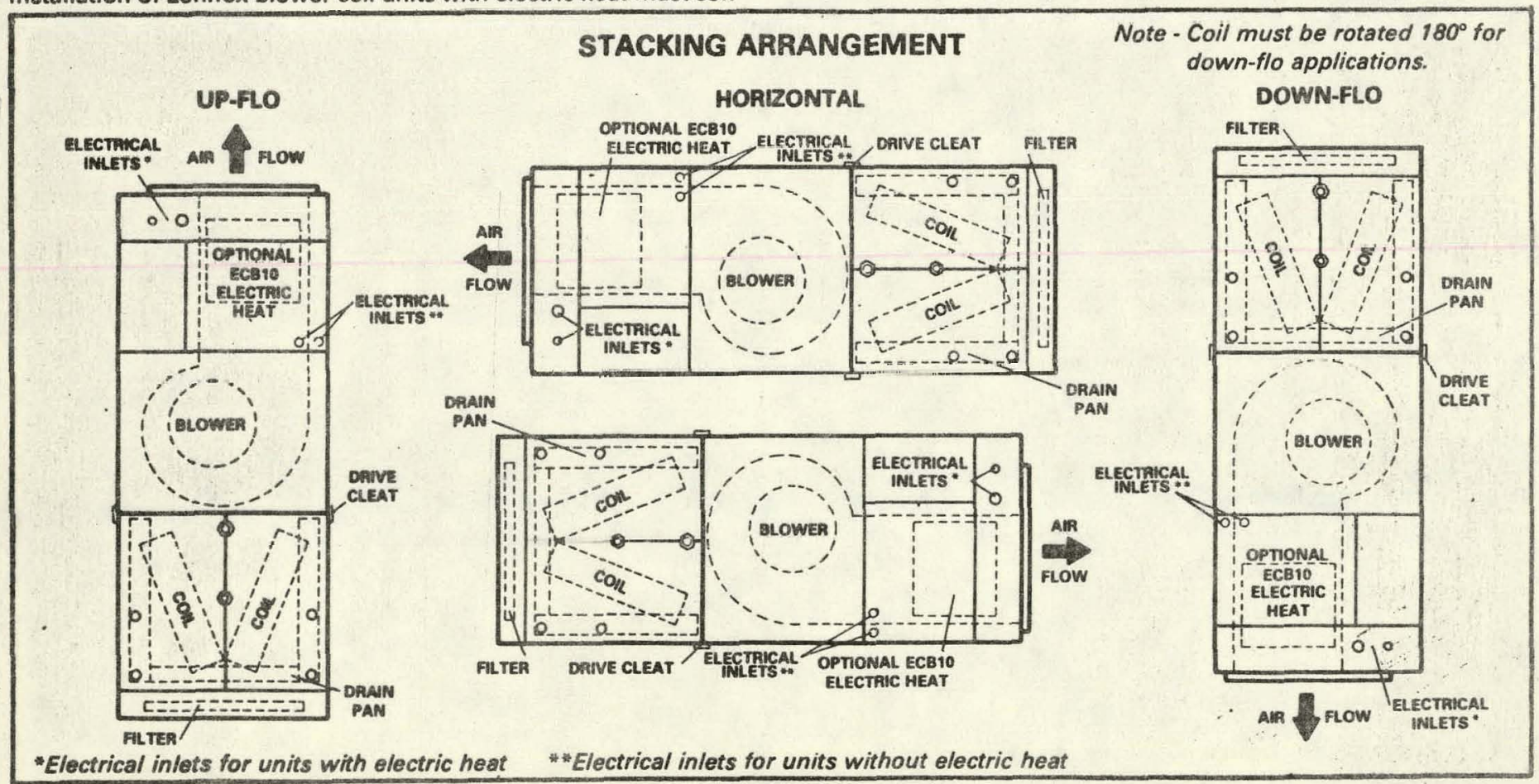

FIGURE 1 


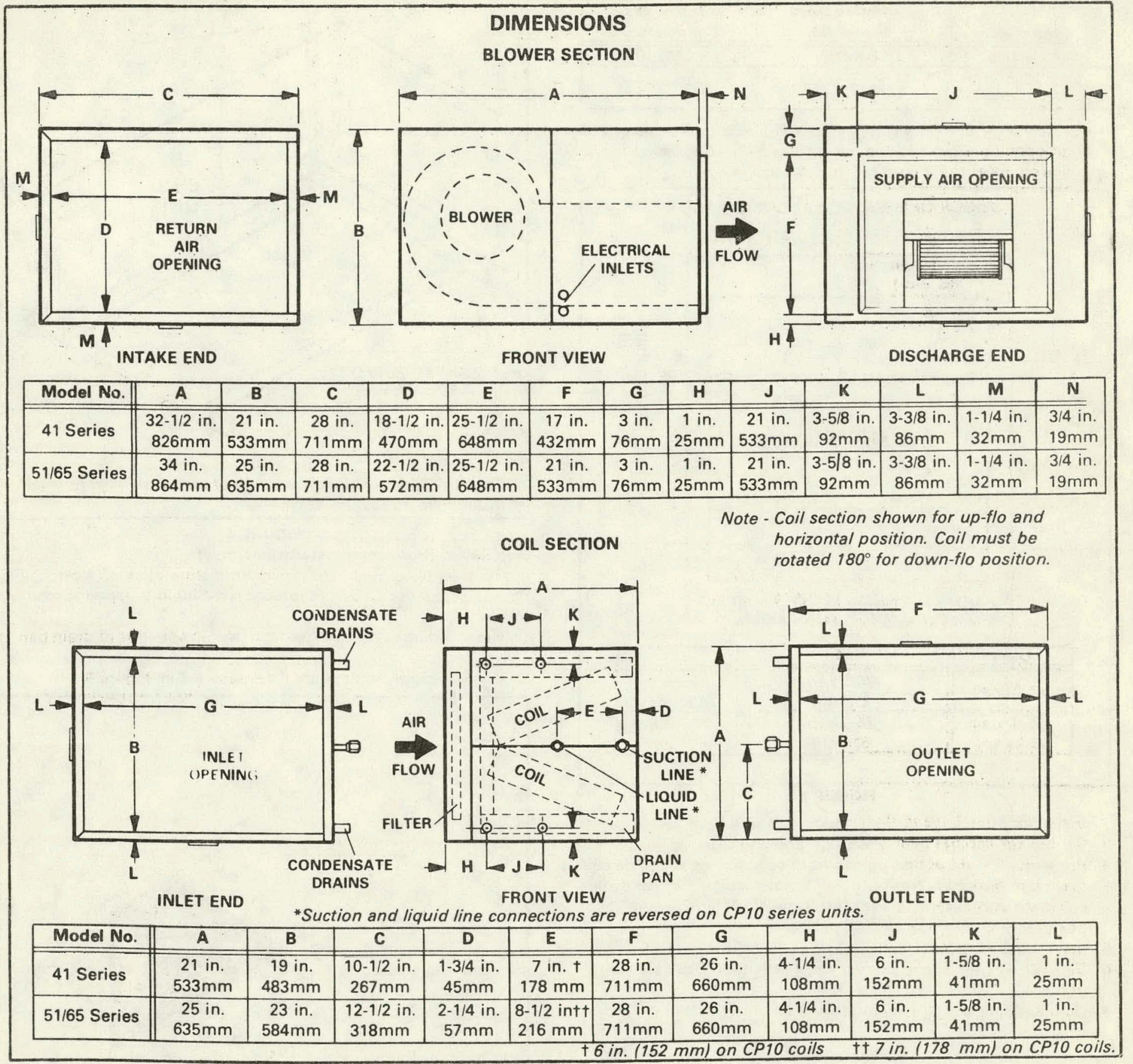

FIGURE 2

\section{VII - INSTALLATION}

See Figure 1 for stacking arrangements for up-flo, down-flo and horizontal air discharge. NOTE-For some applications blower motor must be rotated so oilers are positioned up.

A. Up-flo

NOTE - For up-flo applications, an optional adaptor base (RAB10) is available to provide side return air entry into the unit. Refer to instructions provided with adaptor base for assembly and installation.

1 - Place coil cabinet in desired location.

2 - Install gasketing (provided) around uullel upening of coil cabinet.

3 - Set blower cabinet above coil cabinet and secure cabinets to- gether with drive cleats provided.

4 - Connect supply and return ducts as required. If return air opening of unit is installed flush with wall or other type barrier, the coil and filter must be removed from cabinet, and duct connections secured to the inside duct flange of cabinet opening. After duct connection is made, replace coil and filter.

B - Down-flo

On down-flo applications using ECB10 electric heat, an additive base is required when unit is installed on combustible flooring. The additive hase is not provided and must be ordered separately. Table 1 lists units applicable to each additive base. 
TABLE 1

\begin{tabular}{|c||c|c|}
\hline $\begin{array}{c}\text { Unit } \\
\text { Model No. }\end{array}$ & $\begin{array}{c}\text { Additive Base } \\
\text { Model No. }\end{array}$ & $\begin{array}{c}\text { Additive Base } \\
\text { Catalog No. }\end{array}$ \\
\hline \hline 41 Series & CBA10-41 & LB-26029BA \\
\hline $\begin{array}{l}51 \text { Series } \\
65 \text { Series }\end{array}$ & CBA10-51/65 & LB-26029BB \\
\hline
\end{tabular}

1 - Cut discharge air opening in floor. See Figure 3 for dimensions of floor opening when additive base is used. If additive base is not required, refer to Figure 2 for unit discharge opening.

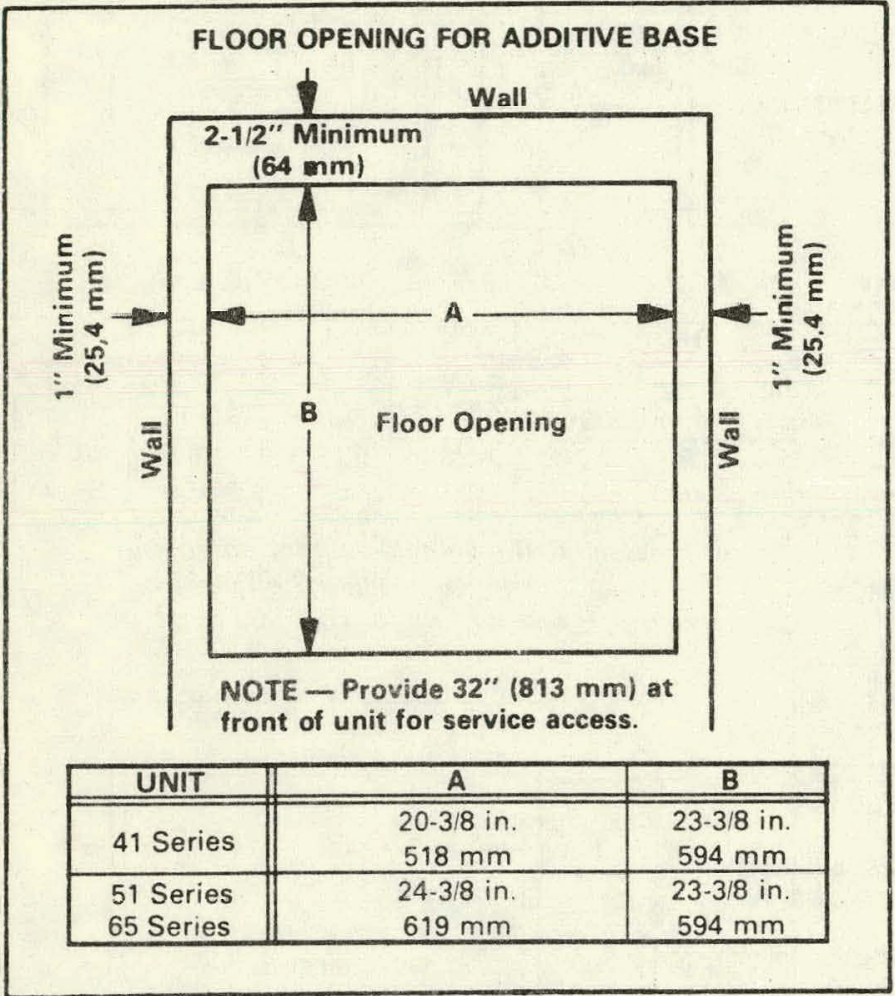

FIGURE 3

2 - Install additive base in floor opening (if required)

3- Sel bluwer cabinet uver discharge openıng

4 - Remove (2) front access panels from coil cabinet and slide coili drain pan assembly from cabinet. Rotate cabinet $180^{\circ}$ and slide coilidrain pan assembly back into cabinet. Refer to Figure 1 for position of coil in down-flo applications.

5 - Install gasketing (provided) around outlet opening of coil cabinet.

6 - Set coil cabinet above blower cabinet and secure cabinets toqether with drive cleats provided

7 - Connect duct work as required.

\section{C. - Hnrizontal}

Units in the horizontal position may be arranged for right or left air discharge. If unit is to be suspended it is recommended that a support frame be constructed as shown in Figure 4 . The frame may be constructed with angle iron, as shown, or other suitable material. This frame will prevent unit sagging which may cause access panels to bind.

1 - Place coil cabinet in desired location.

2 - Install gasketing (provided) around outlet opening of coil cabinet.

3 - Set blower cabinet next to coil cabinet and secure cabinets together with drive cleats provided.

4 - Connect supply and return air ducts as required. If return air opening of unit is installed flush with wall or other type barrier, the coil and filter must be removed from cabinet and duct connections secured to the inside duct flange of cabinet opening. After duct connection is made, replace coil and filter.

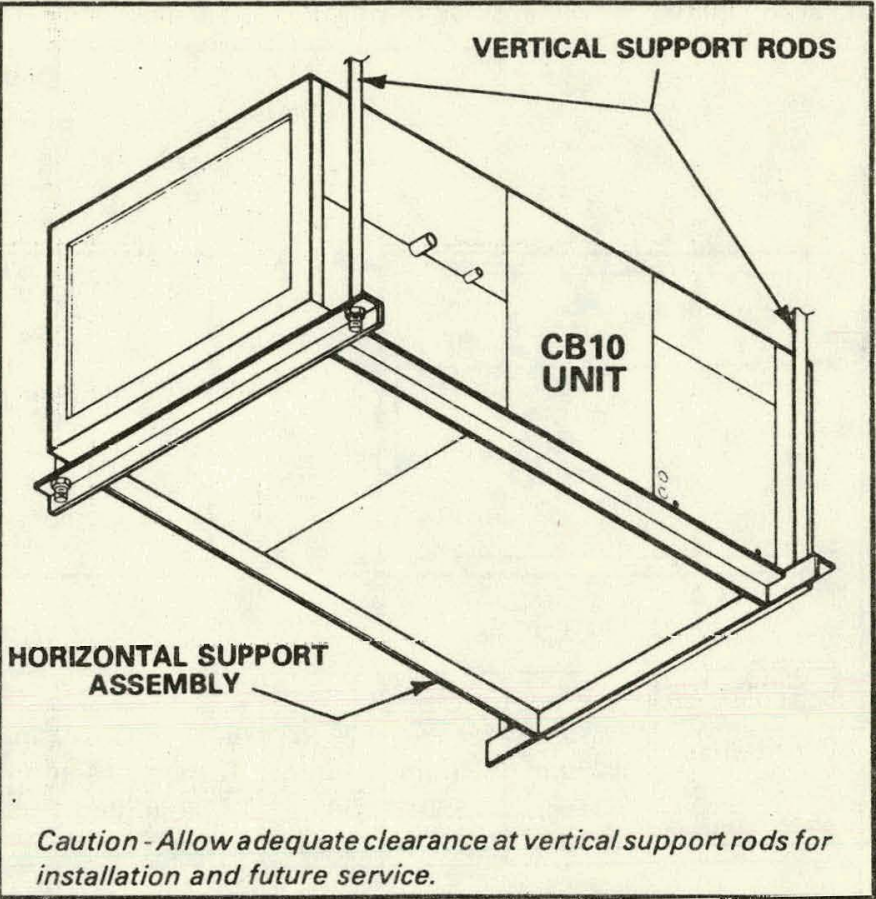

FIGURE 4

Drip Shiedd (Horizontal installations only)

A drip shield is provided to prevent moisture blow-off from coil to blower section in $\mathrm{C} 10-51 / 65$ units only. Shield is taped to coil for shipping.

1 - Slip standing seam of drip shield over lower edge of drain pan in coil section.

2 - Crimp securely with pliers if necessary. See Figure 5.

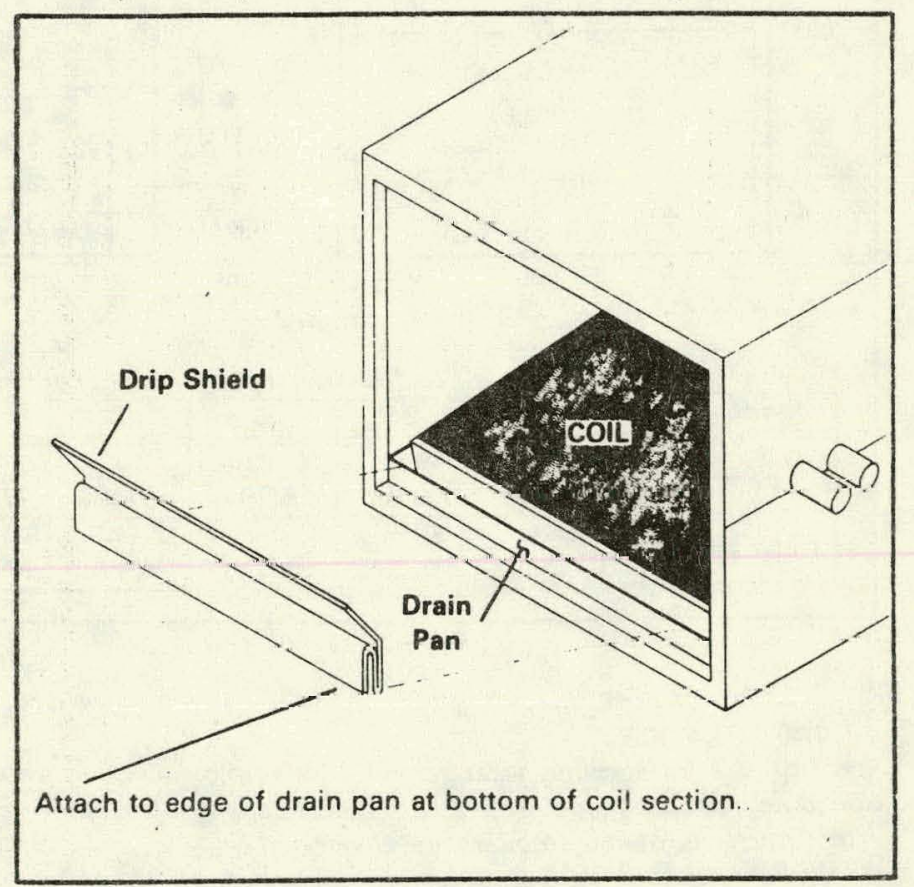

VIII - REFRIGERANT PIPING

TIGURE 5

Suction and liquid lines are equipped with flare fittings on -41 model. Liquid line has flare fittings and suction line requires sweat connections on -51 and -65 models. C10 units may be applied with either Lennox L10 lines sets or field fabricated lines. CP10 units may only be applied with Lennox L10 line sets. Refer to outdoor unit installation instructions for proper application, installation and refrigerant charge for particular systems. 


\section{IX - CONDENSATE DRAIN}

Two sets of drains are provided, $3 / 4^{\prime \prime}$ threaded pipe main drain and $3 / 4^{\prime \prime}$ plain pipe auxiliary drain. Always use lower set of drains. Install the rubber plug (with hole in center) in the auxiliary drain before connecting drain lines. Plug the (2) upper unused drain connections with the solid rubber plugs provided.

1 - Drain piping should not be smaller than the drain connections at drain pan.

2-A trap in the drain line is recommended when drain is on the negative side of the blower system.

3 - The trap must be deep enough to offset the difference in static pressure between drain pan and atmosphere. Generally 2" (51 $\mathrm{mm}$ ) inches is satisfactory for medium static applications.

4 - Horizontal runs must be pitched 1 inch per 10 feet of drain line to offset line friction.

5 - An open vent in drain line will sometimes be required due to line length, friction and static pressure.

6 - Drains should be constructed in a manner to facilitate future cleaning.

\section{$X$ - FIELD WIRING CONNECTIONS}

Wiring must conform to National Electrical Code (NEC) and local codes. Refer closely to application wiring diagram in this instruction for wiring make-up. Field high voltage wiring must terminate at the handy box provided in blower section. If EMT or rigid conduit is used, special fitting may be required. Low voltage connections are to be made external to unit.

\section{XI- CHECKING UNIT AIR VOLUME}

Refer to Table 2 for coil pressure drop readings and corresponding unit CFM.

NOTE - Table 2 lists one set of coil pressure drop readings for coils in the horizontal or up-flo position and one set of readings for coils in the down-flo position. Use the applicable column as indicated in the

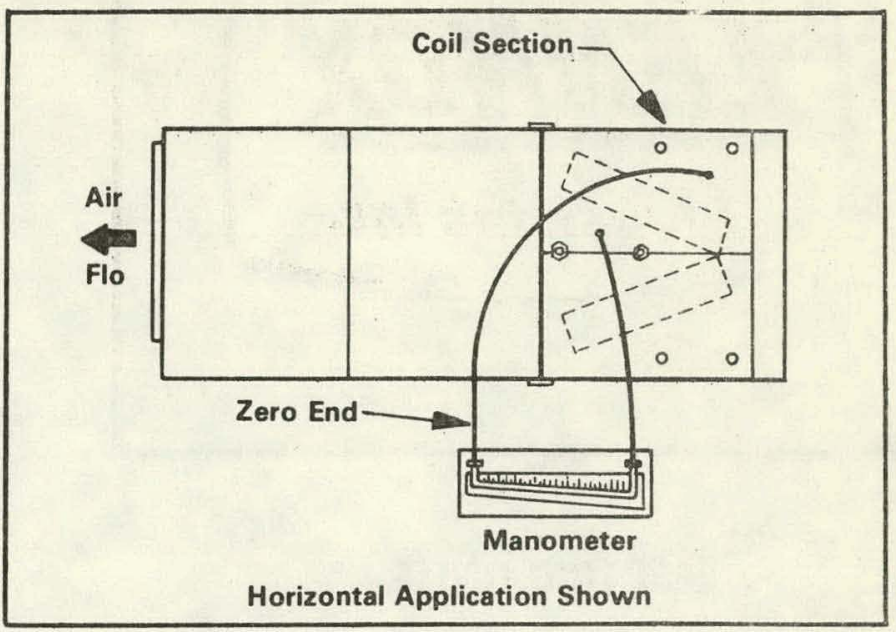

Figure 6

table when taking readings. Checks are made with a clean filter in place, unit panels in place and a dry evaporator coil (blower only operating). Test holes are provided in coil section.

1 - Remove snaphole plugs from unit test holes. Insert manometer hoses $1 / 4$ inch $(6.4 \mathrm{~mm})$ past the inside edge of cabinet insulation. Seal around hoses with permagum or sealing compound. Connect zero end of manometer to entering air side of coil. Refer to Figure 6 .

2 - With only the indoor blower operating, observe manometer reading. If reading is above air volume required, decrease blower speed. See Table 2 for required air volumes. Refer to application wiring diagram in this instruction for changing blower speed.

3 - After required draft gauge readings are obtained, insert snaphole plugs in air test holes.

TABLE 2

\begin{tabular}{|c|c|c|c|c|c|c|}
\hline \multicolumn{7}{|c|}{ DRAFT GAUGE READING (DRY EVAPORATOR) } \\
\hline \multirow{2}{*}{$\begin{array}{l}\text { UNIT } \\
\text { SIZE } \\
\end{array}$} & \multicolumn{2}{|c|}{ AIR VOLUME** } & \multicolumn{2}{|c|}{ *READING (Horizontal or Up-flo) } & \multicolumn{2}{|c|}{ *READING (Down-flo) } \\
\hline & CFM & $\mathrm{m}^{3} / \mathrm{s}$ & in. water & $\mathrm{mm}$ water & in. water & $\mathrm{mm}$ water \\
\hline \multirow{5}{*}{-41 Units } & 900 & 425 & $.085-.09$ & $2.16-2.29$ & $.05-.058$ & $1.27-1.47$ \\
\hline & 1000 & .472 & $.09-.095$ & $2.29-2.41$ & $.06-.065$ & $1.52-1.65$ \\
\hline & 1200 & .566 & $.125-.13$ & $3.18-3.30$ & $.09-.095$ & $2.29-2.41$ \\
\hline & 1400 & .661 & $.17-.18$ & $4.32-4.57$ & $.11-.12$ & $2.79-3.05$ \\
\hline & 1500 & .708 & $.195-.2$ & $4.95-5.08$ & $.13-.135$ & $3.30-3.43$ \\
\hline \multirow{6}{*}{-51 Units } & 1400 & .661 & $.045-.05$ & $1.14-1.27$ & $.075-.08$ & $1.91-2.03$ \\
\hline & 1600 & .755 & $.055-.06$ & $1.40-1.52$ & $.08-.085$ & $2.03-2.16$ \\
\hline & 1800 & .849 & $.06-.065$ & $1.52-1.65$ & $.095-.1$ & $2.41-2.54$ \\
\hline & 2000 & .944 & $.07-.075$ & $1.78-1.91$ & $.115-.12$ & $2.92-3.05$ \\
\hline & 2200 & 1.04 & $.085-.09$ & $2.16-2.19$ & $.125-.13$ & $3.18-3.30$ \\
\hline & 2300 & 1.09 & $.09-.095$ & $2.29-2.41$ & $.14-.145$ & $3.56-3.68$ \\
\hline \multirow{5}{*}{-65 Units } & 1800 & .859 & $.07-.075$ & $1.78-1.91$ & $.1 \quad-.12$ & $2.54-3.05$ \\
\hline & 2000 & .944 & $.08-.09$ & $2.03-2.29$ & $.13-.135$ & $3.30-3.43$ \\
\hline & 2200 & 1.04 & $.09-.095$ & $2.29-2.41$ & $.155-.16$ & $3.94-4.06$ \\
\hline & 2400 & 1.13 & $.095-.1$ & $2.41-2.54$ & $.185-.19$ & $4.70-4.83$ \\
\hline & 2500 & 1.18 & $.11-.12$ & $2.79-3.05$ & $.2-.21$ & $5.08-5.33$ \\
\hline
\end{tabular}

* These are pressure drop readings across the coil only, not total resistance readings.

**Minimum air volume for heat pumps application is $400 \mathrm{CFM} /$ ton of unit capacity. 
4- Remove ECB10 access cover. Slide heater into duct extension opening making sure back of heater aligns with rear duct extension opening.

5 - Secure heater to duct extension with (2) 1/4-20 machine screws and to outside of blower cabinet with (2) sheet metal screws. Use the screws which were removed from blower access panel and duct extension front filler panel. Refer to Figure 2.

\section{VII - FIELD WIRING CONNECTIONS}

Wiring must conform to National Electrical Code (NEC) and local codes. Refer closely to application wiring diagram in this instruction for low voltage wiring make-up and to wiring diagram in ECB10 unit for line voltage make-up. See ECB10 rating plate for minimu m circuit ampacity and maximum rating of over-current protective devices. Connect blue low voltage blower relay leads to black and yellow low voltage leads.

Select appropriate blower speed and make connections as shown on application wiring diagram.

After all wiring is completed, replace ECB10 access cover and blower access panel.

\section{Secure heater to cabinet with}

(2) sheet metal screws

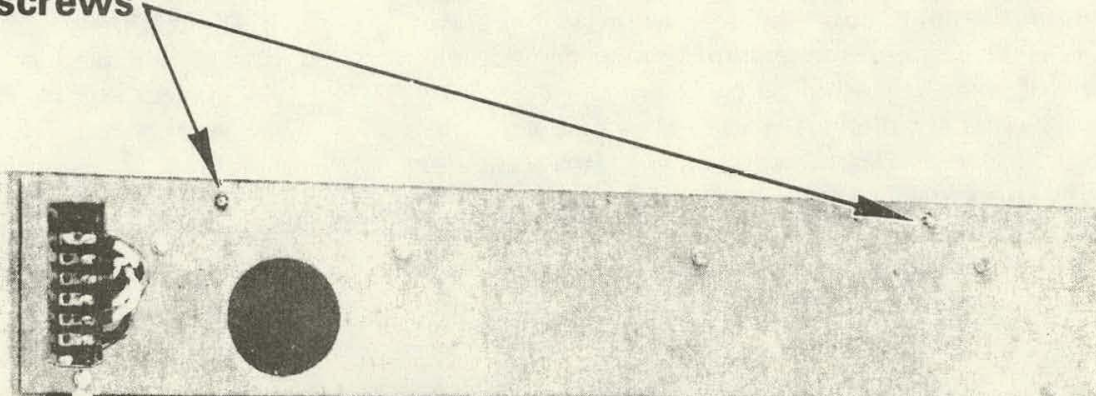

Secure heater to blower duct extension ats.".
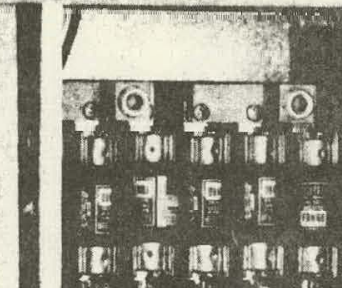

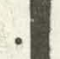

with (2) 1/4-20 machine screws

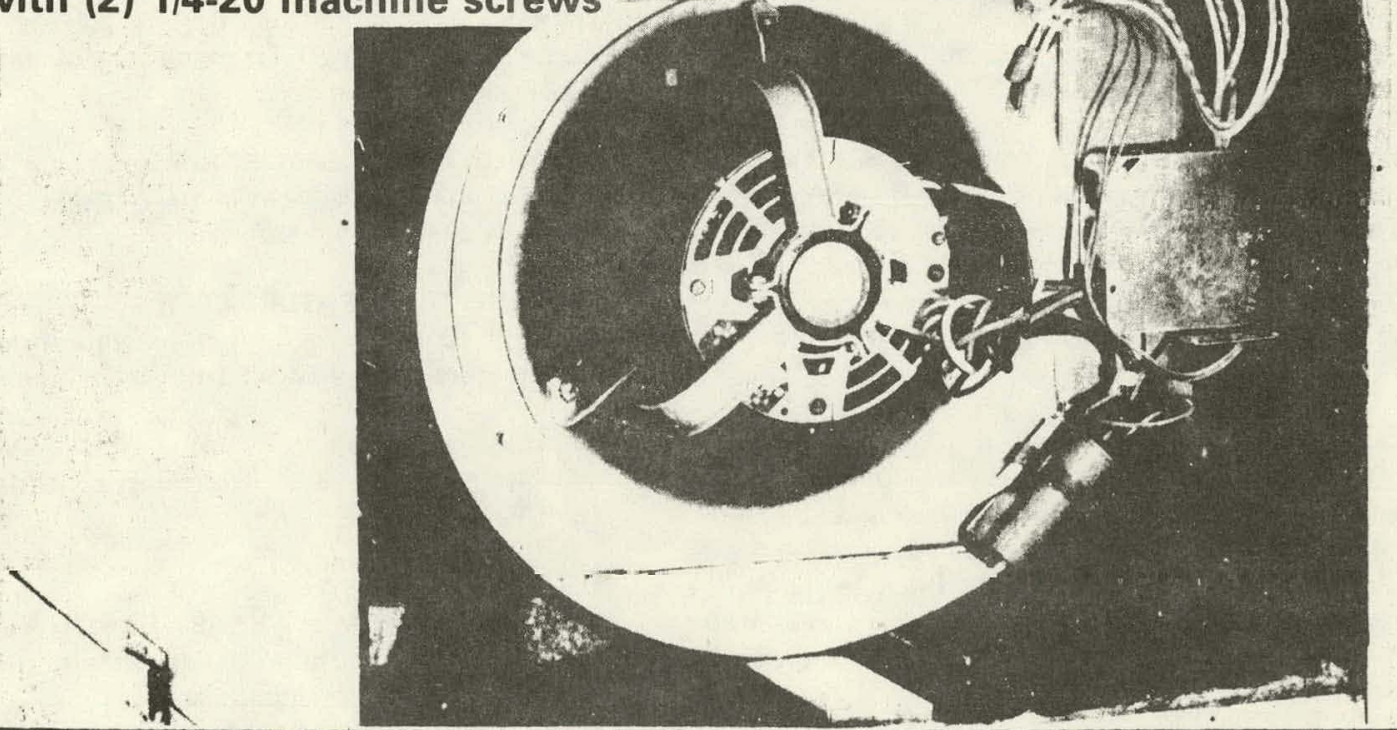

FIGURE 2 


\section{OPERATION AND MAINTENANCE OF CW31-45}

\section{Crenanon}

A- Veter Coil and Auxiliary Energy Subsystem

The CW31-45 space heating coil allows a transfer of solar providad heat into the conditioned area. In normal operation, solar heated liquid in the coil is the first stage heat source. As the room thermosiat demands heat, solar heated water is circulated through the CW31-45 coil and the system blower circulates air through the coil. If solar heated air is sufficient the thermostat requirement will be met. If sufficient heat is not available from the coil, the thermostat will activate the second and third stage heat cources as required to meet heating demalud.

- High Temperature Limit Switch

A high temperature limit switch located on the downstream side of the coil provides overheating protection for the subsystem
Hower motor. If the temperature of air leaving the coil reaches $140^{\circ} \mathrm{F}\left(60^{\circ} \mathrm{C}\right)$ the limit switch stops waterflow through the coil. No additional heat will be available from the coil and the blower motor will not be subjected to excessive temperatures.

II. MAINTENANCE

A - CW31-45 Coil Unit

1. Inspect unit for evidence of coil and plumbing leaks.

2. Inspect coil. The coil must be clean and free of any obstructions.

B- Auxiluary Energy Unit

Refer to the Operation and Maintenanf.e manual arrompanying the auxiliary energy unit for its proper maintenance requirements.

\section{APPLICATION AND INSTALLATION}

\section{- emipPING AND PACKING LIST}

Peekage 1 of 1 contains:

1 - Coillcabinet assembly

3- Drive cleats

1- Roll gasketing

\section{II - EMPPING DAMAGE}

Contact the last carrier immediately if any shipping damage is found.

\section{UI. - APPLICATION}

The CW31-45coil is designed to provide solar heat in CB10 series units. Refer to the total system instructions for solar heat collection and connecting plumbing information. The solar coil installs beiween the evaporator coll cabinet and the blower coll cabinet. Use these instructions only as a general quide, they in no way supersede amy local codes. Consult authorities having jurisdiction before instaltation.

\section{MNSTALLATION (Refer to Figure 1 and 2)}

install gasketing (provided) around the blower side of the CW31-45 cubinet. Position CW31-45 unit between evaporator coil cabinet and blower cabinet. Tapered cabinet securing cleats should match wrth straight cleats. Also, the high temperature limit will be facing the blower compartment. When properly aligned, secure evaporator cabinet to CW31-45 cabinet and CW31-45 cabinet to blower cabınet with provided drive cleats.
Aprembled CB10 unit with CW31 45 coil should be installed sơ that the drain plugs are accessible.

\section{$V$ - PLUMBING CONNECTION}

The solar heater water connections are $5 / 8^{\prime \prime}(15.9 \mathrm{~mm})$ nominal. 3/4" $(19 \mathrm{~mm})$ O.D. copper tubing. Refer tn Figure 1 for proper inlet and ourlet identification. Refer to the total system instruction for proper plumbing specifications.

\section{ELECTRICAL CONNECTIONS}

Refer to the total system instruction for proper connection of the high temperature limit.

\section{VII - HIGH TEMPERATURE LIMTT}

The high temperature limit stops water flow through the coil if the iomperature of the air discharged from the coil redches $140^{\circ} \mathrm{F}\left(60^{\circ} \mathrm{C}\right)$.

\section{VIII - DRAIN PLUGS}

Two drain plugs, one for each internal header, are provided to drain the CW31-45 coil.

\section{IX - BLOWER SPEED}

The CB10 blower MUST BE SET TO RUN AT MEDIUM.HIGH SPEED. Use the orange "common" and brown "med-hi" motor taps. Individually tape unused motor wires. 


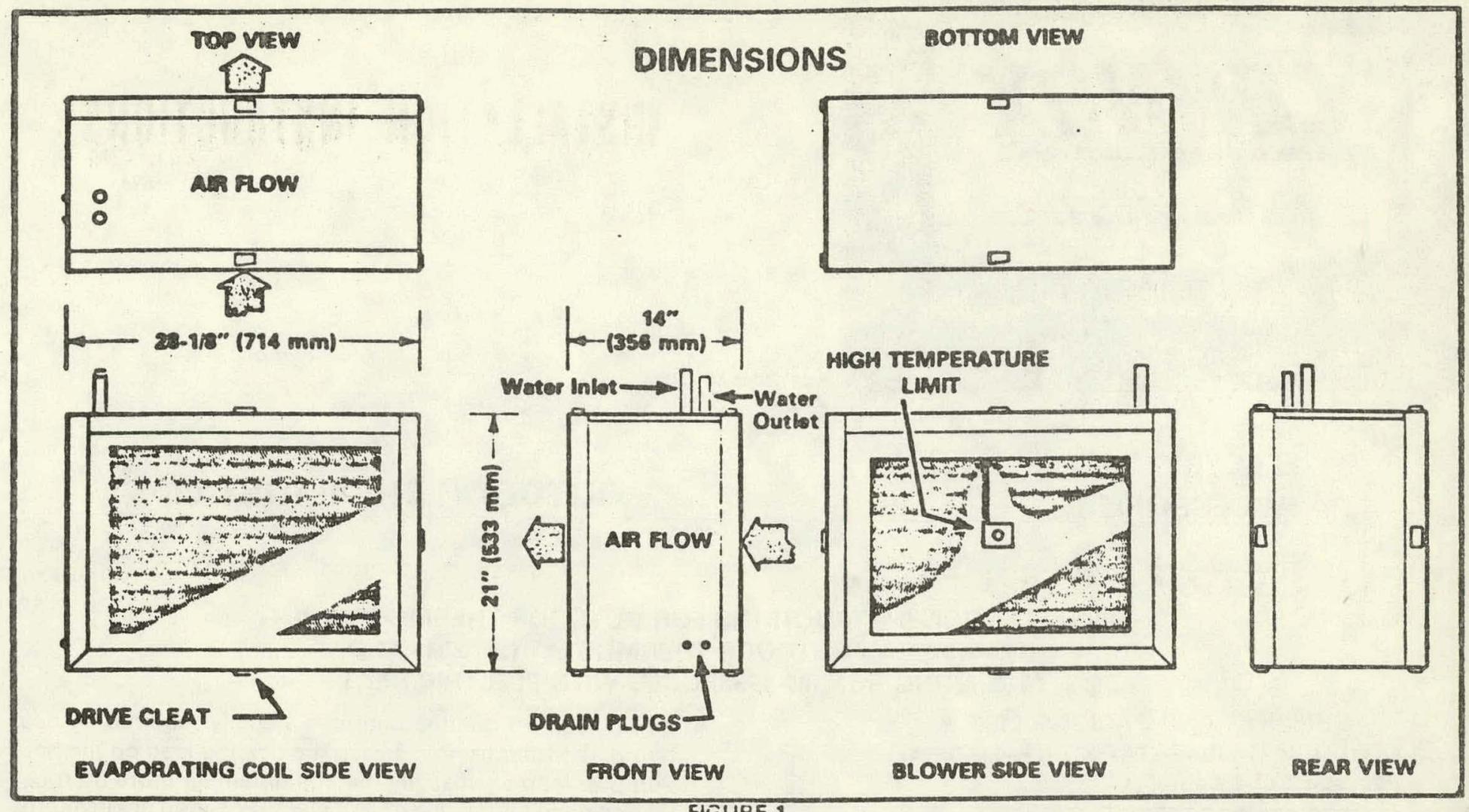

BLOWER MUST BE WIRED

FOR "MED-HIGH" SPEED

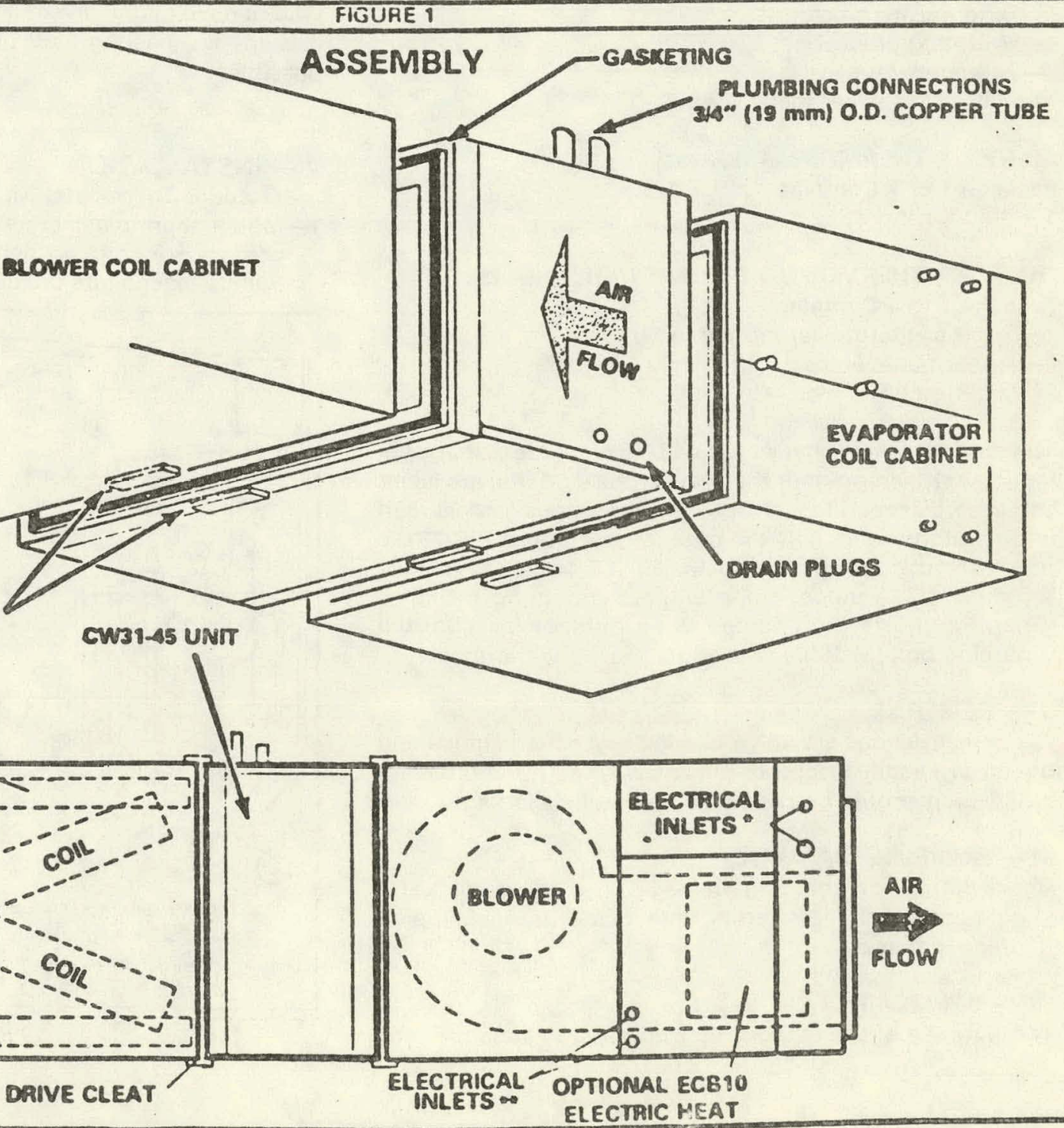




\section{ELECTRIC UNIT ACCESSORIES}

\section{INSTALLATION INSTRUCTIONS $5 / 74$}

\section{INSTALLATION INSTRUCTIONS FOR OUTDOOR THERMOSTAT KIT (LB-44376BA), OUTDOOR THERMOSTAT (PR-231) AND MOUNTING BOX (M-1595) USED WITH ELECTRIC HEAT}

\section{I-SHIPPING AND PACKING LIST}

\section{OUTDOOR THERMOSTAT KIT (LB-44376BA)}

Package 1 of 1 Contains

1-Outdoor thermostat

1-Mounting bracket

2-Tubing clamps

Miscellaneous sheet metal screws

\section{OUTDOOR THERMOSTAT (PR-231) \\ Package 1 of 1 Contains \\ 1-Outdoor thormostat}

\section{OUTDOOR THERMOSTAT MOUNTING BOX (M-1595)}

Package 1 of 1 Contains

1-Oulduor thermostat mounting box

2 Tinnerman clamps

2 - Sheet metal screws

The outdoor thermostat kit (LB-44376BA), outdoor thermostat (PR-231) and outdoor thermostat box (M-1595) are listed and ordered separately. If mounting provisions are included in the outdoor unit, only the outdoor thermostat (PR-231)is needed. An outdoor thermostat kit (LB-44376BA) installs thermostat in outdoor units without mounting facilities. When thermostat is mounted in an outdoor location, the mounting box (M-1595) is used to house the thermostat.

\section{II - GENERAL}

These instructions are only intended as a general guide and do not supersede local codes in any way. Authorities having jurisdiction should be consulted before installation.

\section{III - SHIPPING DAMAGE}

Check items for shipping damage. The receiving party should contact the last carrier immediately if any shipping damage is found.

\section{IV - APPLICATION}

The purpose of the outdoor thermostat is to keep the total power load off the line until it is actually required. In heat pump applications, it will keep the heating load on the heat pump as long as possible thereby obtaining more Btuh per watt of power input. In straight electric heating applications, it keeps the heating load on low power input as long as possible.

\section{V-INSTALLATION}

\section{A-Outdoor Thermostat Kit (LB-44376BA)}

1 -Mount thermostat bracket in a convenient location in compressor compartment which will allow the sensing bulb to extend into the outdoor fan area for sensing out-

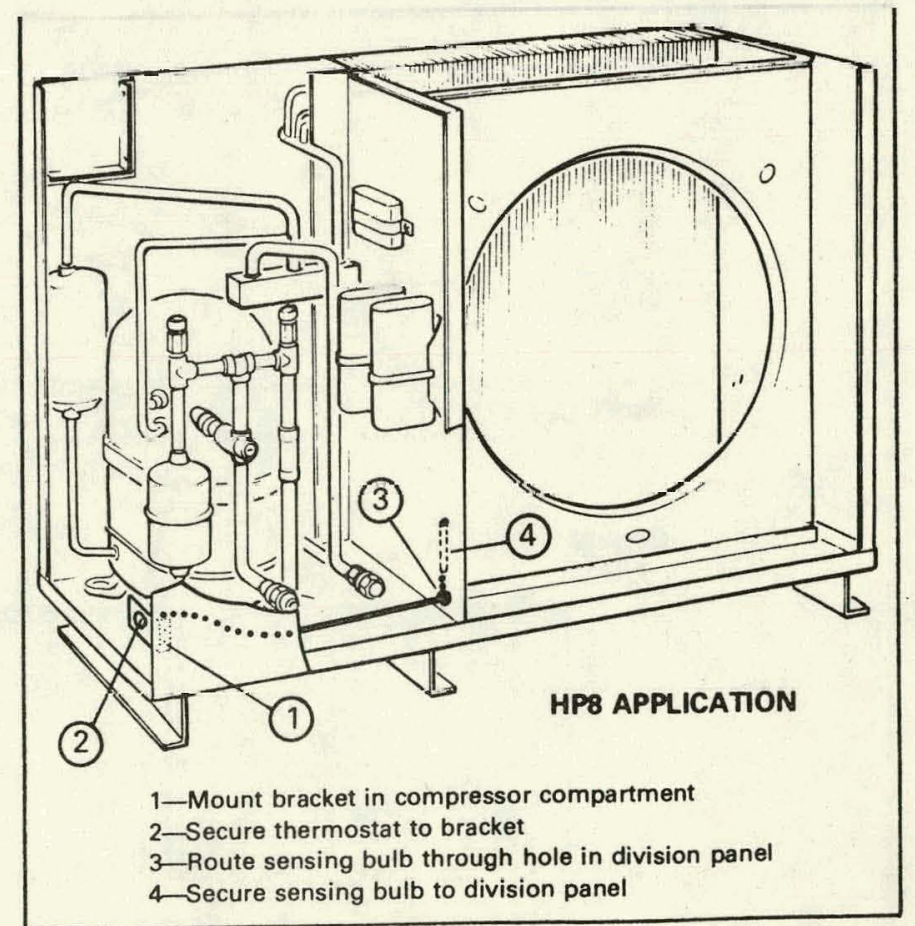

FIGURE 1 
door temperatures. Sensing bulb must not be in direct sunlight or wind.

2-Sheet metal screws are provided for mounting bracket and clamps for securing sensing bulb. Figure 1 illustrates a typical HP8 application.

3-Remove adjustment knob and mounting screws from thermostat. Insert thermostat behind mounting plate of box with shaft extending through the slot. Line up mounting holes and replace mounting screws. Replace adjustment knob.

B-Outdoor Thermostat (PR-231) And Mounting Box (M-1595)

If an outdoor unit has mounting provisions, secure outdoor thermostat (PR-231) in place.

If the outdoor thermostat(s) is installed in outside location, the mounting box should be used to house thermostat(s). Before thermostat(s) are installed in thermostat box, remove the (2) screws on thermostat and install on opposite side of terminals. This must be done so wiring can bc connected to terminals when thermostat is mounted in thermostat box. See Figure 2.

1-Remove cover from thermostat box and insert thermostat through grommetted hole in bottom of box.

2-Remove adjustment knob and mounting screws from thermostat. Insert thermostat behind mounting plate of box with shaft extending through the slot. Line up mounting holes and replace mounting screws. Replace adjustment knob.

3-Secure thermostat sensing bulb to bottom of box with Tinnerman clamps and sheet metal screws provided.

4-Mount box outdoors in a sheltered location where direct sun and strong winds will not affect temperature reading.

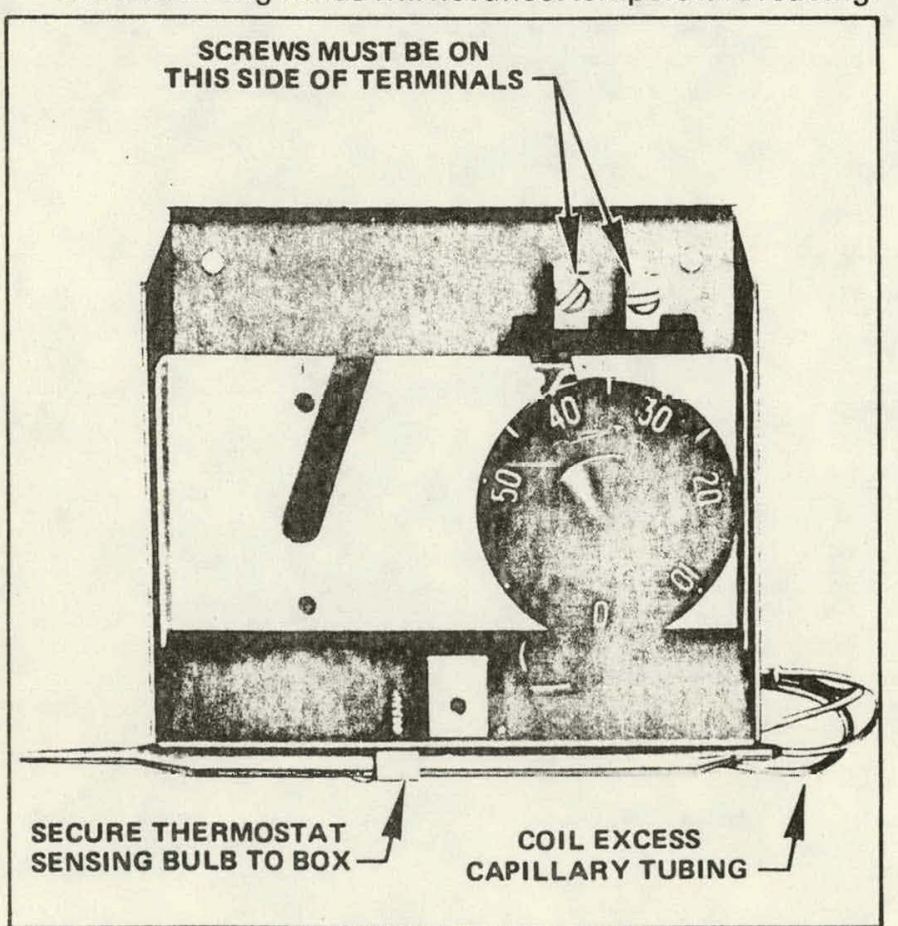

FIGURE 2

\section{VI - WIRING}

Refer to correct application wiring diagram in this instruction for thermostat connections. Class 2 type wire may be used for low voltage wiring.

CAUTION-Outdoor thermostat(s) should never be wired to control the entire auxiliary electric heat section applied to heat pumps. Some auxiliary heat must automatically be energized by the heat pump during a defrost cycle to control indoor air. Wire first stage as indicated on application diagram. 


\section{HEATING PUMP WIRING DIAGRAMS}

The internal electrical wiring diagrams of the heat pump outdoor unit, indoor unit and electric heating coil are shown on the following pages.

For all external or field wiring see control wiring diagram, Figure 2-19. 


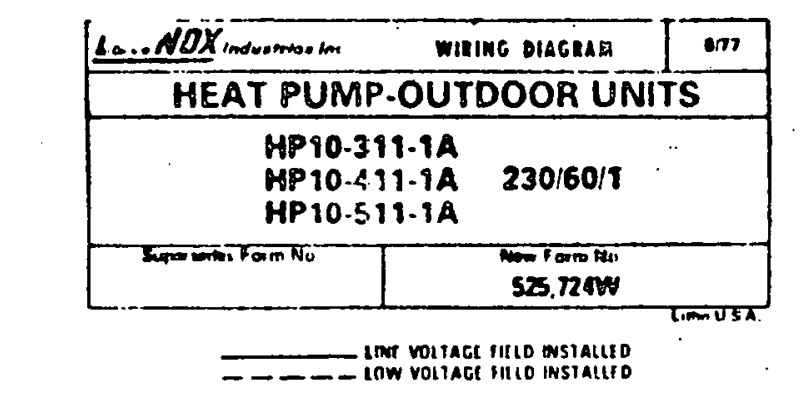

$?$
$\vdots$
0
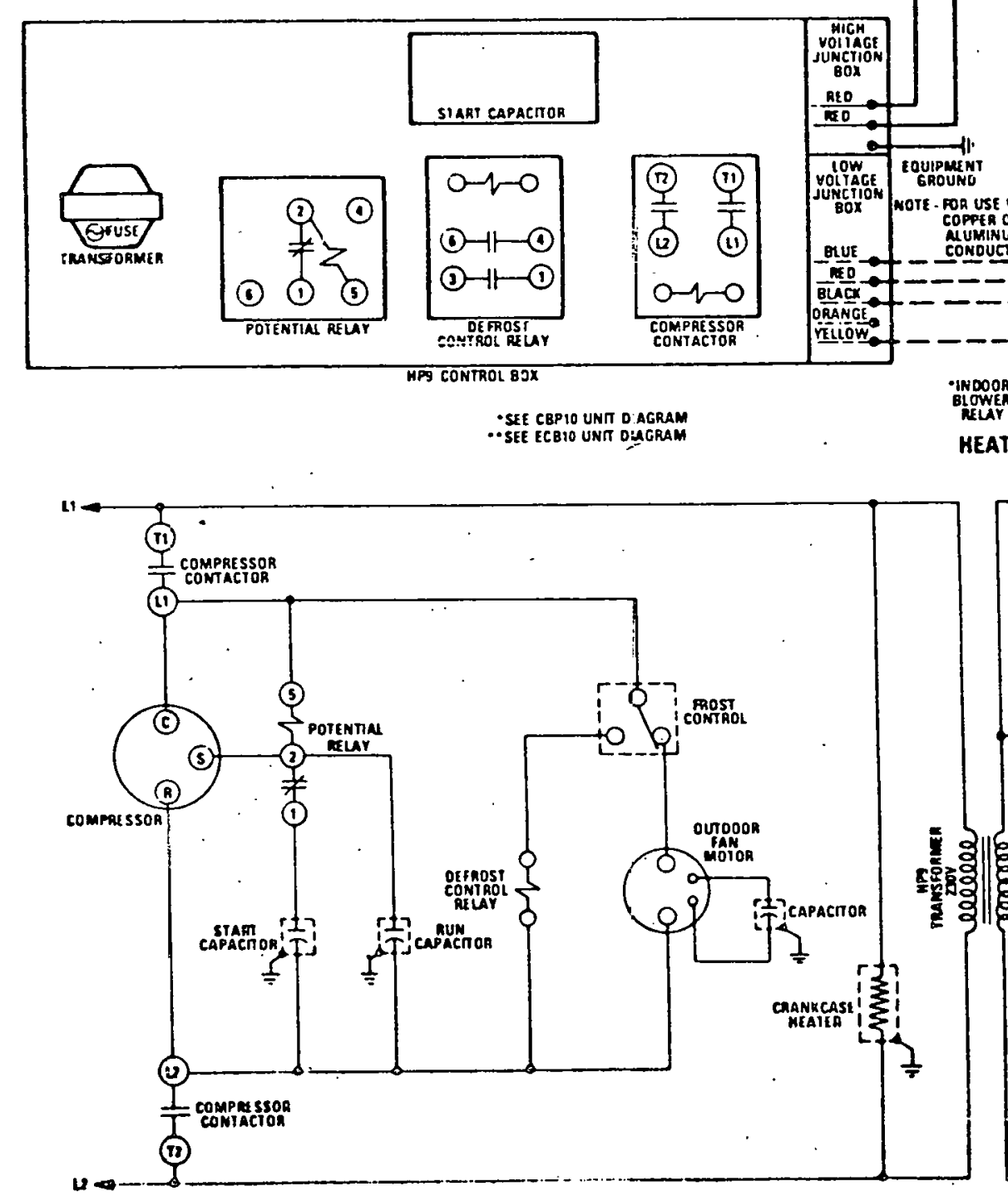

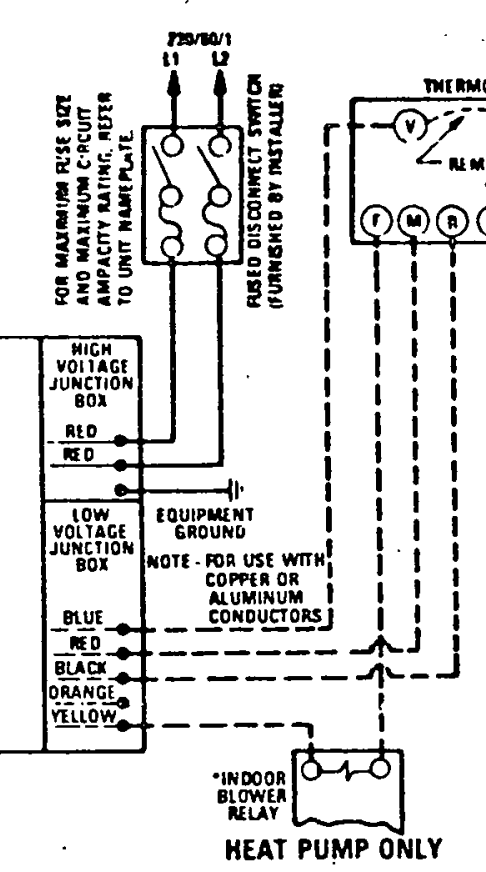

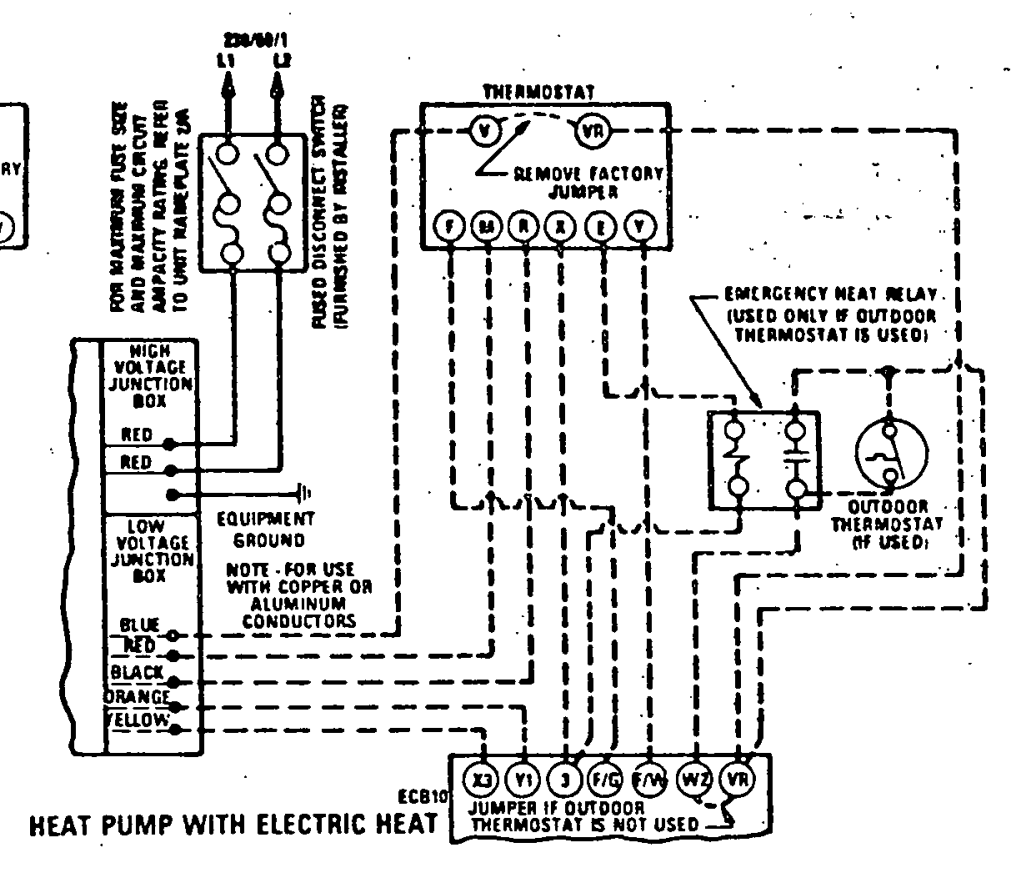

THERMOSTAT

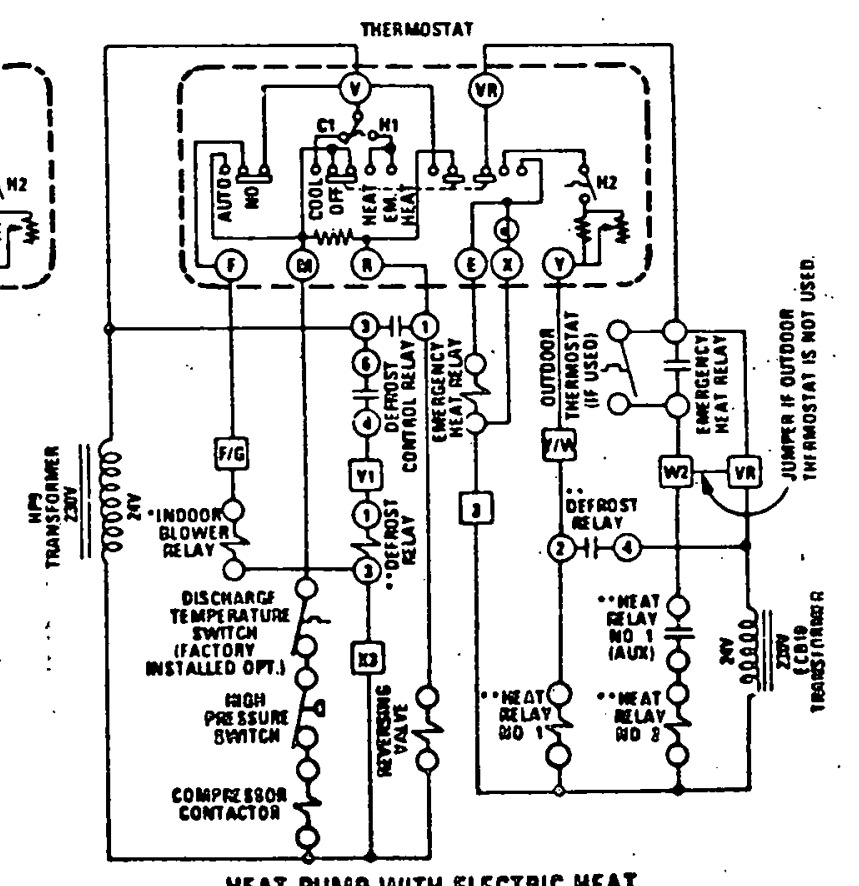




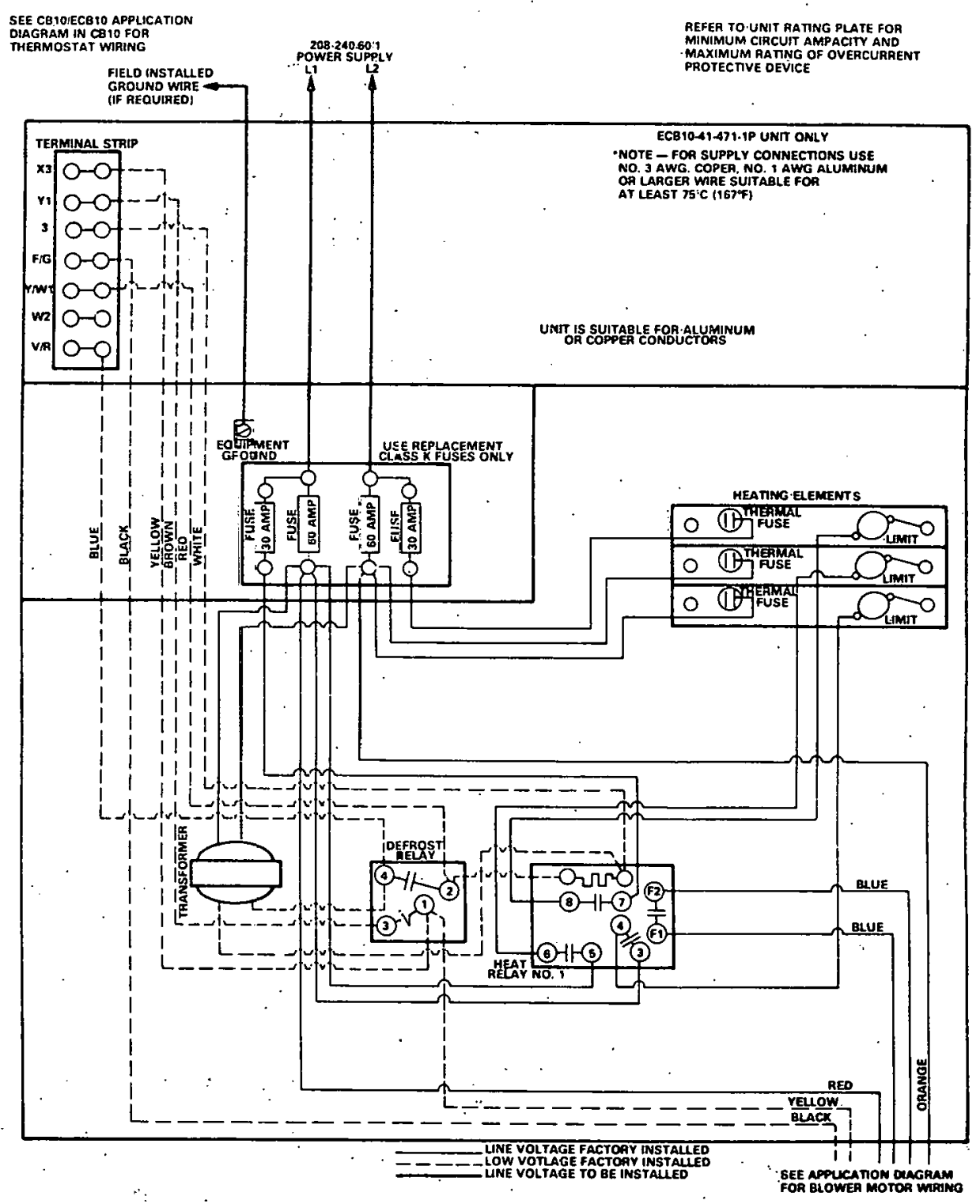

\begin{tabular}{|c|c|c|}
\hline 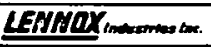 & WIENG OIAGRAM & 1075 \\
\hline \multicolumn{3}{|c|}{ HEATING UNITS - ELECTRIC } \\
\hline \multicolumn{3}{|c|}{$\begin{array}{l}\text { "ЕCB10-41-47.1-1P } \\
\text { ECB10-51/65-471-1P }\end{array}$} \\
\hline Super wodes Form No: & $\begin{array}{l}\text { Nom Form No- } \\
524,894 W\end{array}$ & \\
\hline
\end{tabular}



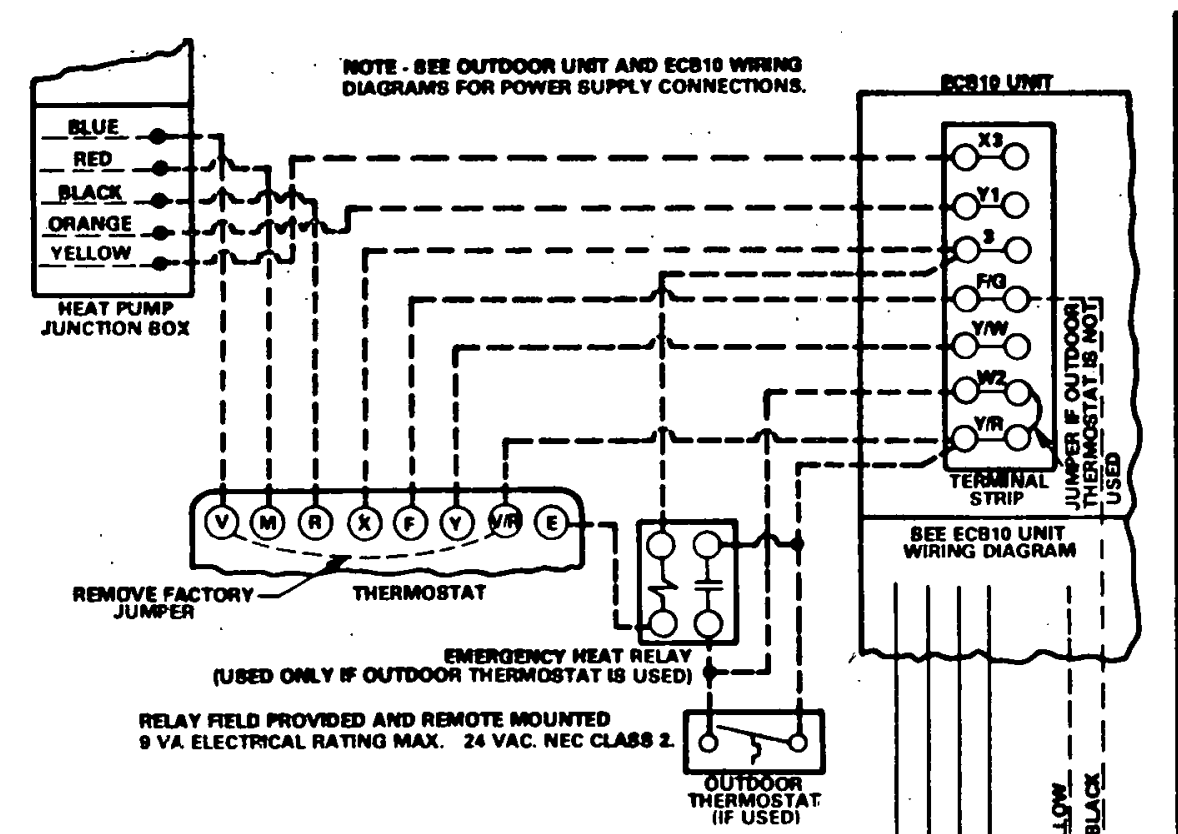

$\stackrel{?}{\mathfrak{n}}$
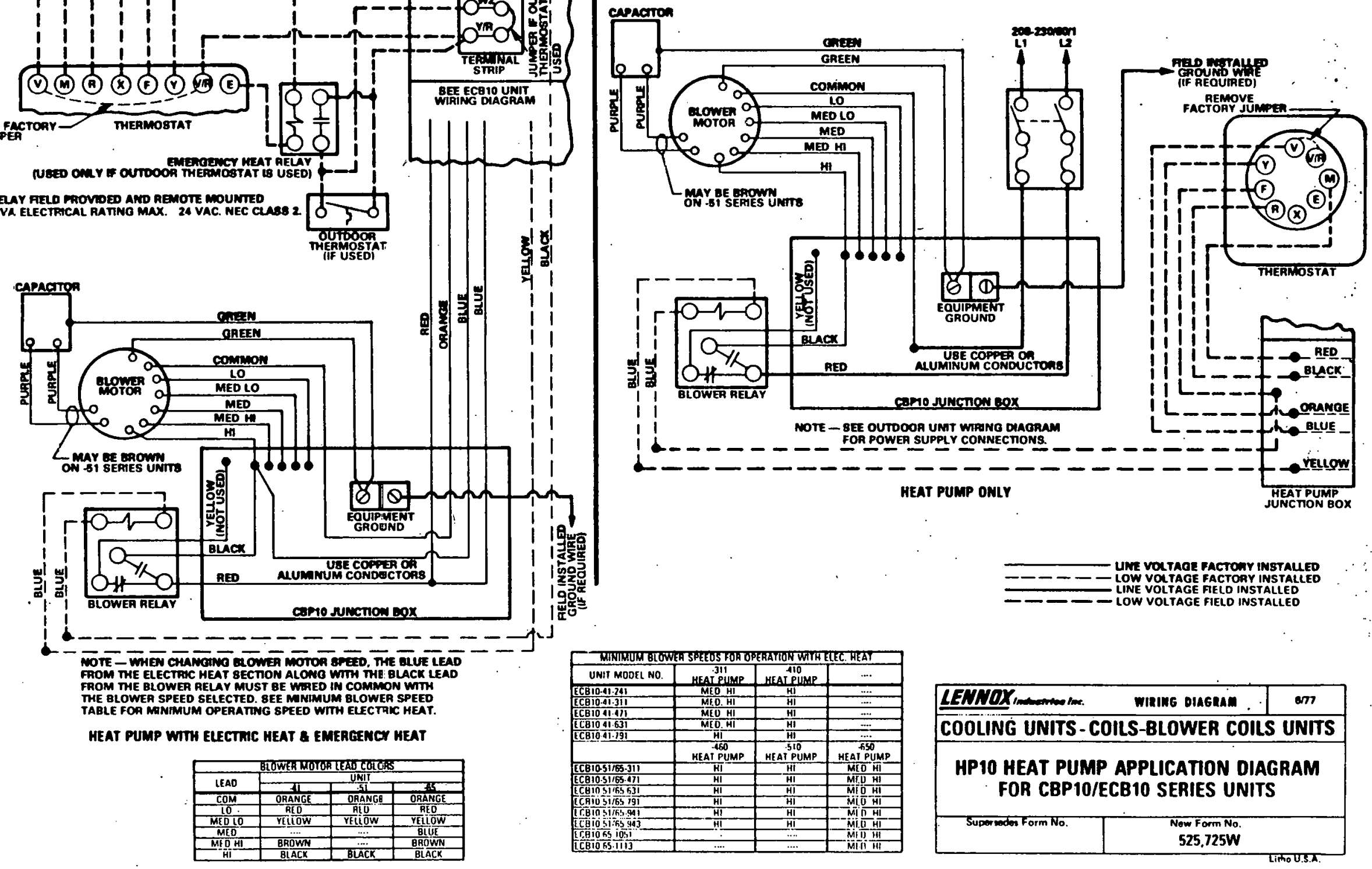

HEAT PUMP ONIY

UME VOLTAOE FACTONY INSTALED

----- L UW VOWTAGE VACTOAYY INSTALLED

- - LINE VOLTAGE FIELO INSTALLED

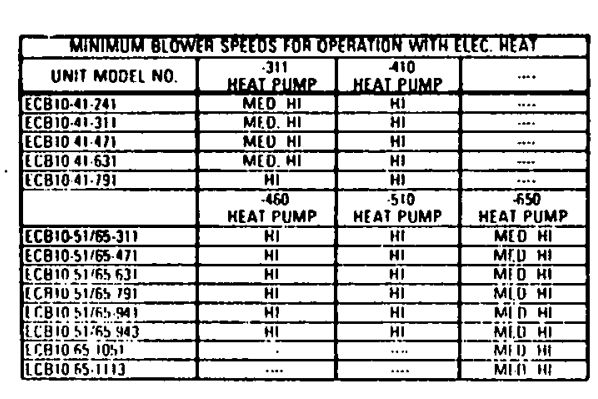

\begin{tabular}{|c|c|c|}
\hline LENWOX & MIRIMG DIAGRAM & an \\
\hline \multicolumn{3}{|c|}{ COOLING UNITS-COILS-BLOWER COILS UNITS } \\
\hline \multicolumn{3}{|c|}{$\begin{array}{l}\text { HP10 HEAT PUMP APPLICATION DIAGRAM } \\
\text { FOR CBP10/ECB10 SERIES UNITS }\end{array}$} \\
\hline Suporseder form No. & $\begin{array}{l}\text { Now Fow Nom No } \\
525,725 \mathrm{~W}\end{array}$ & \\
\hline
\end{tabular}


APPENDIX D

INSTALLATION OF DOMESTIC HOT WATER SUBSYSTEM

Electric Hot Water Heater

Tempering Valve

DHW Preheat Coil 


\section{ELECTR̈IC $\uparrow$ \\ WATER HEATER, Installing and Operating. Instructions}

THE WARRANTY ON THIS WATER HEATER IS INEFFECT ONLY MHEN THE HEATER IS INSTALLED AND OFERATED IN ACCORDANCE MIH THESE INSTRUCTIONS. THE MANUFACTRER OF THIS HEATER WIL NOT BE LIABLE FOR ANY DAMAGE RESULTING FROMFAILURE TO COMPLY WITH THESE INSTRUCTIONS. READ THESE INSTRUCTIONS THOROUGHIY OEFORE STARTING.

LOCATION: Solect a locotion accossible to mater lines and power upply where the floor is levol. Do not locote the heater whore woter lines could be aubjected to freezine remperotures. It is recommended thot the heoter be locoted ineor the center of aneotest hot woter usoge to prevent heat laes through the pipes. Locote the heoter so that access ponols and droin volves are accessible.

WARNING: Do not use or store cosoline or other flammeble Tiquids in the vicinity of this heoter.

THE HEATER SHOULD BE LOCATED IN AN AREA WHERE LEAKAGE OF THE TANK OR CONNECTIONS WILL NOT RESULT IN DAMAGE TO THE AREA AD SACENT TO THE HEA TER OR TO LOWER FLOORS OF THE STRUCTURE. WHEN SUCH LOCATIONS CAN'T QE AVOIDED, A SUITABLE DRAIN PAN SHOULD BE INSTALLED UNDER THE HEATER. SUCH PANS SHOULO BE AT LEAST 2" DEEP, HAVE A MINIMUM LENG TH AND A WIDTH AT LEAST 2" GREATER THAN THE DIAMETER OF THE HEATER, AND SHOULD BE PIPED TO AN ADEQUATE DRAIN.

NOTE: Before procending with the installation, close The moin woter wpply valve, cpen a water foucet to relieve the howse prosure and then clase the foucet.

\section{CAUTION}

DO NOT IURN ON ELECTRICAL CURRENT TO WATER HEATER UNTIL TANK HAS BEEN COMPLETELY FILLED WITH WATER. OPEN SEVERAL HOT WATER FAUCETS TO ALLOW AIR TOESCAPE FROM THE SYSTEM WHILE THE HEATER IS FILLING. THE HEATING E LEMEN TS WILL WURN OUT IF NOT IMMERSED IN WATER.

UPRIGHT MODELS, The hot and cold water commetiom ore identilied on the top of the heoter. Connect the hol and cold woter lines to the installed nipples using unions. Instoll o listed remperoture-presure relief volve in the opening on the side of the heoter.

UTILITY MODELS: The hot and cold water commection are identified on the side of the hearer. Connect the hot and cold woter lines to the instolled nipples using unions. Instoll a liated remporoture-preseure relief volve in the opaning on the side of the hooter.

TABLE TOP MODELS: The hot water outlet and cold waler intef ere identilied on the bock ponol of the hooter. Remove the porcalain top by sliding it formand and lifting it off the cebinet. Core should be teken in hondling the porealain top to prevent chipping of the porceloin. Remowe the four front penel scruws; two of the rop flanos. Check droin volve to moke ure that it is clowed. Remow the nop fibergla insulation to allow occes to the slumbing and electrical commetions. Connect the cold woter wpply line and hat woter outlet lines uding elbows, nipples and unions as shown in the diograms. Instoll a

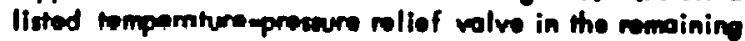
fitting. Roplace the top fiberolos invulation in is originol locotion.

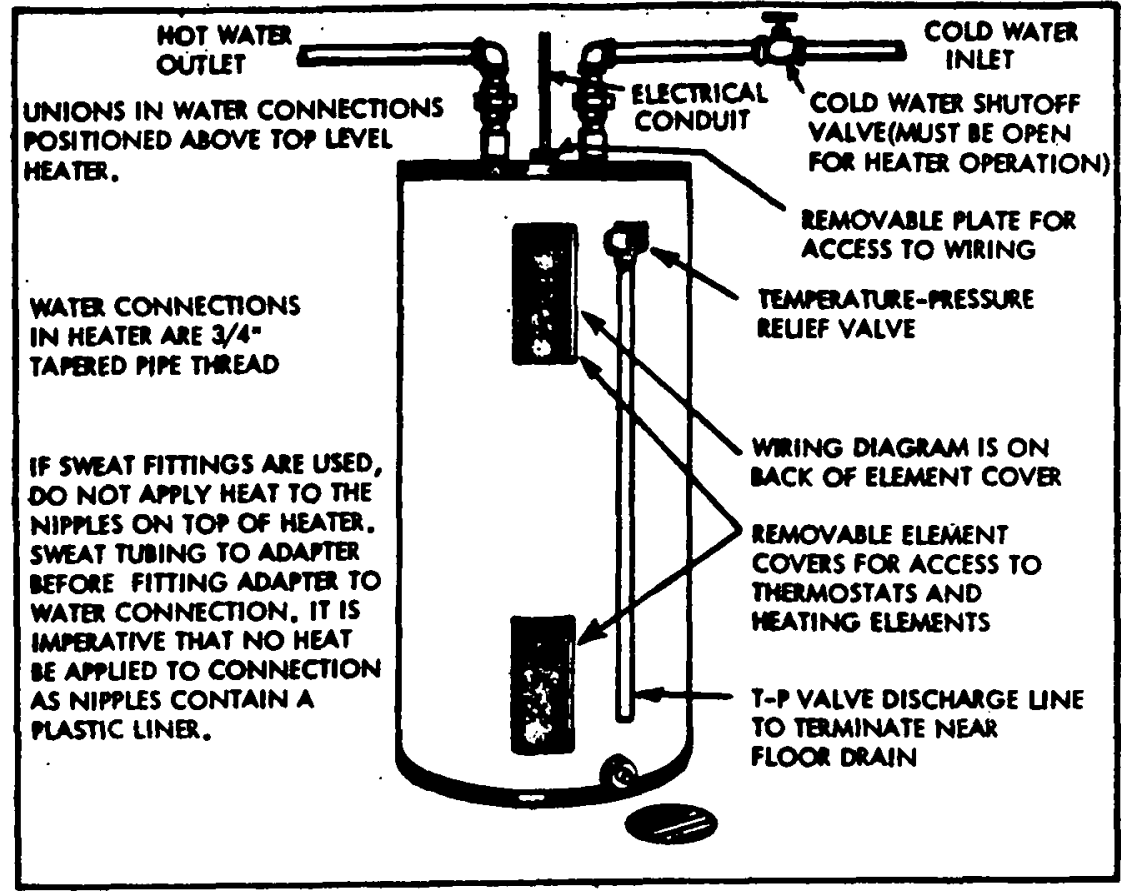

WATE CONNECTIONS IN

MEATER ARE 3/4" TAMERED mOT WATE

MPE TMREAD OUTLET

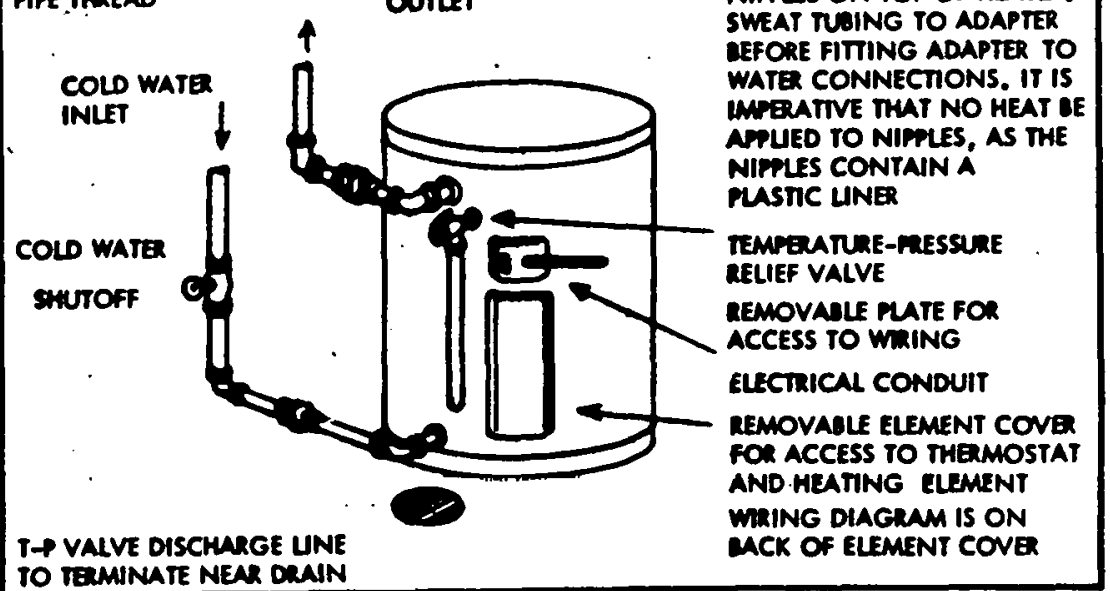

WATE CONNECTONS

IN MEATER ARE 3/4"

TARERED MFE THEAD

colo wate.

INLET
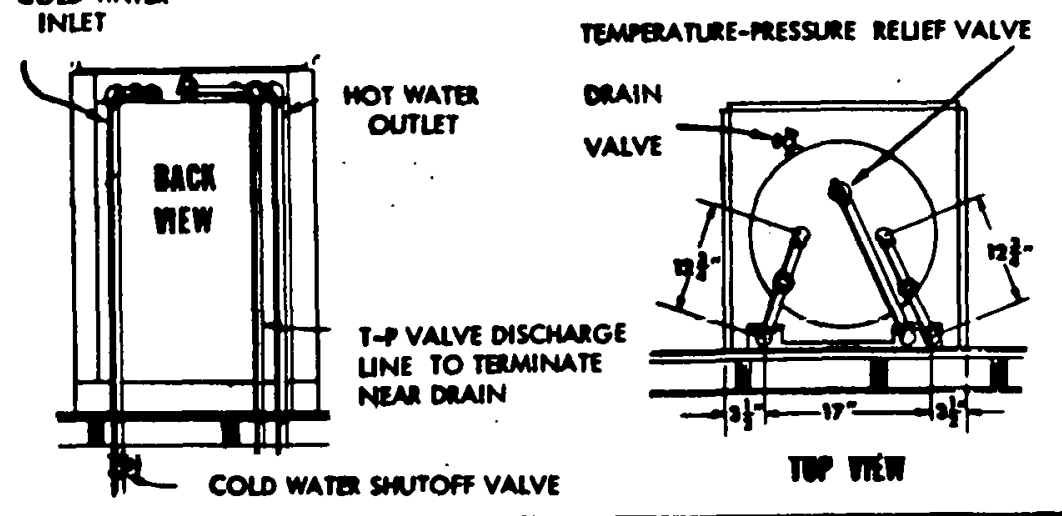

if SWEAT fITITINGS MRE USEd, DO NOT APPLY MEAT tO THE MIMALS ON TOP OF HEATER. SWEAT TUMING TO ADAPTER MEFOAE FITING ADAPTER TO WATER CONNECTION. IT IS MMEZATIVE THAT NO HEAT IE APPLIED TO CONNECTION AS NIPPLES CONTAIN A PLASTIC LINER.

$D-1$ 
Do not install a check velwe or other dovicos that would prevent rewerw flow of water unless required by becal codes. A claed optom will result and frequent eperation of the relief valve will occur.

The end of the relief pipe oponing should terminate noor the floor drain or other witable location not wbject to blocking or freezing. DO NOT thread, plus or cep the relief pipe opening. Leove an air gop of appraximately 6 inchos between the end of the relief pipe and the floor drain.

After the installation of all woter lines, open the moin woter supply volve and fill the heoter. Open soveral hot woter foucets to allow dir to excope from the system while the heoter is filling. When woter poseses throwh the fervents, close them and check for possible looks in the ontem.

\section{ELECTRICAL CONNECTIONS:}

NOTEl betore ony electical comections one mode, be sure thet the hooter is full of woter and thot the valve in the cold woter supply line is open. Check the roting plate and wiring diogram before proceeding. This electric woter hooter was built and wired in occordance with the Underwriters' Laboratories' testing opprovals requirements. The temperature limiling device of the monuol reset, trip-free type has been foctory instolled to internupt all ungrounded power supply conductors in the event of thermostat failure. Thermostats are factory set of $150^{\circ}$ F. and wired in accondonce with the wiring diagram fastened to the inside of the top access panel.

The dealer in your eres ordered this heater wired at the foctory to comply with existing area codes, but local utility codes moy require or allow other circuitry. Consult your local power, company to determine the correct electrical hook -up in onder to moet local utility and building codes and in order to obtain the most economical rotes. Also check to find out if you are required to obtain a permit before starting the installation. The following chart shows the recommended fuse size for the maximum hooter wottoge. The maximum wattoge and roted voltage are hown on the heater data plate.

\begin{tabular}{|c|c|c|c|c|c|c|c|}
\hline \multicolumn{8}{|c|}{ AECOMME NDED FOR AMPERAGE } \\
\hline MAX. & \multicolumn{3}{|c|}{ MAX. VOLTS } & \multirow{2}{*}{$\begin{array}{l}\text { MAX } \\
\text { WAItS }\end{array}$} & \multicolumn{3}{|c|}{ - MAX. VOLTS } \\
\hline WAIIS & IOUV & 2005 & $240 \mathrm{~V}$ & & $120 \mathrm{~V}$ & $208 \mathrm{~V}$ & $240 \mathrm{~V}$ \\
\hline 500 & 10A & $5 A$ & $5 A$ & 3500 & $40 A$ & $20 A$ & $20 A$ \\
\hline 1000 & $15 A$ & $10 A$ & $10 A$ & 4000 & & $25 A$ & $25 \mathrm{~A}$ \\
\hline 1250 & $15 A$ & IOA & $10 A$ & 4500 & & $30 A$ & $25 A$ \\
\hline 1500 & $20 A$ & $10 A$ & $10 A$ & 5000 & & $35 A$ & $30 \mathrm{~A}$ \\
\hline 2000 & $25 A$ & $15 A$ & $15 A$ & 5500 & & 35A & 35A \\
\hline 2500 & $\mathbf{3 0 A}$ & $15 A$ & $15 A$ & 6000 & & $40 A$ & $35 A$ \\
\hline 3000 & 35A & $20 A$ & $20 \mathrm{~A}$ & & & & \\
\hline
\end{tabular}

The heater mast be woll grounded. A green ground screw is provided of the electrical connection point for connecting a ground wire to the upright and roble top units. A green ground wire is provided at the electrical comnetion point on utility models for connections to a ground.

\section{OPERATION:}

NOTE: DTore closing the switch to allow electric surrent to flow to the heater, make certoin that the heoter is full of water and that the cold woter inlet volve is open. Complete foilure of the heeting elements will rewlt if they ore not completely immersed in water at all rimes. When the ewitch is closed, the operotion of this electric water hooter is cutomatic.
The temporature of the water cen be chonged by edjusting the thermostak. Before eny work is done on the heater, disconnact all power to the hooter by opening the switch of the moin electrical ponel. Remove the access panals, or front ponol on Table Tops, fold the insulotion outwond awoy from the controls. Sef the thermostats to the desired woter temparaturn using a screw diver to move the thermostat pointer, roplace the insulation making sure that the controls ore well covered and that the plestic terminal shield has not been disploced; then replace the access panel, of front penel. The hapter is now reody for operation and the main switch can be closed.

When neceseary to completely drain the heoter, shut off the electric power supply to heoter, close cold water inlet valvo, open a hot woter foucet to allow oir to enter the sratem and apan the drain valve, which is threaded to receive a standand hose coupling. On Table Top models, the front ponel must be removed to goin occes to the drain volve.

MAINTENANCE: Shut off the electric power whonever the water Eupply is tumod off.

Shut off the electric power, woter supply and drain the henter completely to prevent freazing whenever the building is leff unoccupied during the cold weother months.

In order to insure officient operotion and long tank life, drain the heoter through the drain volve until woter nuns clear. Droin it af loost once a month. Failure to do this may result in noisy operation and lime and sodiment build up in the bottom of the rank. At the same rime, check the remparature-pressure relief valve. by roising the the lever at the top of this valve to moke certoin that woterwors are clear.

SERVICE: The monuol resert, trip-free temporature limiting devices on This heater will cut off all power to heater if temperature of woter exceads $190^{\circ} \mathrm{F}$. If there is no hot water afler a recosonoble period of iime, shack the main fun box. In the ovent that the fuses huve not blown, coll o sorviceman; hov him check the entire circuit including the elements and thermossats before resatting the temperoture limiting device. Heoter must be disconnected from power supply before servicing switch, Consult the plumber or electric service compony in your area for all envice, mplacement parts or any questions you might hove regording this heoter. Insist on factory inspected ond approvod replocement parts.

REMOVAL OF the magnesium aNOde WILl terminate the WARRANTY.

READ THE WARRANTY ATTACHED TO THIS WATER HEATER FOR A FULL EXPLANATION OF THE TIME PERIOD THAT PARTS AND HEATER ARE WARRANTED. 


\section{INSTRUCTIONS FOR INSTALLING \\ WATTS No. 7OA SERIES \\ Adjustable Water Tempering Valves}

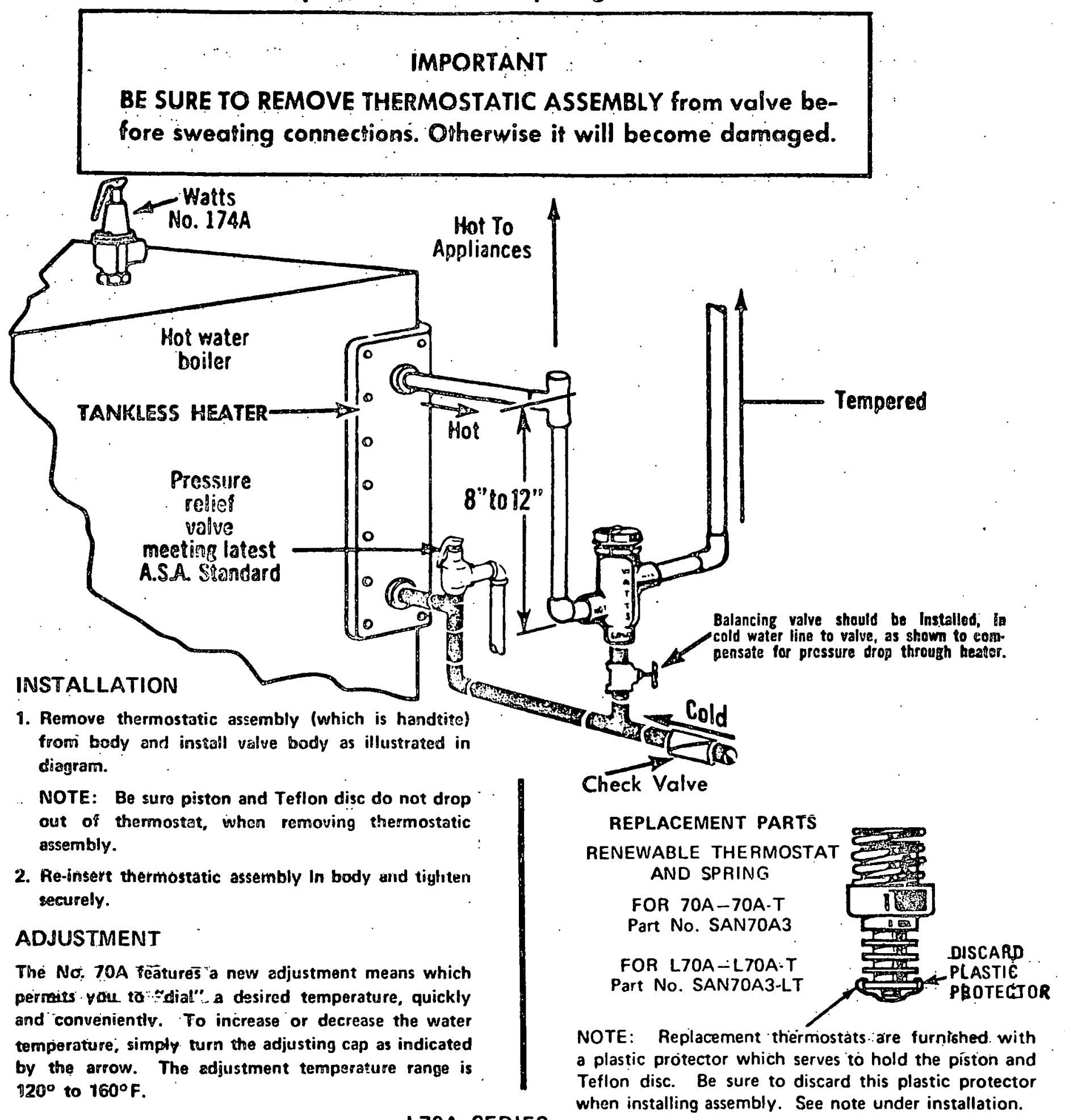

\section{L70A SERIES}

NOTE: For lower tempered water requiremonts at or below $130^{\circ} \mathrm{F}$., use low temperature Model $170 \mathrm{~A}$ Series which prosides adjustment temperature range between $100^{\circ} \cdot 130^{\circ} \mathrm{F}$.
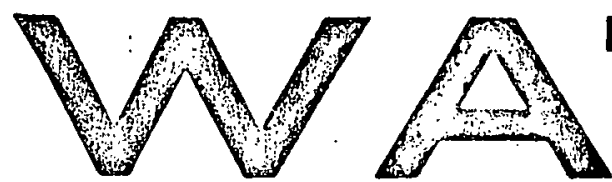

WATTS REGULATOR COMPANY
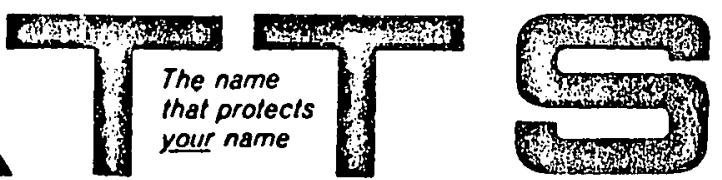

LAWRENEE, MASS., U.S.A. 


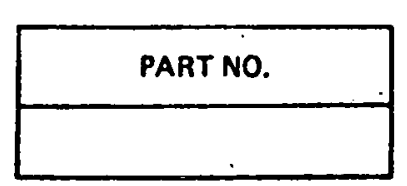

jpecifications

Vaterial - copper alloy-ASTM-B359-B111 ength - approx. 33 fee!

vo. of Coils -17

Joil I. D. $-53 / 4^{\prime \prime}\left(+1 / 8^{\prime \prime}\right)$

rubing Diam. - nom. $3 i 4^{\prime \prime}$

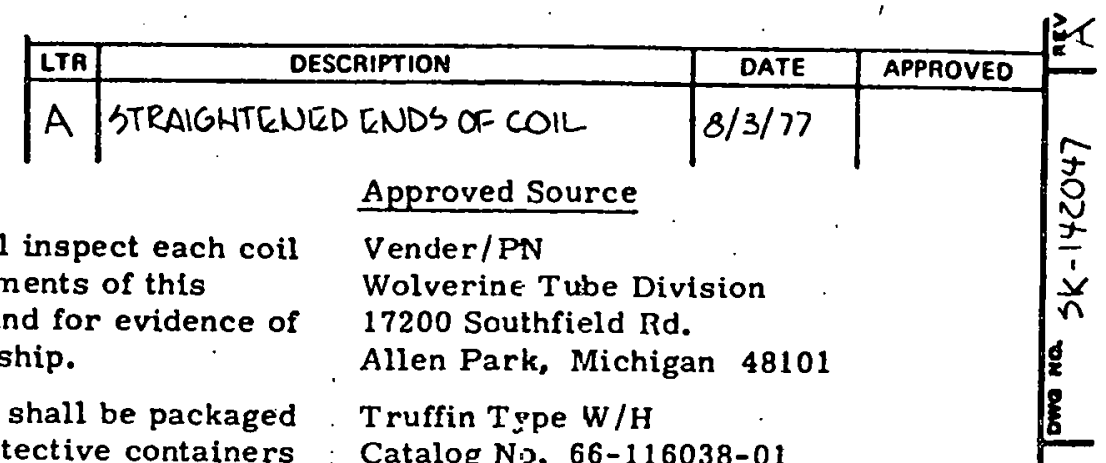

NC.TES

1) The seller will inspect each coil to the requirements of this specification and for evidence of poor workmanship.

2) The heat coils shall be packaged in suitable protective containers that prevent damage to coil when shipped by United Parcel Service.

Catalog No, 66-116038-01 With type 1 ends

PROVIDE PLASTIC CAPS TO PROTECT ENDS OF COIL.

TOTAL COIL LENGTHA APROX. 33 FT.

COLL ID APROX. $53 \frac{34}{4}$

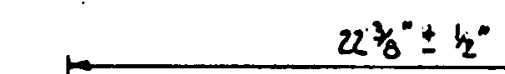

$18 \varepsilon^{\prime \prime} \pm k^{\prime \prime}$

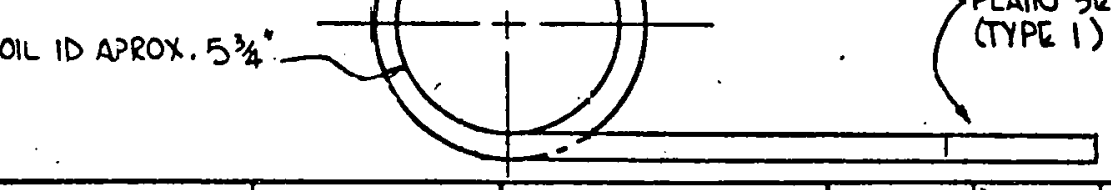

\begin{tabular}{|c|c|c|c|c|c|}
\hline \multirow{4}{*}{ 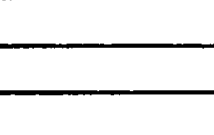 } & & \multirow{2}{*}{\multicolumn{2}{|c|}{$\begin{array}{l}\text { TOL ERANCES UNLESS } \\
\text { NOTED OTHERWISE }\end{array}$}} & \multicolumn{2}{|c|}{ DRAFTSMAN Donahue $8 / 3 / 7$} \\
\hline & & & & \multirow{3}{*}{\begin{tabular}{|l|} 
CHECKEA \\
DEV ENGA \\
ENGRG MGT \\
\end{tabular}} & \\
\hline & & \multirow{2}{*}{$\begin{array}{l}x \\
x x \\
x \times x\end{array}$} & \multirow{2}{*}{ 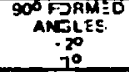 } & & \\
\hline & & & & & \\
\hline . & . & \multirow{4}{*}{\multicolumn{2}{|c|}{ MATERIAL }} & & \\
\hline & & & & \multicolumn{2}{|c|}{ CONTAACT NO. } \\
\hline & & & & \multicolumn{2}{|c|}{ SOURCE CONTRO } \\
\hline NEXT ASSY & USED ON & & & & \\
\hline APP & & \multicolumn{2}{|c|}{$=I N I S H-S E E$ NOTE } & \multicolumn{2}{|l|}{. } \\
\hline
\end{tabular}
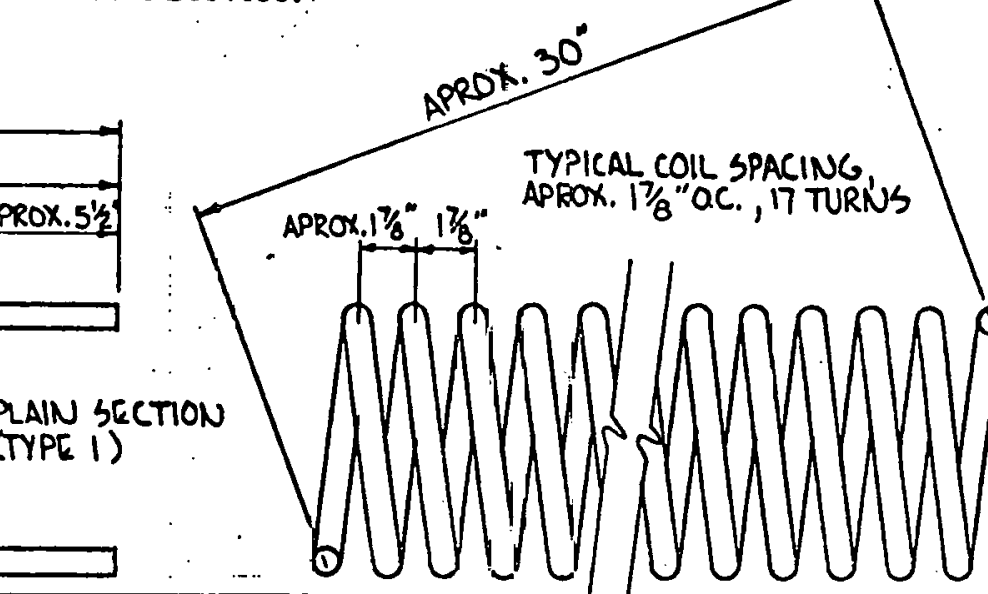

HOAEYWELL ENERGY RESOUACES CENTER INC. MINNEAPOLIS, MINN. 55413

HOT WATER COIL

\section{SIZE CODE IDENT MG. DPAHING NO.}

\begin{tabular}{l|l|l}
$A$ & 55513 & $5 K-142047$
\end{tabular}

SCALE NONE

| CONTROLIA! TI


APPENDIX E

ENERGY TRANSPORT SUBSYSTEM 
Energy Transport Module Replacement Parts

\begin{tabular}{|c|c|c|c|c|}
\hline No. & ITEM & MANUFACTURER & TYPE/PART & QUANTITY \\
\hline 1 & Pump $i$ & Bell\& Gossett & $60-11 \mathrm{~S}, 11 / 4 \mathrm{AA}$ & 1 \\
\hline 2 & Pump $2 \& 3$ & Bell \& Gossett & $\mathrm{PR}-11 / 4,1 / 6 \mathrm{hp}$ & 2 \\
\hline 3 & Heat Exchanger & - Honeywel1 & SK-142187 & 1 \\
\hline 4 & Expansion Tank & Amtrol & 30, Diaphragm & 1 \\
\hline 5 & Air Separator & Amtrol & $444-1 \quad 1 / 4$ & 1 \\
\hline 6 & Air Vent & Amtrol & 690 & 1 \\
\hline 7 & Air Bleed & Hammond & 1/8 Radiator & 2 \\
\hline 8 & Relief Valve & Be11\& Gossett & $480-45$ psi & 1 \\
\hline 9 & $\begin{array}{l}\text { Cọntrol Valve, Dua1 } \\
\text { Diverting }\end{array}$ & Honeywe 11 & $\begin{array}{l}\text { V4331-A1003 } \\
\quad(115 \mathrm{VAC})\end{array}$ & 1 \\
\hline 10 & $\begin{array}{l}\text { Circuit Setter Balancing } \\
\text { Valve. }\end{array}$ & Bell\& Gossett & $\mathrm{CB}-1 \quad 1 / 4$ & 3 \\
\hline 11 & SDA Sensor Wells & Mueller & Bronze, $11 / 4$ & 4 \\
\hline 12 & Lift Check Valve & Bell \& Gossett & $B A-11 / 4$ & 1 \\
\hline 13 & Swing Check Valve & Stockham & $\mathrm{B}-309-1 \quad 1 / 4$ & 2 \\
\hline 14 & Drain/Fill Valve & Hammond & $710-3 / 4$ & 1 \\
\hline 15 & Ball Valve & Hammond & Sweat-1 $1 / 4$ & 1 \\
\hline 16 & Strainer & Strong & $S-1 \quad 1 / 4$ & 1 \\
\hline 17 & Low Level Indicator & F.W. Murphy & $\begin{array}{l}20-\ddot{P C}, 50 \mathrm{psi} \\
24 \text { VAC }\end{array}$ & 1 \\
\hline 18 & Indicator Lamp & & $24 \mathrm{VAC}$ & i \\
\hline 19 & Solar Control Panel & Honeywe 11 & SK-142183 & 1 \\
\hline
\end{tabular}




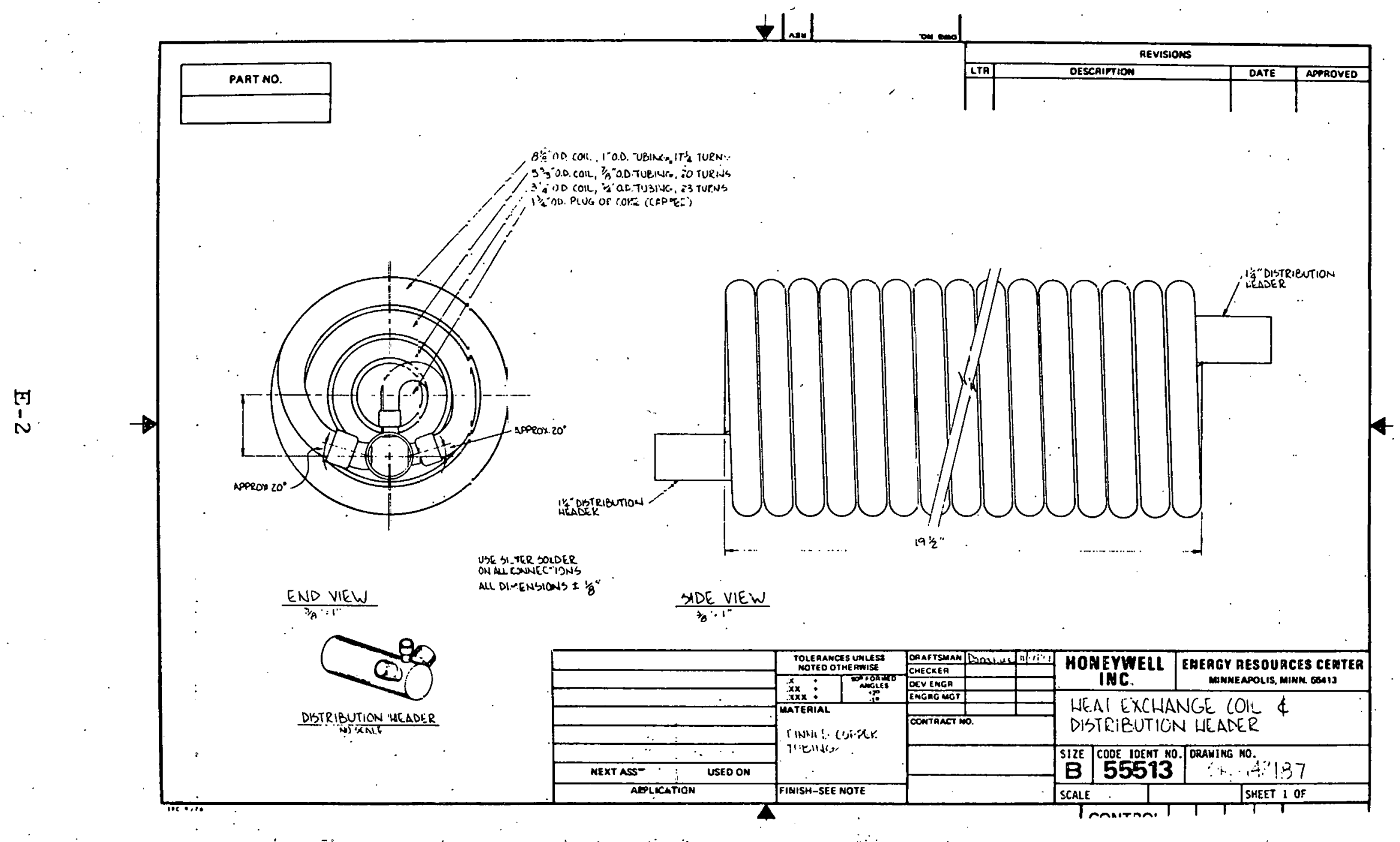


Bell \&: Gossett instruction sheet $\mathrm{S} 16946$ revision 3 pertaining to PD Boosters \& Series "60" In-Line Centrifugal Pumps installation and operation instructions has been removed due to copyright. 
Bell \& Gossett submittal A-120 revision 9 pertaining to Iron \& Bronze Booster Pump has been removed due to copyright. 
Bell \& Gossett instruction manual sheet $\mathrm{S} 17630$ replaces SD-1239-CA revision 4 pertaining to Booster Circulating Pumps installation, operation and service instructions has been removed due to copyright. 


\section{Senserion}

\begin{tabular}{|c|c|c|c|c|c|c|c|c|c|c|c|c|c|c|c|c|c|c|c|}
\hline \multirow{4}{*}{$\begin{array}{l}\text { OOILER } \\
\text { NET } \\
\text { OUTPUT } \\
\text { IN 1OOO's } \\
\text { OF } \\
\text { BIU/HR }\end{array}$} & \multicolumn{8}{|c|}{ 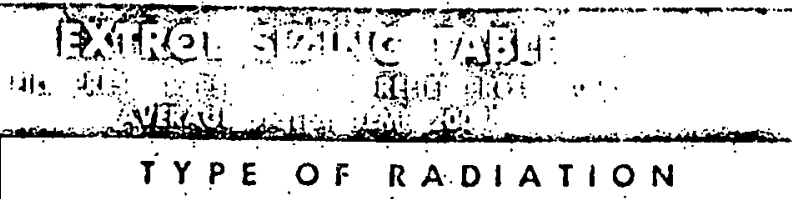 } & \multicolumn{11}{|c|}{$\begin{array}{l}1310 \text { d } \\
\text { SYSTEM CONTENT IN GALIONS }\end{array}$} \\
\hline & \multirow{2}{*}{\multicolumn{2}{|c|}{$\begin{array}{l}\text { Finned Tube } \\
\text { Baseboard or } \\
\text { Radiant Panel }\end{array}$}} & \multirow{2}{*}{\multicolumn{2}{|c|}{$\begin{array}{l}\text { Convectors or } \\
\text { Unit Heaters }\end{array}$}} & \multirow{2}{*}{\multicolumn{2}{|c|}{$\begin{array}{l}\text { Radiators- } \\
\text { Cast Iron }\end{array}$}} & \multirow{2}{*}{\multicolumn{2}{|c|}{$\begin{array}{l}\text { Basebogrd } \\
\text { Cạst Iron }\end{array}$}} & \multirow{2}{*}{$\begin{array}{l}\text { Avorage } \\
\text { System } \\
\text { Temp. Of }\end{array}$} & \multicolumn{2}{|c|}{$\begin{array}{c}\text { Extrot Mo } \\
15\end{array}$} & \multicolumn{2}{|c|}{$\begin{array}{c}\text { Extrol Model } \\
30\end{array}$} & \multicolumn{2}{|c|}{\begin{tabular}{|c} 
Extrol Model \\
60
\end{tabular}} & \multicolumn{2}{|c|}{\begin{tabular}{|c|} 
Extrol Model \\
90
\end{tabular}} & \multicolumn{2}{|c|}{$\begin{array}{l}\text { Extrol Mode } \\
\text { SX-30 }\end{array}$} \\
\hline & & & & & & & & & & $5 w$ & cs & sw & CS & $s w$ & Cs & sw & CS & sw & Cs \\
\hline & $s w$ & CS & sw & CS & sw & CS & SW & 3 & 100 & & 133 & & 305 & & 500 & & 7334 & & 1102 \\
\hline 25 & 15 & 15 & 15 & 15 & 15 & 15 & 15 & 15 & 110 & & 101 & & 232 & & 380 & & 557 & & 835 \\
\hline 50 & 15 & 15 & 15 & 15 & 15 & 30 & 15 & & 120 & & 80 & & 183 & & 300 & & 440 & & $660^{\circ}$ \\
\hline & & & & 10 & 12 & 20 & 13 & 30 & 130 & & 65 & & 149 & & 244 & & 358 & & 537 \\
\hline 75 & 15 & 30 & 15 & 30 & 30 & 30 & 30 & 60 & 140 & & 54 & & 125 & & 204 & & 298 & & 447 \\
\hline 100 & 15 & 30 & 15 & 30 & 30 & 60 & 30 & 60 & 150 & 62 & 47 & 141 & 106 & 230 & 174 & 338 & 256 & 473 & 384 \\
\hline 125 & 15 & 30 & 30 & 60 & 30 & 60 & 30 & 90 & 160 & 58 & 40 & 134 & 92 & 219 & 150 & 321 & 220 & 449 & 330 \\
\hline 150 & 30 & 30 & 30 & 60 & 30 & 90 & 60 & 90 & 170 & 55 & 34 & 127 & 78 & 208 & 128 & 306 & 187 & $42 B$ & 281 \\
\hline 175 & 30 & 60 & 30 & 60 & 60 & $5 x-30$ & 60 & $5 x-30$ & 180 & 53 & 30 & 121 & 68 & 198 & 111 & 291 & 163 & 407 & 245 \\
\hline 200 & 30 & 60 & 60 & 60 & 0 & & 6 & & 190 & 51 & 26 & 116 & 60 & 190 & 98 & 278 & 144 & 389 & 216 \\
\hline & & & & & & 30 & & & 200 & 49 & 23 & 111 & 52 & 182 & 86 & 266 & 126 & 372 & 189 \\
\hline 250 & 30 & 60 & 60 & 90 & 60 & $5 x \cdot 30$ & 90 & $5 x-40$ & 210 & 47 & 21 & 106 & 48 & 174 & 78 & 256 & 114 & 358 & 171 \\
\hline 300 & 60 & 90 & 60 & $5 X-30$ & 90 & $5 x-30$ & 90 & $5 x-40$ & 220 & 45 & 19 & 102 & 43 & 167 & 71 & 246 & 103 & 344 & 155 \\
\hline 350 & 60 & $5 x \cdot 30$ & 60 & $5 X-30$ & 90 & $5 x-40$ & $5 x-30$ & $5 \times .60$ & 230 & 43 & 17 & 98 & 39 & 161 & 64 & 236 & 94 & 330 & 141 \\
\hline 400 & 60 & $5 x-30$ & 90 & $5 \times .40$ & $5 x-30$ & $5 x-40$ & $5 x-30$ & $5 \times-60$ & 240 & 41 & 16 & 95 & 35 & 155 & 58 & 228 & 86 & 316 & 129 \\
\hline
\end{tabular}

SW indicates Summer-Winter hook up where boiler is used for heating, and supplying domestic hot water. Minimum hoiler water temp. of $150=F$. is required CS indicates cold start hook up where hoiler is use for heating only. MAXIMUM WORKING PRESSURE 75 PSI - OPERATING TENP. 40 $=15 \mathrm{EX}-\mathrm{TROL}=109 \mathrm{FILL}-\mathrm{TROL} \quad \neq 30 \mathrm{EX}$-TROL $=110 \mathrm{FILL}-\mathrm{TROL} \quad \# 60$ EX-TROL $=111$ FILL-TROL

\section{Dimensional Data}

EX-TROL TANKS

\begin{tabular}{|c|c|c|c|}
\hline $\begin{array}{c}\text { Model } \\
\text { No. }\end{array}$ & $\begin{array}{c}\text { Diameter } \\
\text { lathes }\end{array}$ & $\begin{array}{c}\text { longth } \\
\text { Inches }\end{array}$ & $\begin{array}{c}\text { Shipping } \\
\text { Wr, lhs. }\end{array}$ \\
\hline 15 & 8 & $111 / 2$ & $b$ \\
30 & 11 & 14 & 9 \\
60 & 11 & 23 & 14 \\
90 & 15 & 21 & 23 \\
\hline
\end{tabular}

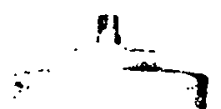

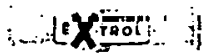

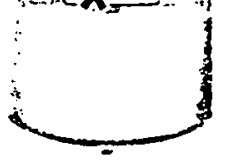

if

EX-TROL WITH FILL-TROL

\begin{tabular}{|c|c|c|c|}
\hline $\begin{array}{c}\text { Model } \\
\text { No. }\end{array}$ & $\begin{array}{c}\text { Diamotor } \\
\text { Inches }\end{array}$ & $\begin{array}{c}\text { Lenglh } \\
\text { Inches }\end{array}$ & $\begin{array}{c}\text { Slippiny } \\
\text { Wt. lbs. }\end{array}$ \\
\hline 104 & 8 & $14 \frac{1}{2}$ & 6 \\
110 & 11 & 17 & 10 \\
111 & 11 & 26 & 15 \\
112 & 15 & $231 / 2$ & 24 \\
\hline
\end{tabular}

\section{EX-TROL COMBINATION PACKAGES}

\begin{tabular}{|c|c|c|c|c|}
\hline \multirow{2}{*}{$\begin{array}{c}\text { Model } \\
\text { No. }\end{array}$} & \multicolumn{3}{|c|}{ I N C L U D E S } & \multirow{2}{*}{$\begin{array}{c}\text { Shipping } \\
\text { Wh. Lbs: }\end{array}$} \\
\cline { 2 - 5 } & EXTROL & Purger * & Vent & \\
\hline 1500 & 15 & $l^{\prime \prime}$ & & 9 \\
3000 & 30 & or & $\# 700$ & 13 \\
6000 & 60 & $11 / 4^{\prime \prime}$ & & 19 \\
\hline
\end{tabular}

*Specify type and size required

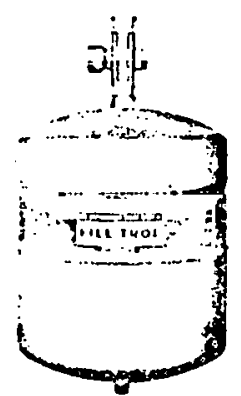

FILL-TROL COMBINATION PACKAGE

\begin{tabular}{|c|c|c|c|c|}
\hline \multirow{2}{*}{$\begin{array}{c}\text { Model } \\
\text { Ho. }\end{array}$} & \multicolumn{3}{|c|}{ INCLUDES } & \multirow{2}{*}{$\begin{array}{l}\text { Shipping } \\
\text { W. Lbs. }\end{array}$} \\
\hline & FILL-TROL & Purger * & Vent & \\
\hline $\begin{array}{l}109 . P \\
110 . P \\
111 . P\end{array}$ & $\begin{array}{l}109 \\
110 \\
111\end{array}$ & $\left\{\begin{array}{c}1 \text { "or } 11 / 4 " \\
1 \text { "or } 11 / 4 " \\
11 / 4\end{array}\right.$ & $\# 700$ & $\begin{array}{l}11 \\
14 \\
18\end{array}$ \\
\hline
\end{tabular}

- Specify type and size required

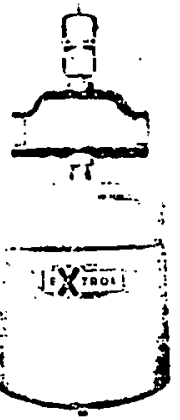

DISTRIBUTED BY

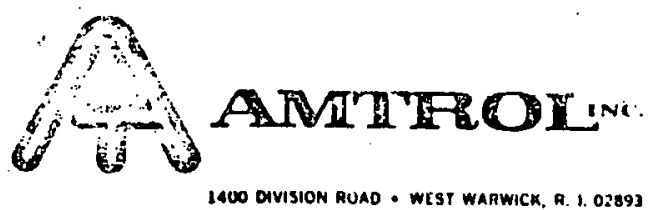




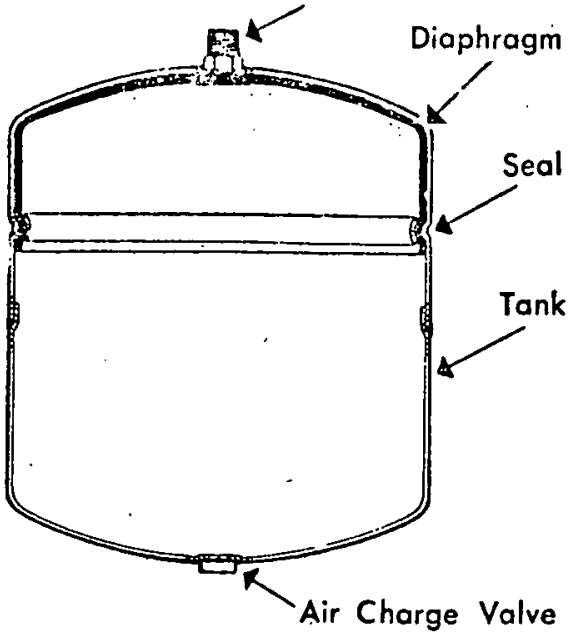

Fig. 2 Extrol tank construction
The EX-TROL Tank is a modern, pressurized diaphragmtype exparsion sank for all hot water heating systems.

It is of welded steel construction; compact and neat in appearance. A rugged, flexible diaphragm of a material specially compounded for long life in hydronic service is the heart of the EX.TROL tank.

This diaphragm separates system water from the (standard 12-lb.) air charge, assuring a permanent air cushion. Because the diaphragm permits the tank to be pressurized, the EX-TROL tank can be smaller than conventional units.

The EX-TROL Tank may be installed into a tee or any other suitable tapping anywhere on a hot water heating system.

It may also be remotely located and piped to convenient point on the system.

An ideal EX-TROL installation is to screw it. into the bottom of an American Air Purger. A single $1 / 2$ " nipple serves as both pipe connection and mounting.

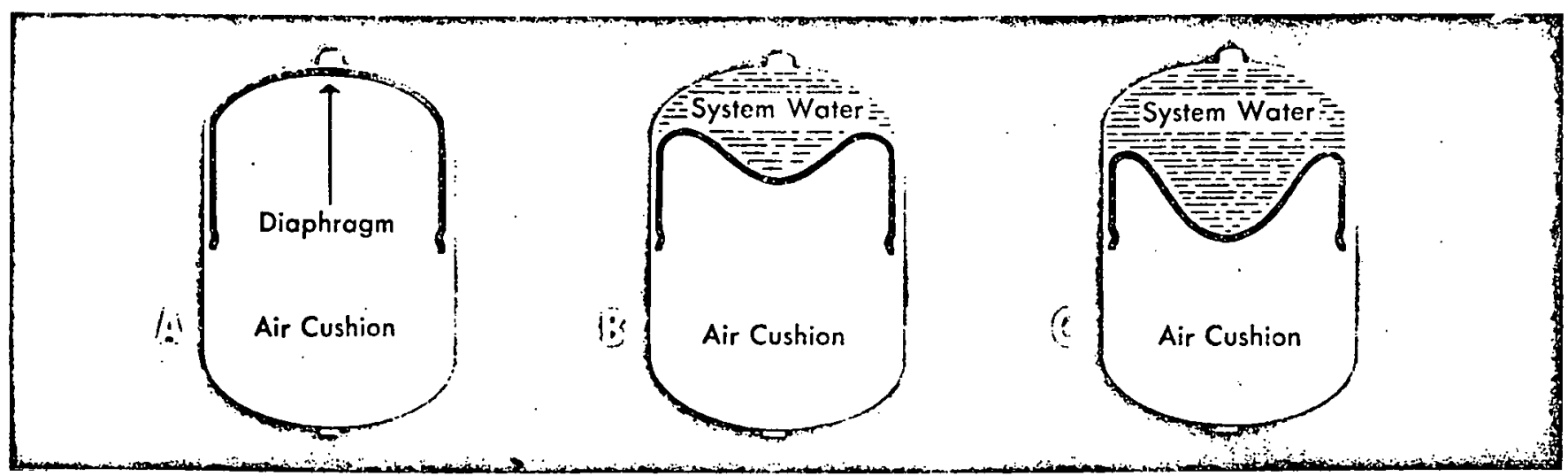

Fig. 3 Extrol tank operation

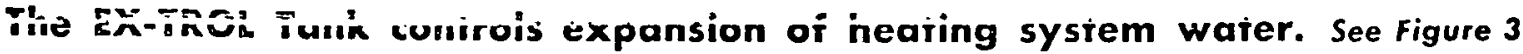

A. When the system is first filled to the setting of the automatic fill valve, no water enters the EX-TROL Tank because of the charge pressure behind the diaphragm.

B. When the system comes up to temperature, the EX-IROI tank receives the expanded volume of water.

C. When the boiler water temperature rises to its maximum, the EX-TROL diaphragm simply flexes against the air cushion.

\section{The American Air Purger continuously separates air from heating system water.}

It is a one-piece cast iron chamber with two passages through which boiler water flows. Internal contours and baffles are designed for low flow resistance characterislics und efficient scparation of the air from the water.

The Air Purger should be installed horizontally on the main as close to the boiler as possible. It must be installed so that water flows through it in the direction indicated by the arrow.

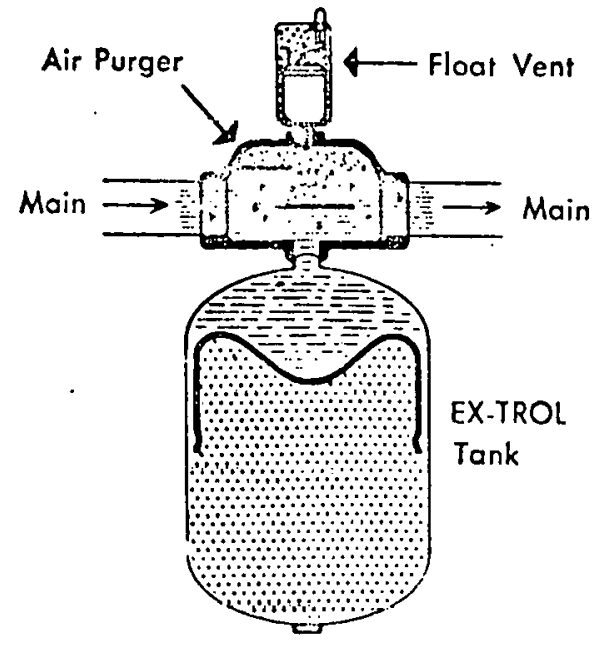

Fig. 4 System view illustrating continvous purging and venting.
All models have tappings for installation of \#700 Float Vents to provide complete continuous purging and venting. Spare tappings are also provided for easy mounting of an EX-TROL for expansion control or FILL-TROL for combining automatic fill valve and expansion control.

\section{EX-TROL systam venting}

After initial purging and venting of air from the system more air will be released from the water as it is healed. The American \#700 float Vent is an advanced type valve designed for venting all hydronic heating and cooling systems. It has a unique construction which insures: Fastest Venting - Positive shut off - Venting through the complete pressure range $(0.45)$ - Long consinuous operation - Trouble free performonce - No spitting or unsightly stains from leaking. No separate air chamber is required.

Even with Air Purger and Float Vent installed on the main or mains, it is recommended the American $\$ 700$ Float Vent to be installed on each return at the elbow that drops to the circulator.

While seldom reciuis.d, it is also recommended that manual (key or coin type) air vents be installed at high points on the radiation.

$\mathrm{E}-7$. 
This product represents the most recent development in providing for the expansion of water in a hydronic heating system.

The unique proven design of this tank, incorporating a flexible diaphragm that keeps the system water from contacting the (standard 12-lb.) tank charge, lets this considerably smaller size give more positive, permanent system protection.

\section{HOW IT WORKS}

Heated water expands, and in a closed hot water heating system, provision must be made for this expansion. The flexible diaphragm in the EX-TROL (ब) provides for water expansion without permitting absorption of the air cushion by the water.

\section{İOINSTALL}

EX-TROL $\odot$ may be installed into a tee or any other suitable tapping anywhere on a hot water heating system. It may be placed in a vertical or horizontal position. It may also be remotely located and piped to convenient point on

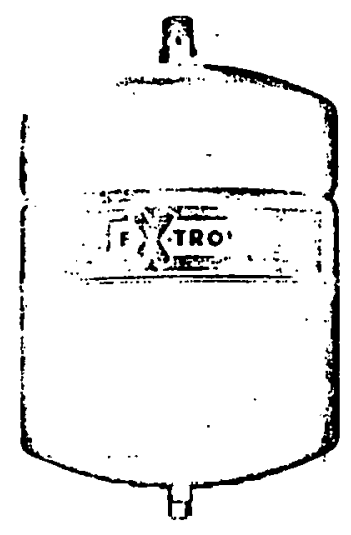

No. 15 EX-TROL the systern.

An ideal EX-TROL @ installation is to screw it into the bottom of an American Air Purger located on the main. This combination offers both a mounting tapping and continuous automatic air removal from the system.

1. Fill system.

After installing EX-TROL @ on the system:

2. Vent air irom system (for purging metnods, refer to AMTROL data sneet on Furgers)

3. Bring system up to shut-off temperature.

4. If a smaller EX.TROL @ is being used instead of that for which the system is sized, system water must bedrawn from the boiler to maintain the proper system pressure. Generally a smaller than normal tank will cause a higher system pressure than is desirable

Note: Never let air from EX.TROL $\oplus$ tank. Air charpe should always equal setting of reducing valve (12-lb. stàndard).

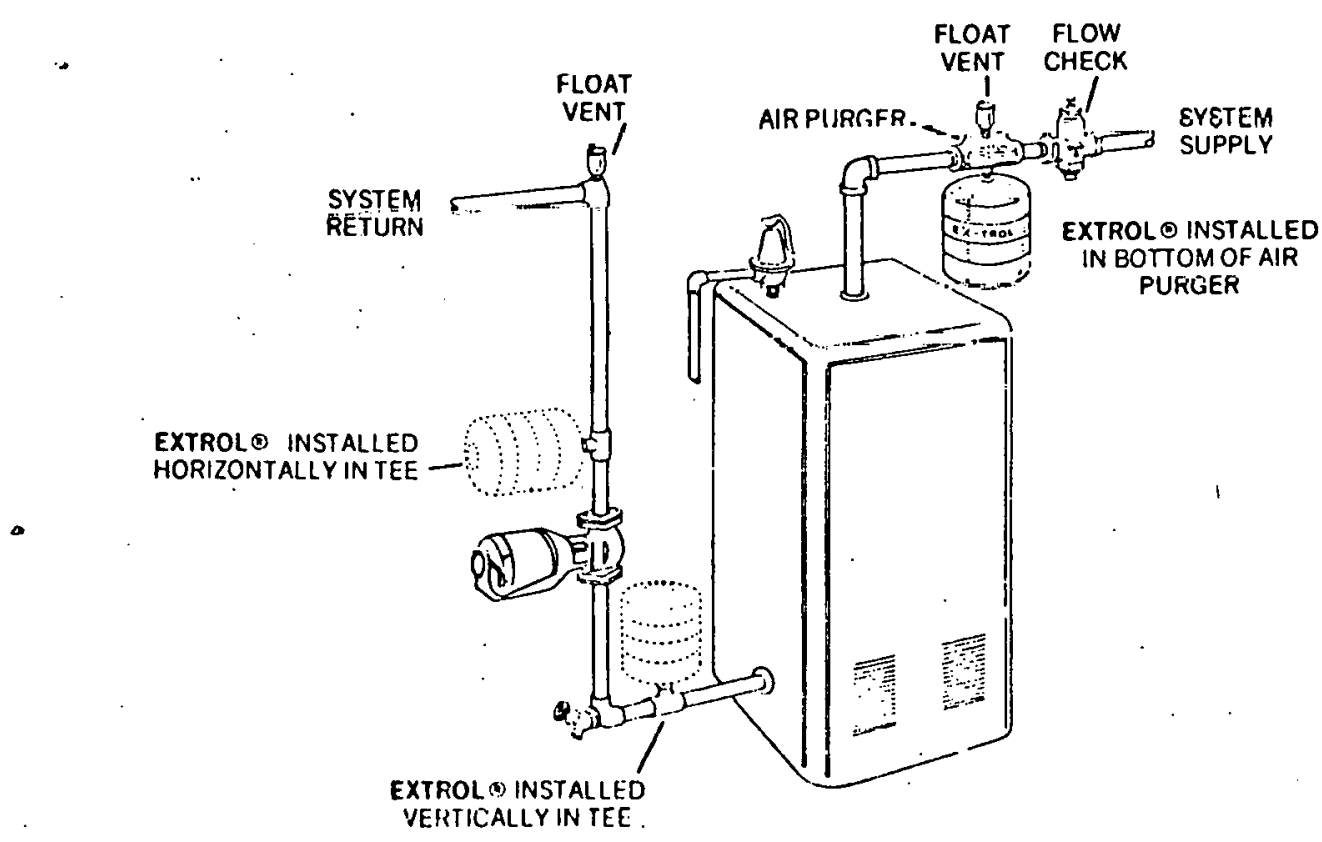




\section{SYSTEM VENTING AND PURGING}

After initial venting and purging of air from the system, more air will be released from the water as it is heated. Therefore, it is recommended that an American Air Purger and $\sharp 700$ Float Vent be installed on the main.

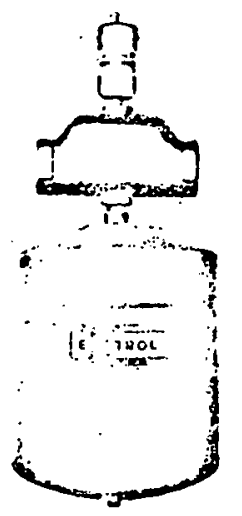

No. 1500 EX-TROL @ Pkg.

If the system has multiple loops or zones, the supply water for all loops and zones must pass through the Air Purger for complete and continuous air removal. In case the piping arrangements does not permit the installation of a single Air Purger on the main, Air Purgers and \#700 Float Vents should be installed on each loop or zone. In this event, only one EX.TROL @ is required for the system.

Even with American Air Purger and Float Vent installed on the main or mains, it is recommended the American $\$ 700$ Fleat Vent be installed on each return at the elbow that drops to the circulator.

While seltom required, it is also recommended that manual (key or coin type) ?ir vents be installed at high points on the radiation.

\section{SERVICE HINTS}

1. If system is shut down for long periods, or emptied for any reason, it may be necessary to repeat steps 2,3 and 4 under INSTALLATION.

2. If the system pressure is too high:

a.) Check gauge calior ation io make certain that the indicator needle has not slipped.

b.) Check to see if EX-TROL @ has lost its air charge.

Note: To get an accurate reading with any tire gauge when checking EX-TROL $\odot$ air pressure, either:

1.) disconnect the EX-TROL $\odot$ from the system or,

2.) draw off system water until boiler pressure reads zero.

c.) Check for faulty fill valve operation. First, close manual shui-off before the fill valve; then, draw system pressure down to $12 \mathrm{PSI}$ (or other pre-set pressure) and observe system for pressure build-up several nours later.

d.) Check for service water entering system from any other source of leak, such as tankless heater. Use same procedure as above after shutting off possible water source.

3. If pressure relief valve drips water:

a.) first, check system pressure. If too high, follow steps 2. b.). c.) and d.) above.

b.) If pressure relief valve continues to drip water, even at reduced pressure, flush relief valve by quickly raising lever several times. If drip continues, it may be necessary to replace relief valve.

c.) If multiple EX-TROLS $\odot$ are installed in the system, check pressure of each for possible air leaks. Be sure red plastic air valve caps are on tight.

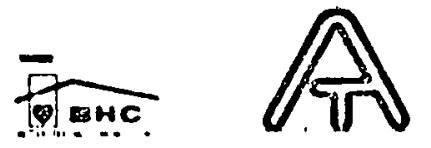

ANITIEOOINC:

1400 DIVISION ROAD - WEST WARWICK, R. I. \$2893

E-9 


\section{PURGING DEVICES FOR HOT WATER HEATING SYSTEMS}

The water that is used initially to fill a hot water heating system contains dissolved air. Make-up water subsequently added will similarly have a high air content. Heating this water releases the air and permits it to be circulated in the system, from which it must be vented.

The purpose of the American Air Purgers and Purger-Trols is to continuously separate and collect any air from the water as it circulates so that it may be vented automatically by an American \#700 Float Vent, without the

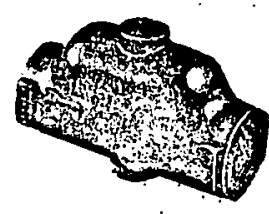

Model \#443 necessity for frequent manual venting.

\section{DESCRIPTION:}

Each Air Purger or Purger-Trol is a one-piece cast iron chamber with two passages through which boiler water flows. Internal contours and baffles are designed for low flow resistance characteristics and efficient separation of the air from the water.

All models have tappings for installation of $\$ 700$ float Vents to provide complete purging and venting. Spare tappings ore also provided for easy mounting of an EX-TROL for expansion control or FILL-TROL for combining automatic fill valve and expansion control.

Purger-Trol models have additional tappings for the optional mounting of pressure relief valve and pressure-altitudetemperature gauge, which groups all items in one location, saving space and providing a neater installation.

\section{OPERATION:}

While the circulaiing pump is operating, system water continuously flows through the purger. The more dense water flows at nearly maximum velocity through the lower passage of the purger and directly to the system piping. The less dense water, containing dissolved air, moves into the upper channel. This area is so designed as to free the air or gases and to accumulate them at the venting port. The water thus freed of its air content rejoins the main flow.

\section{INSTALLATION:}

The Air Purgers and in-line Purger-Trol should be installed horizontally on the main as close to the boiler as possible. These units must be installed so that water flows through them in the direction indicated by. the arrow. An American \#700 Float Vent should be screwed into the opening marked "Vent". (Be sure the air valve cap on the Float Vent is loose to permit air to escope.)

The angle-type Purger-Trol should be installed horizontally and preferably on a nipple in the boiler supply tapping. Flow from the Purger-Trol may. be either right or left or in both directions from the boiler into the main.

\section{Typical Installations with FILL-TROL}

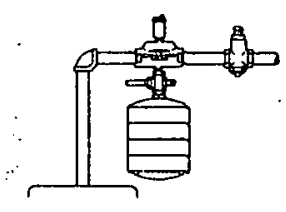
Model \#443
with top outlet boiler

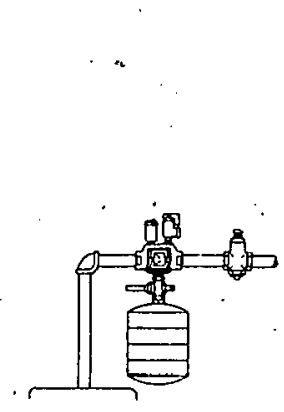

Modiel \#440.
with top outlet boiler

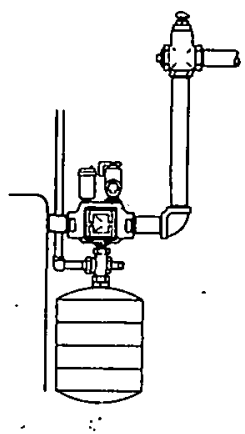

Model \#440 with side outlet boiler

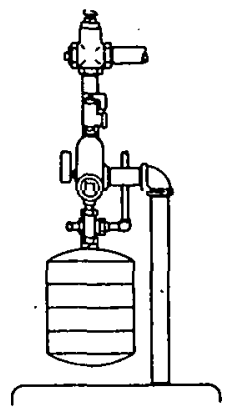

Model \#438 with top outlet boiler

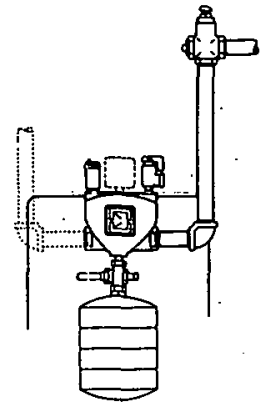

Model \#438 with side outlet boiler 


\section{SPECIFICATIONS:}

Material: Close-grained cast-iron, $90 \mathrm{lb}$. ASA rating.

(Ment

DIMENSIONS \& SHIPPING WEIGHTS:

\begin{tabular}{|c|c|c|c|c|c|c|c|c|}
\hline \multirow{2}{*}{$\begin{array}{c}\text { Modol } \\
\text { No. }\end{array}$} & \multirow{2}{*}{ Size } & \multicolumn{3}{|c|}{ Dimonsions } & \multicolumn{3}{|c|}{ Toppings - NPT } & \multirow{2}{*}{$\begin{array}{l}\text { Ship. } \\
\text { Wt. } \\
\text { Lbs. }\end{array}$} \\
\hline & & A & $\bar{B}$ & C & $U$ & $v$ & $\mathbf{z}$ & \\
\hline 443 & $I^{\prime \prime}$ & $6^{\prime \prime}$ & 4" & $21 / 2 "$ & 1" & $\%$ & $1 / 2 n$ & 4 \\
\hline 444 & $1 / 1 / 4$ & $6^{\prime \prime}$ & 4" & $2 \% "$ & $1 / 4^{\prime \prime}$ & $1 / \%$ & $1 / 2 "$ & 5 \\
\hline 445 & $11 / 20$ & $8^{\prime \prime}$ & 5 & $31 / 2$ & $11 / 2$ & $1 \%$ & $1 / 2 "$ & 9 \\
\hline 446 & $2 "$ & $8^{\prime \prime}$ & 5 & $31 / 2 "$ & 2 & $1 / 2 \cdot \cdots$ & $1 / 2 "$ & 10 \\
\hline .447 & $21 / 20$ & $10^{11}$ & 6" & 5" & $21 / 2^{\prime \prime}$ & $3 / 4$ & $1 / 2$ & 19 \\
\hline 448 & $3{ }^{\prime \prime}$ & $10^{\prime \prime}$ & 6" & 5" & 3" & $3 / 4$ & $1 / 2$ & 20 \\
\hline
\end{tabular}

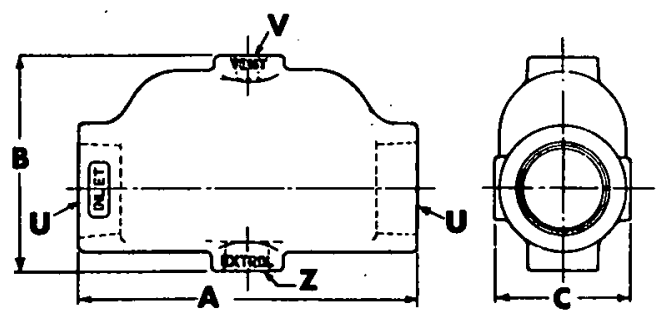

\begin{tabular}{|c|c|c|c|c|c|c|c|}
\hline \\
$\vdots$ \\
$\vdots$
\end{tabular}
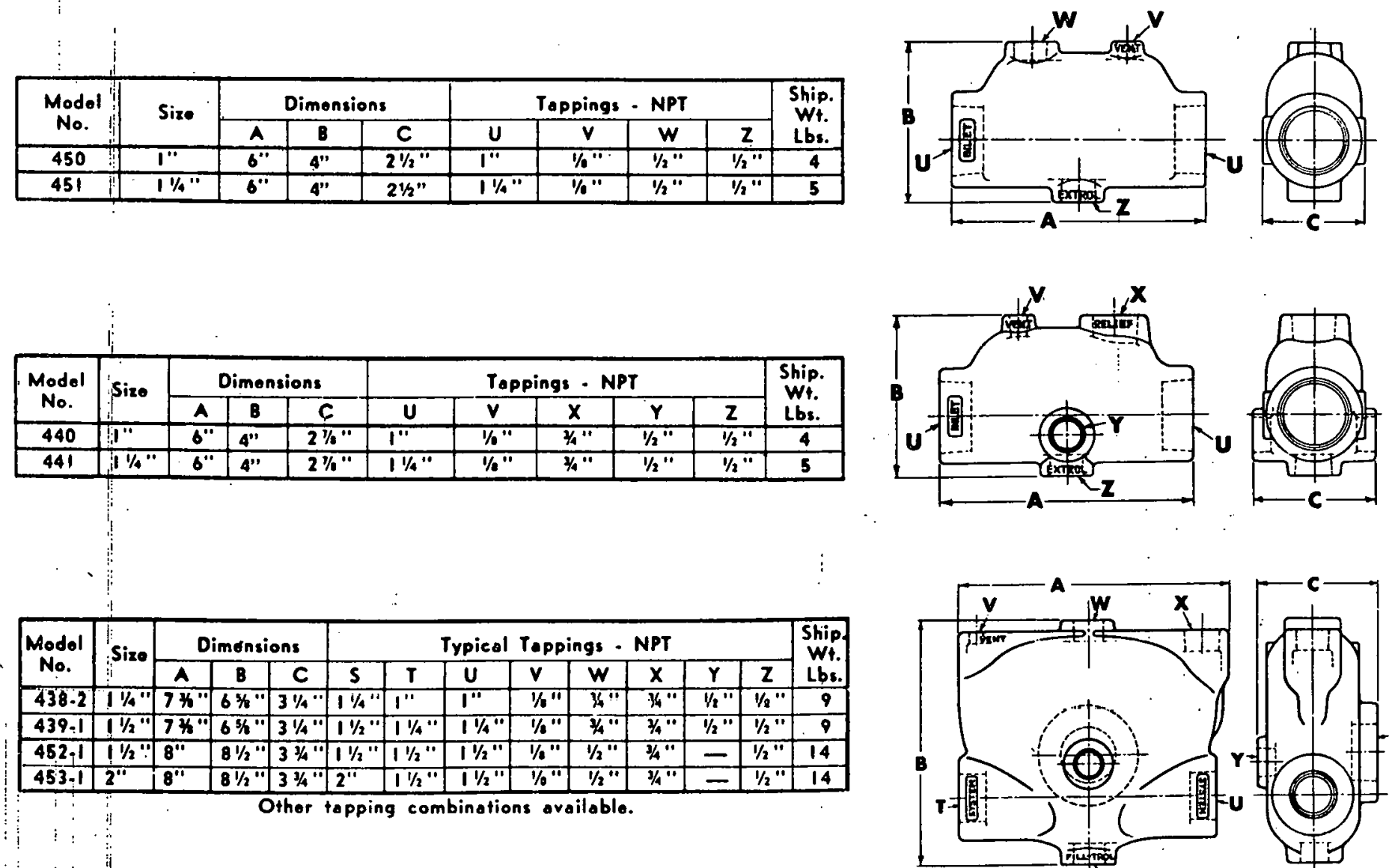

\section{SUMMATION:}

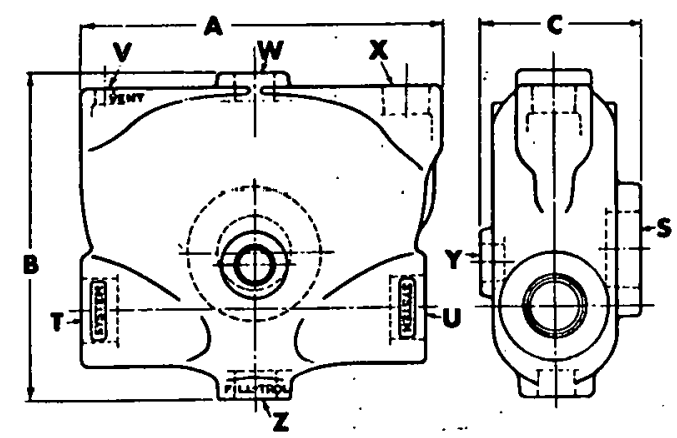

Purging of air from system water must be a continuing process. While the major part of the air removal is accomplished on the initial filling of the system, smaller troublesome amounts of air and gases must be removed continuously.

American Air Purgers and Purger-Trols are designed for maximum effective air removal together with minimum pressure drop and turbulence.

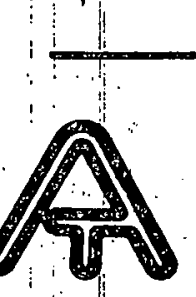




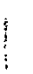

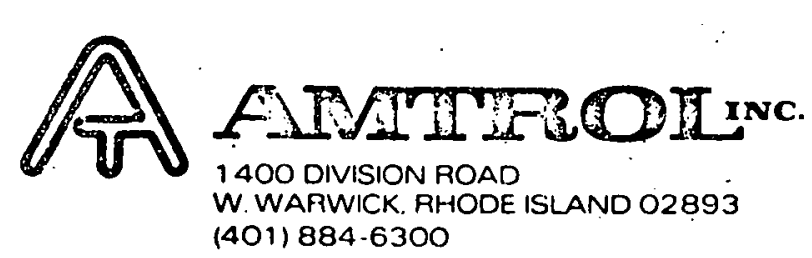

Form SA-AV-690

SUEETITTAL DATA

MODEL 690

ERT

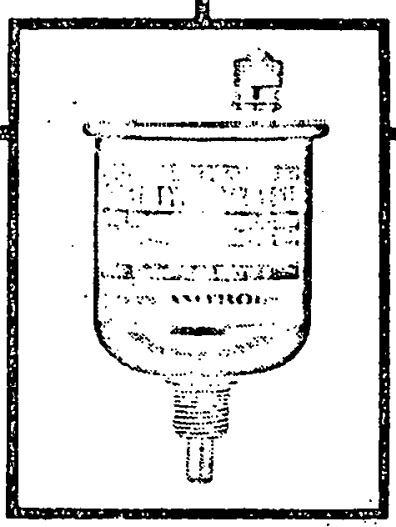

Maximum Working Pressure: 310 kPa (45 PSI)

Maximum Operating Temperature: $116^{\circ} \mathrm{C}\left(240^{\circ} \mathrm{F}\right)$

Material: Stamped brass body and cover:

solid, non-metallic float

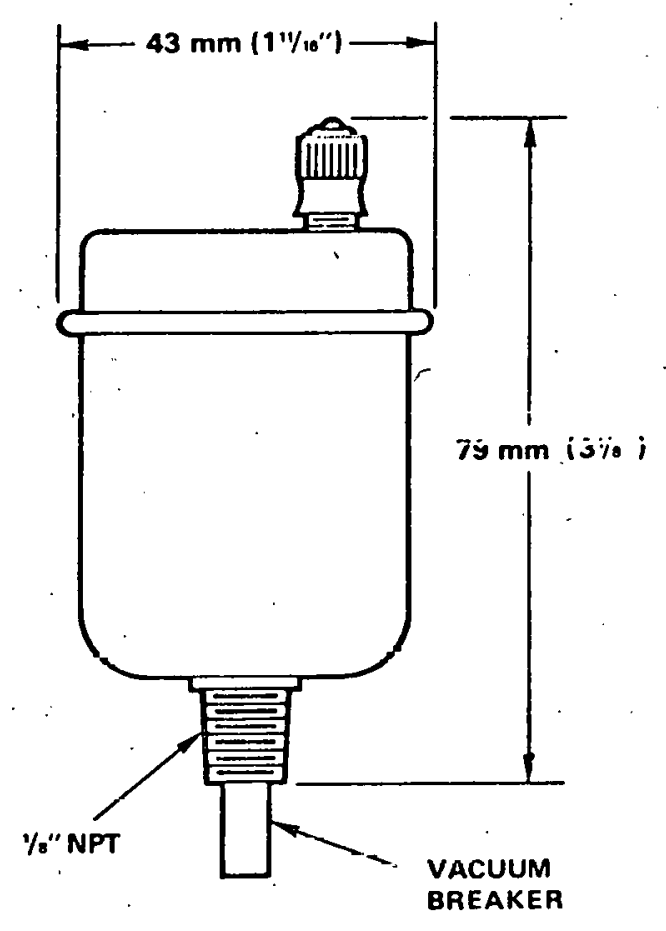

JOB NAME:

ENGINEER:

CONTRACTOR:

CONTRACTOR P.O. NO.

SALES REPRESENTATIVE:

MODEL NO. ORDERED:

DATE SUBMITTED: 
WEST WARWICK, R. I. 02893

American \#690 and \#700 Series FLOAT VENTS are advanced type Air Valves designed for venting all Hydronic Heating and Cooling Systems. They have unique construction which insures - fast venting - positive shutoff - venting through the complete pressure range - (Models 690, 700 and 702 (0-45 PSI) (Models 701 and 703 (0-100 PSI) - trouble free performance - no spitting or unsightly stains, from leaking.

No separate air chamber is required.

\section{HOW IT WORKS:}

Air entering the vent chamber lowers the water ievel, causing the float to fall and open the air valve. As the air is released, the water level rises, raising the float and closing the air valve.

\section{WHERE TO INSTALL:}

1. In EX-TROL ${ }^{\odot}$ systems, there are two preferred locations for the $\# 700$ FLOAT VENT.

a.) Mounted on an American Air Purger (for best results, use an EX-TROL package) on the main from the boiler.

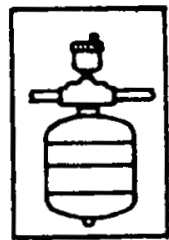

b.) In a vent ell on the return main to the boiler from each zone, before the circulating pump.

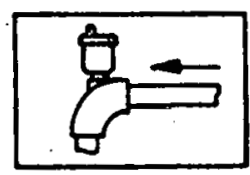

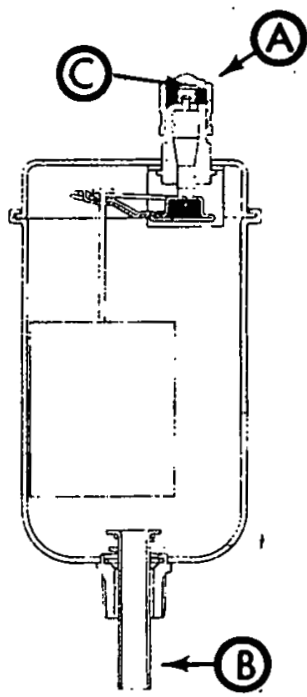

SERIES \#6gO FLOAT VENT

(for vertical installation only)

2. In other types of hydronic systems, the general rule is to install the \#700 FLOAT VENT in the high points of the system - convectors, haseboard radiation, unit heaters or radiant panels.
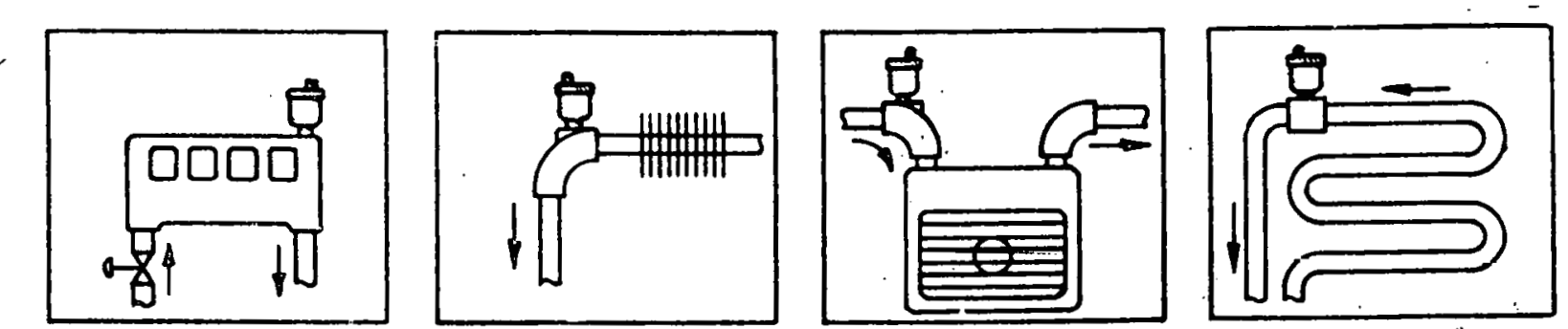

\section{HOW TO INSTALL:}

1. If system is full of water, draw off enough to reduce pressure on gauge to " 0 " or to lower water level to below point where FLOAT VENT is to be installed.

2. Screw inco 1/8" I.P. tapping in vertical position, with cap (A) screwed on tight and vacuum breaker tube (B) free.

3. Tighten by hand - use of a wrench is not necessary.

4. Fill the system with water.

5. When system is filled with water, loosen cap the valve seat by the escaping air.

6. Screw cap down tight to close valve.

7. Open two turns for normal venting.

Suggestions:

Should dirt or scale lodge on the valve seat causing it to leak, remove cap and push the valve core (C) in by hand to permit water to flush the seat clean. Release quickly and replace cap, open one turn for normal venting. 


\section{air vents}

\section{CONNECTOR}

Where a safe waste connector is required the \#71". c.mnector replaces the regular valve cap and provides an attachment for a copper tube drain line. Only required if written in engineer specifications.

712

CONMECTOR

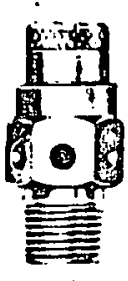

\section{DISC TYPE VENT FOR WATER}

Installation is recommended up to 30 PSI W.P. For normal automatic venting open valve 1 to $1 \frac{1}{4}$ turns after making connecion.

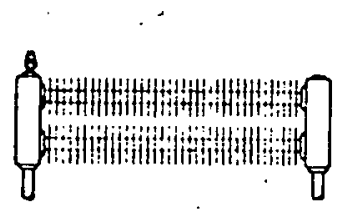

710

WATER VENT

Convectors

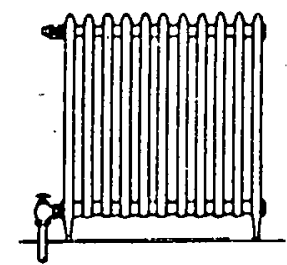

Radletors

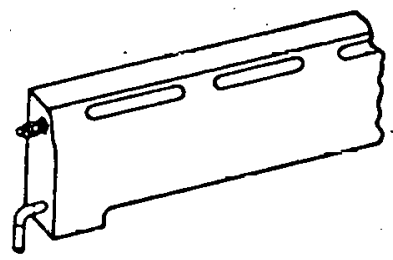

Deseboands

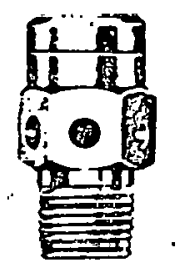

778 STEAM VENT

\section{DISC TYPE VENT FOR STEAM}

Installation is made in steam radiators and stcam mains. Maximum working pressure steam $10 \mathrm{PSI}$. No adjustment is necessary for operation.

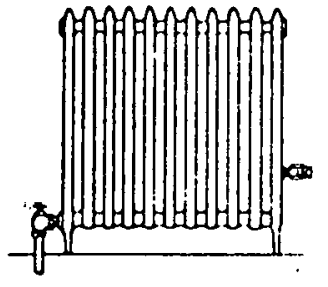

Strom Radiators

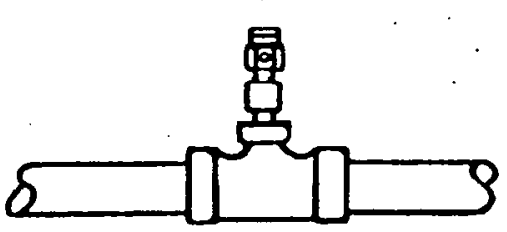

Sream Mains 
Bell \& Gossett submittal sheet A-434 revision 2 pertaining to Relief Valves-ASME valves and fittings has been removed due to copyright. 


\section{Honeywell}

THE Y534A DUAL DIVERTING VALVE ASSEMBLY CONSISTS OF TWO VALVE BODIES WHICH ARE SWEATED TOGETHER AND TWO POWERHEADS WHICH CONTROL EACH VALVE BODY SEPARATELY. WHEN ASSEMBLED, THE Y534A OFFERS FLOW CHARACTERISTICS WHICH ARE COMPATIBLE WITH SOLAR ENERGY SYSTEMS

$\square$ Available for line or low voltage applications (specify when ordering).

$\square$ Assembly provides a flow capacity of $14 \mathrm{Cv}$ [12 kv].

$\square$ Sweat copper end connections may be installed without disassembling the valve.

$\square$ Manual opener for valve operation on power failure. Valve returns to automatic position when power is restored.

$\square$ Complete powerhead may be removed without breaking the line connections.

$\sqcup$ Motor actuator may be replaced without removing the valve body or draining the system.

R.L.

$9.77(.05)$

\section{OUAL DIIEATIING VALVES}

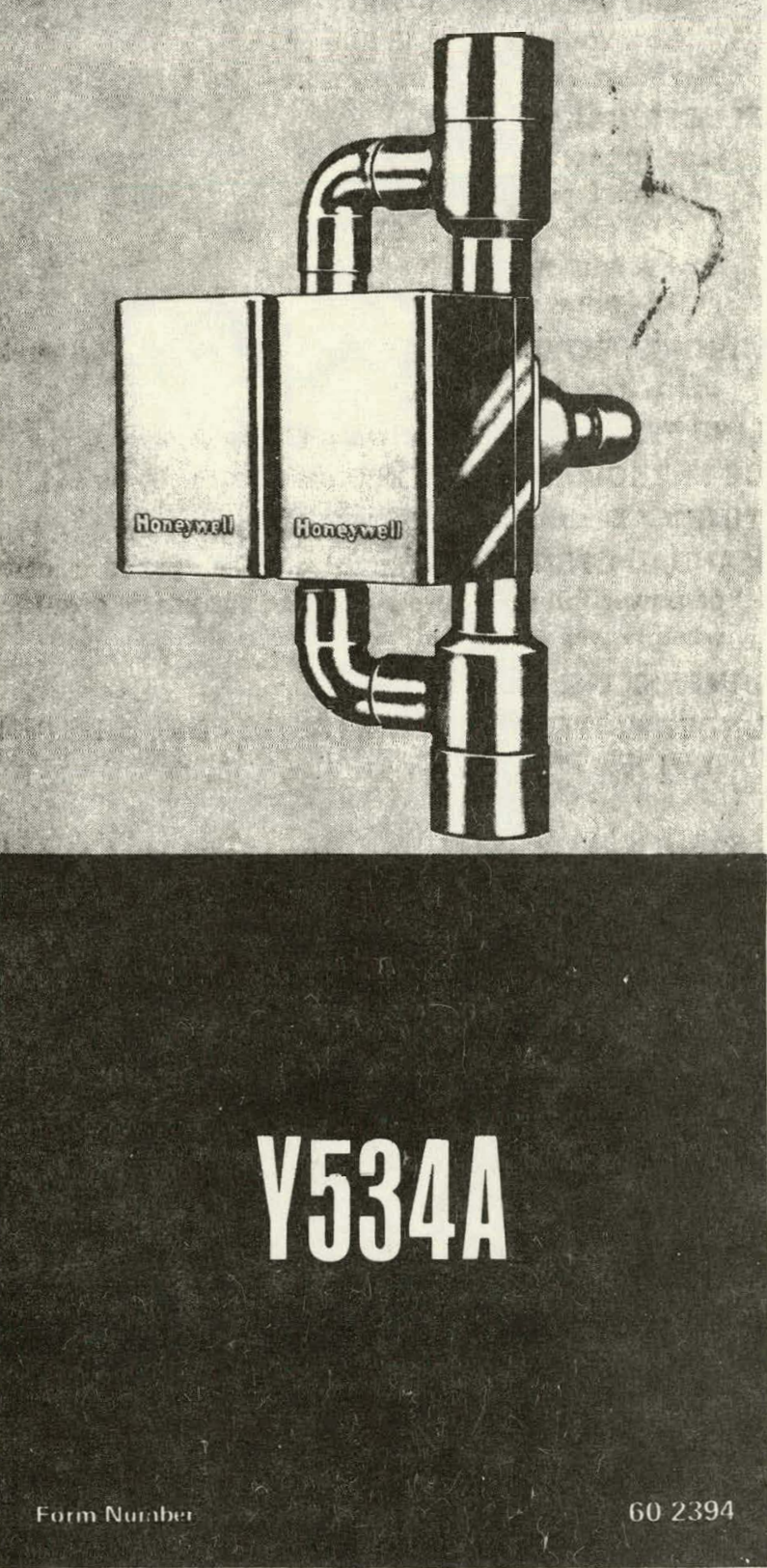


THE SPECIFICATIONS GIVEN IN THIS PUBLICATION DO NOT INCLUDE NORMAL MANUFACTURING TOLERANCES. THEREFORE, THIS UNIT MAY NOT MATCH THE LISTED SPECIFICATIONS EXACTLY. ALSO, THIS PRODUCT IS TESTED AND CALIBRATED UNDER CLOSELY CONTROLLED CONDITIONS, AND SOME MINOR DIFFERENCES IN PERFORMANCE CAN BE EXPECTED IF THOSE CONDITIONS ARE CHANGED.

MODEL:

Y534A-2-position dual diverting valve. The two powerheads must be assembled to the two valve bodies which are shipped sweated together. Available for line or low voltage applications.

TEMPERATURE AND FLOW RATINGS:

Capacity Rating-14 Cv [12 kv].

Maximum Closeoff Pressure-10 psi [69 kPa].

Static Pressure Rating-125 psi [862 kPa].

Maximum Fluid Temperature-

Line voltage model-200 F [93 C].

Low voltage model $-240 \mathrm{~F}$ [115 C].

Maximum Ambient Temperature-125 F [52 C].

ELECTRICAL RATINGS:

Line voltage models-

0.16 amps at $120 \mathrm{~V} \mathrm{ac}, 60 \mathrm{~Hz}$.

0.08 amps at $220 / 240 \mathrm{~V} \mathrm{ac}, 50 \mathrm{~Hz}$.

Low voltage model-

0.64 amps at $24 \mathrm{~V} \mathrm{ac}, 50 / 60 \mathrm{~Hz}$.

WIRING PROVISIONS: 18 in. [457.2 mm] leadwires and $1 / 2$ in. conduit openings.

LINE FITTINGS: $1-1 / 4$ in. sweat (1-3/8 in. O.D.).

DE-ENERGIZED POSITION: Port A normally closed.

TIMING: Diverts flow in 30 seconds.

MANUAL OPENER: Allows valve to be opened in case of power failure. Valve returns to automatic position when power is restored.

DIMENSIONS: See Fig. 1.

UNDERWRITERS LABORATORIES INC. LISTING APPLIED FOR.
REPLACEMENT PARTS:

O-ring-Part No. 802344.

Powerhead-

Line voltage model-Part No. 130441 ARG.

Low voltage model-Part No. 130441 ARA.

DETERMINATION OF WATER FLOW CHARACTERISTICS: The pressure drop in psi [ $\mathrm{kPa}$ ], equivalent feet [metres] of pipe, or feet of water [ $\mathrm{kPa}]$ may be determined by calculating the flow rate, referring to Fig. 2, and using the following procedures.

Pressure drop in psi [ $\mathrm{kPa}]-$

1. Locate the flow rate at the bottom of the graph in Fig. 2.

2. Draw a line upward from the flow rate until it intersects the curve on the graph.

3. Draw a line from the intersection to the lefthand edge of the graph and read the pressure drop in psi [ $\mathrm{kPa}]$.

Pressure drop in equivalent feet [metres] of pipe-

1. Locate the flow rate at the bottom of the graph in Fig. 2.

2. Draw a line vertically to the top of the graph. Read the pressure drop in equivalent feet [metres] of pipe on the $3 / 4 \mathrm{in}$. pipe scale.

Pressure drop in feet of water [kPa]-

1. Locate the flow rate at the bottom of the graph in Fig. 2.

2. Draw a line upward from the flow rate until it intersects the curve on the graph.

3. Draw a line from the intersection to the righthand edge of the graph and read the pressure drop in feet of water $[\mathrm{kPa}]$.

\section{ORDERLYO INFORMATION}

WHEN PURCHASING REPLACEMENT AND MODERNIZATION PRODUCTS FROM YOUR TRADELINE WHOLESALER OR YOUR DISTRIBUTOR, REFER TO THE TRADELINE CATALOG OR PRICE SHEETS FOR COMPLETE ORDERING NUMBER, OR SPECIFY-

1. Order number (specify line voltage or low voltage model).

2. Replacement part, if required.

IF YOU HAVE ADDITIONAL QUESTIONS, NEED FURTHER INFORMATION, OR WOULD LIKE TO COMMENT ON OUR PRODUCTS OR SERVICES, PLEASE WRITE OR PHONE:

1. YOUR LOCAL HONEYWELL RESIDENTIAL DIVISION SALES OFFICE (CHECK WHITE PAGES OF PHONE DIRECTORY).

2. RESIDENTIAL DIVISION CUSTOMER SERVICE

HONE YWELL INC., 1885 DOUGLAS DRIVE NORTH

MINNEAPOLIS, MINNESOTA 55422 (612) 542-7500

(IN CANADA-HONEYWELL CONTROLS LIMITED, 740 ELLESMERE ROAD, SCARBOROUGH, ONTARIO M1P 2V9) INTERNATIONAL SALES AND SERVICE OFFICES IN ALL PRINCIPAL CITIES OF THE WORLD. 

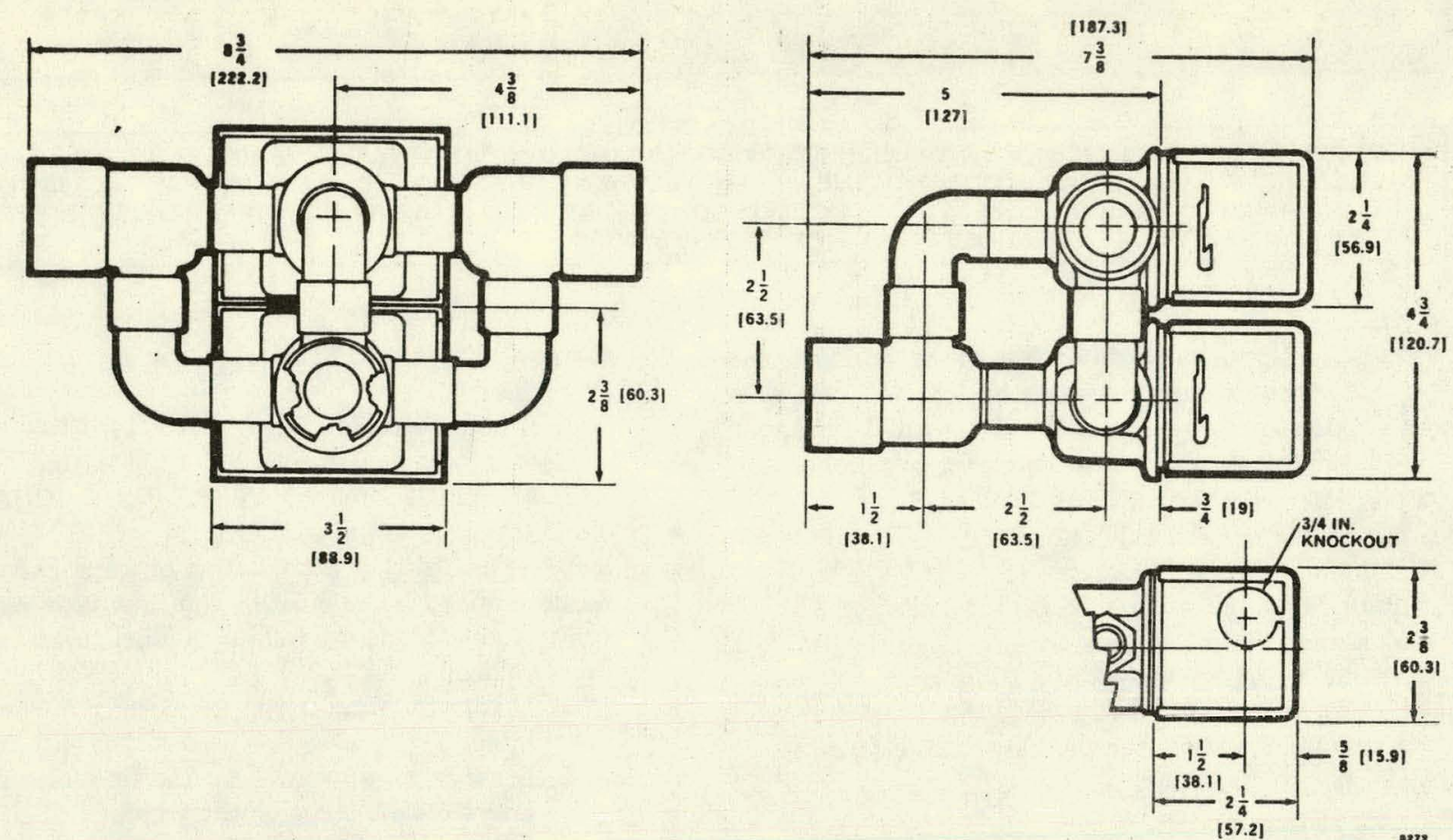

FIG. 1-Y534A DIMENSIONS IN INCHES [MILLIMETRES IN BRACKETS].

PRESSURE DROP

EQUIVALENT FEET OF PIPE [EQUIVALENT METRES OF PIPE]

\begin{tabular}{ccccccccccc}
10 & 13 & 15 & 17 & 19 & 20 & 21 & 22 & 23 & 24 & 25 \\
{$[3]$} & {$[4]$} & {$[4.6]$} & {$[5.2][5.8]$} & {$[6]$} & {$[6.4]$} & {$[6.7]$} & {$[7]$} & {$[7.3]$} & {$[7.6]$} \\
\hline
\end{tabular}

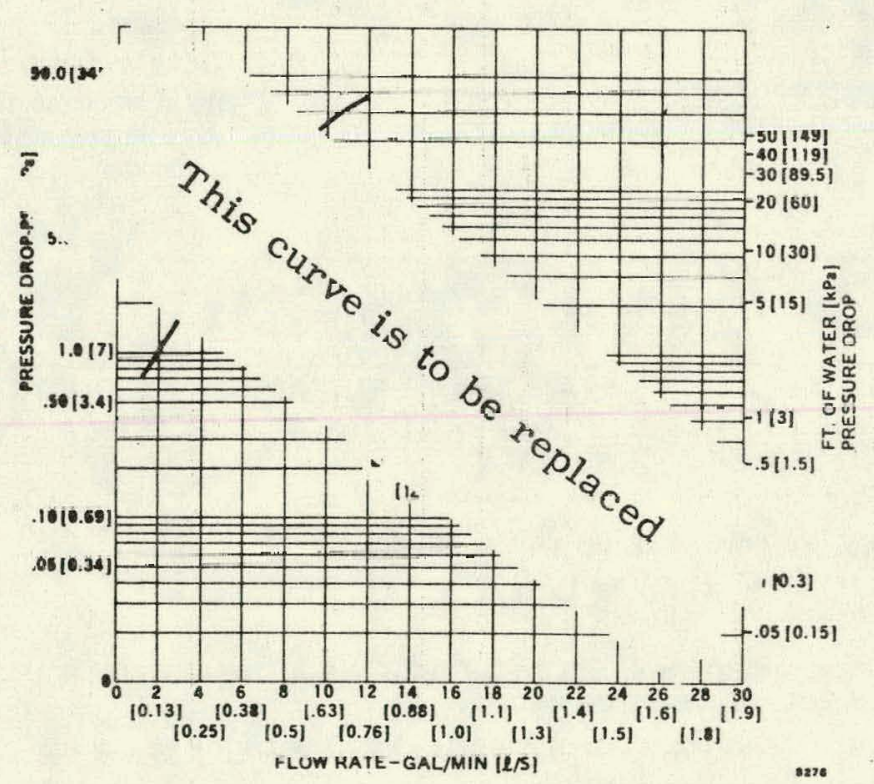

FIG. 2-FLOW CHARACTERISTICS OF Y534A DUAL DIVERTING VALVES. 


\section{CAUTION}

1. Installer must be a trained, experienced service technician.

2. Disconnect power supply before connecting wiring to prevent electrical shock and equipment damage.

3. Always conduct a thorough checkout when installation is complete.

\section{ASSEMBLY}

Each powerhead controls each valve body separately. To assemble a powerhead to a valve body, place an O-ring in the circular slot on the top of the valve body (Fig. 3). Assemble the powerhead to the valve body by placing the manual opening lever on the powerhead in the MAN. OPEN position.

Align the powerhead by fitting the hex head screw on the bottom of the powerhead into the hole on the top of the valve body. The guide pins and the positioning pin in the powerhead should fit the holes in the valve body. Tighten securely and repeat this procedure for the other powerhead and valve body.

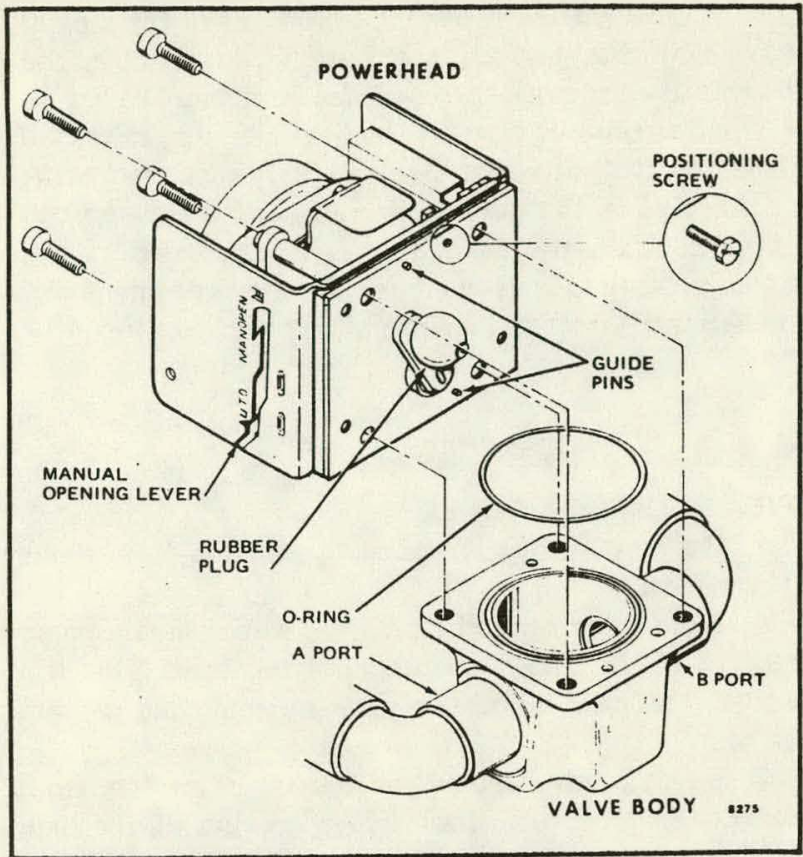

FIG. 3-POWERHEAD MUST BE ALIGNED SO THAT THE GUIDE PINS AND THE POSITIONING PIN IN THE POWERHEAD FIT THE HOLES IN THE VALVE BODY.

\section{MOUNTING}

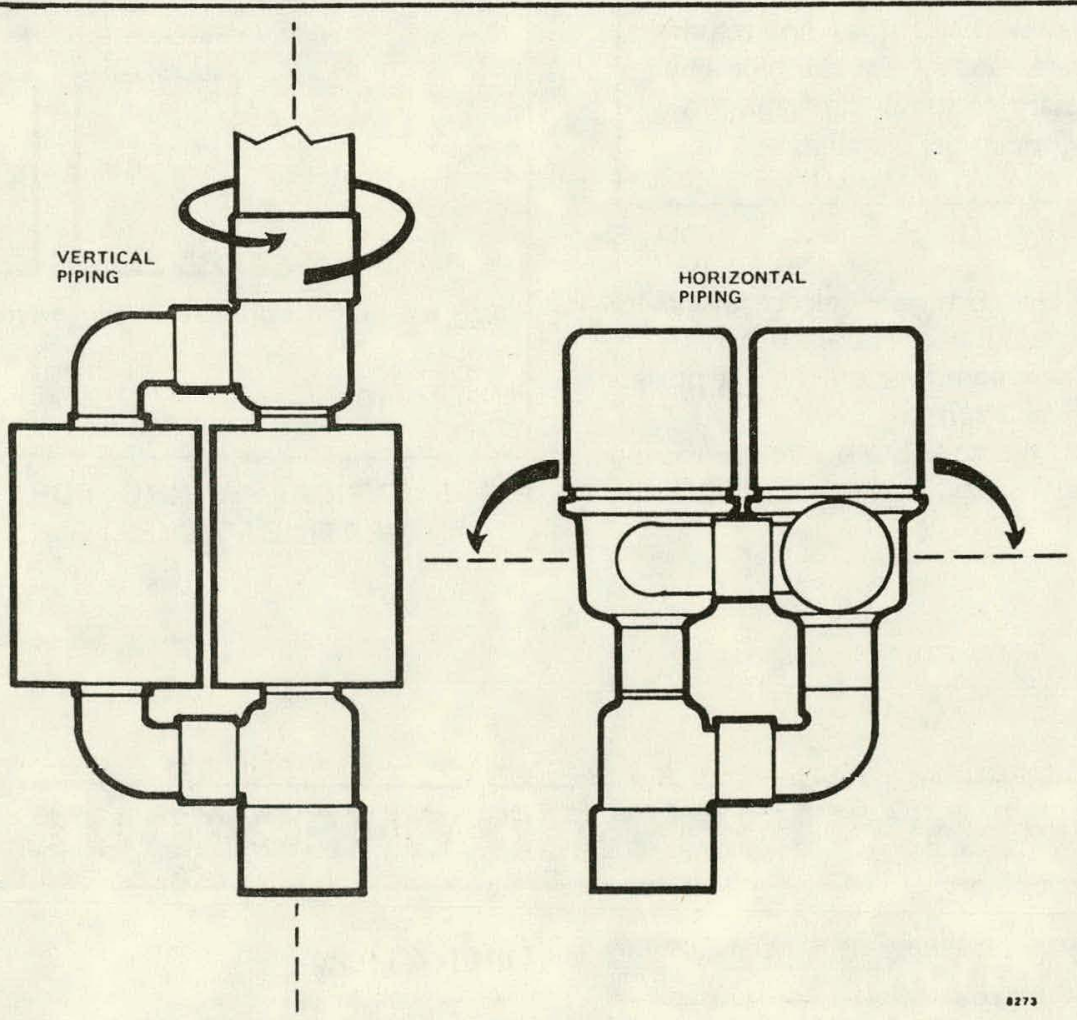

FIG. 4-MOUNTING POSITIONS. 
The valve may be mounted in any position on a vertical line. If valve is mounted horizontally, the powerhead must be even with or above the center line of the piping. Make sure that enough room is provided above the powerhead to remove the cover for servicing. See Fig. 4.

The 3 fittings or ports of the dual diverting valves are labeled on the bottom of the valve body castings. Port $A$ is connected to the purge coil piping and is closed when the valve is deenergized. Port. B is connected to the system bypass and is open when the valve is de-energized. Port $A B$ is the inlet and is open at all times. See Fig. 4.

\section{SWEAT COPPER MODELS}

1. Use new, properly reamed pipe, free from dents or corrosion.

2. Place valve onto the pipe. Set the manual opener lever to $M \cap N$. OFEN lefure applying heat. 'I'his will protect the plug inside the valve by removing it from the heat.

3. Sweat joints keeping the outer surface free from solder. DO NOT use silver solder because of the high melting temperatures required.

\section{TO INSTALL REPLACEMENT POWERHEAD}

Installation of new powerhead does not require the removal of the valve body from the pipe line. It is, however, necessary to drain the water from the system before beginning the installation.

1. Disconnect the valve from the electrical power source and remove the conduit connections if fitted.

2. Place the manual opening lever on the old powerhead in the MAN. OPEN position.

3. With the cover off, remove the 4 screws securing the powerhead to the valve body. Remove the old O-ring from the valve body.
4. Place the new O-ring in the circular slot on the top of the valve body.

5. Install the new powerhead-

-Place the manual opening lever on the new powerhead in the MAN. OPEN position.

-Align the powerhead by fitting the hex head screw on bottom of powerhead into the hole on top of valve body (see Fig. 3).

6. Reconnect electrical connections.

Inspect the powerhead installation and the valve body to insure that all connections and adjustments have been correctly made. Adjust the thermostat or controller connected to the valve so the valve runs through its cycle. Make sure the valve runs smoothly and positively from closed to open to closed again.

\section{WIRING}

All wiring must agree with local codes and ordinances. See Fig. 5 for a typical wiring hookup.

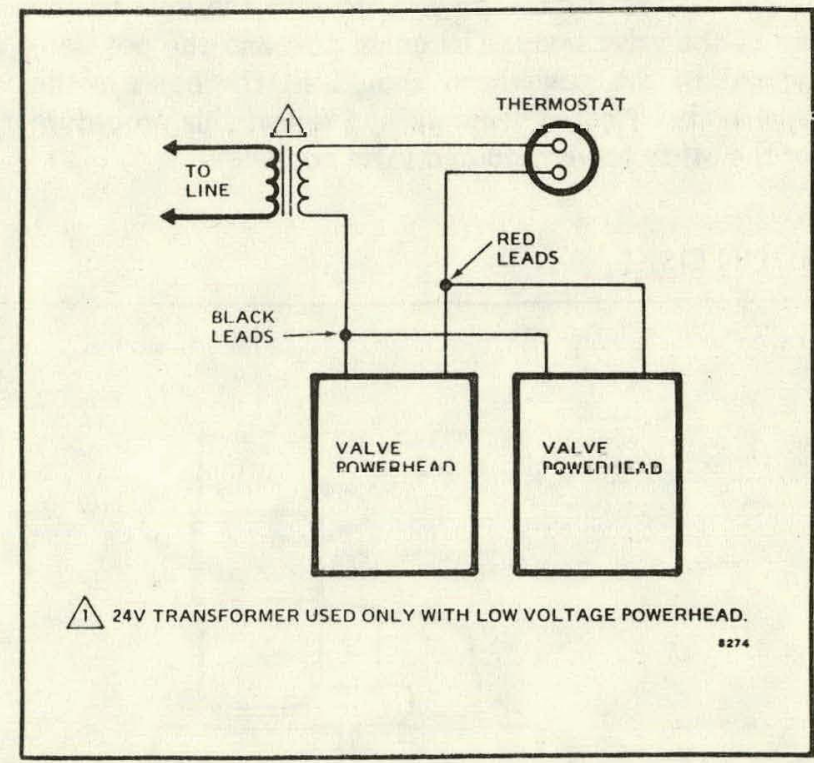

FIG. 5-TYPICAL WIRING FOR Y534 DUAL DIVERTING VALVES.

\section{OPERATION AND CHECKOUT}

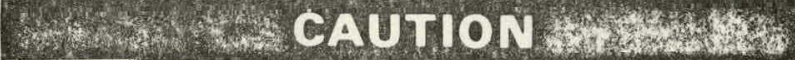

On 24 volt systems, never jumper the valve coil terminals, even temporarily. This may burn out the heat anticipator in the thermostat.

\section{OPERATION}

\section{AUTOMATIC OPERATION}

When the valve is energized, port $B$, the bypass, closes and port $A$ opens. Port $A$ closes by integral spring return when the valve is de-energized. 
MANUAL OPERATION

The motorized dual diverting valves (two with each assembly) can be opened manually by lifting the manual opener lever over the stop and pushing slowly and firmly to the MAN. OPEN position. The stop permits the valve to be locked in the open position. The valve will return to automatic position when the valve is energized.

\section{CHECKOUT}

1. Lower the set point of the high limit controller below the temperature of the collector fluid.

2. Observe that port $A$ of the valve should be open and port $B$ of the valve should be closed.

3. Raise the set point of the high limit controller above the collector fluid temperature.

4. Observe that port $A$ of the valve should close and port $B$ of the valve should be open.

\section{SERVICE}

This valve should be serviced by a trained, experienced service technician.

1. If the valve is leaking, check to see if the O-rings need to be replaced.

2. If the gear train is damaged or the motor is burned out, it is necessary to replace the entire powerhead assembly. See INSTALLATION.

NOTE: Honeywell zone valves are designed and tested for silent operation in properly designed and installed systems. However, water noises may occur as a result of excessive water velocity or piping noises may occur in high temperature (over $212 \mathrm{~F}$ [100 C ]) systems with insufficient water pressure. 
Bell \& Gossett hydronic specialties specification and submittal sheet A-551 revision 2 pertaining to Circuit Setter Balance Valves with NPT, flanged and solder connections has been removed due to copyright. 
Bell \& Gossett ITT Fluid Handling Division, Circuit Setter Balance Valve sheet has been removed due to copyright. 
Bell \& Gossett hydronic specialties specification and submittal sheet A-422 revision 3 pertaining to Flo-Control Valves has been removed due to copyright. 
SEE PAGE 36 FOR PRESSURE-TEMPERATURE RATING. (copyright info.)

\section{SERVICE FEATURES}

Recommended for prevention of backflow in general services. $\bullet$ Solder ends recommended for non-flammable liquids or gases with Types $K, L$, and $M$. copper tubing.

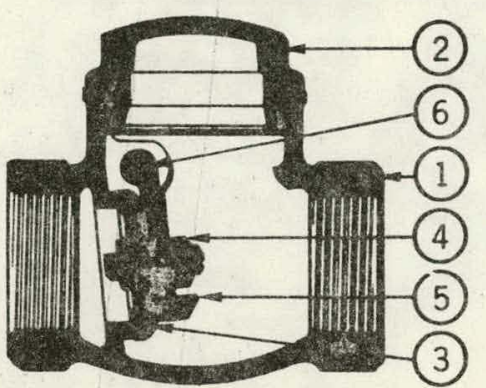

B-319

\begin{tabular}{|c|l|l|l|}
\hline MO. & DESCRIPTION & MATERIAL & ASTM SPEC. \\
\hline 1 & BODY & BRONZE & B-62 \\
\hline 2 & CAP & BRONZE & B-62 \\
\hline 3 & DISC & BRASS $(1 / 4-1 / 2)$ & $B-16$ \\
\cline { 3 - 4 } & & BRONZE $(3 / 4-3)$ & $B-62$ \\
\hline 4 & DISC NUT & BRASS & B-16 \\
\hline 5 & HINGE & BRONZE & B-62 \\
\hline 6 & HINGE PIN & BRASS & B-16 \\
\hline 7 & SIDE PLUG & BRASS & B-16 \\
\hline
\end{tabular}

*Not Shown

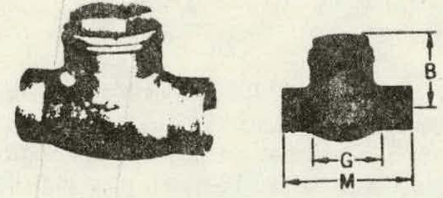

†B-309, SOLDER ENDS

\begin{tabular}{|c|c|c|c|c|}
\hline SIZE & WGT. & B & $\mathrm{G}^{*}$ & \\
\hline $3 / 8$ & .4 & $1^{13 / 32}$ & $15 / 16$ & $21 / 16$ \\
\hline $1 / 2$ & .5 & $119 / 32$ & $17 / 16$ & $27 / 16$ \\
\hline $3 / 4$ & .9 & $1^{57 / 64}$ & $13 / 4$ & $31 / 4$ \\
\hline 1 & 1.4 & $21 / 4$ & 2 & $3^{13 / 16}$ \\
\hline $11 / 4$ & 2.0 & $2^{19 / 32}$ & $25 / 16$ & $41 / 4$ \\
\hline $1 \frac{1}{2}$ & 3.4 & $31 / 32$ & $2^{11 / 16}$ & 478 \\
\hline 2 & 4.8 & $3 \frac{1}{2}$ & $35 / 16$ & 6 \\
\hline
\end{tabular}

+Saturated Steam Pressure for Solder End Valves Should Not Exceed 15 PSI.

*Piping Make-Up Dimension

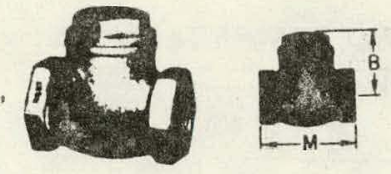

B-319, THREADED

\begin{tabular}{|c|c|c|c|}
\hline SIZE & WGT. & B & M \\
\hline $1 / 4$ & .5 & $1^{13 / 32}$ & $2^{1 / 16}$ \\
\hline $3 / 8$ & .5 & $1^{13 / 32}$ & $2^{1 / 16}$ \\
\hline $1 / 2$ & .7 & $1^{19 / 32}$ & $2^{7 / 16}$ \\
\hline $3 / 4$ & 1.1 & $1^{29 / 32}$ & $2^{13 / 16}$ \\
\hline 1 & 1.7 & $2^{1 / 4}$ & $3^{3 / 16}$ \\
\hline $1^{1 / 4}$ & 2.7 & $2^{19} / 32$ & $3^{3 / 4}$ \\
\hline $11 / 2$ & 3.9 & $3^{1 / 32}$ & $43 / 16$ \\
\hline 2 & 6.1 & $31 / 2$ & $51 / 8$ \\
\hline $21 / 2$ & 11 & $45 / 32$ & $6^{3 / 16}$ \\
\hline 3 & 17 & $4^{13 / 16}$ & $7^{1 / 3}$ \\
\hline
\end{tabular}




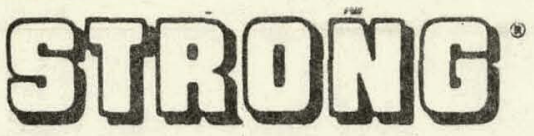

\section{Semi-Steel Y-Type Strainers}

High Tensile Semi-Steel Body ASTM A126 Class B.
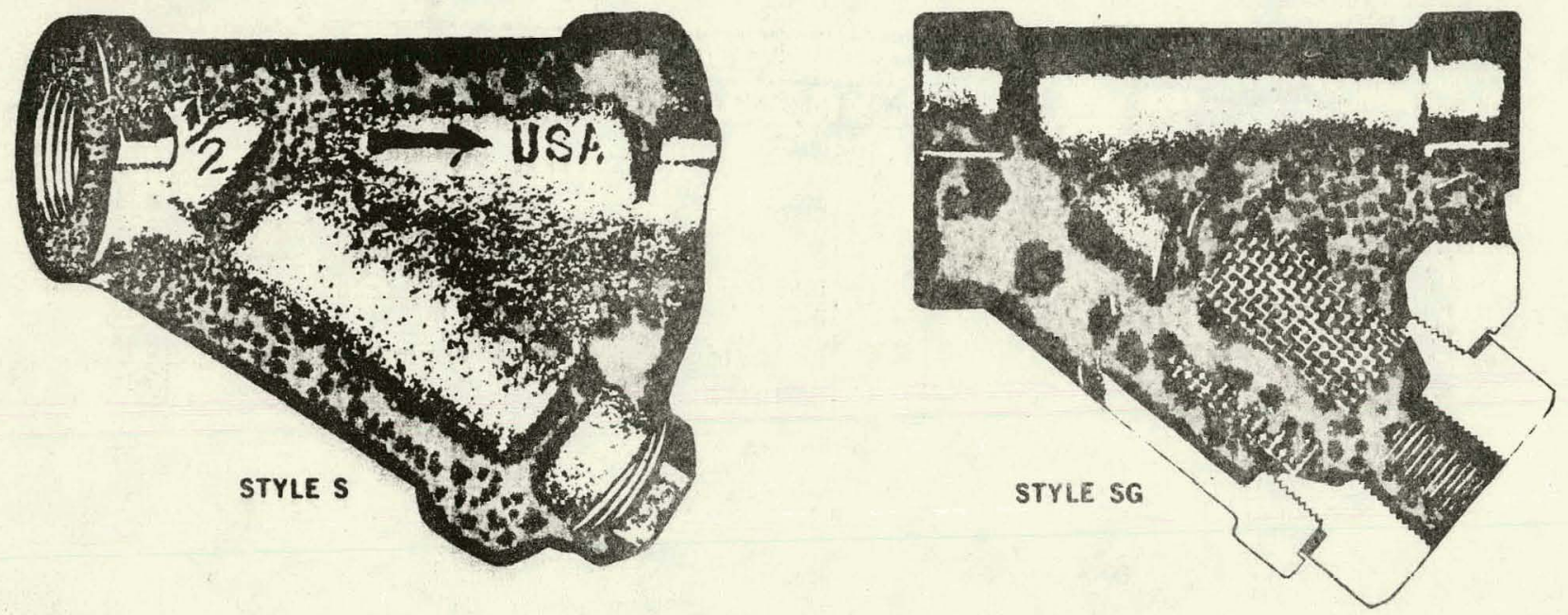

SIZES $1 / 4$ " thru 3"

OPERATING PRESSURES AND TEMPERATURES:

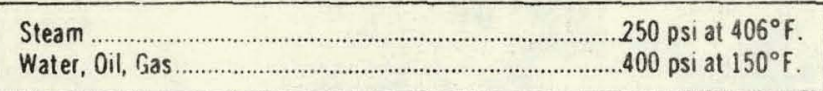

\section{STANDARD SCREENS:}

\begin{tabular}{|c|c|c|c|}
\hline Service & Connections \& Sizes & Screen Openings & Screen Material \\
\hline Liquid & $\begin{array}{l}\text { Screwed } 1 / 4^{\prime \prime} \text { thru } 2^{\prime \prime} \\
21 / 2^{\prime \prime} \text { thru } 3^{\prime \prime}\end{array}$ & $\begin{array}{l}20 \text { mesh } \\
.045 \text { perf. }\end{array}$ & Stainless Steel \\
\hline Steam & $\begin{array}{r}\text { Screwed } 1 / 4^{\prime \prime} \text { thru } 2^{\prime \prime} \\
21 / 2^{\prime \prime} \text { thru } 3^{\prime \prime}\end{array}$ & $\begin{array}{l}20 \text { mesh } \\
.045 \text { perf. }\end{array}$ & Stainless Steel \\
\hline
\end{tabular}

\section{BLOW-OFF OUTLETS:}

N.P.T. tapped in sizes specified on dimension table. Not normally furnished plugged.

\section{CONSTAUCTION:}

Construcled of high-tensile ASTM A126 Class B semi-steel with blow-off connections and easily removable cylindrical screens. A tapered seat allows the screen to be self aligning and assures a perfect fit. $2 \frac{1}{2}$ " and 3 " sizes have a flanged blow-off cover. Strainer with gasketed blow. off plug and straight thread avait able in $1 / 4^{\prime \prime}$ thru $2 "$ size. $18-8$ stainless steel screens.

\section{MILITARY SPECIFICATIONS:}

Model with gasketed blow off plug conforms 10 MIL-S-16293E. Type 1, Style Y, Class 250 when equipped with a brass plug in the blow-off connection. State service when ordering.

\section{PACKAGING:}

Screwed strainers in sizes thru $2^{\prime \prime}$ can be packaged in multiple unit cartons for certain industries. Write for specific information.

\section{DIMENSIONS:}

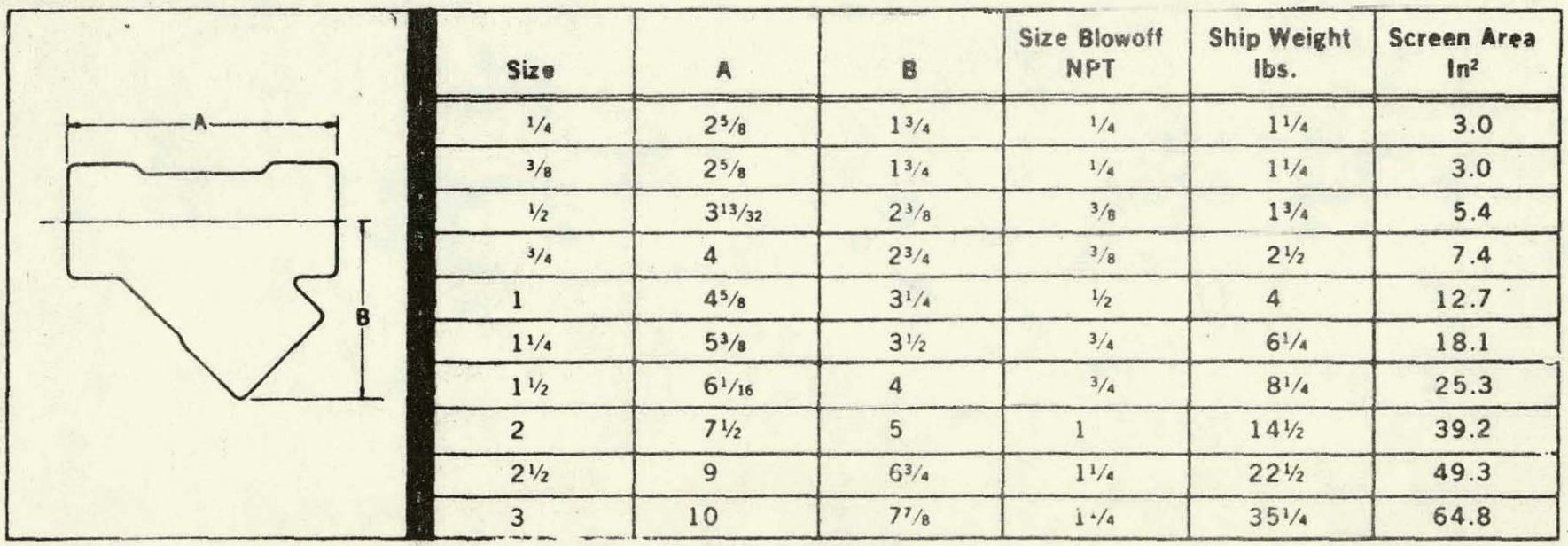

$E-26$ 


\section{Pressure Monitoring SWICHGAGES}

These rugged, pressure monitoring SWICHGAGES ${ }^{\circledR}$ are designed for any critical pressure control function.

Recommended specifically for safety shutdown on oil field, irrigation and industrial engines or as alarm systems on construction equipment, trucks and marine engines.

\section{Offers constant visual indication.}

These instruments offer a constant visual indication of the condition of your lubrication system, or any other vital pressures on your equipment. Their precision construction meets the specifications of those applications which require a higher degree of accuracy and dependability than is available in most standard $2^{\prime \prime}$ diameter instruments.

A SWICHGAGE ${ }^{\circledR}$ performs the job of two ordinary instruments (a gauge and a switch), thus this instrument greatly reduces necessary inventory and installation time.

In addition, each instrument is available with a lockout feature to hold the indicating pointer away from the shut-down contact for start-up. When the oil pressure reaches the normal operating level, the lockout is automatically disengaged.

\section{Durability}

The entire working mechanism of the SWICHGAGE ${ }^{\circledR}$ is assembled completely independent from the case and therefore is not affected by case damage or abuse in normal operation. Also, all moving parts are machined to close tollerence and many parts are interlocking to retard damage from vibration or shock. The unique design of the diaphragm and bearing plate prevent normal overpressures from harming the accuracy of the instrument.

\section{Model 20-P.7}

This model features a "tamperproot" front adjustable contact which can be set with an Allen-Head wrench (also available with standard screwdriver adjustment specify), and a pushbutton for lockout.

Model 20-P-27

A side mounted micrometer - adjustment type contact screw and convenient side lockout are features of this model. It also has a stand-off ring which holds the instrument away from the panel to give access to the contact adjustment and lockout pushbutton.

\section{Warranty}

Like all Murphy instruments, Pressure SWICHGAGES' carry a full one year warranty against defective materials and workmanship. Consult the Murphy Service department for product repairs.

CONTACT RATINGS: 2 amp. (1) 30 v.a.c., 2 amp. @ 30 v.d.c. SHIPPING WEIGHTS: $20-\mathrm{P}-77.8 \mathrm{Oz}-20-\mathrm{P}-2713 \mathrm{Oz}$.
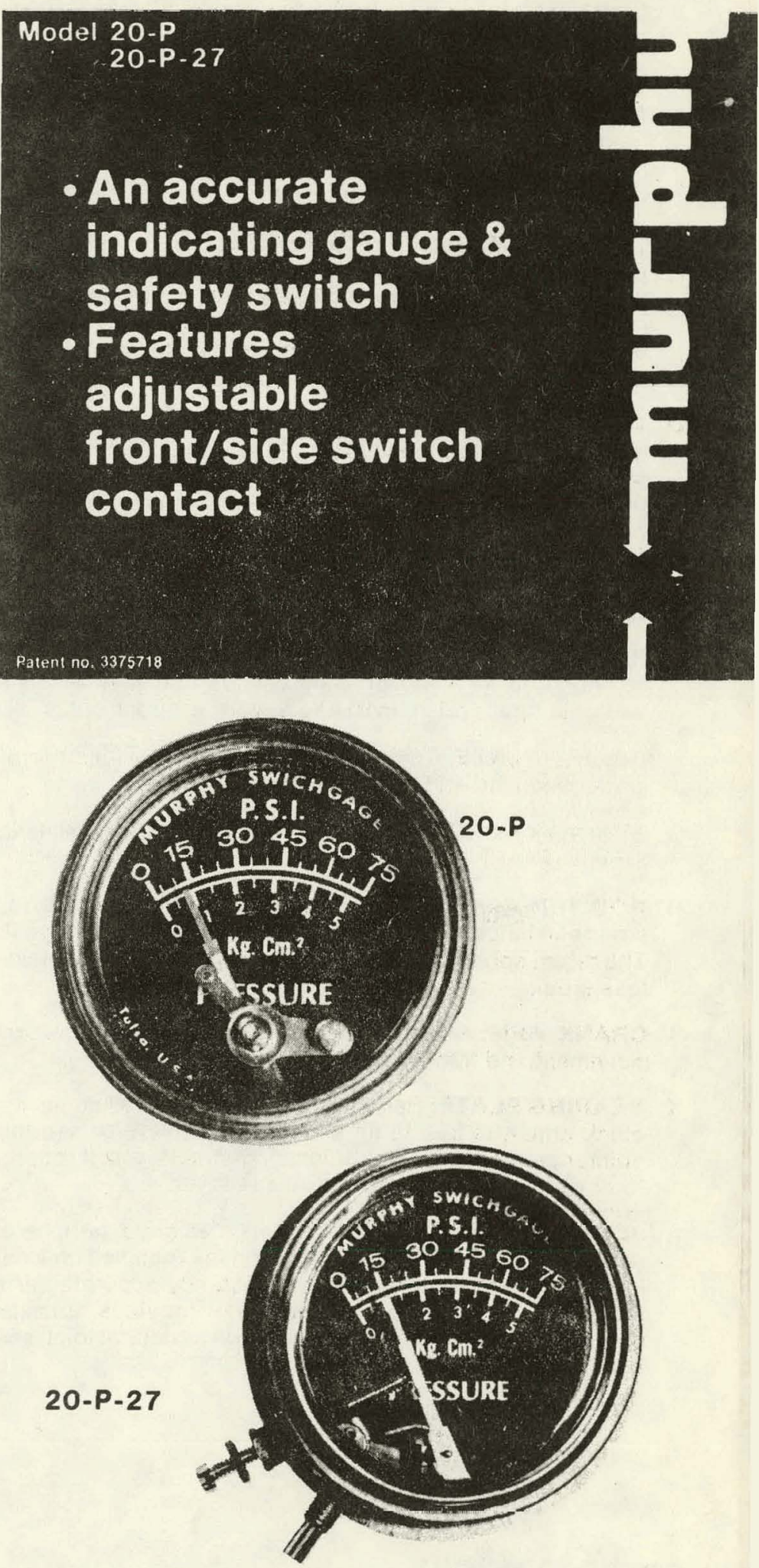

COMPATIBILITY: These simple one-wire to ground SWICHGAGES' are compatible with all Murphymatic' Controls and can be used with any Murphy "Nerve Center."

- To interrupt ignition circuit - Section 25

- To start and start stop engines - Section 40

- To start and stop elec. tric. motors - Section 45

- For fuel shut-off - Section 55 


\section{SPECIFICATIONS}

A. PORT: Machined from brass bar stock. It is accurately threaded for comection to the pressure line. Together with the diaphragm, it forms the pressure chamber.

B. PULSATION DAMPENER: A restricting orifice designed to minimize hydraulic shock within the pressure transmitting fluid, preventing undesirable pointer chatter. It is accessible for cleaning, or removal.

C. DIAPHRAGM: Beryllium copper, procured to very close physical and metallurgical specs. The material is die formed and close control heat treated to insure consistent reliability. Each pressure range is designed to operate well below its maximum capability in order to maintain long life and consistent reliability.

D. MOUNTING PLATE: Machined from brass bar stock. The mounting plate performs threefold function. First, together with the port, clamps back diaphragm in position. Second, it provides a strong back stop for the diaphragm, thereby preventing damage should the gauge experience high over pressure. Lastly, it also provides a stable platform upon which to mount the pointer post and the mechanism which amplifies the diaphragm movement into pointer travel.

E. RECAL SCREW: Provides a measure of adjustment to compensate for wear or disturbances that may result if gauge is operated in unusually severe environment.

F. BRIDGE PLATE: Tempered nickel silver provides norrosion resistance and dimensional stability.

G. SPRING ANCHOR \& POINTER ZERO STOP: StainlesS Steel.

H. POINTER: Tempered nickel silver for strength and corrosion resistance. It is mounted on a machined brass post. The return spring is helically wound of spring temper stainless steel.

J. CRANK ARM: K-Monel. Senses and amplifies diaphragm movement and transmits it to the pointer

K. BEARING PLATE: Beryllium copper. Provides fulcrum for crank arm. It is free to lift off the bridge plate should the pointer be restrained by stationary contacts, etc. It returns to original position when strain is relieved.

L. JOINT AND SEAL: The carefully designed peripheral edges of the diaphragm and port, and the radiused channel in the mounting plate provide consistently accurate parts alignment. The annular solder channel provides optimum conditions for producing a combination structural joint, and seal, with maximum integrity.
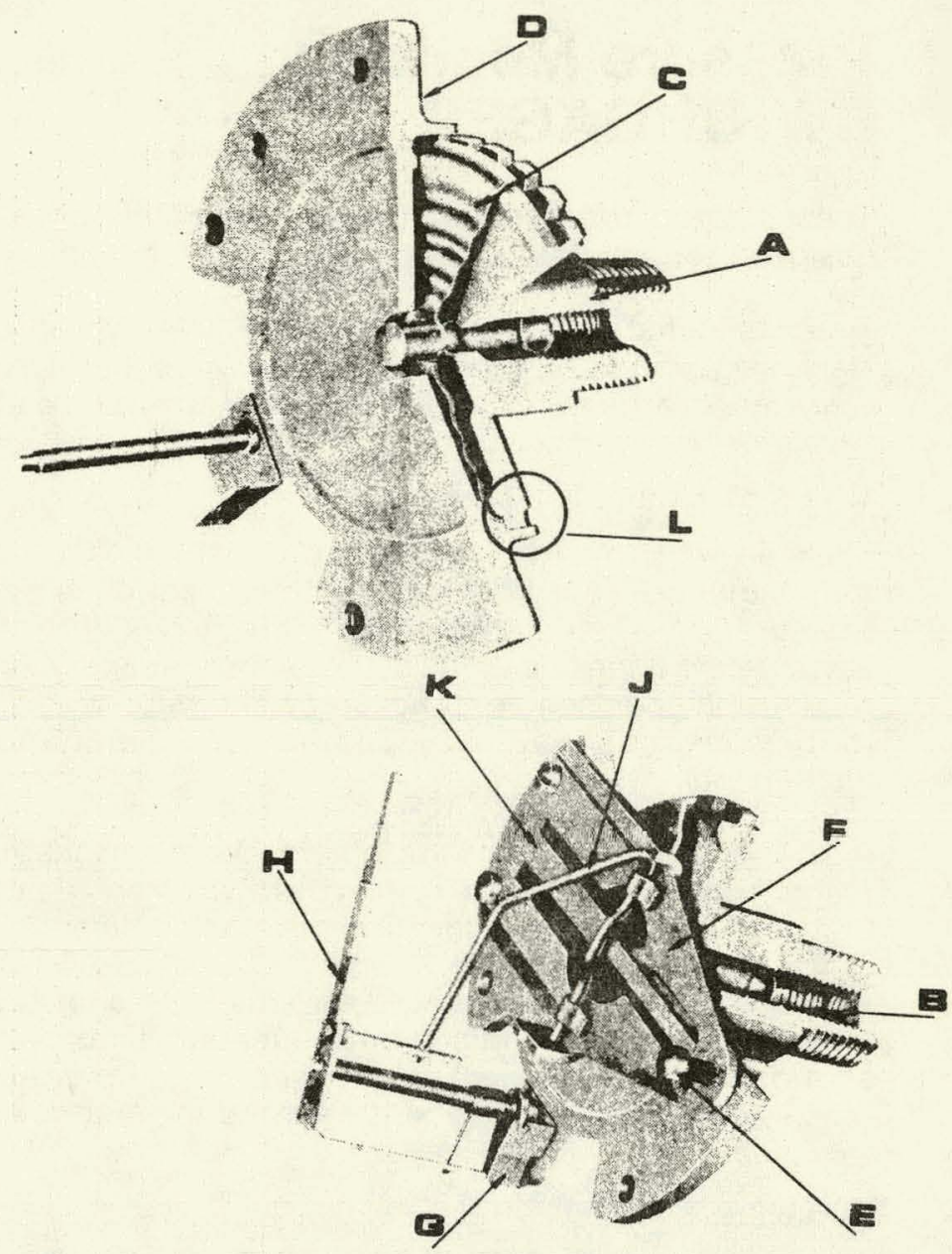

\begin{tabular}{|c|c|c|}
\hline DESCRIPTION & $\begin{array}{l}\text { MODEL } \\
\text { NO. }\end{array}$ & RANGES \\
\hline $\begin{array}{l}\text { 2" Dia. Pressure SWICHGAGE" } \\
\text { Front Contact - No Lockout }\end{array}$ & $20-P$ & $\begin{array}{l}0-30,0-75,0-100 \text { p.s.i. } \\
0-150,0-200,0-300 \text { p.s.i. }\end{array}$ \\
\hline 20-P w/Front Lockout & $20-P-7$ & All Ranges \\
\hline $\begin{array}{l}\text { 2" Dia. Pressure SWICHGAGE } \\
\text { Side Contact - No Lockout }\end{array}$ & $20-P-75$ & $\begin{array}{l}0-30,0-75,0-100 \text { p.s.i. } \\
0-200,0-300 \text { p.s.i. }\end{array}$ \\
\hline 20-P-75 w/side Lockout & $20-P-27$ & All Ranges \\
\hline $\begin{array}{l}\text { 2" Dia. Vacuum SWICHGAGE" } \\
\text { Hi-Lo Contacts - No Lockout }\end{array}$ & $\begin{array}{l}20-V-2 \\
20-V-3\end{array}$ & $\begin{array}{l}0-20 \text { inches Vacuum } \\
0-30 \text { inches Vacuum }\end{array}$ \\
\hline
\end{tabular}

\section{OPTIONAL EXTRAS}

\begin{tabular}{|lll|}
\hline Additional Contact (except 20-V) & add-HL & All Ranges \\
\hline$C$ Contacts -2 wire ungrounded (Not avail. w/Lockout) & \\
Circuit (rated 1 amp (a $125 V$ A.C.) & add-C. & All Ranges \\
\hline Illumination slots. (Front contact only) & add-1 $\quad$ All Ranges \\
\hline
\end{tabular}

Also available in explosion proof case - see bulletin No. EX-5828. Available on front contact models only.

\section{murphy}

"DEVELOPING SOLUTIONS TO YOUR MONITORING \& CONTROL PROBLEMS" Write us today for a no-obligation recommendation

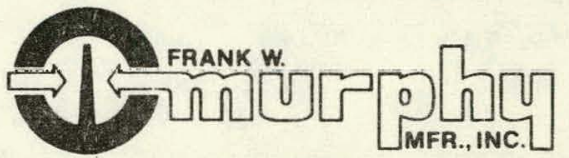

FRANK W MURPHY MANUFACTUREA INC MURPHY SOUTHERN DIVISION MURPHY SAFE IY SWITCH OF CALIFORNIA

O. Box 45248, Tulsa. Oklahoma 74145 $918.627-3550$ O. Box 36638. Houston. Texas 77036 Pox 788. Palmdale. California 93550 805 947.7108

P.O. BOX 45248 • TULSA, OKLAHOMA • 74145 • $918(627-3550)$ 

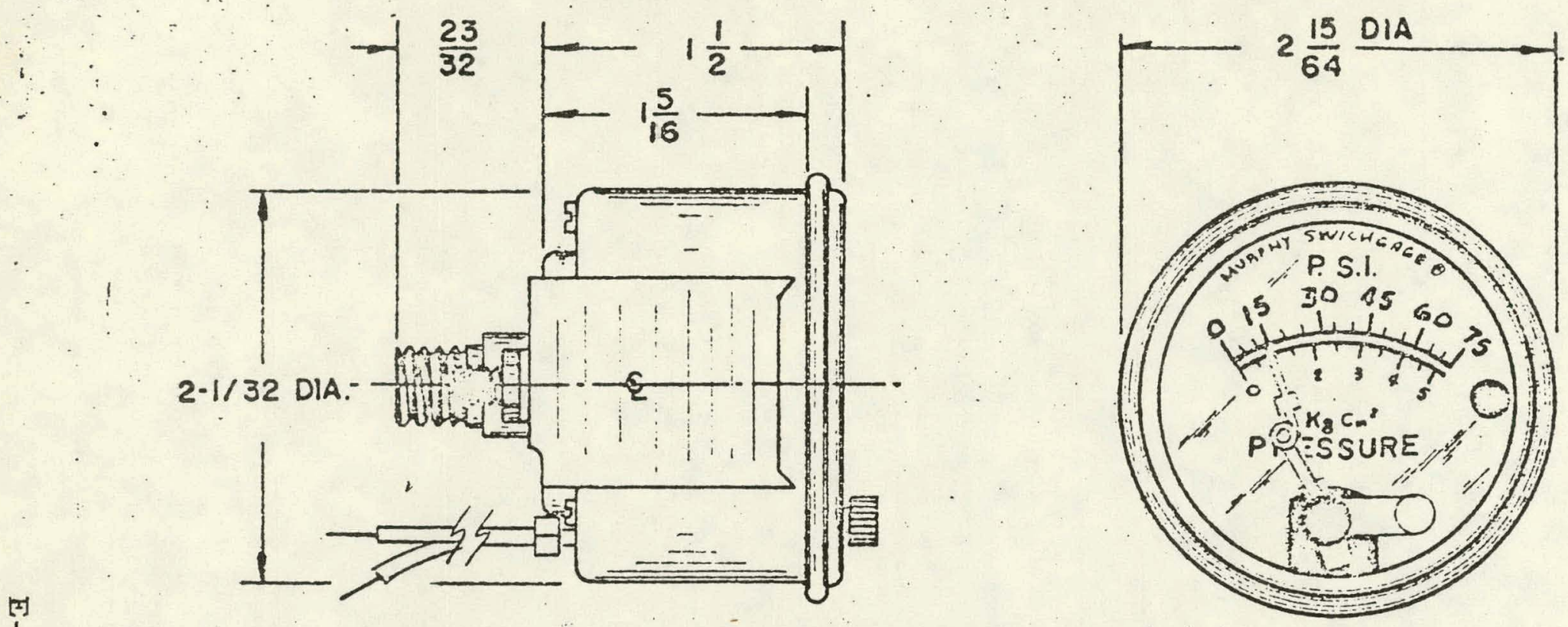

RANGES

CONTACT

AVAILABLE

SETTING

- $0-15$ PSI

3 PSI

$0.30 " 7 . \cdots$

$0-50$ " 10 "

$\therefore$ * $0-75$ " 13 "

- $0-100.20$.

4 0.150 " 30 \%

- $0-200 " 50$ "

$0.300 " 75$.

\section{*STANDARD}

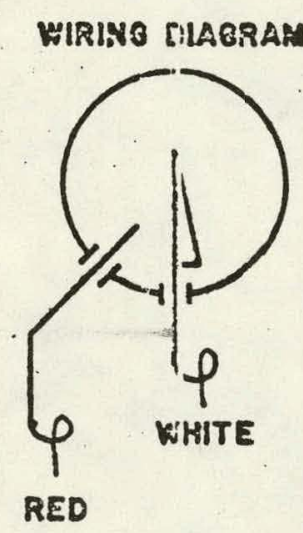

RATING- I ARP I2O VAC - 2 ARP $30 \mathrm{~V}$ AC/OC

WIRE - (1) RED, (I) WHITE, I2 $*$ I8 BA

CONTACT SETTING - SEE AEOVE

TYPE ADJUSTZERIT - NYLON KNOB

DIAL - WHSTE ON QLACK

CLANP - LONG P/IN OS 05-789

MOUNTINSG HOLE - 2.1/15 JIA.

MAX PANEL THICXNESS - 1/

PORT - BRASS 1/8-27 NPT

MAX PRESSURE - $(0=300 P S I)(B=500 P S I)$

PLLSATION DARPENER - BUILT IN (REMOVABLE)

BEZEL - STAIILLSS STEEL

CASE - STEEL, CAD \& IRIDITE

CRYSTAL - LEXAN

STUDS - 10-24 NC

CALIBRATION CONFORMS TO USAS CLASS 8 - FIRST \& LAST I/3 OF SCALE $\pm 3 \%$, MIODLE OF SCALE $\pm 2 \%$

NOTE: NO CUSTORER REPLACABLE PARTS

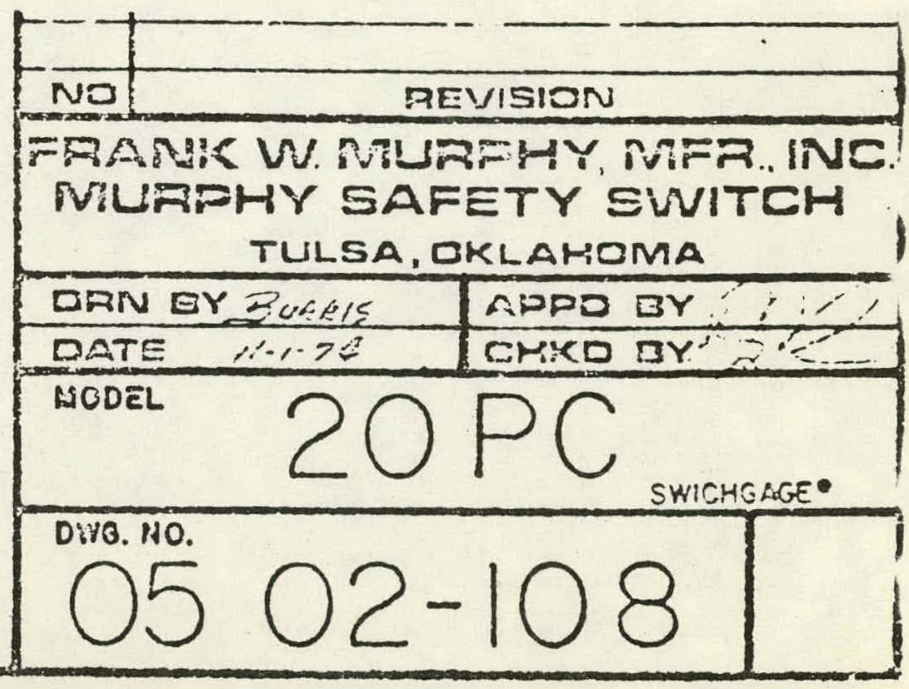




\section{APPENDIX F}

SDAS SENSOR INSTALLATION 


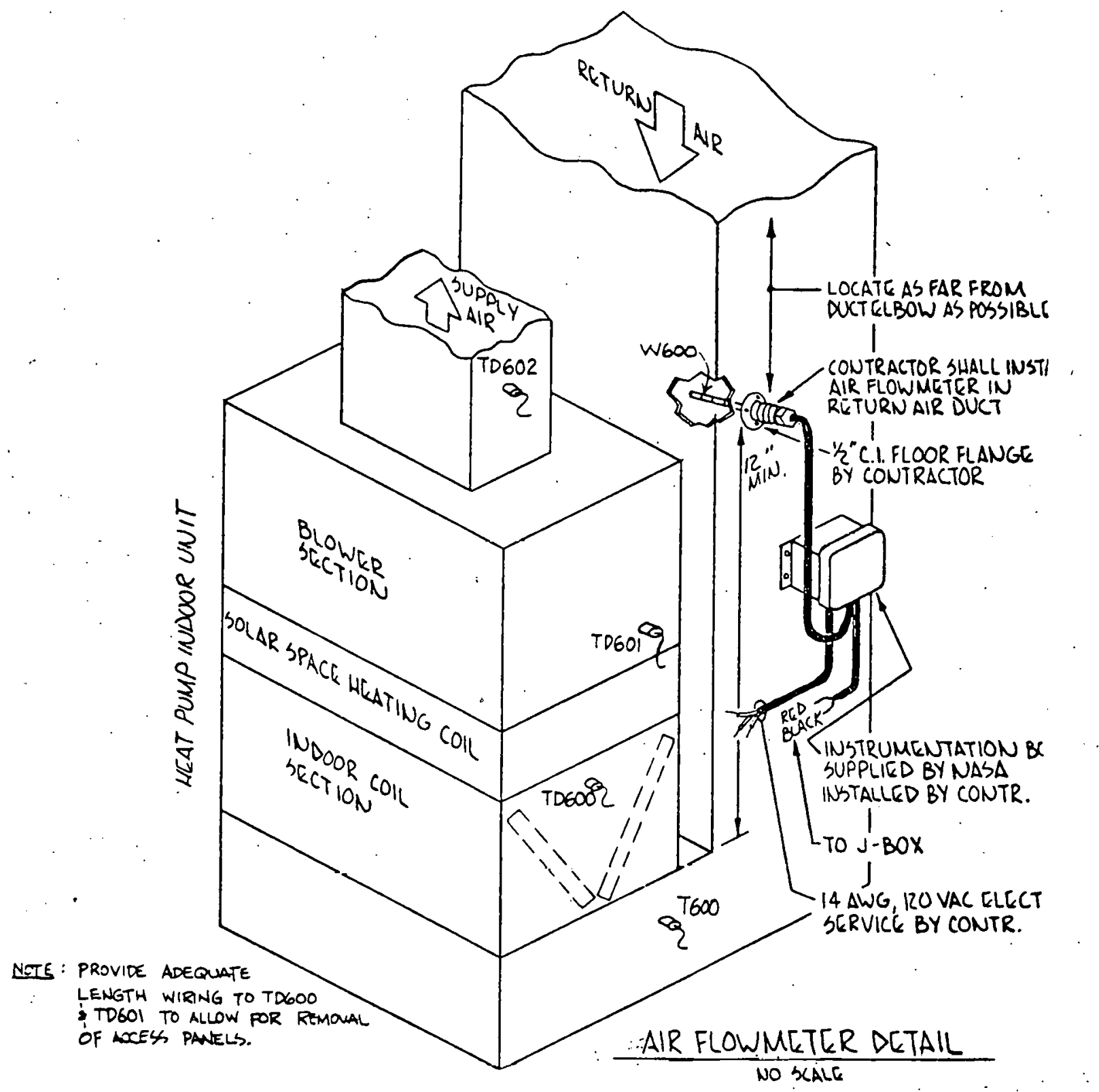



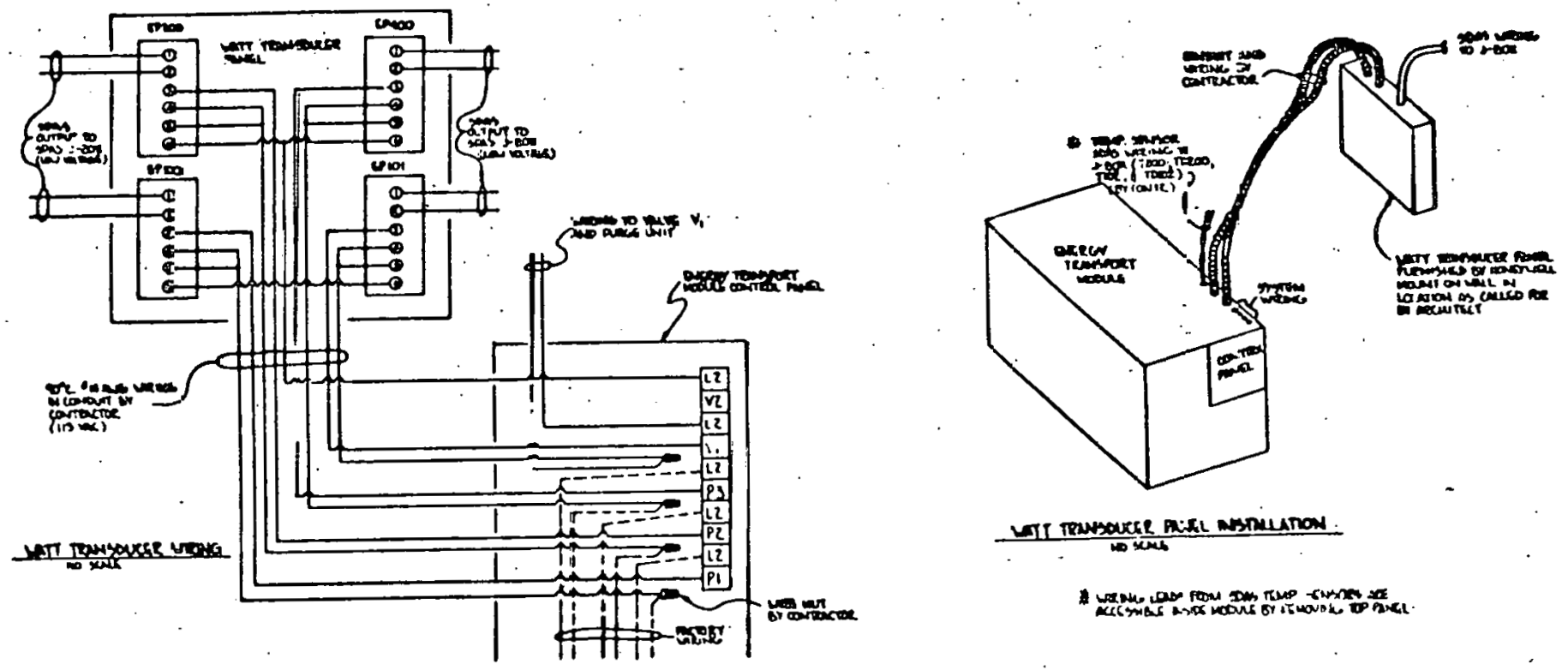

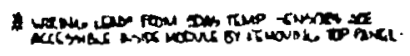

\begin{tabular}{|c|c|}
\hline 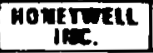 & retaser mioneres akren \\
\hline \multicolumn{2}{|c|}{ 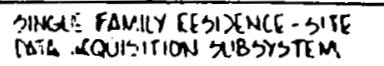 } \\
\hline \begin{tabular}{|l|l|l|}
$\min$ & 55513 \\
\end{tabular} & $x-142055$ \\
\hline 1 & 09 \\
\hline
\end{tabular}
compar D 
APPENDIX G

GENERAL SDAS INSTALLATION 


\section{INSTRUMENTATION INTERFACE REQUIREMENTS}

To transmit data from each sensor to the Central Data Processing System, the hardware components shown in Figure 1 are utilized at each site. A typical layout of the work space required around the SDAS mounting area is shown in Figure 2 .

NOTE: AZL ERDA responsiblities will be performed by NASA.

\section{Hardware Components}

1. Sensor wire (supplied and installed by site contractor)

2. Junction box (supplied by ERDA and installed by site contractor)

3. Junction box/SDAS interface cables (supplied and installed by ERDA)

4. Site Data Acquisition Subsystem (SDAS) (supplied by ERDA and installed by site contractor)

5. SDAS telephone interface (supplied by ERDA)

6. SDAS and telephone electrical power interface (supplied by site contractor)

\section{Sensor to Junction Box Wiring}

A11 wiring from sensors to junction box (J-box) terminal block connections shall be performed by the site contractor in accordance with these guidelines utilizing wire procured by the site contractor and prepared for each sensor according to instructions in Figure 3. The wire size and number of conductors required for each sensor is specified in Table 1 . The sensor-to-junction-box wire shall be color-coded, audio and instrumentation grade cable to minimize noise problems. Conduit shall be used only in accordance with local codes. 


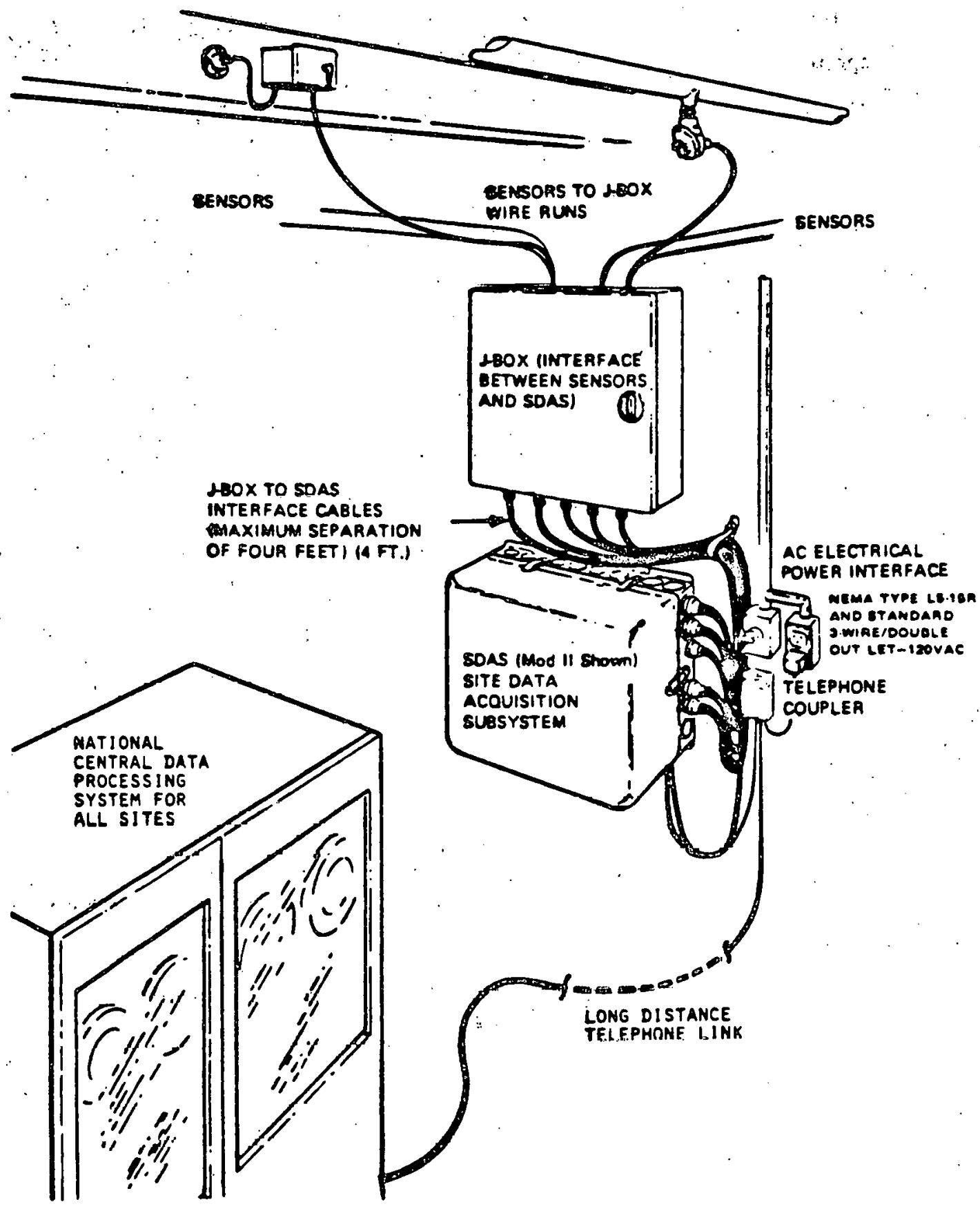

Figure 1. Site Instrumentation Interface Hardware 


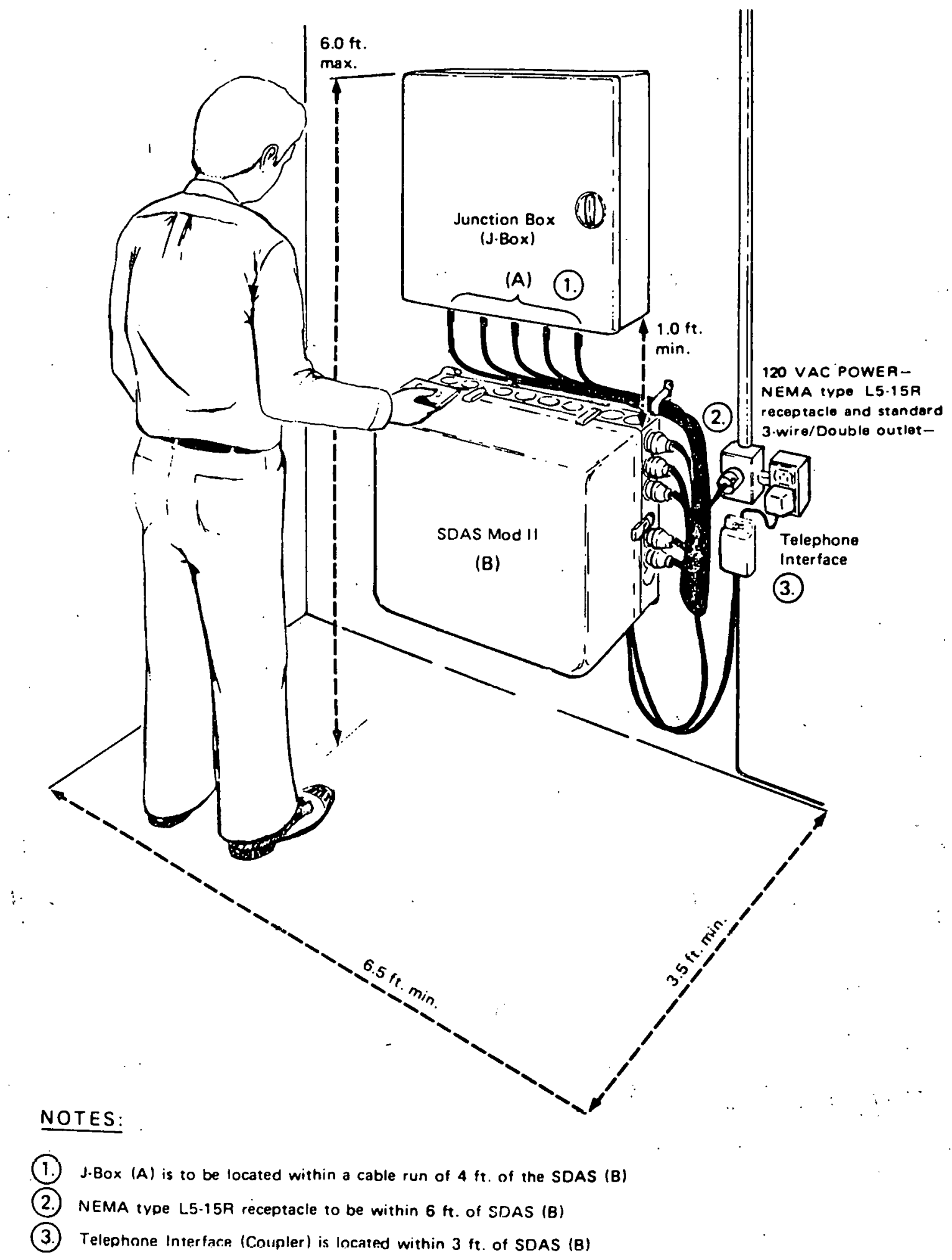

Figurc 2. Typical SDAS Installation Laynut. Profile 
(3) CUT SHIELD WIRE NEXKT TO JA.CKET, SENSOR END ONLY

(2) TRIM FOIL SHIELD BACK TO JACKET, BOTH ENDS

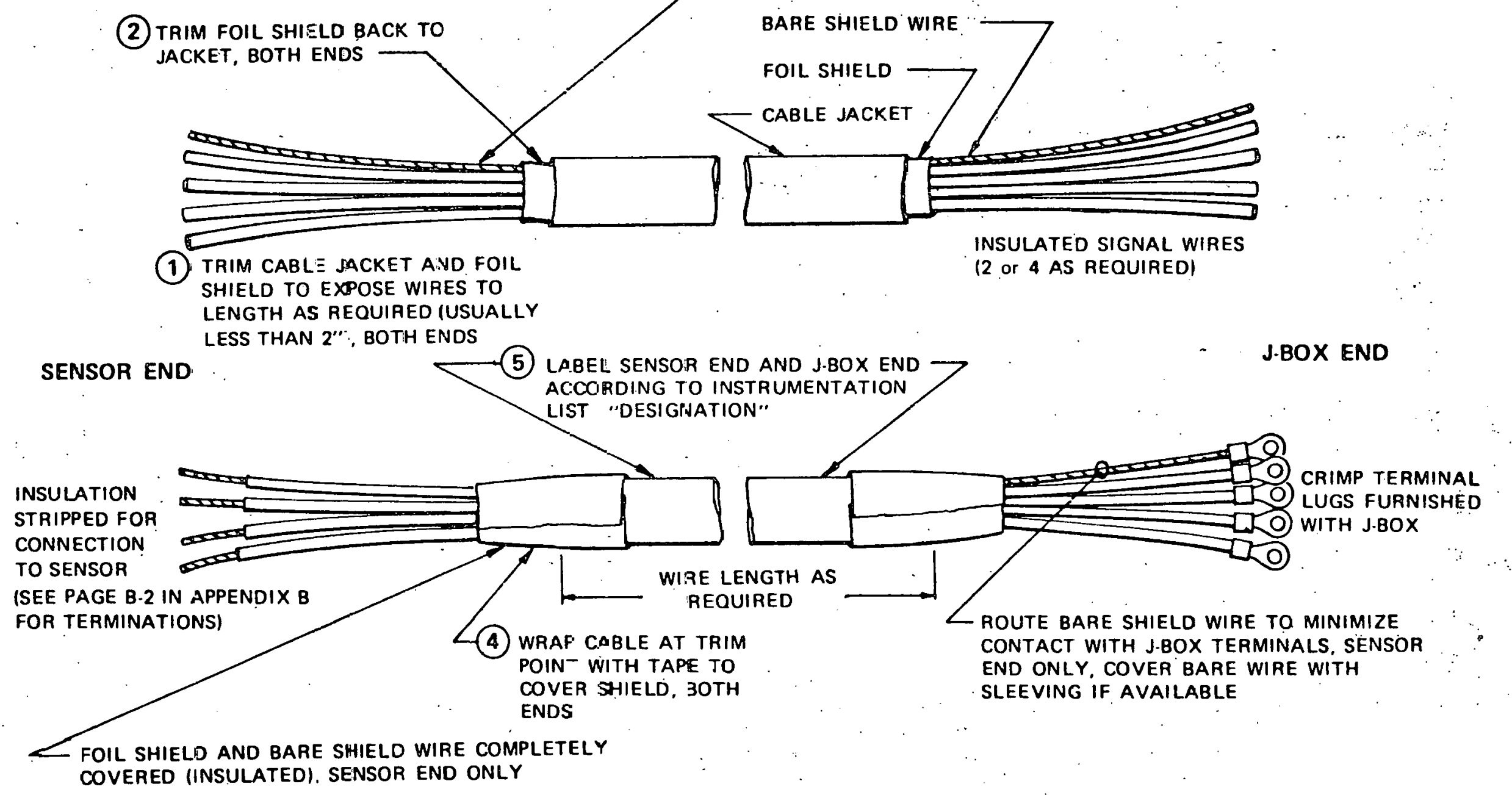

Figure 3. Sensor Wire Preparation Procedure 
Table 1. Sensor Wire Requirements

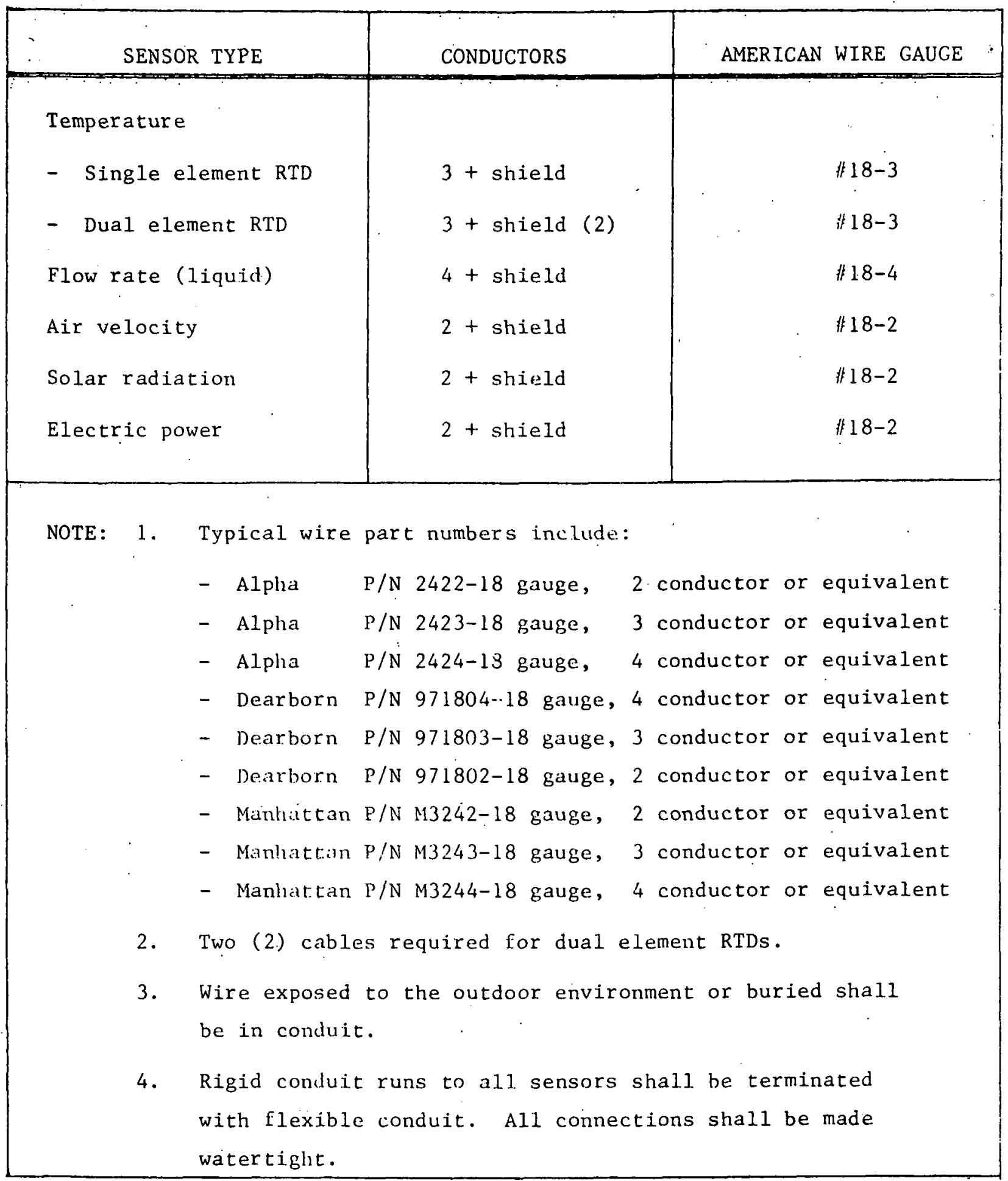




\section{CAUTION}

AC PONER LINES AND OTHER POTENTIAL NOISE INDUCING LINES SHOULD HOT BE PLACED IN THE SENSOR WIRING CONDUIT OR ROUTED NEAR THE INSTRUIIENTATION CABLES. ALSO, THE INSTRUMENTATION CABLES SHOULD HOT BE ROUTED NEAR NOISE GENERATING EQUIPMENT.

Junction Box

ERDA will provide a junction box (Figure 4) to the śite contractor for installation In a central location with respect to the snlar energy system. The in stallation location shall. be selected by the site contractor and shall be specified in the ISPI.

As defined by ERDA, noise suppression may be required at the sensor, J-Box or both to provide acceptable data. Remote signal conditioning may be required to improve the signal-to-noise ratio that would improve data accuracy.

Junction Box Location -- The junction box, Figure 4, shall be mounted by the site contractor so that it is accessible for wiring connections from the sensors and is within four feet of the SDAS location on the same side of the wall.

junction Box Mounting -- At the predefined mounting lncatinn, the junstion box shall be mounted by the site contractor using the four mounting holes located at the back of the unit. Figure 4 provides the dimensional information for mounting. Depending on the characteristics of the mounting surface, Molly bolts, wood screws, or bolt/nut combinations shall be used to mount the unit. lhe junction box shall be installed in a top-up orientation.

Junction Bux Interfaces -- EKUA will establish the wire run list which identifies where each sensor wire attaches to the junction box terminal strips. This vire run list will be a part of the AIP which the site contractor will implement. A typical example of a rire run list and the connection of typlical measurements 


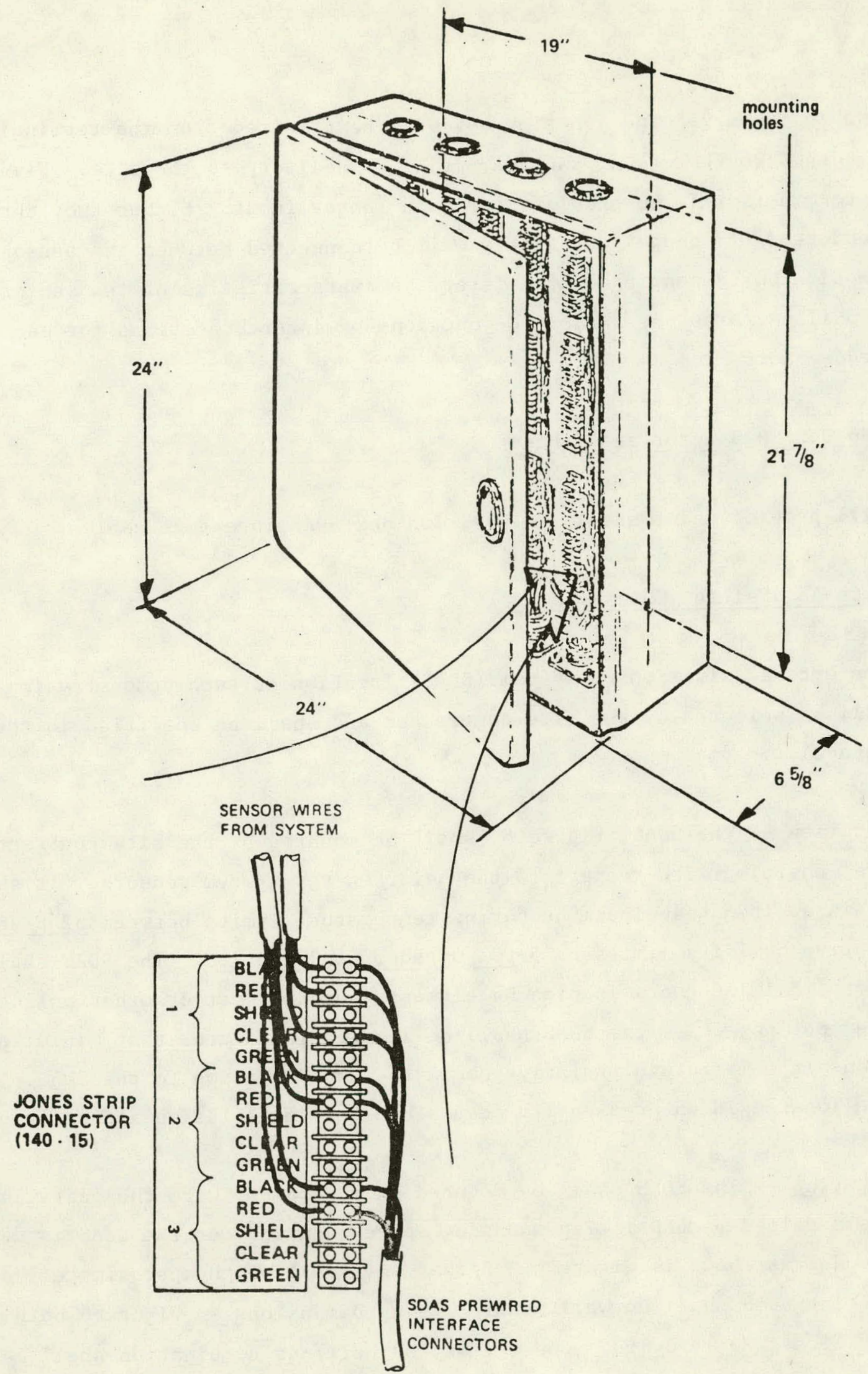

Figure 4. Junction Box/SDAS Interface with typical Sensor connection 
is shown in Table 2. The junction box will be prewired from the terminal strips to the output connectors of the SDAS prior to delivery to the site. Five con-ductor terminals will be provided for each sensor input. Either two, three, or four conductor (18 gauge) and shield will be connected between the sensors and the junction box depending on the interface characteristics of the sensors. Figure 5 illustrates the sensor-to-junction-box interconnections for each of the approved sensors.

Junction Box/SDAS Intertace Cables

ERDA will provide and install the junction box/SDAS interface cables.

Site Data Acquisition Subsystem

The Site Data Acquisition Subsystem (SDAS) location at each demonstration project will be selected by the site contractor and shall be specified in the ISPI for approval.

SDAS Location -- The SDAS, Figure 5, shall be mounted by the site contractor in a central position with respect to the solar energy system sensors. It shall be located in an indoor environment having temperature limits between $32^{\circ} \mathrm{F}$ and $100^{\circ} \mathrm{F}$ and relative humidity 1 imits of $5-80 \%$ without condensation. The SDAS shall be located to minimize contamination by elements such as dust or other pollutants. To the extent possible, the SDAS shall be located in an area that minimizes the variations in temperature, relative humidity, and vibration to the SDAS. The SDAS shall be located in an area easily accessible for installation and maintenance.

SDAS Mounting -- The SDAS shall be mounted in accordance with the installation drawings supplied by ERDA. The mounting space required for the SDAS is dependent on the model as shown in Figure 6 . Either unit will weigh approximately 70 pounds. The SDAS shall be wall mounted using dimensions in Figure 6 both top and bottom. Either Molly bolts, wood screws, or bolt/nut combination shall be used 
Table 2. Typical Wire Run List for J-Box Terminal Connection

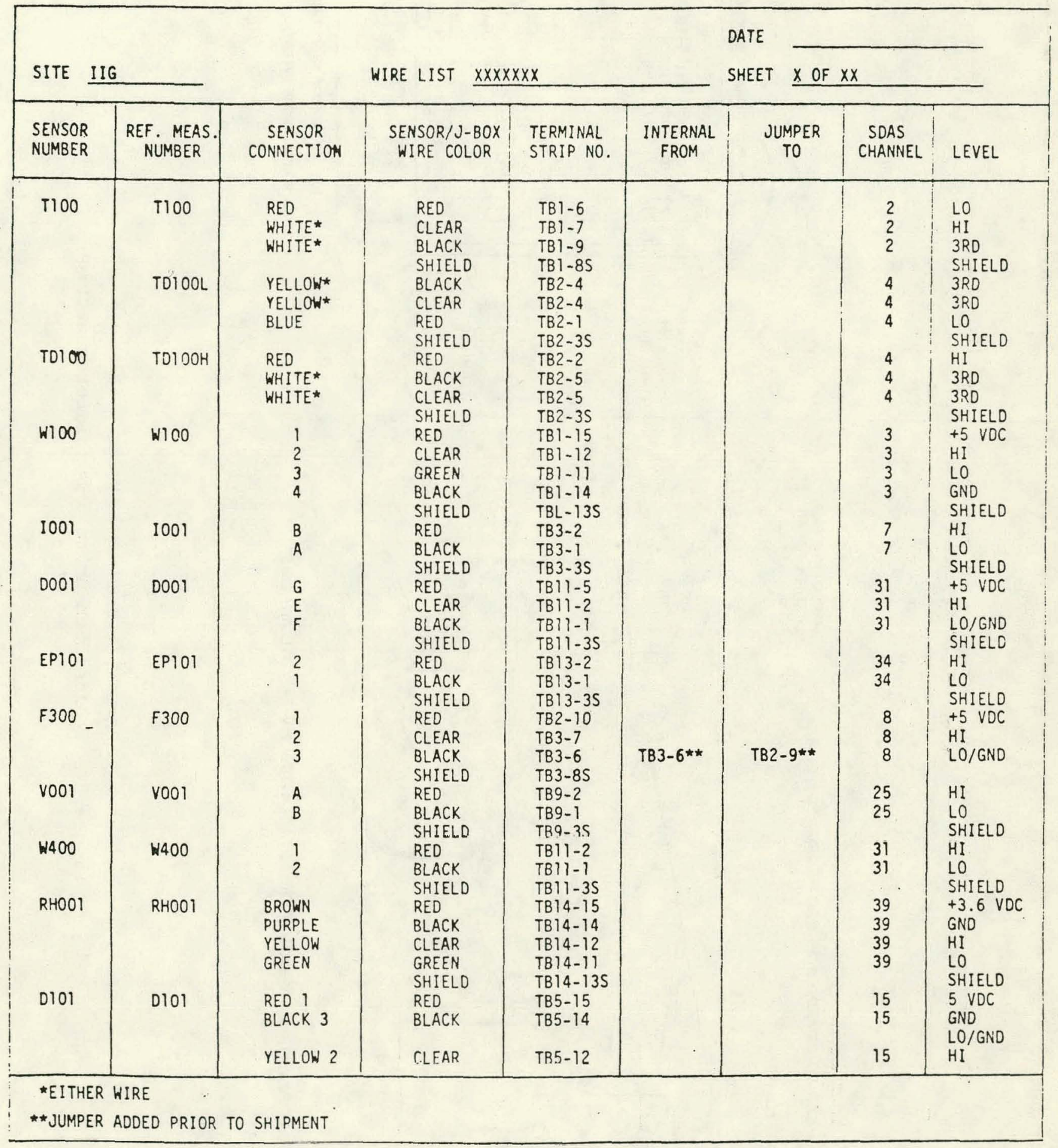




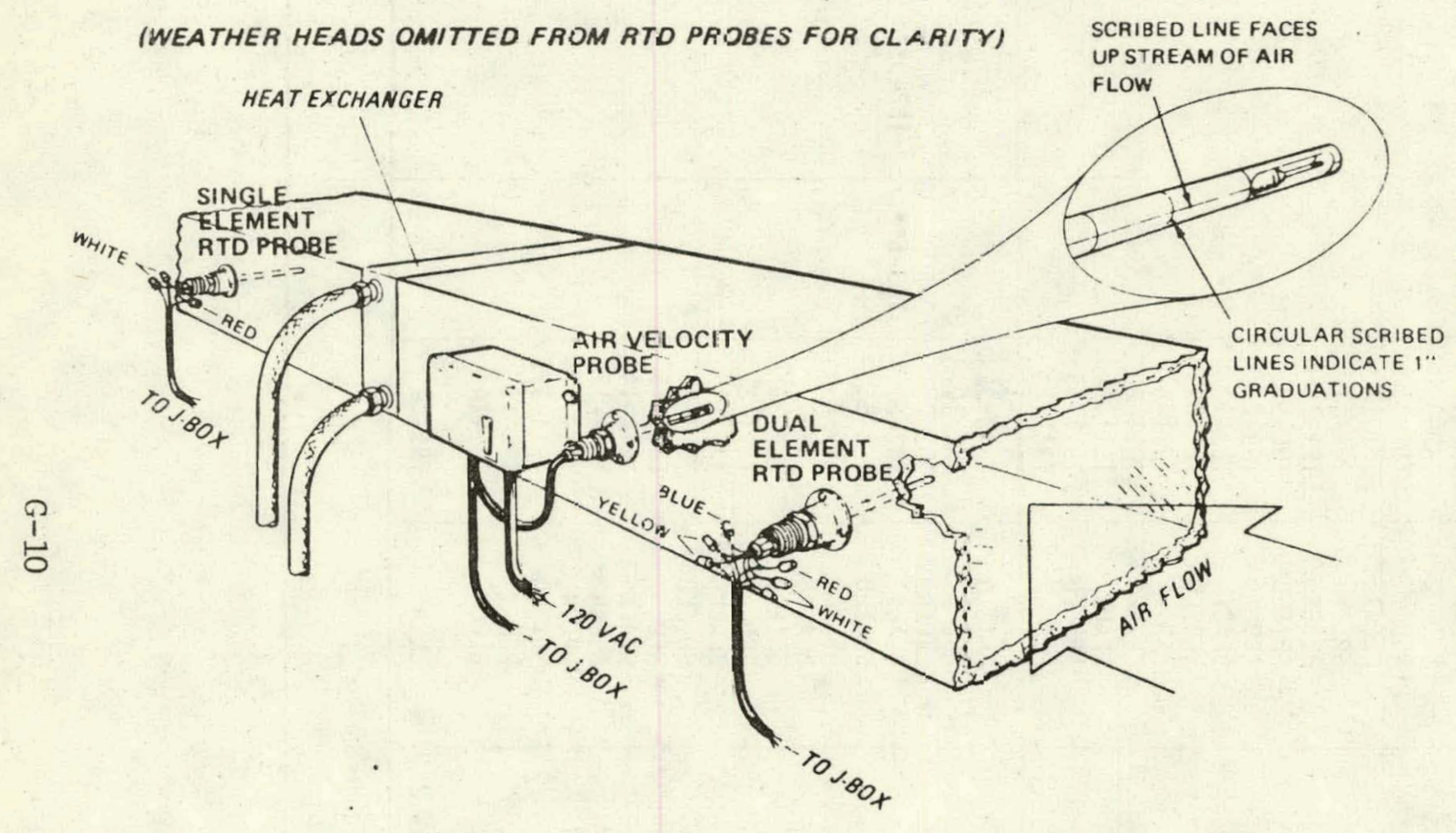

TEMPERATURE SENSOR \& ANEMOMETER INSTALLATION ON TYPICAL AIR DUCT

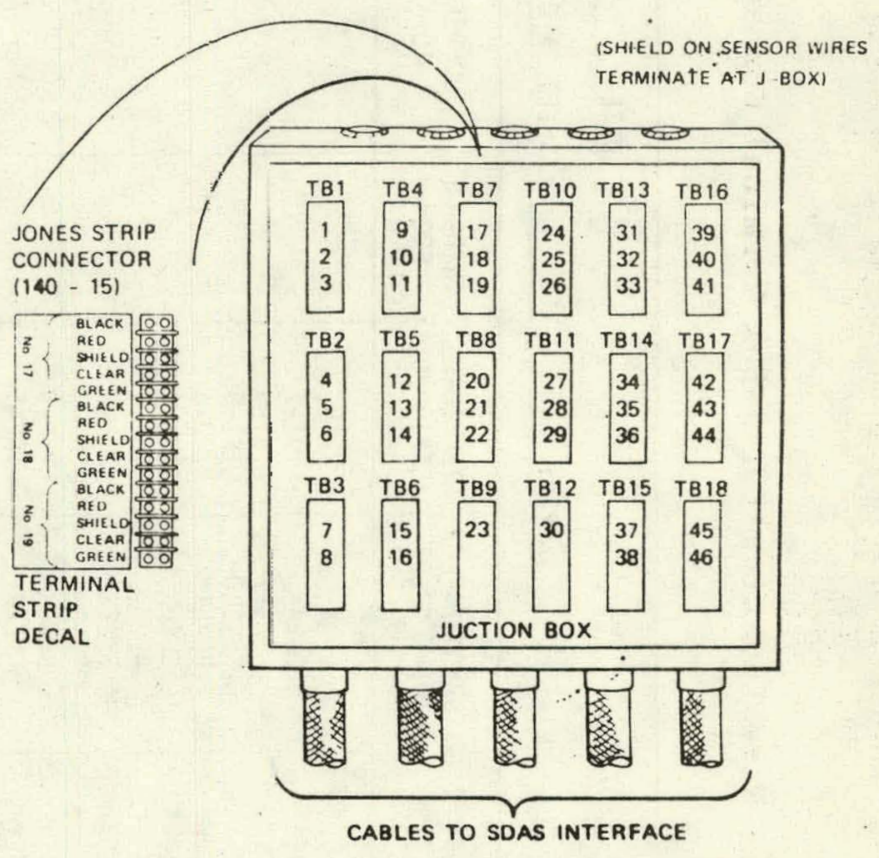

JUNCTION BOX-SENSORS INTERFACE TO SDAS

Figure 5. Typical Sens or to J-Box Interconnection 


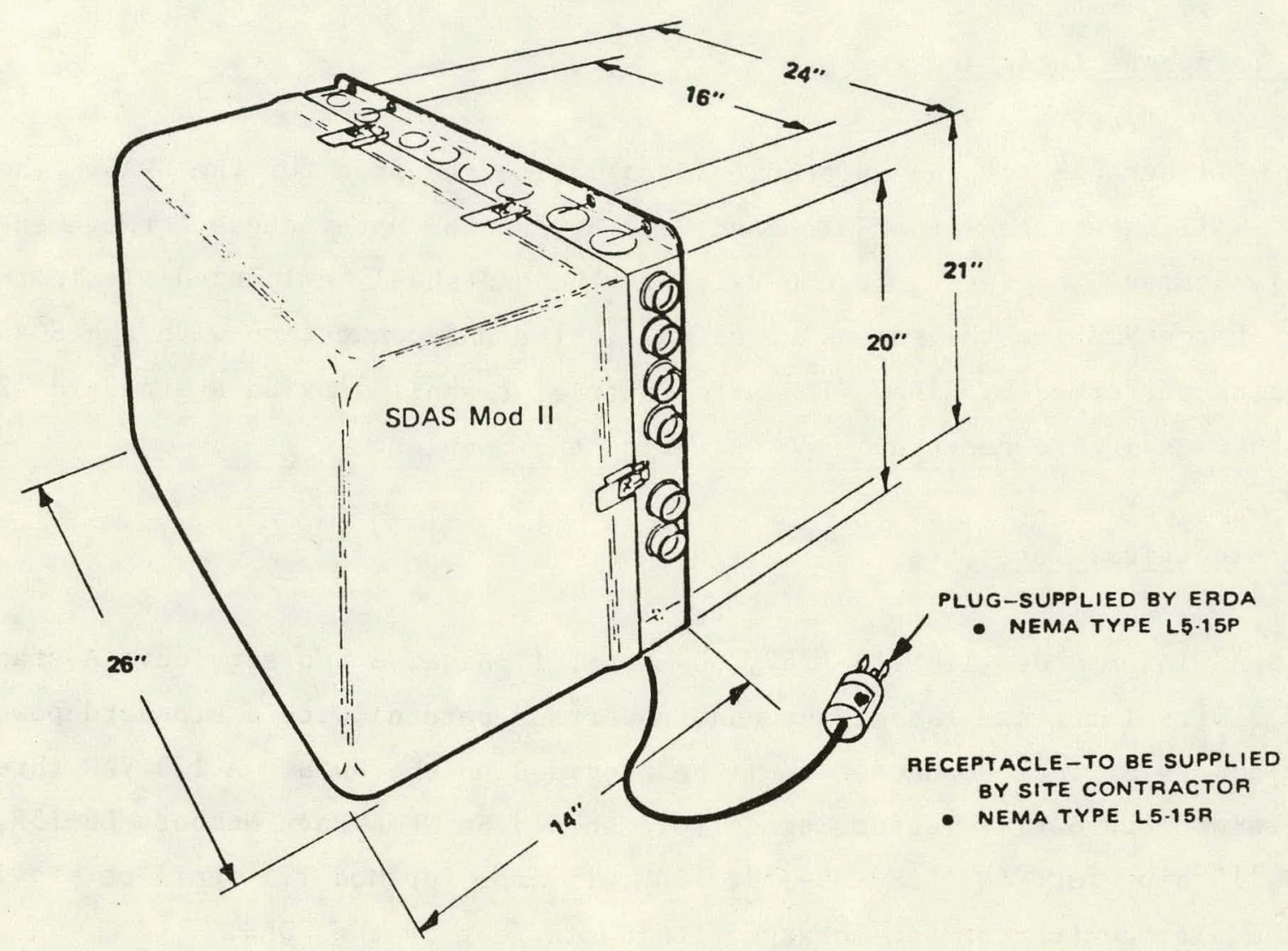

Figure 6. Site Data Acquisition Subsystem 
to mount the unit depending on the characteristics of the mounting surface. The SDAS shall be mounted between two feet and four feet above floor level measured from the bottom of the SDAS.

\section{SIAS Telephone Interface}

ERDA will arrange for the telephone installation required for the SDAS. The SDAS shall interface with a standard Be11 System CBS Data Access Arrangement (DAA), Series 5 or later, or equivalent. The DAA shall be located within three feet of the SDAS on the same side of wall. The DAA connection with the SDAS shall be performed by ERDA. The site contractor shall provide a standard 120 VAC three (3) wire receptacle for power to the coupler.

\section{SDAS Electrical Interface}

The SDAS interfaces with 110-125V, 60 Hertz, 1 phase, 3 anp service. A standard 3 wire interface (safety ground, power and return) with a standard power cord and twist lock connector shall be provided on the SDAS. A 120 VAC three pin twist lock outlet (actual receptacle should be NEMA Part Numbers L6-15R, 250V, 15 amps for Mod 1 and L5-15R, 120V, 15 amps for Mod II) shall be provided by the site contractor and located within six feet of the SDAS. 